\title{
Great aims, small gains: Jatropha-based biofuels and competing discourses of development in Kenya
}

by

\section{Carol Hunsberger}

A thesis submitted to the Faculty of Graduate and Postdoctoral Affairs in partial fulfillment of the requirements for the degree of

Doctor of Philosophy

in

Geography with Specialization in Political Economy

Carleton University

Ottawa, Ontario

(C) 2012

Carol Hunsberger 
Library and Archives

Canada

Published Heritage

Branch

395 Wellington Street

Ottawa ON K1A ON4

Canada
Bibliothèque et

Archives Canada

Direction du

Patrimoine de l'édition

395 , rue Wellington

Ottawa ON K1A ON4

Canada
Your file Votre référence

ISBN: 978-0-494-87770-8

Our file Notre référence

ISBN: $978-0-494-87770-8$

\section{NOTICE:}

The author has granted a nonexclusive license allowing Library and Archives Canada to reproduce, publish, archive, preserve, conserve, communicate to the public by telecommunication or on the Internet, loan, distrbute and sell theses worldwide, for commercial or noncommercial purposes, in microform, paper, electronic and/or any other formats.

The author retains copyright ownership and moral rights in this thesis. Neither the thesis nor substantial extracts from it may be printed or otherwise reproduced without the author's permission.
AVIS:

L'auteur a accordé une licence non exclusive permettant à la Bibliothèque et Archives Canada de reproduire, publier, archiver, sauvegarder, conserver, transmettre au public par télécommunication ou par l'Internet, prêter, distribuer et vendre des thèses partout dans le monde, à des fins commerciales ou autres, sur support microforme, papier, électronique et/ou autres formats.

L'auteur conserve la propriété du droit d'auteur et des droits moraux qui protege cette thèse. $\mathrm{Ni}$ la thèse ni des extraits substantiels de celle-ci ne doivent être imprimés ou autrement reproduits sans son autorisation.
In compliance with the Canadian Privacy Act some supporting forms may have been removed from this thesis.

While these forms may be included in the document page count, their removal does not represent any loss of content from the thesis.
Conformément à la loi canadienne sur la protection de la vie privée, quelques formulaires secondaires ont été enlevés de cette thèse.

Bien que ces formulaires aient inclus dans la pagination, il n'y aura aucun contenu manquant. 


\section{ABSTRACT}

Biofuels have received significant recent attention for their perceived potential to promote climate change mitigation, energy security, and rural development, even as critical scholarship has challenged each of these claims. Jatropha curcas, a hardy shrub with inedible oilseeds, gained prominence among donors, investors and the media due to hopes that it could produce renewable energy without compromising food production. This thesis investigates the promotion of Jatropha in Kenya and situates these observations in relation to international discourses and policies on biofuels. Adopting a political ecology perspective, it examines the rise of interest in Jatropha in relation to themes of power, development and scale. Drawing on field work conducted in 2009, this research asks how Jatropha came to be promoted as an energy crop in Kenya, and compares the experiences of small-scale farmers with the motivations and claims of NGO, government, private sector, donor, and research representatives.

Findings include that different actors attached strikingly different discourses of development to Jatropha: one market-led, focusing on large-scale goals; another livelihood-oriented, focusing on small-scale goals. Neither of these had become dominant, nor had any related activities produced a significant amount of fuel from Jatropha at the time of research. Consistent with Hilhorst's (2001) 'duality of discourse,' this coexistence of perspectives produced competition, but also granted actors the flexibility to invoke Jatropha as a means of achieving a variety of objectives. This was evident in Mpeketoni, Coast Province, where farmers, donors, and project coordinators approached a Jatropha initiative with different priorities, but showed signs of mutual learning and potential to achieve multiple goals. A second finding is that a lack of reliable 
information about Jatropha created a climate of uncertainty where conflicting views could spread unchecked. In Nguruman, Rift Valley Province, farmers who already grew Jatropha as fencing were exposed to mixed messages and wildly fluctuating price signals from seed buyers from outside the area, leading to confusion and diverse expectations. The multiple discourses that this research shows have been activated to encourage the spread of Jatropha among small-scale farmers in Kenya are equally relevant in other contexts where biofuels are concerned. 


\section{ACKNOWLEDGEMENTS}

This research was financially supported by a Canada Graduate Scholarship from the Social Sciences and Humanities Research Council, a Doctoral Research Award from the International Development Research Centre, and a Torrance Graduate Research Award from Carleton University.

I would like to thank all of the participants in this research for generously sharing their time and perspectives.

I am also grateful for assistance I received in the field, particularly from Dr. Miyuki liyama who served as my supervisor at ICRAF in Nairobi. For special help with coordination and logistics of the case studies, I am indebted to Leonard Ndungu, Joseph Migui and Paul Mbole. James Washika was a wonderful research assistant and translator. I am also grateful to Norwegian Church Aid for agreeing to have me study the Jatropha Integrated Energy Project in Mpeketoni. My two "Kenyan families," including David John Bwakali, Grace Ochami, Mama and Baba Leonard, and Lillian made me feel right at home.

My thesis supervisor, Mike Brklacich, and my committee members, Patricia Ballamingie and Blair Rutherford, always provided excellent advice delivered with compassion and care. Many other colleagues and fellow students provided ideas along the way, for which I am extremely thankful.

Finally, words cannot express the gratitude I feel towards my family and friends who kept me going through this long and often solitary process. 


\section{TABLE OF CONTENTS}

ABSTRACT

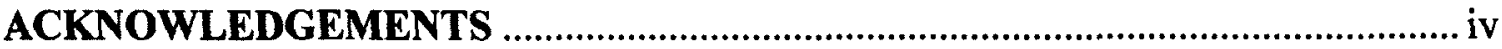

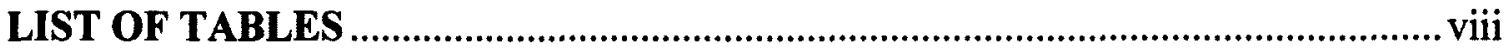

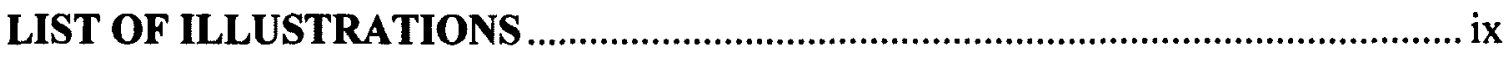

LIST OF APPENDICES

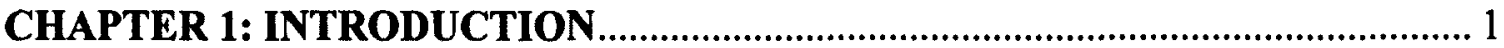

CHAPTER 2: INTELLECTUAL ROOTS AND RESEARCH FRAMEWORK ..... 11

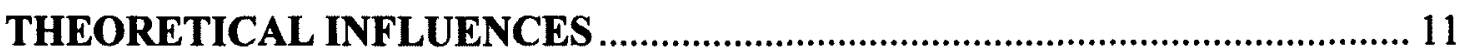

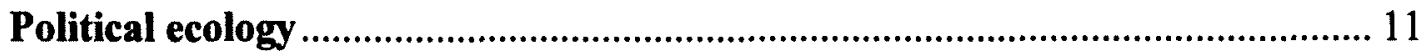

Discourses of development .......................................................................... 18

Key concept: Development.......................................................................... 19

International connections and NGOs............................................................... 28

Key concept: Scale …………………………................................................... 30

Summary of intellectual roots........................................................................... 33

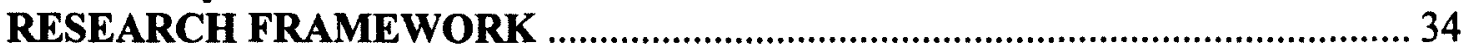

Methodological decisions ................................................................................. 34

Research process .............................................................................................. 36

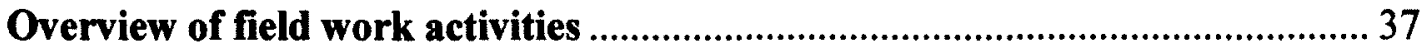

Positioning myself as a researcher.................................................................... 47

Chapter Summary ....................................................................................... 52

CHAPTER 3: BIOFUELS: INTERNATIONAL DEBATES AND DISCOURSES 54

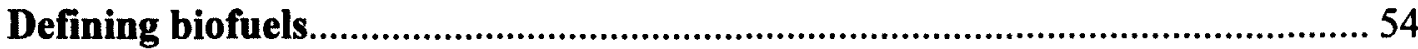

Discourses and themes linked to biofuels........................................................5

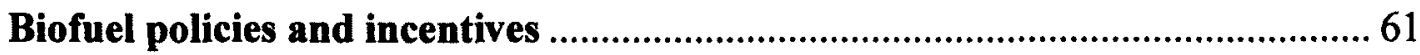

Critiquing the 'biofuels complex': Key points of debate........................................... 66

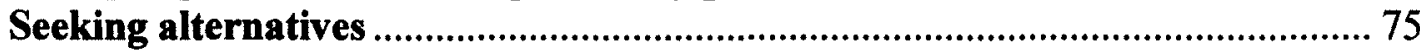

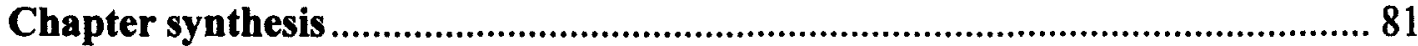

CHAPTER 4: JATROPHA AND ITS INTERNATIONAL SPREAD ……............8 84

LITERATURE PERSPECTIVES ON JATROPHA ………................................... 84

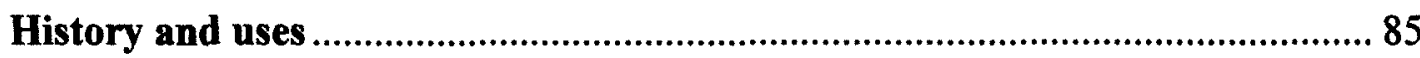

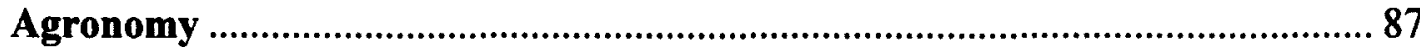

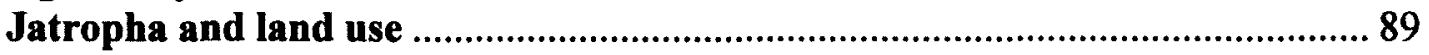

Contested discourses of 'marginal' lands .............................................................. 91

Labour................................................................................................................... 93

Energy and greenhouse gas balance.................................................................. 95

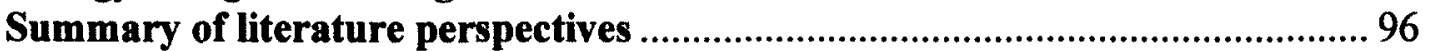

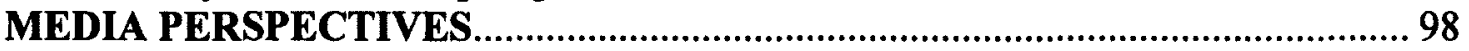

Positive claims and media enthusiasm ......................................................... 99

Critiques and media backlash ...................................................................... 101

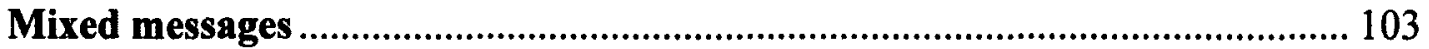

GLOBAL CULTIVATION AND SPREAD ………...................................... 108

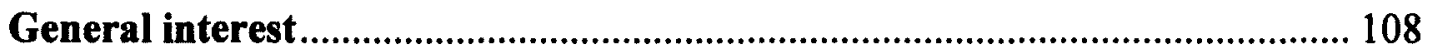

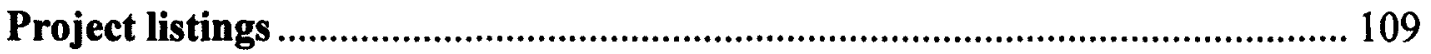

Project announcements ........................................................................... 112 


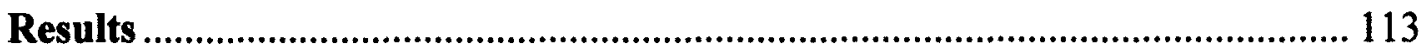

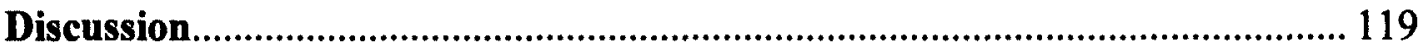

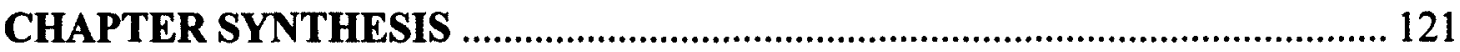

CHAPTER 5: JATROPHA IN KENYA: ACTORS AND ACTIVITIES................ 123

KENYAN CONTEXT ............................................................................... 123

Historical context of land and agriculture issues in Kenya............................... 123

Jatropha's spread in Kenya ........................................................................... 127

Key informant perspectives on Jatropha in Kenya ........................................... 132

MAJOR PLAYERS IN KENYA'S JATROPHA ACTIVITIES .......................... 133

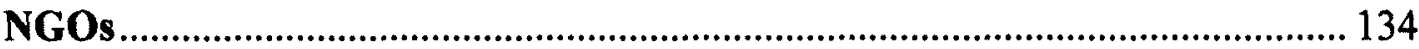

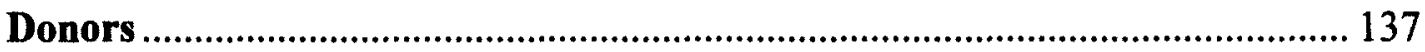

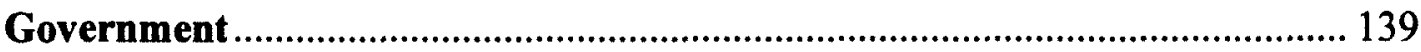

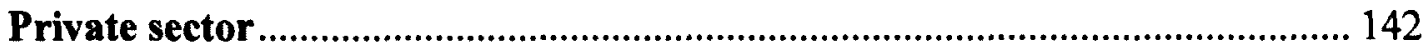

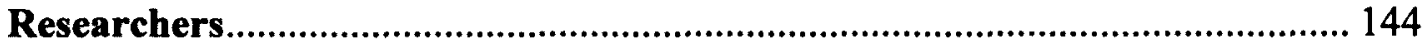

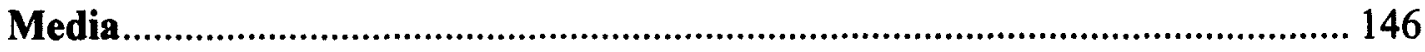

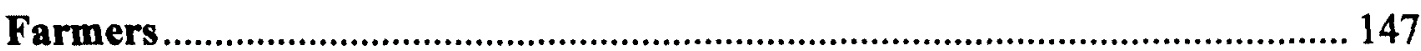

Actors revisited........................................................................................... 148

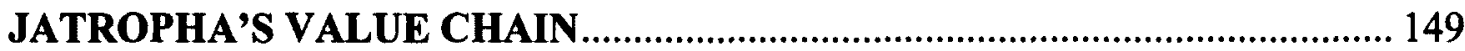

Experiences from Tanzania ...................................................................... 154

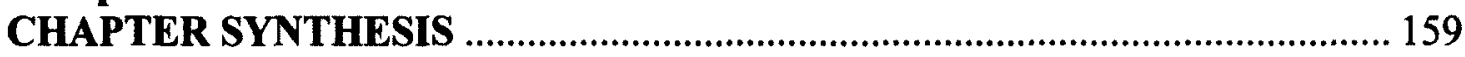

CHAPTER 6: MOTIVATIONS, INFLUENCES, AND DISCOURSES OF

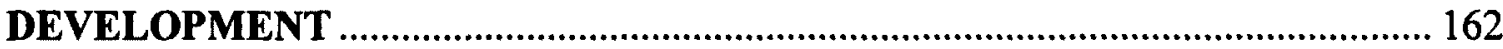

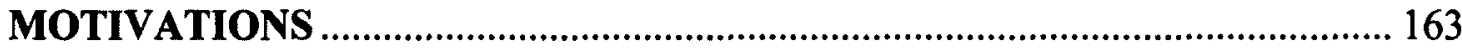

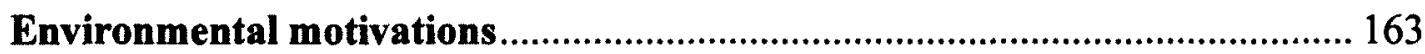

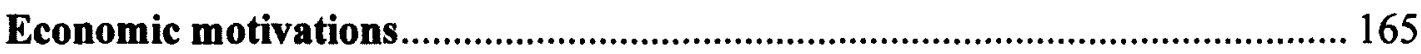

Humanitarian or social motivations.......................................................... 168

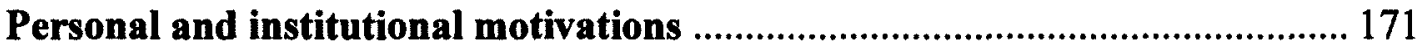

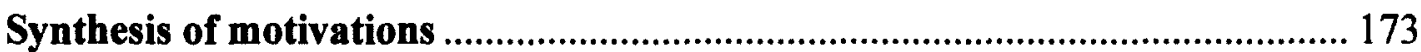

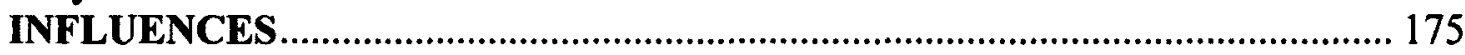

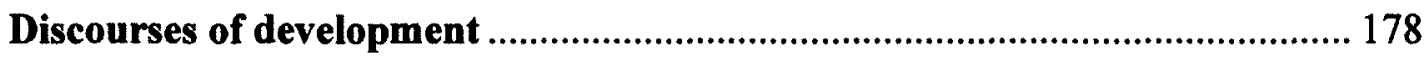

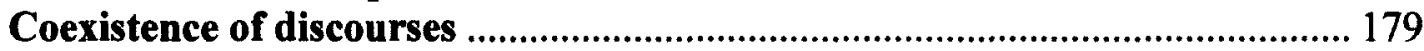

Competition between discourses.................................................................. 181

Perceived complementarity of discourses ..................................................... 186

Divergence and convergence........................................................................ 189

INSIGHTS FROM MPEKETONI ............................................................ 190

Motivations and expectations..................................................................... 193

Tensions and disconnects .............................................................................. 198

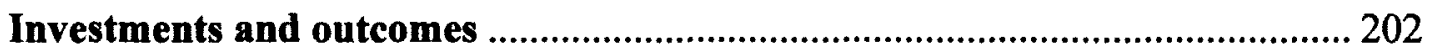

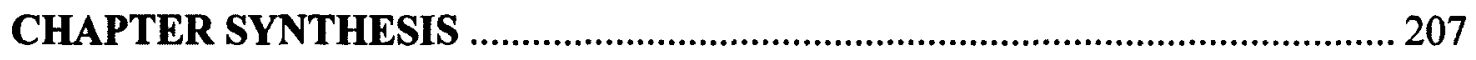

CHAPTER 7: JATROPHA'S ECONOMY OF APPEARANCES ……………...... 212

STATE OF INFORMATION ABOUT JATROPHA IN KENYA ..................... 212

Gaps and weaknesses in knowledge .......................................................... 213

Access to knowledge............................................................................................. 215

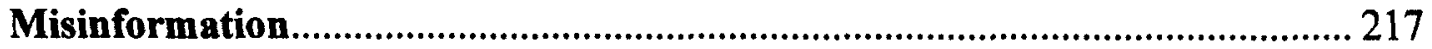

Filling knowledge gaps I: Importing exogenous knowledge ............................ 218

Filling knowledge gaps II: Parallels to other crops ........................................... 221 


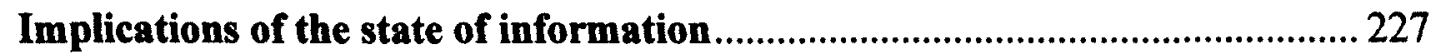

JATROPHA AND THE "ECONOMY OF APPEARANCES" …….................. 230

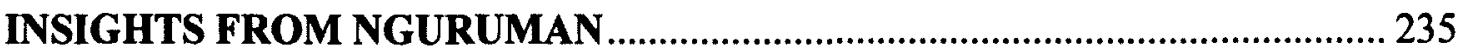

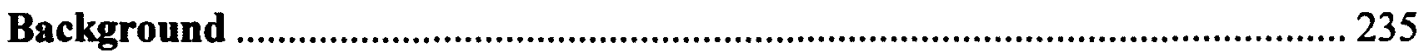

Jatropha activities in Nguruman ..................................................................... 238

Patterns in the circulation of knowledge ................................................... 242

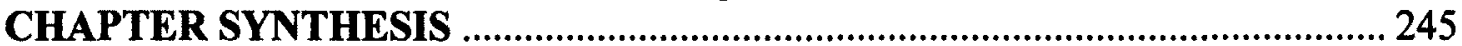

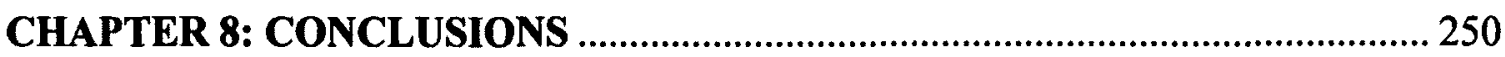

RESEARCH QUESTIONS REVISITED ...................................................... 251

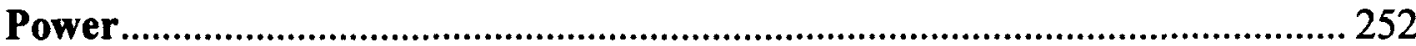

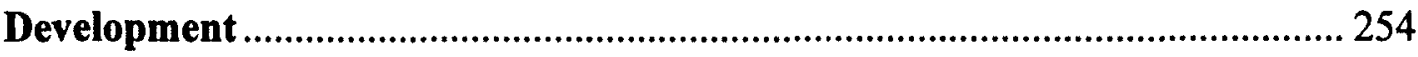

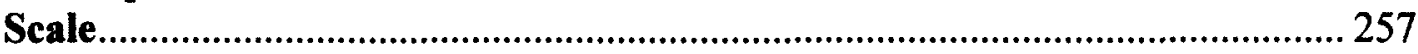

REFLECTIONS ON THE RESEARCH PROCESS.............................................. 261

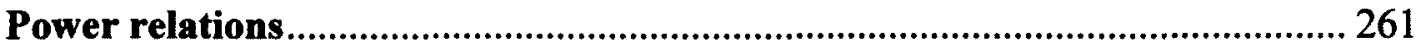

(How) did I contribute to a disproportionate focus on Jatropha? ................... 266

Subjectivity: on being an 'outsider' ...................................................................... 270

RECOMMENDATIONS FOR FURTHER RESEARCH ….......................... 272

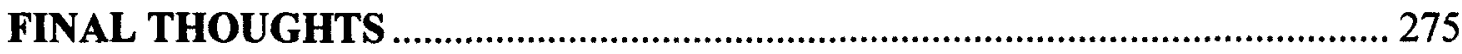

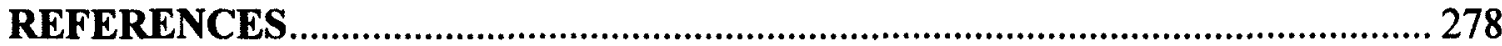

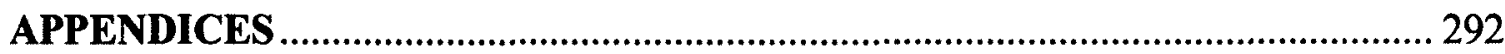




\section{LIST OF TABLES}

Table 2.1: Intersections between key concepts and research questions.................33

Table 2.2: Guide to research components, methods and thesis chapters......................36

Table 4.1: Summary of overall positions on Jatropha from key literature sources........97

Table 4.2: Headlines about Jatropha from various media sources, $2007-2010 \ldots \ldots \ldots . .104$

Table 4.3: Hectares to be planted with Jatropha, derived from announcements reported in Biofuels Digest, July 2008 - December $2010 \ldots \ldots \ldots \ldots \ldots \ldots \ldots 113$

Table 4.4: Strengths, limitations, and contributions of various sources of information on spatial and temporal patterns in Jatropha's spread.........120

Table 5.1: Who controls what with respect to Jatropha in Kenya?............................149

Table 6.1: Summary of perceived influences on Jatropha activities in Kenya.........176 


\section{LIST OF ILLUSTRATIONS}

Figure 1.1: Map of Kenya showing case study areas................................

Figure 2.1: Conceptualization of scales of activity for Jatropha in Kenya...............32

Figure 3.1: Global production of ethanol and biodiesel equivalent, 1975-2007.............57

Figure 4.1: Google search trends for the term "Jatropha".............................109

Figure 4.2: Jatropha projects and hectares cultivated by region ......................111

Figure 4.3: Jatropha project announcements, July 2008-December 2010 ..............114

Figure 4.4: Overlay of Jatropha project announcements, Google search trends, and Google news reference index, with timeline of key events,

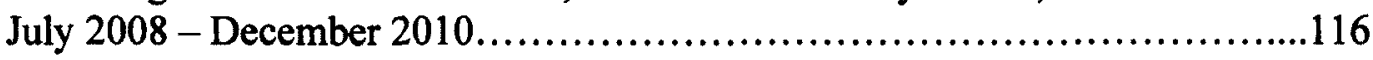

Figure 5.1: General value chain for Jatropha products............................151

Figure 5.2: Jatropha value chain, northern Tanzania .............................152

Figure 5.3: Jatropha value chain, Kenya.......................................152

Figure 6.1: Map of Mpeketoni area............................................. 190

Figure 7.1: Map showing Nguruman area .......................................236 


\section{LIST OF APPENDICES}

Appendix 1: Sample research questions for semi-structured interviews.........292

Appendix 2: Farmer survey ..........................................294 


\section{CHAPTER 1: INTRODUCTION}

In 2007-8, rising oil and food prices triggered international alarm. The price of oil reached record highs, putting economic pressure on the transport, agriculture and manufacturing sectors. For many countries this provided a painful reminder of their dependence on imported fossil fuels. As the price of staple foods sharply increased, riots and unrest occurred in several countries across Africa, central Asia, Latin America and the Caribbean (FAO 2008). Meanwhile, the Intergovernmental Panel on Climate Change (IPCC) released a sobering assessment of climate change scenarios and impacts (IPCC 2007), and negotiations intensified over a successor agreement to the Kyoto Protocol with the aim of dramatically reducing greenhouse gas emissions. Together these developments made the problem of producing low-carbon energy a higher priority on many national agendas and intensified the search for alternative energy sources.

Although these issues - food security, energy security and climate change - were by no means new, they converged in $2007-8$ in a way that collectively drew attention to their interrelationships from local through to global scales. In response to concerns about climate change and the stability of future oil supplies, biofuels ${ }^{1}$ have received an enormous amount of recent attention as a potential solution to the linked problems of energy, environment and development. Enthusiasm over biofuels has focused on three main discourses: environmental benefits (especially climate change mitigation), energy security, and rural development (Howarth et al. 2009; Ulmanen et al. 2009; Borras et al. 2010). Numerous governments have endorsed biofuels by establishing fuel blending targets (see Timilsina and Shrestha 2010), while media reports have at times trumpeted

\footnotetext{
${ }^{1}$ In this context, referring to liquid, combustible energy derived from organic matter (oils, starches or sugars), which are harvested more or less directly from plants, algae or animal tissue. See Chapter 3 for a more complete discussion of definitions and interpretations of the term "biofuels."
} 
biofuels' purported environmental and financial value using phrases like "wonder crop" and "green gold" (see Chapter 4).

However, some of these choruses of support for biofuels have diminished in the face of mounting social and environmental concerns. The food price crisis of 2007-8 drew particular attention to the potential for biofuel production to compete with food production, with many blaming biofuels for causing a significant share of the food price increases (Chakrabortty 2008; Muller et al. 2008; Rosegrant 2008; Pimentel et al. 2009). At the same time, researchers have increasingly scrutinized the attractiveness of biofuels as a 'clean' energy source by questioning their carbon balance (Creutzig and Kammen 2010) and introducing the concept of indirect land use change to account for hidden carbon emissions (Searchinger et al. 2008; Melillo et al. 2009). Attention has also turned to the negative impacts of biofuel production on people and environments at sites of production (e.g. Hall et al. 2009). Land rights have become prominent in debates over specific large-scale investments in biofuels (Cotula et al. 2008; Knaup 2008), while biofuels have been implicated in a series of international land deals, also known as "land grabs," an accelerating phenomenon with enormous implications for food security and social justice (Borras, McMichael, and Scoones 2010; Cotula et al. 2009; Borras and Franco 2010). Together, these concerns have tarnished the image of biofuels, particularly where their production is seen to divert or displace food crops, occupy highly productive areas or disrupt local people's access to land.

This suite of issues has compelled some governments and investors to shift their attention to biofuels that are, or at least appear to be, 'sustainably' produced (e.g. European Union 2010). Jatropha curcas, a small tree that produces inedible oilseeds, has 
received sustained attention because of its potential to produce biodiesel in a way that supposedly addresses concerns related to land use change, competition with food production, and the social and ecological impacts of large plantations. Jatropha's proponents claim that it flourishes in semi-arid areas that cannot sustain food crop production (e.g. Francis et al. 2005); together with the fact that it cannot be consumed by humans, this supports the perception that Jatropha circumvents the direct trade-off of "food versus fuel." Reports suggesting that Jatropha produces abundant seeds using little to no irrigation, fertilizer or pest control (e.g. Green Africa Foundation 2008) have further supported a perception that it is a low-input, high-output crop that produces positive outcomes for emissions reduction, food security and economic development at sites of production. Large plantations have been portrayed as a way to produce commercial quantities of Jatropha oil for domestic fuel blending or export (Jain and Sharma 2010), while smallholder cultivation has been presented as a "pro-poor" strategy for generating household income or improving rural livelihoods (Achten et al. 2010; Brittaine and Lutaladio 2010). In other words, on paper, Jatropha appears to qualify as an environmentally sustainable and socially just energy crop.

This thesis examines the international rise of interest in Jatropha curcas as a biofuel crop and situates this in relation to broader discourses of biofuels and development. Case research focuses on experiences in Kenya, where Jatropha has gone through a period of rapid promotion with mixed results. Some reports have hailed Jatropha as a promising solution to several interconnected problems, encouraging the national government, international donors and Kenyan non-governmental organizations (NGOs) to endorse its use. Although academic studies, media coverage and farmers' 
experiences have increasingly questioned this view, efforts to promote the crop to farmers have continued. Most of the research on Jatropha has so far has focused on questions of agronomy, life cycle assessment, or economics, leaving its political and social implications largely unexplored. This thesis addresses this gap by adopting a political ecology perspective to examine the motivations, strategies and experiences of actors who have been involved with Jatropha in Kenya. The empirical research presented here focuses on smallholder production because of emerging scholarship that identifies small-scale cultivation as the most socially and environmentally responsible way to produce biofuels (Milder et al. 2008; Hall et al. 2009). Focusing on the key concepts of power, development and scale, this research is guided by the following questions:

1. How did Jatropha come to be promoted in Kenya in the ways and to the extent that it has?

2. How do the experiences of smallholder farmers who are growing Jatropha compare with the claims of its promoters?

The first of these questions probes the political dimensions of Jatropha in Kenya, raising further questions about the key actors, influences, motivations and power relations that have shaped Jatropha activities in the country so far: On what grounds has Jatropha been promoted? By whom? For whom? How have multiple perspectives interacted with each other, including both official and dissenting views? Drawing on interviews conducted in 2009 with representatives of government departments, NGOs, private companies, donor organizations and research institutions who have worked with Jatropha in some capacity, 
this thesis analyzes the motivations and perceptions of these actors vis-à-vis Jatropha and asks how their views correspond to broad visions of progress identified in the development literature. The second question considers the perspectives of small-scale farmers in two areas of Kenya who have grown Jatropha under very different circumstances, asking: what range of hopes, expectations and intermediate outcomes have farmers expressed? In what ways and to what extent do their views align with the messages about Jatropha that were expressed by the key informants? Where they differ, how have these tensions played out? Here interviews with farmers are supplemented with observations from farm visits, interviews with local officials and group discussions.

Taken together, these questions lead to two major lines of thinking that are pursued throughout this thesis. The first explores the discourses of development that different actors have associated with the promotion of Jatropha in Kenya and considers their broader implications. A case study of the Jatropha Integrated Energy Project in Mpeketoni, Coast Province - an internationally funded initiative that involves over 1,000 smallholder farmers in growing Jatropha to produce energy for local use - illustrates how the meeting of actors with different agendas has played out in relation to a specific project. The research compares and contrasts the initial priorities of donors, coordinators and farmers and explores the extent to which these actors might be able to leverage the same set of resources to achieve multiple goals. 
Figure 1.1: Map of Kenya showing case study areas (CIA 1988: Nguruman and Mpeketoni added by author)

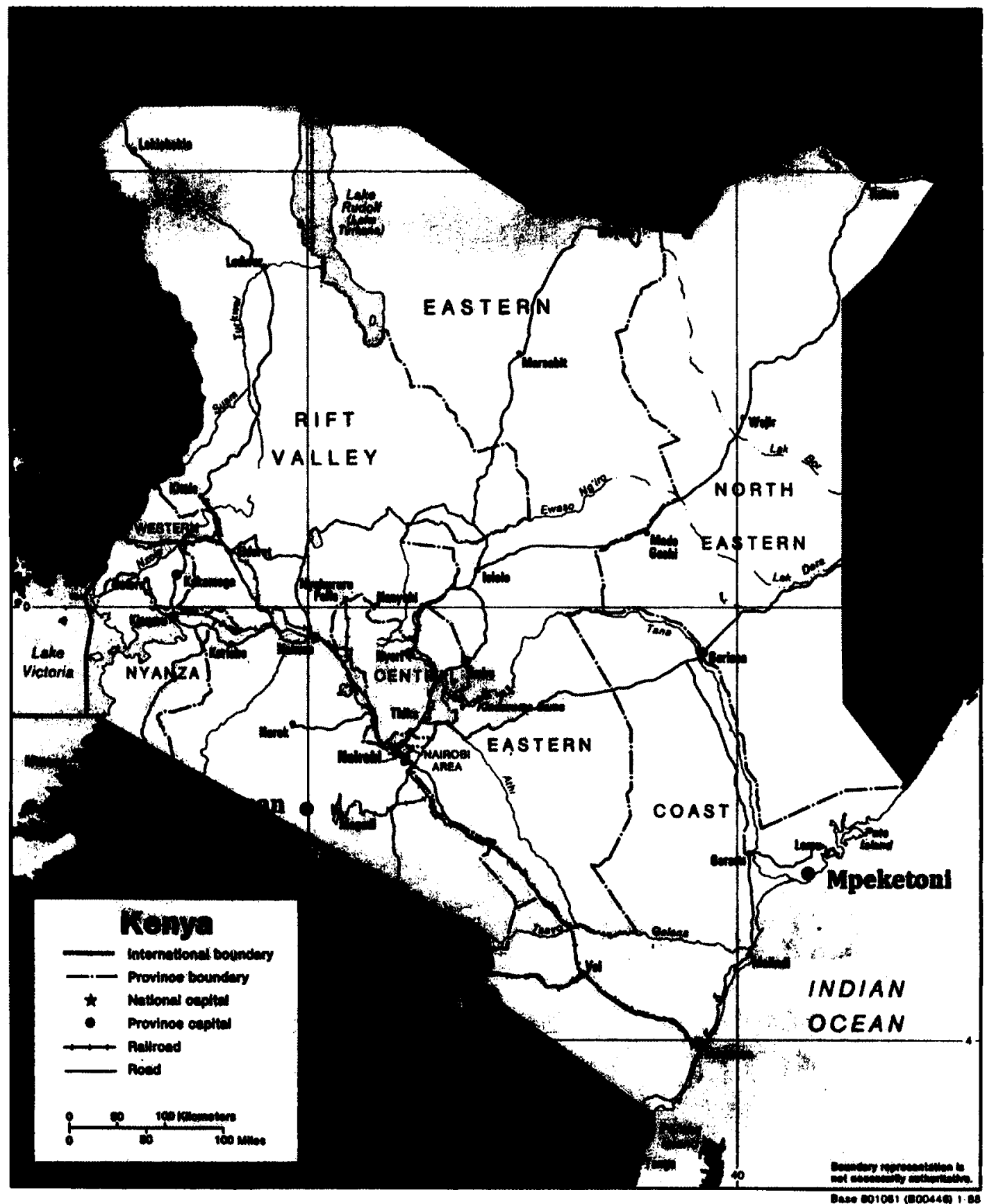

The second major theme of the empirical research considers the role that information and access to knowledge have played in influencing the trajectory of Jatropha activities in Kenya. Insights are drawn from the concept of an "economy of appearances" (Tsing 2000), where optimistic claims about an emerging market are seen to produce a surge of 
interest from investors - or in this case, development practitioners. An initial reading of Jatropha activities in Kenya suggests they have been characterized by a flood of favourable media and promotional reports, availability of donor money and a scramble of actors working to promote the crop. On closer inspection, unusual market conditions become apparent. This thesis considers to what extent various actors' interests may have become tied to propagating Jatropha itself instead of achieving the potential outcomes that made it initially attractive, and asks what role may have been played by a weak state of information surrounding Jatropha as a largely experimental venture at the time. A case study of Nguruman, Rift Valley Province - an area where smallholder farmers have grown Jatropha as fencing for decades, and which in recent years has attracted strong interest from researchers and entrepreneurs as a source area for Jatropha seeds in Kenya investigates how the behaviour of these outside actors corresponds to farmers' widely varying expectations of, and hopes for, Jatropha.

This research aspires to contribute to scholarship in three ways. First, examining farmer experiences in the context of Kenya's Jatropha experiment can inform efforts to develop integrated strategies for promoting rural energy sufficiency, livelihood opportunities and environmental integrity in the developing world. Second, critically documenting the evolution of a Jatropha industry in Kenya can provide insights into issues of mobilization and governance in the context of a largely untested development venture, where the choice of development paradigm has enormous influence on the outcomes. Finally, multiple-scale analysis connects Jatropha production by smallholder farmers in Kenya with some of the pressures and agendas that are driving international interest in biofuels, thereby speaking to broader questions about the linkages, tensions, 
synergies and contradictions involved with using biofuels on both individual farms and the international stage to approach the tightly connected challenges of energy, environment and development.

\section{Overview}

This chapter has introduced the issues that frame the research problem and presented the overall questions guiding the investigation that follows.

Chapter 2 identifies the intellectual roots of the thesis and describes the research process. Political ecology provides an overall theoretical perspective, while scholarship on discourses of development, NGOs and the "economy of appearances" are also influential. Power, development and scale are identified as key analytical concepts. Methodologically, the research follows a qualitative, inductive approach. The chapter concludes by discussing the field research process, giving particular attention to issues of case study and participant selection.

Chapter 3 delves into the substantive context, asking: What issues and concerns have motivated and influenced different actors' positions on biofuels in an international context? This big-picture analysis examines literature on biofuels, drawing out themes and competing agendas related to environmental integrity, energy security, and economic opportunities. Critiques of, and alternatives to, the dominant, large-scale model of biofuel production are presented. The chapter considers how different actors have activated the same discourses, but interpreted them in different ways, in order to justify contrasting positions on biofuels. Finally, Chapter 3 reflects on whether and how this range of opinions and strategies reflects different discourses or paradigms of development. 
Chapter 4 introduces Jatropha, reviewing literature on its characteristics, history and spread throughout the tropics. A survey of agronomic research plays an important role in assessing claims that Jatropha produces abundant oil when grown on semi-arid land - the basis of the argument that Jatropha is a 'sustainable' source of energy. An analysis of media coverage of Jatropha explores the messages and tone of debate. The final section of Chapter 4 tracks the spread of global interest and investments in Jatropha over time, providing context for the Kenyan case.

Chapter 5 turns specifically to the story of Jatropha in Kenya. It provides historical context and introduces the key players in Kenya's nascent Jatropha industry. The chapter then reviews the nature and extent of Jatropha activities in the country, including some unusual features that have characterized its spread.

Chapter 6 unpacks the motivations, agendas and influences that have driven the promotion of Jatropha in Kenya. Key informant perspectives are examined in relation to the discourses of development that they express. The chapter explores evidence of both competition and coexistence between these perspectives. Experiences from the Jatropha Integrated Energy Project in Mpeketoni are used to probe the tensions and opportunities that have arisen in a specific case where actors with divergent objectives have come together, each hoping to draw on the same set of resources to reach their goals.

Chapter 7 applies the concept of an "economy of appearances" to Jatropha in Kenya, asking what role a weak state of information may have played in influencing the crop's fast distribution. Experiences from Nguruman, Rift Valley Province explore the connections between the speculative behaviour of seed buyers from outside the area, a 
lack of coordination of Jatropha activities, and feelings of uncertainty and widely varying expectations on the part of farmers.

The final chapter reviews the main findings of the thesis and locates the implications of Jatropha's trajectory in Kenya in relation to broader patterns and trends. It returns to the questions posed in Chapter 2 on power, development and scale. Chapter 8 also reflects on the research process, revisiting some of the challenges identified in Chapter 2 with respect to power relations, reciprocity and subjectivity. Finally, it summarizes the contributions that this research makes to the bodies of scholarly literature identified in Chapter 2 and provides recommendations for future research. 


\section{CHAPTER 2: INTELLECTUAL ROOTS AND RESEARCH}

\section{FRAMEWORK}

This chapter introduces the theoretical, conceptual and methodological origins of the thesis and describes the research process that was undertaken. It draws on theoretical work from three bodies of scholarship that have inspired the research: political ecology, discourses of development, and international connections. The key concepts of power, development and scale are discussed alongside these theoretical influences in terms of their contribution to the conceptual framework used to investigate the research questions. The chapter then explains methodological decisions that guided the design and implementation of the project and outlines the research process that was followed. Reflections on the implications of these decisions can be found in the final chapter of the thesis.

\section{THEORETICAL INFLUENCES}

\section{Political ecology}

This research is strongly informed by political ecology, a "coming together" of political economy and cultural ecology that crosses several disciplines and focuses on factors that affect power relations both among people and between people and their environments (Paulson et al. 2003). Political ecologists place emphasis on understanding the political and economic systems that produce conflicts over access to resources, as well as the disproportionate impacts on impoverished people that can result from such conflicts (Bryant 1998). It is critical and normative in character, challenging dominant views of knowledge production and seeking "better, less exploitative and more sustainable" 
courses of action (Robbins 2004: 12). The explicit attention given to justice issues, alternative explanations, and real-world problem solving make this approach well suited to an examination of the political, environmental and practical aspects of using biofuels to approach local energy sufficiency.

As with much political ecology work, this research acknowledges both materialist and constructionist perspectives and does not align itself with one at the exclusion of the other. The materialist contribution comes from the biophysical ecology and political economy traditions. Biophysical ecology, concerned with "biological / biochemical and physical characteristics of particular environments," has been central to many foundational studies in political ecology (Walker 2005: 74), several examples of which are described below. A materialist political economy position holds that societal organization influences social relations and "recognizes how the strategic choices of social actors are limited by circumstance, time and space" (Clement and Vosko 2003: xv). In other words, the influence of biophysical, social and economic pressures on human decisions and actions must not be dismissed. Harvey (2006: 75) sees structural aspects of capitalism (such as the "material embedding of capital accumulation processes in the web of socio-ecological life") as central to understanding and explaining patterns of uneven development. He summarizes the tension between social structures and human agency by observing that agents "make their own way... not under conditions of their own making nor with results that are free of multiple determinations deriving from the actions of others" (p. 76). Political economy thus contributes to political ecology a theoretical framework for interpreting broad, structural forces that support prevailing 
systems of political and economic organization, and identifying forms of related tension and resistance that can and do foster changes in these systems.

A constructionist view, while not rejecting the existence of a material world, stresses the importance of social perception and linguistic expression in shaping human understandings of, and experiences with, our surroundings and interpersonal relations. From a Foucauldian perspective, "the social, how people act, think, and perceive, is actually constituted within linguistic description not merely revealing or reflecting it" (Waitt 2005: 164). Such a view has been applied by political ecologists who point out that the very definition of an environmental problem (e.g. land "degradation") involves social, even normative criteria that condition our interpretation of the issue (Blaikie and Brookfield 1987). This viewpoint pushes to the forefront the social and contested nature of knowledge, the framing of problems and the range of actions that actors perceive to be possible.

Political ecology draws on both of these perspectives to "understand the complex relations between Nature and Society through careful analysis of social forms of access and control over resources - with all their implications for environmental health and sustainable livelihoods" (Peet and Watts 2003: 4). In this way political ecology envisions two-way relationships between environmental changes and social, political and economic forces. It appreciates the importance of structural forces in shaping the course of events as well as the potential for resistance and change.

Further, political ecologists have set a strong precedent for digging deeply to understand complex and interconnected social and environmental problems in the developing world. This has meant challenging prevailing assumptions about human- 
environment interactions, no matter how entrenched they may be. Hecht (1985) provides a foundational example of this type of work, exposing political and economic forces that encouraged the conversion of Amazonian forest into pastureland while presenting soil quality data that contradicted the view that peasant agriculture was more ecologically destructive than large-scale farming. In another highly influential study on forest change, Fairhead and Leach (1997) showed how official explanations of an apparent problem of forest loss in Guinea were based on a fundamental misinterpretation of the causal relationship between human actions and land cover change, which had in turn led to the application of inappropriate 'solutions.' On the topic of agricultural production and soils, Blaikie and Brookfield (1987) radically reinterpreted the relationship between land degradation, hunger and social marginalization, concluding that political, economic and environmental processes strongly reinforced one another - work that has been credited with both exemplifying and advancing political ecology as a field of scholarship (Paulson et al. 2003). Forsyth's (1996) research on Himalayan soil erosion built on this tradition by using both social and biophysical evidence to overturn perceptions that upland farmers were carelessly cultivating steep slopes and worsening erosion. Moving beyond a focus on rural areas, Myers $(1999,2005)$ has pushed political ecology into African cities to help problematize and understand urban interactions between the social, the political and the ecological.

These selected examples illustrate the breadth and analytical power - as well as the diversity - of research within political ecology. Common threads include a commitment to challenging assumptions about causal relationships; elevating nondominant perspectives or voices; and seeking multiple or alternative explanations for 
human-environment relations with the intention of debunking or avoiding unhelpful strategies and promoting more beneficial ones, particularly from the perspective of marginalized people. These features make political ecology a suitable framework for this research, which aims to explore contrasting agendas, interests and interpretations of Jatropha's potential in Kenya - potential that has been expressed using a combination of biophysical, economic and humanitarian arguments - and to consider what these framings have meant for farmers who committed themselves to the Jatropha experiment.

\section{Key concept: Power}

A key concept for political ecology is power, or "the ability to achieve certain ends" based on the relationships between individuals and/or groups (Johnston 2000: 629). While some consider power to be a coercive force, in contrast to a 'softer' concept of persuasive influence (Pomerantz 2004), here I adopt a broader view of power that includes both of these interpretations. Allen (1997; in Johnston, 2000) describes three understandings of power: as an inscribed capacity ("power over" others), as a resource ("power to" do things), and as a set of strategies and practices used to reach desired goals. These conceptualizations of power can interact in complex ways. One way to interpret this interplay is through Foucault's (1980) view of power as a web, in which individuals simultaneously undergo and exercise power.

For the research problem considered here, one can anticipate that several forms of power relations and dynamics will be involved. These include obvious factors such as political power, land rights and access to financial resources, as well as less obvious characteristics such as status, social connectedness and access to knowledge. These 
overlap and interact, all linked in some way to access to (or exclusion from) resources and decision-making opportunities.

Political power in the research context represents a form of formal authority or inscribed capacity. Among other dynamics, Cooper (2002) points out that postcolonial governance in many African countries continues to follow a 'gatekeeping' model, where those who have managed to acquire political power are acutely aware of both its benefits and its fragility, and consequently focus much of their energy on maintaining their position. This strategy works against the objective of approaching a more equitable distribution of power and access to resources after a transition to independence (Cooper 2002), and can also lead to ethnically divisive rhetoric. These features - political gatekeeping (including patronage) and the alignment of political parties with particular ethnic groups - strongly characterize Kenyan national politics and will be re-examined later in the thesis. Aside from the personal power that can be gained through political office, national governments clearly also have the authority to create and enforce policies that have crucial influence over the terms of doing business - or development projects.

Power dynamics associated with the development and transfer of knowledge are another important aspect of the research problem. The brief examples of political ecology work described above show how particular assumptions or 'expert' assessments that development actors made in interpreting human-environment relations took priority over local understandings of the same issues, leading to the imposition of inappropriate strategies intended to remediate perceived environmental damage. The tension between exogenous and endogenous knowledge, together with the relative privilege assigned to the former, lies at the heart of not only academic debates over development but also 
tangible disputes over land (Mackenzie 1998). When exogenous knowledge becomes connected to political, financial and/or social power (for example, by becoming the official view of a government or donor organization), its "power to" achieve associated objectives is greatly amplified. The research questions that guide this thesis seek to investigate whether those who hold one or more particular understandings of Jatropha may have gained power by becoming linked to financial and other resources (e.g. those of donors and organizations promoting Jatropha), while other understandings (such as farmers' direct experiences) may have been suppressed or ignored.

This research departs from a point of awareness that connectedness to key individuals can represent a crucial form of social power, by enabling people to leverage status and popular opinion as well as (often) access to tangible resources in order to promote desired outcomes. I will return to this issue in relation to participant selection as well as potential self-censorship on the part of interviewees.

Where there is a distinct power differential, inevitably resistance can be expected. Scott (1990) eloquently describes how this resistance need not appear in overt, confrontational ways; rather, those with less power can employ an array of 'everyday' forms of resistance that include 'footdragging,' 'false compliance' and 'feigned ignorance,' as well as jokes and mockery about the more powerful when they are out of earshot. I will return to these topics in my reflections on the research process in the final chapter. 


\section{Discourses of development}

The empirical research is further guided by literature on discourses of development. Actions such as suppression of dissent and exclusion from so-called 'multi-stakeholder' processes align with Gaventa's (2006) assertion that when powerful actors adopt inclusive language or 'participatory' institutional structures, these can sometimes obscure rather than open up existing power relations - words taken as a warning of something to watch for in the analysis to come.

These power dynamics need not produce a single, dominant discourse ${ }^{2}$ of development (Grillo 1997). As Hilhorst (2001) observes, a plurality of discourses may persist, leaving room for conflict between competing perspectives as well as "room to manoeuvre" for individuals and groups who may invoke particular discourses to achieve different ends. This concept of coexisting discourses rests on Long's (1992: 22) actororiented perspective, which recognizes that although individuals and social entities inhabit different social worlds that are conditioned by power dynamics, each actor also has agency in the form of "the capacity to process social experience and to devise ways of coping with life." In other words, actors have some flexibility to interpret the conditions surrounding their lives and make decisions accordingly. This also implies that discourses themselves are not fixed; actors can interpret, reinterpret, and to some extent, modify them.

\footnotetext{
${ }^{2}$ Here, discourse is interpreted broadly as a paradigm or narrative that includes language as well as the assumptions and representations through which language is translated into social meaning (Grillo 1997).
} 


\section{Key concept: Development}

Before going further, it is crucial to discuss the concept of development and briefly outline some of the competing discourses that have been attached to it. Development, interpreted most broadly, can be taken to mean the idea that things are getting better. However, tremendous variation in the interpretation of this term makes it highly contentious. Hulme (2008), for example, differentiates between "little-d development" as "the broad set of processes underlying capitalist development," and "big-D development" as "the subset of consciously identified interventions aimed at the "third world" (337). This thesis draws on both of these meanings and more, recognizing that when some actors (international donors, for example) discuss development objectives their ideas may fit within Hulme's "big-D" of strategies targeted at the so-called 'developing world;' for others, comments on economic development may be linked to a neoliberal view of capital accumulation, while in still other situations, interviewees (particularly NGO representatives) may speak of 'rural development,' 'clean development,' etc. in ways that imply adherence to the sustainability or capabilities paradigms discussed below.

Competing perspectives on the concept of development have enormous influence on the ways in which people understand what is happening in the world, identify the root causes of problems, and recommend particular courses of action. One's ideas of what constitutes desirable development, and thus progress, have descriptive, explanatory, ethical and prescriptive implications. Most definitions of development attach normative value to both outcomes (ends) and processes (means). This section briefly introduces three development paradigms of relevance to discussions of biofuel production in Africa: neoliberal, sustainability and capabilities perspectives. 


\section{Neoliberal}

The central premise of a neoliberal perspective on development is that economic growth is desirable, and policies should focus on enabling "free markets" to deliver such growth. While its specific forms vary, a neoliberal governance strategy is generally characterized by a commitment to removing obstacles to the functioning of markets, curbing social spending, and promoting "the virtues of individualism, competitiveness and economic self-sufficiency" (Peck 2001: 445). In practice, this has translated into deregulating markets, privatizing public service delivery, weakening labour unions, and increasing transnational economic activity. These strategies have been championed through the World Bank's Structural Adjustment Programs, among other governance instruments.

A crucial feature of neoliberalism is its ability to reshape the state, sometimes described as a "hollowing out." Carroll (2005) argues that the cumulative effect of neoliberal policies is a shift in the balance of power in favour of capital at the expense of social democratic objectives, thus eroding many of what were traditionally viewed as core functions of the state. Scale considerations are also at play: the rise of neoliberalism has been accompanied by a shift of power away from the level of the state in two directions. "Globalization" and "localization" mean that power is simultaneously shifted upwards to multilateral bodies, and downwards onto provinces, municipalities, etc. through a process of devolution. Peck (2001: 447) contends that these processes produce qualitative changes in the functioning of the state, making it "differently powerful," rather than simply reducing it to a "less powerful" role.

A neoliberal approach is characterized by an emphasis on national comparative advantages. For sub-Saharan Africa this has historically meant promoting export-based 
agriculture and seeking foreign direct investment for primary mineral extraction. International land deals (also known as land grabs), where investors purchase or lease large tracts of land to produce food or biofuels, have emerged as a more recent manifestation of this approach (Knaup 2008; Cotula et al. 2009). This does not challenge a core-periphery view of (hierarchical) international relations. A neoliberal or growth paradigm is also applied by those who promote entrepreneurship and private sector activity, i.e. market-based strategies, as the best way to make social gains (e.g. Moyo 2009).

A neoliberal perspective tends to focus on changes to a country's Gross Domestic Product (GDP) or other economic measures as indicators of progress and success. Such definitions of 'standard of living' that are based on income or national economic growth have had a major influence in shaping government policies, development strategies and values, with major implications for social issues including the place of women in society (Waring 1999). Critics point out that measures of well-being based on income or GDP per capita fall short of representing local economic realities because they fail to account for the role played by informal economic activities and support networks (Fuess and Van den Berg 1998). More importantly, economic factors alone give an incomplete picture: they represent "well-having" rather than a broader state of "well-being" (Hopwood et al. 2005), which includes opportunities as well as people's perceptions of the quality of their own lives. A growing body of work argues that impoverishment represents exposure to multiple stresses or deprivations that extend beyond low income (Satterthwaite 2003), while for those with higher incomes, one's sense of well-being may depend less on additional income and more on factors such as social relationships and satisfaction at 
work (Diener and Seligman 2004). Thus, overemphasis on GDP hides many other important aspects of well-being and progress.

More pointedly, volumes have been written about the specific, negative impacts of Structural Adjustment Programs (SAPs) in the developing world. Critics argue that SAPs coincided with a drop in living standards, a severe weakening of public services, and a worsening of the economic situation in countries where they were applied (e.g. Escobar 1995; Ferguson 2006). As a development paradigm, the neoliberal view does not contest the economic superstructure or the idea that insertion into global capitalism is the way to achieve progress for developing countries (Wallace 2004).

What might a neoliberal perspective on development look like in relation to the research questions considered here? Neoliberal discourse could help to explain the worldviews and understandings of actors who prefer market-based or commercial approaches to promoting Jatropha in Kenya. For example, this could take the form of endorsing the idea of establishing centralized Jatropha plantations to support national fuel blending or export, where local benefits such as employment and cash income could be said to 'trickle down' from large-scale, private sector investments. Arguments for Jatropha that are based on increasing household income, or on the availability of energy being able to nurture small- to medium-sized enterprises could also fall into this category.

\section{Sustainability}

The term 'sustainable development' entered mainstream use through the report of the Brundtland Commission in 1987. The Commission defined sustainable development as "development that meets the needs of the current generation without compromising the 
ability of future generations to meet their own needs" (WCED 1987: 43), making explicit that decisions surrounding the use of natural resources must be made with due consideration to temporal (intergenerational) equity. However, the report extends this definition to include spatial (intragenerational) equity, identifying international inequality as the main problem for both environment and development. Importantly, working to attain a just distribution of resources in the present as well as into the future necessitates redistribution of resources and lessening of gaps in consumption - "sustainable global development requires that those who are more affluent adopt life-styles within the planet's ecological means" (WCED 1987: 9) - a position that is quite distinct from the neoliberal vision of striving to raise the standard of living 'for all.'

Sustainable development is often represented using a metaphor of three pillars (also depicted as legs of a stool or stones supporting a cooking pot), where the constituent elements are environment, society and economy. This image projects a need to equally balance attention to concerns in these (presumably discrete) areas; clearly an object held up by supports of different heights would be unstable. A variation on this theme portrays environment, society and economy as nested spheres, concentric circles or layers of a pyramid, where a functioning economy is seen to rely on a functioning society, which in turn depends on a functioning ecosystem. This adds a hierarchical element to the relationships between these three domains, prioritizing a healthy environment as a necessary foundation for social and, in turn, economic progress. A third type of metaphor - interlocking circles - stresses the need to integrate environmental, economic and social considerations by showing only the overlapping area in the middle as sustainable development. This suggests that the goal of sustainability cannot be reached by separately 
pursuing environmental, social and economic gains; rather, decision-making must be based on a holistic view that encompasses all of these areas.

These metaphors recognize the same three principal areas of concern and emphasize different kinds of relationships among them. These differences can be largely explained by the concepts of strong and weak sustainability, which offer contrasting opinions about the acceptability of trade-offs between different forms of capital (economic, social and natural). A weak sustainability perspective argues that it is permissible to substitute manufactured goods for natural ones as long as the total sum of assets (natural and human-made) does not decrease, while a strong sustainability perspective rejects this kind of trade-off and insists that the stock of natural capital must be held steady in its own right in order to maintain valuable ecological services that are excluded from cost-benefit calculations (Wackernagel and Rees 1996).

In other words, weak sustainability sees different forms of capital as substitutable while strong sustainability does not. In the context of this project this could mean the difference between, for example, supporting the idea of growing Jatropha on plantations that replace natural forest as long as these plantations provided at least as much revenue as the forest, versus protecting forests for their own sake. Another possible example would be growing Jatropha instead of food crops as long as the resulting income could pay for the same quantity of food, versus opposing such an approach on the grounds that local food production is sacrosanct.

Critics allege that the term 'sustainable development' is too malleable and has often been interpreted in ways that contradict the original spirit of the term (e.g. Lele 1991). In particular, a weak sustainability definition of development is seen to creep close 
to neoliberal conceptions of economic development, leaving the moral high ground associated with sustainable development open to appropriation by those who have a vested interest in promoting conventional economic growth. For example, so-called corporate social responsibility strategies are often accused of being little more than a public relations exercise, or "greenwashing," as opposed to motivating or reflecting any significant change in corporate practice (Munshi and Kurian 2005).

These concerns may be partially addressed by dropping the word 'development' and using the term 'sustainability' instead, while attaching it to a broader set of criteria that insist on a strong sustainability view of trade-offs and explicitly take into account the interests of marginalized people. Moving beyond the three 'pillars' of environment, economy and society, Gibson's (2000) sustainability principles include integrity, efficiency, equity, sufficiency, opportunity, civility, democracy, and integration. Importantly, participation, equity and redistribution are of primary concern in this interpretation of sustainability. This means not just raising the standard of living for everyone, but also a voluntary reduction in consumption on the part of relative socioeconomic élites. These critiques and responses show that understandings of sustainable development have evolved considerably, and continue to do so.

What might a sustainability perspective contribute to the topics and questions considered in this thesis? The literature reviewed in Chapter 3 suggests that the three constituent elements of environment, society and economy broadly match the main arguments made in support of biofuels globally. The thesis will later examine whether the themes emerging from the stated motivations and perspectives of those involved with Jatropha in Kenya bear any resemblance to these loose categories. If so, sustainability 
debates could provide insights into how actors see the possible synergies, tensions and trade-offs between these considerations, or indeed whether they seem open to viewing them in a holistic or integrated way. Other questions that sustainability literature could contribute to the analysis include: To what extent are the Jatropha activities described in the thesis participatory? Do they consider issues of intragenerational equity (i.e. redistribution and efforts to enhance opportunities for those with fewest means) and intergenerational equity (protecting resources and opportunities for the future)? For example, are there any signals that richer or more powerful actors (especially international players and potential trade partners) are seeking to redistribute resources, as opposed to pursuing their further enrichment at the potential expense of others? Do different actors' perspectives show signs of strong or weak sustainability perspectives on the substitutability of forms of capital, as suggested in the hypothetical examples above? Do ongoing discussions, let alone actions, reflect any desire to rectify systemic pressures that act as barriers to alleviating poverty, which the Brundtland Commission identified as the number one problem for both environment and development?

\section{Capabilities approach}

The capabilities approach focuses on expanding the range of what people can be and doin other words, the choices available to them - both by removing obstacles and enabling positive freedoms (Sen 1999). This interpretation of well-being has been taken up by a range of development actors as a paradigm that provides a conceptual framework without prescribing particular actions (Fukuda-Parr 2003). Autonomy and agency are strongly emphasized within the capability approach (Comim 2005), while gender perspectives 
have contributed to broadening the definition of agency from a focus on individuals to include the concept of collective agency (Fukuda-Parr, 2003).

While the capability approach generally entails qualitative, multiple and normative determinations of well-being that are based in moral and philosophical thought (Comim, 2005), it is also closely associated with the human development approach adopted by the United Nations Development Programme and expressed through the Human Development Index (HDI) (Fukuda-Parr, 2003). The HDI is a measure of average achievement based on literacy and education, life expectancy, and average income. These capabilities were selected for inclusion based on two criteria: first, they are considered to be 'universal' in the sense that they are valued by people all over the world; second, they are seen as 'basic' in that if they were taken away, many other capabilities would become impossible as a result (Fukuda-Parr, 2003). Critics have pointed out that because these variables are mathematically averaged in calculating the HDI they are treated as being substitutable, which goes against the idea that they are each basic and essential to wellbeing (Sagar and Najam 1998) - an argument that is conceptually parallel to the substitutability of forms of capital linked with weak sustainability.

The human development approach acknowledges that the choice of relevant capabilities is open-ended and will vary over both time and place (Fukuda-Parr, 2003) in other words, that definitions of well being and progress can be spatially specific. This is consistent with Sen's view that democratic deliberation should be used to approach questions of equity and social justice, and stands in contrast to Martha Nussbaum's efforts to define a set of central (universal) human capabilities (Feldman and Gellert 2006). 
A shift in the generally accepted working definition of well-being toward more inclusive concepts such as the capabilities approach elaborated by Sen (1999) is evidenced by - among many other examples - UNEP's (2007: 13) assertion that "human well-being is the extent to which individuals have the ability and the opportunity to live the kinds of lives they have reason to value."

What can a capabilities approach offer to this thesis? Clearly this is a paradigm which gives priority to human needs and aspirations, yet does not attach an operational set of criteria to a normative definition of development. The theme of expanding the range of possibilities and opportunities - choices - that are available to people provides a powerful way to interpret the motivations and goals of Jatropha actors in Kenya. What opportunities could different visions of Jatropha in Kenya create, and for whom? To what extent might the expansion of possibilities and choices for some people diminish the range of options available to others?

\section{International connections and NGOs}

The second research question (How do the experiences of smallholder farmers who are growing Jatropha compare with the claims of its promoters?) delves into the realm of global connections involving development NGOs and international donors. Here the discussion draws on Ferguson's (2006) observation that when international NGOs fund or deliver programs in particular places, the "point-to-point" character of these interactions can create trans-national connections that blur the distinction between "local" and "global." A case study of the Jatropha Integrated Energy Project in Mpeketoni 
provides an opportunity to scrutinize the extent to which the perspectives of international and "local" actors have become blurred in one such case.

Critical scholarship on development warns about the conflict of priorities that can arise through such arrangements (Mosse 2005), highlights the importance of connecting small scale projects to broader systems of influence (Edwards and Hulme 1992), and questions the extent to which NGOs offer genuine alternatives to state or market mechanisms (Petras and Veltmeyer 2001; Bebbington et al. 2008). These critiques of international development actors resonate with Tsing's (2005: 8) observation that "those who claim to be in touch with the universal are notoriously bad at seeing the limits and exclusions of their knowledge." With these cautionary words in mind, the Mpeketoni case probes the expectations of donors, project coordinators and farmers involved in the same Jatropha project.

Next, it is worth examining a more specific line of thinking within the critical literature on development: that of the perpetuation of myth. Tsing (2000) invokes the concept of an "economy of appearances" to explain how spectacle - mystery, drama and miraculous claims - played a pivotal role in attracting investment and driving forward private sector mining activities in Indonesia. Extending her analysis to other types of start-up companies, she writes: "In speculative enterprises, profit must be imagined before it can be extracted... The more spectacular the conjuring, the more possible an investment frenzy" (Tsing 2000: 118). At first glance, this depiction of a wellorchestrated performance sustaining "frenzied" interest in a new enterprise appears to have something in common with the case of Jatropha in Kenya. Whether the behaviour of 
NGOs and donors in Kenya mirrors that of Tsing's start-ups and investors in Indonesia is a question that will be examined later in the thesis.

Certainly many have critiqued development NGOs for acting opportunistically and tailoring their activities to donors' desires in order to secure funding (Petras and Veltmeyer 2001; Wallace 2004). Vivian (1994) sees the perpetuation of myths by the NGO sector being upheld by donors' excessive focus on "success stories" as a condition for future funding, with the result that failures are often covered up or misrepresented. Such a scenario encourages NGOs to minimize risk by engaging in activities which are popular at the moment, as well as to seek "magic bullet" interventions where a simple solution is expected to solve a complex development problem. In other words, NGOs can reap tangible rewards for jumping on a bandwagon and perpetuating myths of success. This view will be revisited throughout the thesis as one possible interpretation of events surrounding the spread of Jatropha in Kenya.

The theoretical perspectives presented here on the politics of development will be called upon throughout the thesis. Consistent with the political ecology work described above, critical literature on NGOs, knowledge and development discourses seeks to challenge dominant views in relation to highly normative interventions and planning.

\section{Key concept: Scale}

Scale refers to interacting levels of activity, and is one of the organizing concepts of geography. Geographic scale, as opposed to cartographic or methodological scale, reflects "the dimensions of specific landscapes" in relation to biophysical or human processes (Smith 2000). Smith (2000: 725) explains that scale is a product of human 
conceptualization, and therefore units of scale are not "natural" or given: "There is nothing inevitable about global, national or urban scales, for instance. These are specific to certain historical and geographical locations, they change over time... and in some cases a scale that operates in one society may fail to appear in another." Soja (1989) shares this view that scale is not fixed, calling it a "mutable hierarchy of nested locales." These definitions of scale highlight the close connections that exist between these "nested" levels of activity, as well as the subjectivity and fluidity that can characterize their conceptualization.

Literature on the politics of scale points out that the decision to recognize and emphasize particular levels of activity - in other words, the production of scale - has important consequences (Smith 1992). Tsing (2000) argues that creating a dichotomy between "global" and "local" is not helpful; instead, she encourages us to recognize that all scale-making projects are political. For example, framing a problem (e.g. the Chipko tree-hugging movement in northern India) as one of "community" or "local" politics can obscure both macro- and micro-level aspects of the situation: links to markets and broader political ambitions on one hand, and the diversity of identities and positions adopted by members of "the community" on the other (Peet and Watts 2003). In this sense, an understanding of broader influences as well as nuanced motivations may be lost by concentrating too closely on one level of analysis. The choice of which level(s) of activity form the basis of analysis can also lead to different conclusions about power relations (Neumann 2009). "Who controls what?" becomes a very different question depending how widely one looks for patterns of influence. Similarly, shifts in scales of activity can be understood as being coupled to shifts in power (Weller 2007). 
With these perspectives in mind, in designing this research I envisioned the interactions between scales as a set of nested spheres of influence, roughly corresponding to household or village, national, and international levels (see Figure 2.1).

Figure 2.1: Conceptualization of scales of activity for Jatropha in Kenya

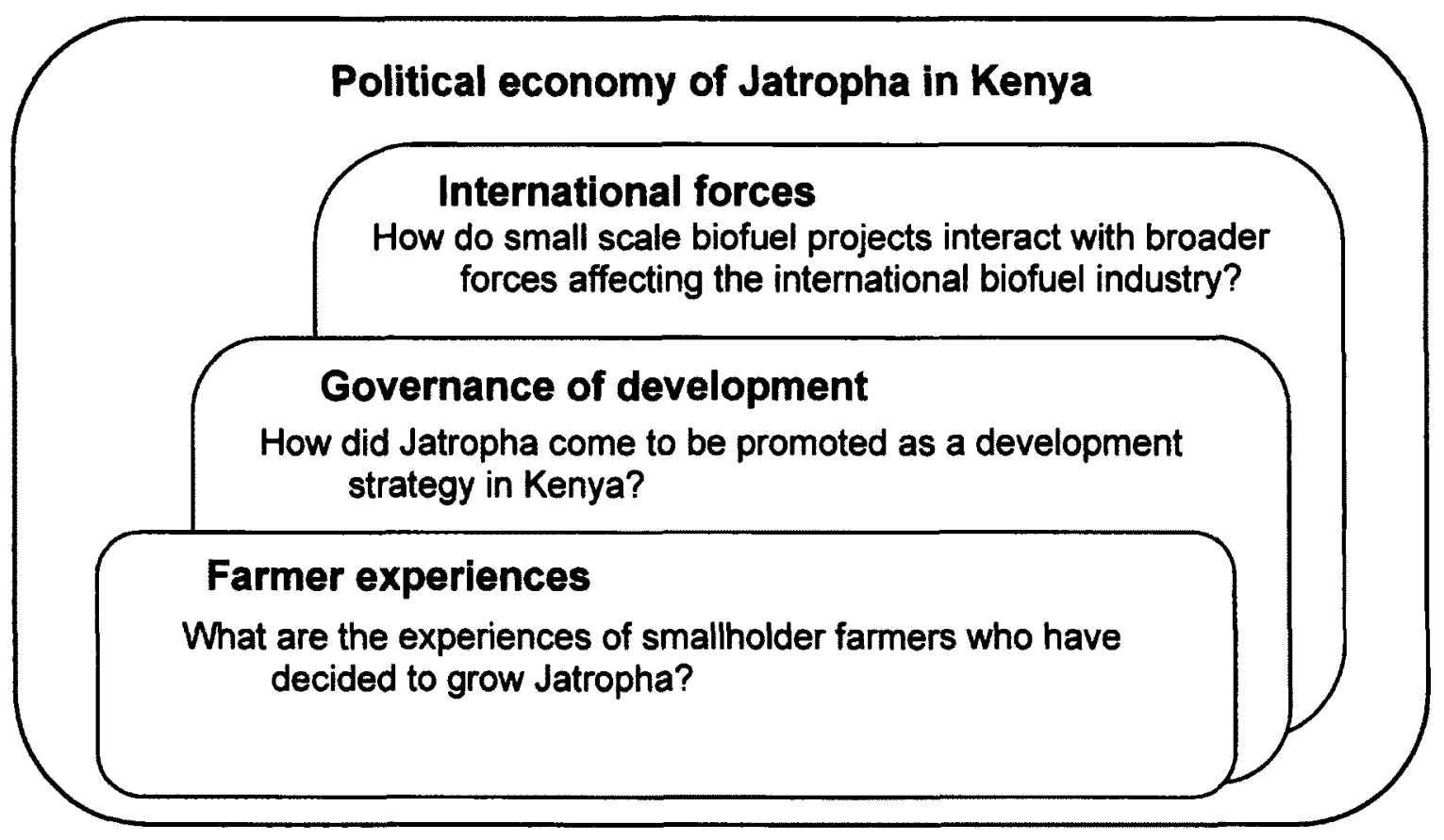

While these layers appear to be hierarchical, I do not mean to suggest that there is a unidirectional "downward" pressure created by processes at larger scales acting upon decisions and actions at smaller scales. Certainly I expected that small-scale projects would be strongly influenced by processes at the regional, national and international levels, but I also recognize and appreciate Gibson-Graham's (2002) assertion that resistance to "global" hegemonic power can meaningfully occur through decentralized, grassroots, locally-oriented actions. In this context, I also set out to consider ways in which efforts to achieve rural energy sufficiency in specific places could "push back" or influence developments occurring at broader scales. 


\section{Summary of intellectual roots}

This section has introduced several bodies of literature that comprise the intellectual roots of this thesis. Political ecology, discourses of development, and international connections form the theoretical foundation of this investigation, while the key concepts of power, development and scale will serve as recurring points of reference throughout the thesis. Table 2.1 summarizes the links between these key concepts and the research questions introduced in Chapter 1. These points of intersection will guide the analysis that follows.

Table 2.1: Intersections between key concepts and research questions

\begin{tabular}{|c|c|c|c|}
\hline & Power & Development & Scale \\
\hline $\begin{array}{l}\text { Question 1: } \\
\text { How did } \\
\text { Jatropha come } \\
\text { to be promoted } \\
\text { as it has in } \\
\text { Kenya? }\end{array}$ & $\begin{array}{l}\text { What power relations } \\
\text { characterize the } \\
\text { funding, introduction } \\
\text { and governance of } \\
\text { Jatropha in Kenya? } \\
\text { To what extent have } \\
\text { powerful actors } \\
\text { enabled participatory } \\
\text { decision-making or } \\
\text { benefit sharing? }\end{array}$ & $\begin{array}{l}\text { How do the goals } \\
\text { and motivations of } \\
\text { key actors relate to } \\
\text { development } \\
\text { discourses? } \\
\text { Is there a dominant } \\
\text { discourse of } \\
\text { development } \\
\text { attached to Jatropha } \\
\text { in Kenya? }\end{array}$ & $\begin{array}{l}\text { How have broader } \\
\text { forces or events } \\
\text { elsewhere influenced } \\
\text { Jatropha's promotion } \\
\text { in Kenya? } \\
\text { Is there evidence that } \\
\text { lessons from the } \\
\text { spread of Jatropha in } \\
\text { Kenya have been } \\
\text { applied elsewhere? }\end{array}$ \\
\hline $\begin{array}{l}\text { Question 2: } \\
\text { How do } \\
\text { farmers' } \\
\text { experiences } \\
\text { with Jatropha } \\
\text { compare with } \\
\text { the claims of its } \\
\text { promoters? }\end{array}$ & $\begin{array}{l}\text { What power relations } \\
\text { characterize the } \\
\text { enrollment of small- } \\
\text { scale farmers in } \\
\text { growing Jatropha? } \\
\text { Who has benefited } \\
\text { from Jatropha, in what } \\
\text { ways, and who has } \\
\text { not? }\end{array}$ & $\begin{array}{l}\text { What vision(s) of } \\
\text { development or } \\
\text { progress exist in } \\
\text { case study areas? } \\
\text { How do farmers' } \\
\text { priorities for } \\
\text { development } \\
\text { compare to those of } \\
\text { other actors? }\end{array}$ & $\begin{array}{l}\text { How do small-scale } \\
\text { biofuel projects } \\
\text { interact with broader } \\
\text { forces and discourses? } \\
\text { In what ways have } \\
\text { farmers attempted to } \\
\text { influence events at } \\
\text { other levels of } \\
\text { activity? }\end{array}$ \\
\hline
\end{tabular}




\section{RESEARCH FRAMEWORK}

\section{Methodological decisions}

This research falls within the qualitative research paradigm and involves case studies as a conduit through which insights are derived. A case study approach was deemed appropriate for this project because it explores "how" and "why" questions, does not require control over behavioural events, and focuses on contemporary phenomena (Yin 1996). The cases investigated here were chosen not to test theory, but to generate it by following a cyclical process of observation, reflection and comparison to literature in order to develop and refine explanatory ideas (Baxter 2010).

This research was guided by some features of genealogy as elaborated by Foucault, including a commitment to documenting non-linear processes, discontinuities, "accidents," dead ends, and dissenting voices not represented in the master narrative (Foucault 1977). While I did not design and carry out the project as a Foucauldian discourse analysis, I have adopted several aspects of this methodological approach. These include reflecting on the social and institutional conventions that affect the relative empowerment of my research participants, scrutinizing my positionality as a researcher, and remaining open to letting themes and categories emerge through the analysis rather than imposing rigid analytical categories from the start (Waitt 2010). ${ }^{3}$ I depart from a Foucauldian approach by placing emphasis on individual perspectives; however, I strive to identify discursive structures in order to locate actors' stated views within a broader social, political and institutional context. For example, as Ferguson (1994) notes, statements produced by members of the development establishment (and perhaps any

\footnotetext{
${ }^{3}$ I will return to a more in-depth discussion of how critical reflexivity influenced the project in the final chapter of the thesis.
} 
institutions) are often biased or misleading, but even so they reveal important insights about the institutional culture in which they are expressed.

This research has followed an iterative process where reflexivity has played a central role. Preliminary reading and field work in 2008 informed the research questions, which in turn guided the initial selection of participants and interview questions. However, as the research progressed I used an inductive approach to identify patterns and themes in participants' messages, adapting the research plans to follow up on new threads while acknowledging that some of my preconceived ideas turned out to be less relevant than I expected (as is inevitably the case). The analysis of actors' motivations and expectations was strongly inductive, and led to a schematic diagram of relationships between themes and strategic approaches that I derived from interviewees' perspectives rather than a predetermined set of categories. Throughout this process I wrote almost daily in a 'thesis journal' where I developed my ideas and reflected on my role in relation to the research participants, motivated by Maxey's (1999) view that reflexivity represents a constructive way to confront and engage with power relations that it is not possible to simply identify and avoid.

The result of this process is a complex story of how the promotion of Jatropha in Kenya evolved - including ways in which influential players have dealt with dissenting voices - rather than an account of a linear chain of causal events leading to a single interpretation of the present. The rest of this chapter discusses the research process in detail. 


\section{Research process}

The core of this research comprises empirical field work that was conducted in Kenya in 2008 and 2009. The field work followed a two-pronged approach: exploring the perspectives of key actors who had worked on promoting, studying or regulating Jatropha, and exploring the perspectives of smallholder farmers who were already growing the crop. One-on-one interviews served as the primary research tool, supplemented by farm visits, participant observation, group discussions and a review of scholarly, 'grey' and media reports. Research participants included farmers, researchers, and representatives of NGOs, donor agencies, government and private companies. Table 2.2 shows how these approaches match with the major research components and questions already presented, and indicates where in the thesis the results of each part of the investigation can be found.

Table 2.2: Guide to research components, methods and thesis chapters

\begin{tabular}{|l|l|l|}
\hline Research component & Methods & Thesis Chapter \\
\hline Context: Biofuel discourses & Literature review & Chapter 3 \\
\hline $\begin{array}{l}\text { Context: Jatropha and its } \\
\text { international spread }\end{array}$ & $\begin{array}{l}\text { Literature review; analysis } \\
\text { of project announcements }\end{array}$ & Chapter 4 \\
\hline $\begin{array}{l}\text { Question 1: How did Jatropha } \\
\text { come to be promoted in Kenya? }\end{array}$ & Interviews with key actors & Chapters 5, 6,7 \\
\hline $\begin{array}{l}\text { Question 2: How do farmers' } \\
\text { perspectives compare with other } \\
\text { actors? }\end{array}$ & $\begin{array}{l}\text { Case studies: farm visits, } \\
\text { interviews with farmers and } \\
\text { local officials }\end{array}$ & $\begin{array}{l}\text { Mpeketoni: Chapter 6 } \\
\text { Nguruman: Chapter 7 }\end{array}$ \\
\hline
\end{tabular}

This section describes the activities I undertook during the research process including criteria that I used to make decisions along the way. This is followed by a discussion of decisions and actions that I took to attend to issues of power, reciprocity and trust during 
my time in the field. ${ }^{4}$ A deeper reflection on the relative successes and shortcomings of these strategies, as well as the limitations they may place on the research findings, appears in the final chapter of the thesis.

\section{Overview of field work activities}

I conducted a short period of preliminary field work in Kenya in July-August 2008. In preparation for the trip, I read as much as I could about Jatropha and identified some of the players I wished to meet. While in Kenya in 2008, I met with representatives of NGOs, government, research institutes and the private sector in Nairobi and traveled to field sites in Rift Valley, Eastern and Coast provinces where I met with farmers and visited their fields of Jatropha. I began to plan my strategy of using key informant interviews to investigate the politics of Jatropha by interviewing actors who were involved in its promotion and regulation, and using case study research in two rural areas to investigate the implications of its promotion from farmers' point of view. I identified a few possible case study locations and began to establish connections with actors who I would later interview in depth. Expanding my network of contacts and establishing a preliminary link with ICRAF, which later hosted me as a Degree Fellow in 2009, were other important steps made during my first field visit.

The main period of field research took place from February-July 2009, during which time I based my research activities out of the office of the World Agroforestry Centre (ICRAF) in Nairobi, with periods of travel to two case study sites in Nguruman and Mpeketoni. The case study research involved a two-week initial visit to each location

\footnotetext{
${ }^{4}$ My work benefited from the input of researchers at the World Agroforestry Centre (ICRAF) in Nairobi, where I was hosted as a Degree Fellow during my 2009 field season in Kenya. Some of these colleagues were undertaking agronomic and socio-economic research on Jatropha and other biodiesel crops.
} 
followed by one or two return visits to conduct follow-up visits, interviews and discussions. I used the time between field visits to interview key informants, plan upcoming arrangements and consolidate the data gathered up to that point. Before I left Kenya, I prepared summary reports of my observations and presented these to strategic individuals in each case study location, as explained below.

\section{Key informants}

In order to probe the political aspects of Jatropha activities I interviewed representatives of government agencies, ${ }^{5}$ non-governmental organizations, ${ }^{6}$ private companies, ${ }^{7}$ private consulting firms, ${ }^{8}$ and donor agencies. ${ }^{9}$ In total, 22 representatives of these groups were interviewed. None of those who I approached declined to participate. Interviewees were drawn from organizations that have been active in promoting Jatropha specifically, and/or biodiesel more broadly, in Kenya to date. It was not my intent to conduct an exhaustive survey of all actors who were involved with Jatropha in Kenya; rather, I sought to include influential figures, actors from a range of sectors and types of institutions, and views that fairly reflected alternative perspectives about Jatropha. Preliminary field work in 2008 enabled me to develop a sense of the institutional landscape and establish initial contact with many of these actors. Further contacts were identified through a snowball process

\footnotetext{
${ }^{5}$ Ministry of Energy, Ministry of Agriculture, Kenya Agricultural Research Institute, Kenya Forest Research Institute

${ }^{6}$ Green Africa Foundation, Vanilla Development Foundation, Vanilla-Jatropha Development Foundation, Help Self Help Centre, Community Project Support Organization, Africa Youth Initiative on Climate Change, UNDP/DED/WWF

${ }^{7}$ Better Globe Forestry Ltd, Energy Africa Ltd, Biogreen Technologies

${ }^{8}$ Endelevu Energy, Pipal Ltd, Camco

${ }^{9}$ United Nations Development Programme - Small Grants Programme, Kenya Agricultural Productivity Project (funded by World Bank), Norwegian Church Aid
} 
that built on the networks of existing contacts, ${ }^{10}$ including a database compiled by ICRAF on behalf of the National Biodiesel Research Subcommittee. As the research proceeded, I sought out interviewees who had given up on Jatropha or shifted their emphasis to other activities as well as those who remained committed to advocating it.

Interviews with these informants explored questions such as how and where they first encountered Jatropha, what caused them to decide to work with it, who they saw as the major players surrounding its use, what encouraging signs they encountered, what obstacles they saw, where they thought the industry would go in the future, and what (if any) doubts they had about Jatropha's ability to play a positive role. ${ }^{11}$ These interviews, ranging from 30 minutes to two hours in length, were audio recorded and transcribed in full.

In addition to key informant interviews, I conducted a review of grey literature and media coverage including consultants' reports, news stories, organizational newsletters, websites, blogs and government documents. Attending a meeting of the National Biodiesel Research Subcommitte ${ }^{12}$ and a National Biodiesel Workshop ${ }^{13}$ provided important snapshots of current influences on decision-making surrounding Jatropha and biodiesel strategies in Kenya. These events gave me an extremely valuable opportunity to observe many of the key informants who I had interviewed individually as they interacted with each other in a setting where they discussed and responded to recent

\footnotetext{
${ }^{10}$ I am aware that using a snowball approach could create a situation where potential participants might feel compelled to participate and/or to answer interview questions in a particular way if they were recommended by someone who has power over them. I tried to avoid this situation in two ways: first, by considering the power dynamics involved before contacting any potential participant recommended by another; and second, by reassuring potential participants that they could choose not to have direct quotations attributed to them (even anonymously) in the research outputs.

${ }^{11}$ See Appendix 1 for a sample list of interview questions.

${ }^{12}$ Held April 7, 2009, in Nairobi at the Ministry of Energy offices

${ }^{13}$ Held June 9, 2009, in Nairobi at the World Agroforestry Centre (ICRAF)
} 
research findings. Together, the key informant interviews, careful reading of documents and participant observation of meetings have enabled me to build a critical 'back story' of the actors and events that converged to make Jatropha the top priority in the Kenyan government's draft renewable energy plan of 2008 and a popular choice for donor funding within just a few years of being recognized as a potential energy crop in Kenya.

\section{Case study selection}

The key actors outlined above were well placed to discuss their motivations and the pressures that influenced the spread of Jatropha, but I also wanted to learn about the experiences of farmers who were actually carrying out this experiment. To explore farmer perspectives, I selected two case studies where groups of farmers were already growing Jatropha and pursuing the option of collectively processing Jatropha in order to support local energy needs. The initial selection criteria for case studies were as follows:

a) A group has formed to coordinate or deliberate over a strategy to grow and locally process Jatropha (i.e. there is an expressed desire to use Jatropha as an energy source);

b) Some Jatropha is already growing (i.e. the discussion is more than hypothetical);

c) The group shows willingness and interest to participate in the research (i.e. the case study is accessible).

Based on these criteria and initial contact in 2008, I selected Nguruman (Kajiado District) and Mpeketoni (Lamu District) as the two case studies for the research. Ongoing Jatropha 
projects in Kwale and Shimba Hills, Coast Province, would also have met the criteria but were already being studied by other graduate students. These locations both fit within the selection criteria but showed some marked differences from one another: while Mpeketoni was the site of a major Jatropha project funded by an international NGO, Nguruman had been treated as a source of seeds by researchers and seedling nursery managers who bought small quantities of seeds on a sporadic basis, but no one had attempted to organize Jatropha growers or initiate a project. Thus, in both locations farmers had high hopes that growing Jatropha could represent a beneficial enterprise. However, those in Mpeketoni had an existing framework on which to pin those hopes, while those in Nguruman were still seeking a viable way to move forward with Jatropha production and processing. The two case studies thus provide an intriguing contrast and an opportunity to explore factors that contributed to farmers' different experiences with Jatropha production in the two places.

\section{Research assistant}

While in the case study locations, I travelled with a research assistant who performed Kiswahili-English translation during most of the interviews. I made the decision to bring an assistant from Nairobi rather than to hire someone in each case study area for two reasons. First, this strategy enabled me to choose someone with an appropriate skill set, including prior experience working for a researcher as a field translator. This made it easier for me to be confident in the quality of the translations and reduced the time it would take to train the assistant. Second, I thought it would be better to share the public "face" of my research with someone who was not bound up in the social dynamics of the 
places I was visiting. At first I thought of this mainly in terms of avoiding the perception that we were connected to local loyalties and social networks, but I realized that there was also a relevant ethnic dimension. While I did not make ethnicity a significant factor in my search for an assistant, I was aware that there were two major ethnic groups in each location (Maasai and Kikuyu in Nguruman; Swahili and Kikuyu in Mpeketoni), and I was slightly relieved that the most suitable of the three candidates who I interviewed for the job did not belong to any one of these groups. I hoped this would help us avoid being caught up in any "us-and-them" thinking that might exist in each place, particularly given the history of settlement and land distribution in each area, discussed in Chapters 6 and 7 . My assistant, James, was a young man in his early twenties who proved to be well suited to the role. He showed genuine curiosity for the research topic and asked me endless questions at the beginning of the project. I was impressed by his ability to interact comfortably, naturally and respectfully with everyone we encountered, and to quickly connect with others. Those who we interviewed together seemed to warm to him regardless of their age, gender or ethnicity. His polite inquisitiveness helped both of us to learn about the people and places we encountered. He was often able to draw more insights out of an interviewee by describing how something worked in his own rural home area, and asking the interviewee how the same thing worked where we were. In a way, he was an intermediate outsider - not as "different" as I was, which seemed to help people feel comfortable explaining things to him that they might not have told me alone. 
Case study activities: Nguruman

In Nguruman, I interviewed 26 individuals during my first stay: farmers, Jatropha buyers and sellers, agricultural officers and managers of the Community Information Centre. I revisited most of these participants for at least one follow-up discussion during my second and third visits to the area. During each farm visit, I conducted a survey covering socio-economic characteristics of the interviewee and household, current farming practices, energy use patterns, and Jatropha management practices, investments and outcomes (see Appendix 2). This questionnaire was consistent with the one being used for a baseline survey of oilseed production in Kenya taking place at the same time (GTZ 2009). I then conducted a semi-structured interview asking the farmer about their motivations, expectations and experiences so far with growing Jatropha. Most of these surveys and interviews were conducted in Kiswahili and translated by my research assistant. Where farmers were comfortable using English, I conducted the interviews myself. In addition to farmers, I interviewed officers at the Ministry of Agriculture office in Entasopia and managers of the Community Information Centre.

During my second visit, I shared some early findings with the farmers and asked about their own priorities for learning about Jatropha: what lingering questions they had, what they felt were the priority issues to address, and in what format they would like to discuss these topics. On my third and final visit to Nguruman, I hosted a public forum addressing these topics, inviting all of the research participants as well as all other interested individuals who wished to come. The forum was attended by 11 interviewees and approximately 20 other people. The purpose of this forum was to share preliminary findings with research participants and respond to their questions, as well as to create an 
opportunity for them to discuss the topic of Jatropha with each other. Reflections on the forum can be found in Chapter 8. During my final visit, I also spoke with several shopkeepers about fuel consumption patterns in the area. After this visit, I sent a short summary report and the minutes of the public forum to a few individuals who I believed were in a good position to disseminate these messages to others.

Most of the participants in Nguruman were identified either by one main contact or through a group discussion with local youth who were engaged in thinking about Jatropha. I targeted farmers with a range of experiences: those who were growing Jatropha as fences, experimenting with it in their fields, collecting it from the 'wild,' buying and selling it as entrepreneurs, and contrasted their perspectives with those not interested in pursuing it.

I chose not to audio record my interviews with farmers because I worried that doing so might inhibit their expression of views. I reached this decision after my first few farm visits in Nguruman. When I consulted with my research assistant, he affirmed that he thought farmers might feel shy or awkward if they were not only being asked for their opinions by a foreign visitor, but also being recorded by an unfamiliar piece of technology at the same time. I therefore relied on taking extensive notes during farmer interviews and typing these up as soon afterwards as possible, annotating them with additional information that I did not have time to record during the interview itself. The implications of this decision, in terms of privileging the perspectives of key informants whose words were recorded and directly transcribed, are discussed in the final chapter. 
Case study activities: Mpeketoni

In Mpeketoni, I followed a similar strategy of visiting farmers on their farms and engaging them in both a socio-economic survey and a semi-structured interview. First, though, it was necessary to gain approval to study the project from Norwegian Church Aid (NCA), its sponsor.

During my first stay, in May 2009, I was based in Mpeketoni with day excursions to visit farmers in the surrounding areas of Ngoi, Bomani, Mapenya, Hongwe, Ziwani, Lake Amu and Hindi (see map in Chapter 6). I interviewed 28 farmers in depth, 26 of whom were growing Jatropha. I also interviewed coordinators of the Jatropha Integrated Energy Project (JIEP) and other relevant actors including representatives of the Lamu Cotton Growers and Industrial Association, the Government of Kenya Agricultural Training Centre (Mpeketoni), Kenya Power and Lighting Company Ltd, and local youth leaders. These interviews were semi-structured. My research instrument for these interviews comprised a prepared question list, but I diverged from this to discuss particular topics in more depth depending on the expertise of the interviewee. Like the farmer interviews, I conducted these discussions in English (by myself) or Kiswahili (with my research assistant translating), whichever was more comfortable for the interviewee. During my second trip to Mpeketoni (in July 2009), I attempted to visit each of these farmers again and succeeded in reconnecting with over half.

Most of the farmers who took part in this research were suggested by JIEP leaders, thus allowing for the project leadership to play a screening or gatekeeping role. As well, one of the JIEP leaders accompanied me to the farms. This had the benefit of allowing farmers to address questions about the project directly to the leader, but had the 
disadvantage of possibly making farmers reluctant to express negative views about the project. I will return to reflect on this issue further in the final chapter of the dissertation. Transportation constraints provided another limitation on the research. My assistant and I traveled to most farms by bicycle or motorbike. Given the large expanse of the project area (approximately $75 \mathrm{~km}$ in diameter) and the paucity of vehicles, it was not possible for us to reach more distant areas until the end of the visit when an NCA project car became available.

Near the end of my stay in Kenya, I prepared a short report of my observations and some recommendations for the JIEP project, which I submitted to NCA at their request. I gave a verbal summary of this report to the JIEP coordinator on my final visit to Mpeketoni.

Analysis

All audio-recorded interviews were transcribed in their entirety. I typed up my handwritten notes from the farmer interviews as soon afterwards as possible, adding any details that I remembered but had not had time to write down while the interview was taking place. I then coded the interview transcripts and notes, assisted by the software package Atlas.ti.

I began with a set of codes loosely drawn from the research questions and my initial observations. As I went along, I added more codes in response to emergent themes, while adjusting some of the ones I had started with to more meaningfully reflect the content of the interviews. As outlined by Cope (2010), some codes focused on manifest messages using terms mentioned by the interviewees (e.g. "market," "benefits," 
"environment") while others focused on latent messages that required more abstraction (e.g. "motivations," "shady business"). After coding and recoding the interview data I extracted and reread each set of quotations that were assigned to the same code, making additional notes of themes and patterns. This reexamination of the data helped me to organize the logic of the writing as well as to select particularly vivid quotations to include in the text.

During the analysis and write-up stages, I occasionally kept in touch with key contacts in Nguruman, Mpeketoni and Nairobi - mainly by e-mail, and occasionally by telephone. In this way, I continued to receive updates on Jatropha activities in the case study areas, and was alerted to the release of relevant reports and the announcement of new developments in the policy formation process. Maintaining contact in this way also enabled me to gather some feedback from participants on my preliminary results and work in progress.

The writing process followed a cyclical pattern where I built a tentative structure for the thesis, developed the main ideas and arguments by writing draft material, critiqued what I had produced, and revised the logic - and even the structure - of the thesis accordingly. I simultaneously developed written material for different audiences including conference presentations and articles for scholarly and popular publication.

\section{Positioning myself as a researcher}

This project was approved by the Carleton University Office of Research Ethics, whose guidelines I followed in designing the consent procedure and other mechanisms for protecting participants from possible harm (e.g. withholding their names from the final 
write-up; allowing them to review and approve specific quotations). In planning this research I identified several interpersonal challenges that I hoped to overcome. These were to establish a relationship with participants based on a mutual feeling of reciprocity; give back something worthwhile to the participants; and acknowledge power imbalances and mitigate or manage them appropriately. This section discusses the strategies I employed in order to attend to these issues. In the final chapter, I will return to these challenges and reflect on the extent to which my efforts produced the kinds of outcomes that I hoped they would.

\section{Reciprocity}

Consistent with the aims of action research, I approached this project wanting to establish a tone of trust and mutual respect as well as to give something useful back to its participants. In Nguruman and Mpeketoni, I sought to build trust by returning more than once to each place and making sure that I visited each participating farmer at least twice. In addition to my research activities I made a conscious effort to take part in informal activities and to pay visits that were social in nature (e.g. paying respects to a new baby, hiking on the weekend with local youth, helping to prepare food, or dropping by a participant's roadside shop for a chat).

For farmers in both locations I brought token gifts to express my appreciation for their time and participation. For example, on my first visit to each farm I brought tea leaves and sugar, a standard gift in Kenya when visiting someone's home. I presented these at the end of the visit after the interview was complete. Nearly all participating farmers agreed to let me photograph them on their farms; on my second visit, I gave each 
one a print copy of their picture. Several commented that this was unusual - that many visitors had taken their picture before, but had never given them back the photo. I believe that these small actions were important in building a positive rapport with participants. By contrast, I did not give gifts to participants who I interviewed in their professional capacity (e.g. local government officers).

Beyond these small gifts and efforts to spend quality time with participants, I saw my main contribution as my ability to link each group of actors with the insights and experiences of the others, ideally helping them to learn from each other and inform their strategies for moving forward. This was the main thing that I offered to 'give back' to my participants when I approached them.

Toward this end, during my final visit to Nguruman I held a public forum to share some of my findings and facilitate a discussion about Jatropha. I personally invited everyone who had participated in my research, in most cases by making a personal visit, and by telephoning those who were not in when I passed by their homes. I also extended a general invitation to anyone who was interested in discussing Jatropha, conveyed by word of mouth and by putting up Swahili-language posters around the main cluster of shops. Eleven interviewees and approximately 20 other people attended the forum. For the research participants in Nguruman, I also prepared a short report that included insights from my research and contact information for some individuals and organizations who I thought they might find helpful should they choose to pursue the possibility of establishing a local Jatropha processing operation.

In Mpeketoni, I submitted a report to NCA and gave a verbal summary of my thoughts to the JIEP coordinator during our last meeting, as noted above. As NCA asked 
of me, I have continued to provide them with materials I have written about the project so that they can have advance notice before these outputs are published. To date, they have not provided substantive feedback or any objections. Because of the centralized leadership of this project, I felt constrained in my ability to share insights with the farmers directly. Nonetheless, I respected NCA's request to maintain oversight of communications surrounding the project.

For key informants, the main output that I have given back so far was the manuscript of a journal article based on this research. For those who I quoted in the article, I sent an electronic copy of the proof after the manuscript was accepted for publication but before the print version was finalized. I invited the research participants to review the document and alert me to any matters that needed correction, as well as to share any more substantive comments that I could incorporate into my thesis and subsequent written outputs. For the remainder of key informants, I sent the final (print) version of the article and similarly asked for their comments and critiques to inform my future writing. I will discuss the nature of the feedback that I received in the final chapter.

\section{Power dynamics and participant selection}

Two forms of asymmetrical power relations existed between me as a researcher and the participants. The first, and most significant, was the "potentially exploitative" type of research relationship where I had more power than the case study participants (Dowling 2010), particularly farmers who had little education and access to resources. On the other hand, some key actors potentially had more power than I did in the form of seniority, influence and access to social and financial resources, although this was probably offset 
to some extent by the privilege that I experienced due to being a foreign visitor. With some interviewees, particularly researchers of a similar age, I felt that power differences were minor. I will discuss the ways in which being an 'outsider' affected the research in more detail in the final chapter of the thesis. For now I wish to focus on how power issues may have influenced participant selection.

Working closely with local contacts made it difficult to include people who were disempowered in relation to the social structures to which these local guides belonged. Vivian (1994) points out that in spite of the general perception that NGOs work with "the poorest of the poor," in fact they are usually unable to break down the same barriers that prevent the most marginalized members of society from benefiting from government initiatives. In Nguruman and Mpeketoni, these hard-to-reach individuals included those who faced specific obstacles to participating in Jatropha projects or discussions (e.g. financial hardship, extraordinary family responsibilities), as well as those who belonged to under-represented groups in these undertakings (e.g. women, particular ethnic communities) or were simply opposed to growing Jatropha for any number of reasons. With this in mind, I made a special effort to interview women who were decision-makers about their farms (e.g. widows and unmarried women) in addition to those who had a joint or supporting role in running family farms. I also tried to seek out Maasai participants in Nguruman and Swahili ones in Mpeketoni, since members of these ethnic groups have historically relied less on agricultural cultivation for their livelihoods and were generally less active in growing Jatropha than residents from other ethnic communities. In an effort to break out of the "pro-Jatropha" network in each place, I asked farmers if they knew of anyone who was not planting Jatropha or thought it was a 
bad idea. However, several of the participants who I expected to have a low level of interest in Jatropha based on advice from local contacts - including some people who I was specifically told were not growing it - turned out to have planted the crop after all.

Actors who occupied professional positions related to promoting, regulating or studying Jatropha were perhaps easier to identify and approach than marginalized farmers, but it was still apparent that institutional and interpersonal dynamics affected the extent to which they were 'in the loop' of various networks and thus accessible to me as a researcher. Word-of-mouth and even chance encounters helped me to expand my set of contacts beyond those who belonged to existing formal or informal Jatropha networks. The persistence with which some interviewees alleged that their peers engaged in exclusionary behaviour, conflict of interest and unethical practices highlighted the degree to which power relations among these actors conditioned their relative positions in terms of access to financial resources, business opportunities and influence within the policy process. These interactions will be examined more fully in Chapters 6 and 8 .

\section{Chapter Summary}

This chapter has discussed the problem statement for the research, traced its intellectual roots, discussed important methodological decisions and described the research process. The thesis explores the political and social aspects of promoting Jatropha as a biofuel crop among small farmers in Kenya and situates this within a broader analysis of competing agendas and alternative visions of development. A political ecology perspective is adopted in order to move iteratively between materialist and discursive analyses of the political, economic, social and environmental influences affecting the 
trajectory of Jatropha-based biofuels. Literature on discourses of development, critical perspectives on international NGOs and the "economy of appearances" has been influential in framing the research. Power, development and scale are introduced as key concepts that will recur throughout the thesis. Methodologically, the research adopts a commitment to uncovering dissenting voices as well as practicing critical reflexivity. Qualitative, theory-building case studies form the core of empirical field work which was carried out in Kenya in 2008 and 2009. Strategies for collecting data, practicing reciprocity and identifying the influence of power dynamics on participant selection are discussed.

The following chapter focuses on the substantive context surrounding the politics of Jatropha-based biodiesel in Kenya by looking at the 'big picture' of international discussions on biofuels. It surveys sympathetic and critical perspectives on biofuels, examining the themes, discourses and policies that various actors have attached to them and linking these to broader visions of development and progress. All of this sets the scene for a more specific examination of Jatropha's characteristics and the story of its rise to prominence as a biofuel crop promoted throughout the tropics. 


\section{CHAPTER 3: BIOFUEL DEBATES AND DISCOURSES}

This chapter explores the agendas and discourses that are represented in 'big picture' debates over biofuels in order to provide substantive context for the examination of Jatropha that will follow. The chapter's objectives are to: 1) define biofuels and set boundaries on the discussion; 2) identify motivations and pressures that have provided incentives for large-scale production of biofuels for transport; 3) present critiques of this production model and alternative trajectories; and 4) summarize the relevance of these different currents of thought and action to the spread of Jatropha in Kenya.

The first section introduces biofuels in their various forms and reviews their global status and trends. The chapter then describes the dominant model of large-scale biofuel production and some incentives that support it, discusses social and environmental concerns associated with this trajectory, and presents alternative possibilities for producing and using biofuels. The discussion then turns to a review of discourses that have appeared in international debates over biofuels. It concludes by linking the persuasive use of these themes to fundamentally different agendas and visions of development. These insights will be re-examined later in the thesis in relation to divergent agendas and claims that a range of actors have attached to Jatropha.

\section{Defining biofuels}

Biofuels $^{14}$ are forms of combustible energy derived from organic matter: oils, starches or sugars, which are harvested more or less directly from plants, algae or animal tissue. By

\footnotetext{
${ }^{14}$ Some use the term 'agrofuels' instead of 'biofuels' to highlight the agricultural origins of first-generation feedstocks and to contest the use of the prefix 'bio,' which implies that these fuels originate from 'life' in general instead of agricultural processes in particular (e.g. TNI 2007). I use the term 'biofuels' out of recognition that not all forms of biofuel production resemble the model of industrial agriculture to which users of the term 'agrofuels' object.
} 
contrast, fossil fuels are composed of plant matter that has been transformed by physical pressure over the course of millennia. Biofuels can be made from a number of different source materials, or feedstocks. So-called first generation biofuels are made from the high-energy portion of agricultural crops such as seeds or fruits, while second generation biofuels are produced by using advanced technologies to convert total plant biomass (including cellulose and lignin) into liquid fuels (Bacovsky, Dallos, and Worgetter 2010; Worldwatch Institute 2007) ${ }^{15}$. Starches and sugars are used to produce ethanol, which can be blended with petroleum; oils and fats are converted into biodiesel, which can be blended with fossil fuel diesel. Solid biomass (from firewood, charcoal, compacted plant residues or dung) and biogas (methane produced from digested food scraps or animal wastes) are considered part of the broader category of bioenergy and represent a significant portion of the energy used in rural areas of the developing world, though they have received only a tiny fraction of the attention given to liquid biofuels in recent years (FAO and PISCES 2009).

This discussion focuses on first generation liquid biofuels, which have dominated the recent wave of interest in bioenergy in many parts of the world. While second generation biofuels have experienced a period of growth in research, development and the construction of processing facilities, an international survey of second generation projects in 2010 concluded that based on current trends, their output is likely to remain small compared to first generation biofuels until at least 2015 (Bacovsky et al. 2010).

\footnotetext{
15 Some consider oilseeds from trees to be a second generation feedstock because the plant remains standing while the seeds are harvested. Following this system of numbering, cellulose and algae are seen as "third generation" feedstocks. Yet another numbering system considers biofuels derived from crops that can be used as feed or fodder as first generation, non-food crop and wood sources as second generation, and algae as third generation (UNEP 2009).
} 
Municipal waste, crop and forest residues are low-cost feedstocks that are expected to provide most of the second generation biofuels for at least 10 years, at which point cellulose crops such as willow and switchgrass may begin to make substantial contributions (Worldwatch Institute 2007). In the meantime, it seems likely that highenergy parts of purpose-grown crops will continue to be the dominant form of biofuel production in the short- to medium-term.

\section{Short history and current status}

Although ethanol was used to run combustion engines as long ago as the $1820 \mathrm{~s}$, and the first automobiles of the 1900 s were designed to burn a blend of gasoline and ethanol, the availability of cheap oil has historically suppressed the use of biofuels outside of wartime (Worldwatch Institute 2007). The oil crisis of the 1970s prompted some countries to seriously consider energy alternatives, and it was during this period that ethanol strategies were implemented in Brazil, the US, Malawi, and - less lastingly - in Kenya and Zimbabwe. China encouraged farmers to grow oil plants to buffer against unreliable supplies of diesel until the mid-1980s, while in the European Union, a trade dispute stimulated biodiesel production starting in the early 1990s (Worldwatch Institute 2007). 
Figure 3.1: Global production of ethanol (upper line) and biodiesel equivalent (lower line), 1975-2007 (Howarth et al. 2009)

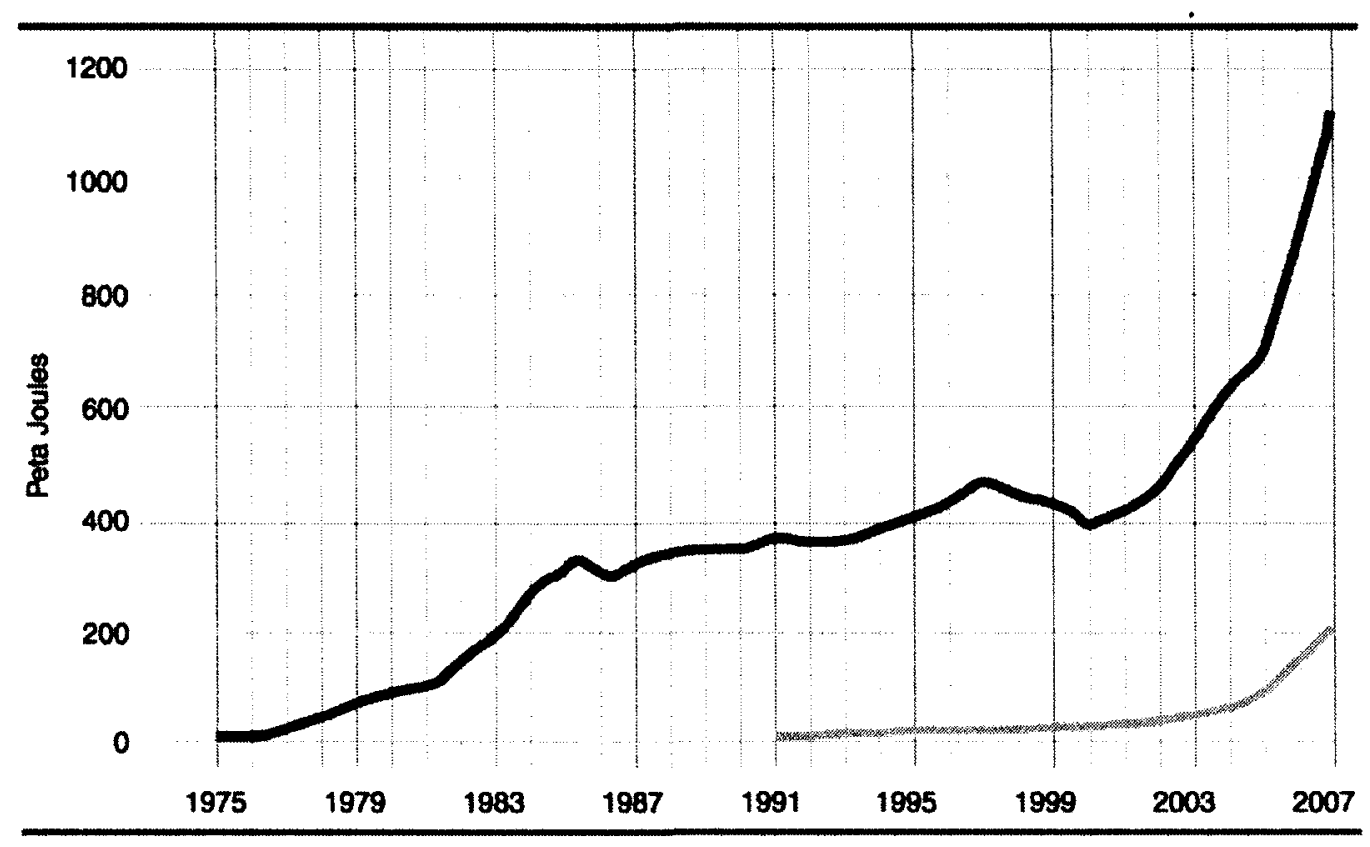

Global production of biofuels began to rise sharply around the year 2000 (see Figure 3.1). Between 2001 and 2006, the production of fuel ethanol more than doubled while that of biodiesel (a much smaller amount) increased almost six-fold (Worldwatch Institute 2007). By 2008, biofuels accounted for about $1.5 \%$ of global liquid transportation fuels, or 83 billion litres (Eisentraut 2010). Globally, Brazil and the US have been the largest ethanol producers for many years, deriving most of their ethanol from sugar cane and corn, respectively. Together, in 2006 these two countries accounted for $75 \%$ of global ethanol production, while China and India, the next largest producers, together accounted for $12 \%$ of global production. Biodiesel is mostly produced in Europe, with $50 \%$ of the 2006 world supply produced in Germany (from canola) (Howarth et al. 2009). 
At present, sugar cane, oil palm and soybeans are the predominant biofuel feedstocks in the tropics, while temperate areas draw primarily on corn, wheat, canola (rapeseed) and soybeans. All of these crops are generally associated with large-scale, monoculture plantations. Efforts to promote biofuel cultivation by smallholder farmers have focused on crops such as Jatropha, castor, sunflower, coconut and cotton. As discussed later in the chapter, these different feedstocks and approaches have vastly different implications for energy efficiency, cultivation patterns and social relations of production.

\section{Discourses and themes linked to biofuels}

Biofuel production has increased dramatically in recent years (Figure 3.1). What factors have contributed to such a surge in demand? Observers have identified three main motivations for pursuing biofuels: climate change, energy security, and rural development (Howarth et al. 2009; Ulmanen et al. 2009; Brittaine and Lutaladio 2010). This section briefly explores how these themes have been applied, as a prelude to examining some of their implications in terms of biofuel policies, investments and interventions.

The argument that biofuels help to combat climate change is based on the premise that they release fewer greenhouse gas emissions over their life cycle than fossil fuels. Although this claim is contested, particularly by the research on land use change presented below, climate change mitigation is perhaps the most straightforward of the three discourses in terms of its consistency of use. Legislation governing biofuels with 
names such as "Renewable Energy Directive" (EU) and "Low-Carbon Fuel Standard" (US) serve to reinforce this theme.

Energy security objectives in relation to biofuels take a greater number of forms. Ulmanen et al. (2009) describe how in Sweden and the Netherlands, biofuels have been promoted as a substitute for oil in the face of a perceived supply crisis. In this sense, energy security refers to simple stability of supply - in other words, ensuring that energy will still be available if and when fossil fuels become increasingly scarce. In some countries, notably Brazil, biofuel production and use have been encouraged as a form of import substitution (Worldwatch Institute 2007), thus contributing to discussions of energy and economic security. In the United States, the energy security agenda has been expressed in a more "militaristic" way (Fast 2009). President Barack Obama has promoted alternative energy, including biofuels, as a way to bolster American "energy independence" (U.S. Department of Energy 2010), while George W. Bush before him explicitly warned that the US faced a major economic problem because it was "addicted to oil, which is often imported from unstable parts of the world" (Wolinsky 2009: 551). This emphasis on producing energy domestically is tied to security objectives in a foreign policy sense, implying that the US would be better off if it reduced its dependence on particular oil-exporting countries, i.e. in the Middle East. Legislation including the US "Energy Independence and Security Act" of 2007 invokes such a discourse of energy security.

In numerous countries, biofuels have been presented as a means of encouraging economic growth in the agriculture sector. Ulmanen et al. (2009) argue that biofuels have been portrayed as a response to problems of overproduction and high subsidies within the 
European agricultural system. In the US, Agriculture Secretary Tom Vilsack explicitly linked biofuel production to rural opportunities, saying: “Advancing biomass and biofuel production holds the potential to create green jobs, which is one of the many ways the Obama Administration is working to rebuild and revitalize rural America" (U.S. Department of Energy 2010). The expectation that biofuel production could "revitalize rural America" is a strong example of the rural development theme attached to biofuels. Meanwhile, in sub-Saharan Africa, arguments in favour of large-scale land deals to foreign investors, including for biofuels, have focused on perceived benefits in the form of investment revenue, job creation and infrastructure development (Cotula et al. 2009). Although these examples vary widely in terms of the mechanisms through which rural betterment is expected to take place, they share the common theme of biofuels as a catalyst for agricultural growth and improvement.

These discursive themes of climate change mitigation, energy security and rural development have far-reaching influence. Borras et al. (2010:576) contend that the "winwin narrative" of biofuels as a way to address energy challenges, while simultaneously benefiting the environment and not interfering with economic growth, "has dominated the framing of the biofuels debate globally." The following section describes policy and economic incentives that reflect how these discourses have been translated into concrete actions in support of biofuels, while the remainder of this chapter presents critiques of these messages and alternatives to the dominant, large-scale model of biofuel production. Chapter 4 provides a more detailed examination of the claims and counter-claims that have characterized discussions about Jatropha, many of which overlap with and extend the broad themes introduced here. 


\section{Biofuel policies and incentives}

Government policies have played a major role in promoting the production of biofuels. Numerous countries have established fuel blending mandates or minimum targets for biofuel use, creating enormous demand for ethanol and biodiesel. For example, the United States Renewable Fuel Standard required the use of 12.95 billion gallons of renewable fuels (excluding advanced biofuels) in 2010, rising to 30 billion gallons by 2020 and 36 billion gallons by 2022 (U.S. Government 2007). The European Union's 2009 Renewable Energy Directive mandates that the transport sector use 10\% renewable energy by 2020 (Eisentraut 2010). In the United Kingdom, the Renewable Transport Fuels Obligation requires that $3.25 \%$ of road fuels by volume be renewable fuels by 2009-10 (Renewable Fuels Agency 2010). Meanwhile, China has set a target of increasing ethanol production to 3 million tonnes per year by 2010 and 10 million by 2020, while increasing biodiesel production to 300,000 tonnes per year by 2010 and 2 million by 2020 (APEC 2008). India's 2009 National Policy on Biofuels proposes an ambitious $20 \%$ blending of ethanol and biodiesel by 2017 , though the country is currently unable to enforce a $5 \%$ ethanol mandate because of a supply shortfall due to low sugar cane production in 2008-9 (USDA Foreign Agricultural Service 2010). These are but a few examples of existing biofuel policies and mandates, illustrating how governments in the global North and South alike have identified the use of biofuels for transportation as a national priority.

Such mandates can only be met by producing vast quantities of feedstocks, which requires either large-scale, high-yield production methods or an extremely well coordinated system of smallholder production. Of course, energy crops are subject to the 
same competitive pressures as other forms of agriculture: the bigger, the more highly mechanized, and the more heavily subsidized the operation, the greater the financial returns. Examples from Brazil and the United States illustrate these trends.

Many consider Brazil to be a biofuel success story. Strong government interventions have supported its biofuel industry since the 1970s. The country became the world's leading producer of ethanol, thanks to the massive production of sugar cane, a position it held until 2006 when it was overtaken by the US. By substituting domestically produced ethanol for imported gasoline, Brazil achieved fuel import savings of over $\$ 60$ billion (in 2004 USD) during the period from 1976 to 2004 (Worldwatch Institute 2007). By $2007,80 \%$ of cars in Brazil were flexible fuel vehicles, meaning that they could run on ethanol, gasoline, or any blend of the two (Houtart 2010). Brazil's already substantial exports of ethanol are expected to grow; meanwhile, it is nurturing a growing biodiesel industry based largely on soybeans (Hall et al. 2009). Government and private sector actors from Brazil have established partnerships with counterparts abroad to promote biofuel production and technology development in other countries, including Mozambique (Katerere 2009), Kenya (Maliti 2010), and Pakistan (AFP 2011). However, the national economic benefits of Brazil's ethanol program have come at a high cost: critics point out that its sugar cane plantations are associated with a host of ecological problems, rural displacement and poor working conditions (Houtart 2010), while at a more fundamental level, ethanol policies have contributed to social exclusion and exacerbated an already unequal distribution of wealth (Hall et al. 2009). These aspects of Brazil's large-scale biofuel production will be explored in more detail below. 
The United States provides a marked example of a country that uses subsidies to encourage domestic biofuel production, while perhaps also using the perceived need for biofuels to justify agricultural subsidies. This fits with the "rural development" biofuel discourse presented above. Government support for biofuel production in the US totaled between \$6.3-7.7 billion in 2006 and was expected to rise to $\$ 13$ billion in 2008 (Koplow 2006). Weis (2008) argues that an unlikely and highly vocal collection of "corporate, auto and big-farmer interests" has emerged to lobby in favour of biofuels in the name of energy security. However, the US case also demonstrates how biofuels - in this case, corn-based ethanol - can be used to mask the distorting effects of existing subsidies by creating new markets for surplus commodities. US agricultural policies encourage the vast overproduction of corn using high-input methods to maximize yield, with biofuel proponents now seeing ethanol for transport as one strategy among others for turning excess corn into marketable products and thus keeping its price from falling too low (Pollan 2006). The Worldwatch Institute (2007: 87) identifies this type of regional overproduction of a crop that can be used to produce biofuels as "one of the primary reasons governments have launched conventional biofuel programs to begin with." Thus, government subsidies for corn-based ethanol in the US appear to have been driven by a combination of interest in biofuels as an energy source, and investment in corn production as an agricultural support strategy.

However, even with these subsidies in place, it remains extremely difficult for the US to reach its biofuel target. This is partly due to the relative inefficiency of converting corn into ethanol. In 2007 , the US diverted $24 \%$ of its corn harvest to ethanol production, but this only supplied $1.3 \%$ of national liquid fuel use (Howarth et al. 2009). To achieve 
the US ethanol blending mandate, Roberts and Schlenker (2009) calculate that $5 \%$ of global caloric production would need to be turned into ethanol, with major repercussions for world food prices. In order for the US to meet its biofuel production goals in the future, it will need to devote much more land to feedstock production, increase its yields even further, or achieve significant breakthroughs in second generation biofuel technologies. In the meantime, imports are used to fill the gap: in 2005, the US imported $58 \%$ of its ethanol from Brazil (Houtart 2010).

The US is not alone in relying on imports to meet its obligations. No country with biofuel targets currently achieves them solely through domestic production, with most relying heavily on international trade. Given that an estimated 500 million ha of additional land would need to be converted to biofuel production in order to meet global biofuel demand by 2020 (Gallagher, 2008, in Borras et al. 2010), it is virtually impossible for most countries with temperate climates to produce enough biofuels domestically to meet their own fuel blending mandates. The relative efficiency of producing biomass in the tropics, together with financial subsidies and pressure to meet climate change targets, provides strong incentives for northern actors to invest in biofuel production in the global South (Borras et al. 2010).

Zoomers (2010) identifies governments seeking to meet their demand for biofuels as one of the key drivers of recent "land grabs" or "land deals," where foreign governments or companies have gained control over large tracts of land in Africa, Asia and Latin America, either through long-term leases or outright purchase. Biofuel investments of this type form part of a larger trend of agricultural land acquisition by foreign actors for both food and biofuel production. This has intensified as developing 
countries arguably turn to the private sector to capitalize on foreign investment opportunities and make up for shortfalls in development aid (Robertson and PinstrupAndersen 2010). An inventory of land investments in five African countries since 2004 documents a dramatic rise in the number of projects and size of land parcels involved, as well as the dominance of private sector and foreign investment (Cotula et al. 2009). Although it is not always easy to separate food from biofuel investments, Borras et al. (2010, p. 577) summarize recent research on the scale of global land allocations for biofuels as follows:

Some estimates show that European firms already claim over five million hectares of land for biofuel development across the global South. At present Brazil plans to replace $10 \%$ of the world's fossil fuels by 2025 with sugar ethanol, Malaysia and Indonesia are expanding oil palm plantations to supply $20 \%$ of EU bio-diesel needs, India plans $14 \mathrm{~m}$ hectares of land for Jatropha plantations, and Africa $400 \mathrm{~m}$.

This trend fits with the narratives of biofuels as engines of agricultural development and national economic growth. Many in developing countries see an economic opportunity in the growing international biofuel trade, despite concerns that foreign investment in agricultural land displaces local people, exacerbates poverty or further marginalizes already vulnerable members of the rural population. Land deals have been linked to discourses of food or energy security for the investor country (Zoomers 2010); however, this is ironic in light of their potential impacts on food security and /or security of land tenure in the host country (see for example Friends of the Earth 2010). This theme of land rights and social exclusion associated with international investment in biofuels will be discussed in more detail below.

This section has outlined strong pressures influencing the political economy of biofuels: pressures that incentivize scaling up, subsidizing and intensifying production, as 
well as engaging in international investment and trade. While fuel blending mandates have tended to be justified on the grounds of climate change mitigation and energy security, subsidies and trade arrangements for biofuels have often been attached to the goal of promoting rural development and boosting economic growth in the agriculture sector. This pattern fits within a neoliberal narrative of development that equates increased agricultural productivity and economic growth with normative progress. It also forms part of a broader trend where subsidies and externalities have "enhanced the competitiveness of industrial capitalist agriculture relative to more labour-intensive agricultural systems," (Weis 2010: 317), thereby favouring large-scale, highly mechanized production methods. However, both this system of biofuel production and the powerful discourses that support it have come under attack on several fronts.

\section{Critiquing the 'biofuels complex': Key points of debate}

Enthusiasm over biofuels has been increasingly challenged by concerns over social and environmental trade-offs, particularly those that occur in places where energy crops are grown. Some see the dominant, industrial model of biofuel production as a global 'complex' of investors, policy makers and farmers bound together by market logic, with

particularly problematic outcomes for marginalized people and environments at sites of production. Along these lines, Borras et al. (2010) identify "market environmentalism" as the driver of international relationships involved in industrial biofuel production, explaining this as an arrangement "whereby planetary resources are to be managed through the application of the market paradigm to the environment... The consequences are a deepening of a North/South asymmetry (via the 'ecological footprint'), and the 
privileging of corporate management of energy resources." This critique contests all three of the core narratives discussed above: that biofuels, through market-based mechanisms, contribute to improved environmental conditions, energy security, and rural development. Instead, this position holds that large-scale biofuel production and trade leads to inappropriate use of natural resources, concentration of control over energy supplies in corporate hands, and an increase in global inequities. The specific elements of this critique include concerns over food security, ecological integrity, and exploitative social relations. A critical perspective on biofuels also challenges the very heart of claims over their perceived benefits by calling into question their ability to mitigate climate change.

\section{Carbon balance}

Biofuels vary in their carbon intensity depending on which feedstocks are used, where they are grown and what methods of production are used (Pimentel et al. 2009; Johnston

et al. 2009). These differences have enormous implications for the carbon balance of biofuels derived from different sources; some fare much better than others with regard to the claim that biofuels can mitigate climate change by reducing greenhouse gas emissions.

In terms of the simple efficiency of converting plant matter into usable energy, the life cycle assessment literature on biofuels concludes that sugars produce higher yields of ethanol than starches, while production in tropical areas is more efficient than in temperate regions (Von Blottnitz and Curran 2007). Yield is a major determinant of a biofuel crop's energy balance; however, recent analysis of regionally-specific agricultural census data concludes that biofuel yield estimates for 20 crops have been consistently 
overestimated in the literature (Johnston et al. 2009). This suggests that the energy that can be gained from cultivating a given area of biofuel crops is likely lower than previously thought.

The issue of land use change has become increasingly central to analyses of the carbon balance of biofuels. Direct land use change refers to clearing vegetation, such as forest or grassland, in order to plant energy crops in the same location. The implications for climate change mitigation (or exacerbation) vary tremendously based on the location, type and prior condition of the land being converted. Gibbs et al. (2008) contend that expanding agricultural land for biofuels into productive tropical ecosystems produces a "carbon debt" that takes decades to centuries to repay, while expanding into degraded or already cultivated areas leads to carbon savings on a relatively short time scale. Removing tropical forests is particularly severe in this regard, yet tropical deforestation to produce biofuels has already been observed. For example, in Indonesia, two-thirds of oil palm expansion is estimated to occur by converting rainforest into palm plantations and in 2009 plans were in place to expand Indonesia's existing six million hectares of plantations by an additional 20 million hectares (UNEP 2009).

Indirect land use change refers to a ripple effect whereby biofuel feedstock production in one part of the world triggers land use decisions that cause crop substitution, deforestation or degradation of other ecosystems in different parts of the world, possibly causing the destruction of distant carbon sinks (Searchinger et al. 2008). Several studies indicate that once indirect land use change is taken into account, under some conditions the carbon balance of biofuels becomes negative, meaning that more carbon is released in the process of producing and using biofuels than from the equivalent 
amount of energy derived from fossil fuels (Searchinger et al. 2008; Fargione et al. 2008; Melillo et al. 2009).

The choice of crop production techniques is also highly important to determining the greenhouse gas balance of biofuels. Higher levels of mechanization and the use of agricultural chemicals both contribute to higher crop yields, though in terms of energy balance, these gains may be offset by emissions from higher inputs of fossil fuels, fertilizer use, and soil degradation (TNI 2007). For example, Melillo et al. (2009) conclude that an increase in fertilizer use to produce biofuel crops will produce nitrous oxide emissions with an even greater impact on global warming than the carbon emissions related to land use change.

These research contributions reflect increasing acknowledgement that different biofuel feedstocks and methods of production have profoundly different outcomes in terms of energy balance and greenhouse gas emissions. While the dominant policy and private sector narrative may suggest that biofuels automatically contribute to climate change mitigation, there is strong evidence to show that under many conditions, they may actually have the opposite effect.

\section{Food security}

For many, the question of "food versus fuel" captures the central tension of the biofuel industry. In 2007, Jean Zeigler, then the United Nations' special rapporteur on the right to food, famously declared biofuel production a "crime against humanity" because of the extent to which using arable land to produce grains for fuel allegedly contributed to 
hunger (Ferrett 2007). Lester Brown (2007) similarly critiqued crop-based biofuel production, framing it as a struggle between gas tanks and empty stomachs:

The stage is now set for direct competition for grain between the 800 million people who own automobiles, and the world's 2 billion poorest people. The risk is that millions of those on the lower rungs of the global economic ladder will start falling off as higher food prices drop their consumption below the survival level.

These arguments both portray biofuels as threats to food security, pointing out two different, though linked, fundamental issues: impacts on food supplies and on food prices. Food security as defined by the Food and Agriculture Organization of the United Nations (FAO 2008) comprises four main elements: physical availability of food, physical and economic access to food, food utilization, and stability of these dimensions over time. This definition includes attention to food supply issues, distribution patterns, and socio-economic considerations that affect households' ability to produce or purchase food.

Biofuel production can impact food supplies - the first of these elements - by diverting food crops to produce fuel, influencing land use decisions about which crops are planted, and competing with food production for agricultural resources such as irrigation and arable land (La Via Campesina 2009). Biofuel demand has also contributed to drawing down grain reserves, affecting the available supply of food crops such as maize (Ogg 2009).

In addition to these impacts on food supplies, biofuels can also influence access to food - the second element of food security - by changing patterns of trade in agricultural commodities and contributing to higher food prices. Dramatic increases in grain prices throughout much of 2008 brought food security and vulnerability issues under intense 
scrutiny. While experts disagreed over the extent to which biofuel production contributed to the price increases, some attributed as much as $75 \%$ responsibility for the price increases to a combination of diverting grains into biofuels, farmers setting aside land for energy crops, and financial speculation on agricultural commodities likely linked to rising interest in biofuels (Chakrabortty 2008). Others estimate that biofuels caused approximately $30 \%$ of food price increases from 2000-2007 and suggest that a moratorium on biofuels would lead to lower food prices in the future (Rosegrant 2008). Still others have identified a less clear relationship between biofuels and food prices, contending that biofuels may actually be able to reduce local food shortages and raise incomes for the world's most impoverished if policies are implemented to integrate their production with that of food and feed (Muller et al. 2008).

Many actors now consider non-edible biofuel crops to be preferable to edible ones because they appear to sidestep this actual or perceived competition between food and fuel production (e.g. Government of Kenya and GTZ 2008). India's biofuel policy exemplifies this position, focusing on cultivating non-edible oilseeds on "wastelands" (Baka 2011). This line of reasoning has helped to fuel interest in Jatropha, as will be discussed in Chapter 4.

Land deals can also jeopardize domestic food security by increasing competition for land with high irrigation potential or proximity to markets (Cotula et al. 2009). Concerns have been raised that many of the large-scale land deals currently being negotiated for biofuel production, for example tracts of up to 100,000 ha in Tanzania, cannot be met without displacing people from their land, thus compromising their access to land and in turn, their food security (FAO 2008). 
Critics have pointed out a series of ways in which biofuels can compromise food security: by affecting the physical availability of food, and impacting access to food by increasing food prices and in some cases, restricting access to land. These arguments present a strong challenge to the "win-win" discourse of biofuels presented above in terms of their ability to create economic opportunities and enhance rural well-being.

\section{Environmental integrity}

Critics of crop-based biofuel production have extended their use of environmental themes beyond climate change to include issues such as biodiversity loss, soil degradation, water quantity and quality concerns, and competition with conservation lands. The discourse of biofuels harming the environment includes phrases such as "ecological destruction" (Houtart 2010).

Large, monoculture plantations spark environmental concerns related to intensive chemical use, biodiversity loss and soil degradation. The Transnational Institute (TNI 2007) activates these arguments when it alleges that demand for biofuels creates pressure to convert low-input agricultural systems to intensive ones, and encourages the production of crops that are particularly deleterious for wildlife.

Water issues related to biofuels include the depletion of aquifers for irrigation, and contamination with agricultural chemicals and other effluents. In Brazil, sugar cane plantations covered over 8.5 million ha in 2009 (FAOSTAT 2011), with $88 \%$ of national production of this crop used to generate ethanol (Houtart 2010). These plantations demonstrate strong linkages between land use decisions and impacts on water. While Brazil is considered a water-rich country, local shortages can occur, leading some sugar 
producers to draw on aquifers to supplement rainfall with surface irrigation; at the same time, effluent from sugar operations contaminates groundwater reserves, surface water and soils (Tagnin and Mattes 2008).

Heightened demand for arable land means that some areas designated for conservation have been reallocated for biofuel production. In Brazil, 162,000 ha of designated 'conservation zone' have been replaced with sugar cane (Houtart 2010). Similarly, in the US, between late 2007 and early 2009 almost 1.3 million ha of set-aside lands (known as Conservation Reserve Program areas) were lost, broadly coinciding with an increase in the area planted with corn in the US, which jumped by $20 \%$ from 2006 to 2007 (Gillon 2010). Sacrificing these conservation lands, at least in part to increase biofuel production, has contributed to claims that biofuels disrupt ecological functioning and biodiversity.

These selected examples illustrate the breadth of the environmental critique that has been directed at biofuels, challenging the idea that they are "clean" or "green" fuels. These arguments have played an important role by expanding the discourse of biofuels and the environment beyond a singular focus on climate change.

\section{Social impacts}

Some have countered the claim that biofuels enhance rural development and create opportunities for farmers by advancing counter-arguments that under some conditions, large-scale biofuel production promotes poor working conditions, social exclusion, gender inequalities, and insecurity of land tenure. 
To some observers the establishment of large energy crop plantations in the developing world represents another manifestation of an exploitative agricultural model in which cash crops that are grown for export become the basis of a country's agricultural sector, with accompanying negative impacts on global equity (Knaup 2008). Particularly where leases give transnational corporations or foreign governments control over large tracts of land for agriculture in the global South, many are skeptical that such arrangements could lessen rather than worsen poverty, even if codes of conduct are in place (Zoomers 2010). Cotula et al. (2008) report that in places where land tenure is insecure or contested, an increase in biofuel production can cause already disadvantaged groups to lose their vital access to land.

Rossi and Lambrou (2008) identify a number of ways in which biofuel production could have gender-specific social impacts, among them: women are less likely than men to own land; accessing credit is more difficult for women than men, hampering their participation in high-input agriculture; and "marginal" or low-quality land tends to be particularly important to women in order to support a range of subsistence activities, which may be impacted by the expansion of biofuel crops into these areas.

Hall et al. (2009) show that Brazilian ethanol policies produced social exclusion by favouring the large-scale, technologically advanced production of sugar cane, thus excluding small farmers from participating in the growing industry. Further, Brazil's ethanol policies encouraged the expansion of plantations and mills in parts of the country that were already wealthier, thus missing an opportunity to spur economic growth in areas that perhaps needed it more. While Brazil appears to be trying to avoid these problems through its biodiesel policies, which are intended to support crops that can be 
more easily grown by smallholder farmers, similar economic pressures appear to be pushing biodiesel production, too, towards larger-scale, more "efficient" methods that are not possible for small-scale farmers to pursue (Hall et al. 2009).

These social justice arguments contend that instead of enabling agricultural growth and rural economic opportunities, the dominant scenario of large-scale biofuel crop production can exacerbate social and gender inequalities, and entrench poverty rather than alleviating it.

\section{Seeking alternatives}

These critiques of the "win-win" messages about biofuels have manifested themselves in numerous ways. Some have tried to stop actions that are already occurring; for example, Friends of the Earth (2010) explicitly calls for an end to biofuel policies in Europe. Others have sought to change the way in which biofuels are produced, for example by creating certification standards or modifying biofuel policies to place more emphasis on "sustainable" sourcing. Finally, some advocate producing biofuels in alternative ways, to achieve different ends than the dominant scenario of biofuels for transport. Strategies such as ecoagriculture and "pro-poor" approaches radically reinterpret the themes of environmental benefits, energy security and rural economic opportunities from biofuels, applying them to ambitions at a more localized scale. Examples from each of these types of alternatives are discussed below. 


\section{Revisiting biofuel policies}

Concerns such as those detailed above have compelled several governments to revisit their biofuel targets. New Zealand went as far as to repeal its Biofuel Bill of 2008 only three months after it was enacted. National media reported that the bill was withdrawn over fears that too much fuel would have to be imported and the price of fuel would likely rise as a result of the bill (TVNZ 2008). However, it appears that concerns raised by Dr. Jan Wright, Parliamentary Commissioner for the Environment, over carbon accounting and the impacts of imported feedstocks, also proved influential. The Commissioner argued that when importing biofuels, it would be extremely difficult to verify whether feedstocks grown overseas were produced, for example, in deforested areas or from crops that impacted food production - both of which ran counter to the Biofuel Bill's intent. The Commissioner recommended against the bill's fuel blending requirement on the grounds that it would be impossible to meet the supply requirements through domestic production, and that importing biofuels would risk damaging New Zealand's "clean green image" (Parliamentary Commissioner for the Environment 2008) - a clear refutation of the claim that biofuels represent "clean" or "green" fuel.

A New Zealand Green Party member subsequently introduced a Sustainable Biofuel Bill. In response to this new bill, the Commissioner made the case that importing biofuels does not make "good sense" in terms of energy security. On this topic Wright wrote: "Importing biofuels does nothing for energy security. If New Zealand is fuelled by ethanol from the distant state of Brazil, instead of petroleum from the distant state of Saudi Arabia, we remain dependent on a willing seller and an unbroken supply chain," going on to point out that if fuel blending were required, then both of these supply chains 
would need to remain stable, effectively leaving New Zealand with two energy dependencies instead of one (Parliamentary Commissioner for the Environment 2009). This is a relatively rare critique of the energy security agenda associated with biofuels.

New Zealand is a particularly dramatic case of a government backpedalling from a commitment to biofuels. Other governments, for example in the United Kingdom and European Union, modified their biofuel legislation by specifying conditions related to "sustainable" sourcing of feedstocks. The European Union Renewable Energy Directive of 2009 mandates that member states must meet their renewable fuel target $(10 \%$ renewable fuels for transportation by the year 2020) by following a set of criteria for sustainable production that include guidelines on land conversion and greenhouse gas reduction (Roundtable on Sustainable Biofuels 2009). The UK Renewable Fuels Agency adopted a similar "meta standard" approach to regulating the sustainability of biofuels based on a series of environmental and social criteria, meant to ensure that biofuel production does not impact carbon stocks, biodiversity, soil and water quality, air pollution, workers' rights or land rights (Renewable Fuels Agency 2010). While the meta standard approach has been criticized for being insufficient, relying too heavily on voluntary compliance, and "out-sourcing" responsibility for sustainable governance to private actors (Lin 2010), the fact that governments are pursuing such measures at all shows that they have undergone a shift in position, from enthusiastically endorsing biofuels to adopting a more cautious and considered approach.

These actions suggest that several governments are experiencing unease with the "business-as-usual" scenario of large-scale, monoculture feedstock production, particularly where energy crops are grown in the developing world for export to countries 
with fuel blending mandates. Changes to biofuel legislation and the proliferation of thirdparty sustainability standards for biofuels are evidence that the counter-discourses presented above - that biofuels can cause environmental and social harm under some sets of conditions - have successfully entered the policy making arena. Arguably, they also suggest that some governments may be expanding their core set of priorities from a narrower focus on domestic economic and energy interests plus climate change goals, to a broader view of global environmental and social well-being.

Alternative strategies: Ecoagriculture, "pro-poor"

Requiring that (voluntary) sustainability criteria be met is a relatively mild form of resistance to what some have termed the industrial biofuel 'complex' (Borras et al. 2010). Others have turned to more radical ideas about how biofuel production could be delinked from industrial agriculture and used to benefit people and environments close to where they are produced. Ecoagriculture and "pro-poor" approaches are two alternative biofuel discourses; both are based on the belief that biofuels can bring positive outcomes to rural areas in the developing world.

Using biofuels to achieve multiple benefits is a common theme within these perspectives. Tilman et al. (2009) spell out criteria for "good" biofuel development based on a "food, energy and environment trilemma", saying that biofuels must have lower carbon emissions than fossil fuels throughout their life cycle while having minimal or no impact on food production: "Good public policy will ensure that biofuel production optimizes a bundle of benefits, including real energy gains, greenhouse-gas reductions, preservation of biodiversity, and maintenance of food security" (Tilman et al. 2009, p. 
271). Based on the critiques already discussed, many feel that it is impossible to achieve such a "bundle of benefits" under the dominant system of large-scale, crop-based biofuel production that is focused on maximizing yields and economic returns. Borras et al. (2010: 578) articulate this position:

Many believe corporate-driven and controlled biofuels represent shortterm responses sustaining an unsustainable model of agroindustrialization, and energy consumption, in the name of arresting climate change... Substituting an alternative energy commodity to address greenhouse gas (GHG) emissions, the market paradigm thus 'externalizes' the profound social and environmental contradictions stemming from an industrial biofuel complex.

Given the depth of this critique, one wonders whether there is any way at all to produce biofuels in a socially and environmentally responsible manner. By reimagining discourses of environmental benefits, energy security and rural development, some have reached the conclusion that it is indeed possible. From this point of view, growing biofuel feedstocks through smallholder cultivation and processing them locally may offer a promising way to simultaneously realize economic, social and environmental objectives (Ejigu, 2008).

Proponents of an ecoagriculture approach believe that small-scale farmers who produce biodiesel or vegetable oil for local use can achieve environmental benefits including crop diversity and restoration of degraded land, while also enhancing local energy security, increasing household incomes and generating new economic opportunities that rely on a small but steady energy supply (Milder, McNeely, Shames, \& Scherr, 2008). Others have outlined a discourse of "pro-poor" biofuel production, which they see as providing income for those with the lowest income, creating opportunities specifically for women, protecting environmental sustainability, and not interfering with 
food or water security (Brittaine and Lutaladio 2010). The International Crops Research Institute for the Semi-Arid Tropics (ICRISAT 2007) describes pro-poor biofuel initiatives as those that ensure "energy, livelihood and food security" for farmers, while substituting for fossil fuel use, thus helping to mitigate climate change.

How do these perspectives rest on a recasting of the themes of environment, energy security and rural development? Ecoagriculture, in particular, expands the environmental dimension of biofuels from a narrower focus on climate change (though it retains an awareness of the carbon impacts associated with land use change), to a broader focus on ecological functions and services, including biodiversity. These ecological considerations are primarily local in scope, in contrast to the global issue of climate change, which dominates the environmental discourse in favour of large-scale biofuel production.

In the area of energy security, pro-poor and ecoagriculture approaches emphasize a local rather than national focus. Some replace the term "energy security" with "energy self-reliance" (ICRISAT 2007). Instead of focusing on securing steady energy supplies in the face of fossil fuel shortages or disruptions to international trade, these alternative points of view highlight the potential to expand access to energy in rural areas. A number of organizations in the South are advancing the concept of "energy sovereignty" in relation to biofuels, which builds on the idea of food sovereignty by insisting on the integrated, locally autonomous production of food and energy (Moreno and Mittal 2008).

Finally, advocates of small-scale biofuel production activate the theme of rural development, again at a local level. Instead of focusing on national ambitions for growth in the agriculture sector or producing biofuels for export, they highlight the potential for 
income generating opportunities to benefit individuals and households (Brittaine and Lutaladio 2010). These include the potential to earn direct income from producing and selling biofuel feedstocks, as well as other economic activities that could become possible with improved access to energy.

Thus, although large-scale and small-scale approaches to biofuel production appear to have dramatically different features and potential outcomes for people and environments, the arguments in favour of each rest in many ways on the same discursive themes. The polarized nature of debates over biofuels obscures a diverse suite of options that defy attempts to reach a single conclusion about their overall merits and risks. Approaches such as smallholder production for local use pose a creative challenge to the dominant model of large-scale biofuel projects for transport, and represent an important ongoing experiment within the broader effort to promote rural energy sufficiency, livelihood opportunities and environmental integrity in the developing world.

\section{CHAPTER SYNTHESIS}

Global biofuel production has expanded rapidly in recent years and many governments have committed to biofuel targets that will ensure this trend continues. Throughout this period of growth, biofuels have been the subject of heated debates. The discourses and counter-discourses involved reflect contrasting assumptions and aspirations with respect to development and progress.

Biofuels' supporters have portrayed them as a way to achieve three main things: environmental benefits, energy security, and agricultural development. When the theme of "environment" has been focused on climate change mitigation, "energy security" on 
national energy supplies and foreign policy objectives, and "rural development" on subsidies to farmers and national targets for the agriculture sector, these arguments have been activated to promote fuel blending mandates and the accompanying large-scale production of biofuels. Several countries have adopted such legislation, causing a cascade of effects both domestically and abroad. These decisions rest on a broadly neoliberal interpretation of development, one that prioritizes market-based mechanisms, trade, and foreign direct investment.

Critics have objected to this model of biofuel production on a number of fronts, for example by contesting the notion that biofuels produce fewer greenhouse gas emissions than fossil fuels. Other counter-discourses claim that biofuels threaten food security, environmental integrity and social justice. These perspectives likely influenced some governments when they decided to revise their biofuel mandates to include "sustainability" criteria, or in the case of New Zealand, to fundamentally reexamine its commitment to biofuels. These arguments and actions directly challenge the ideas that biofuels are automatically beneficial in terms of the environment, energy security and socio-economic well-being.

Alternative forms of biofuel production, particularly cultivation by smallholder farmers, have been championed using a different set of objectives. These can be seen as a reinterpretation of the original arguments in favour of biofuels. Ecoagriculture and "propoor" approaches to biofuel production extend the environmental argument beyond climate change to include a broader set of ecological and biodiversity considerations, while considering energy security in terms of local, rural access to energy. Likewise, proponents of this approach cast the rural development theme in local rather than national 
terms, focusing on household income generation and economic opportunities that could be enabled through the availability of new energy sources. These interpretations of the potential benefits of biofuels are perhaps more closely linked to sustainability or livelihoods perspectives on development.

The remainder of this thesis explores these themes in more detail and examines how they play out under particular circumstances. The discursive framing of biofuels as well as the policies and economic forces described in this chapter form a crucial part of the context in which the promotion of Jatropha in Kenya has occurred. Concerns over "food versus fuel" and the push for "sustainable" biofuels are especially relevant to Jatropha because they link directly to claims about Jatropha's ability to produce energy on semi-arid lands without irrigation, while maintaining or even enhancing food security.

Chapter 4 examines contrasting representations of Jatropha that have accompanied its international spread, while Chapters 5-7 delve into the specific case of Jatropha's deployment in Kenya. Understanding the broader patterns of debate and action over biofuels that were presented above will help with the task of interpreting and situating people's opinions and decisions with regard to Jatropha, both globally and within Kenya. 


\section{CHAPTER 4: JATROPHA AND ITS INTERNATIONAL SPREAD}

This chapter introduces the plant Jatropha curcas, examining several assumptions that form the basis of enthusiastic claims over its potential to produce clean energy, enhance local environments and promote rural economic opportunities. After surveying the literature on Jatropha's history, agronomy and uses, the chapter explores how messages about Jatropha have been propagated through the media. It then charts the recent global expansion of Jatropha as a biofuel crop, summarizing what inventories exist and tracking new announcements of Jatropha-related investments and land deals. The chapter concludes by examining the extent to which polarized messages about Jatropha have been taken up in the literature as well as the media, and considers whether patterns in these discourses can help to explain spatial and temporal patterns in the global spread of Jatropha biofuel projects.

\section{LITERATURE PERSPECTIVES ON JATROPHA}

Jatropha curcas is a small tree or large shrub of the Euphorbiaceae family. Also known as physic nut, it grows to an average height of 3-7 $\mathrm{m}$, though it can reportedly reach up to $10 \mathrm{~m}$ under favourable climatic conditions. After flowering, which occurs one or more times per year depending on water availability, the plant produces seeds containing inedible oil. Under most circumstances the plant is not considered safe for human or animal consumption because it contains toxins including phorbol esters and curcains (Jongschaap et al. 2007). However, in Guinea, ashes from the roots and branches have been used as a cooking salt and the young leaves eaten when stewed, while in Mexico, even the seeds can apparently be eaten after roasting (Orwa et al. 2009). Heller (1996) 
suggests that Jatropha seeds originating from Mexico are less toxic than those from other sources.

\section{History and uses}

Indigenous to Latin America, Jatropha has been spread throughout the tropics and used for a wide variety of purposes. Portuguese traders are believed to have introduced it to parts of Africa and Asia (Jongschaap et al. 2007), including the Cape Verde islands, where as early as 1836 Jatropha seeds were grown and exported to Portugal and France so that the oil could be used for street lighting and soap production (Heller 1996). Its oil has also been used for street lighting in Brazil, and was used to run engines in Mali during World War II (Orwa et al. 2009).

Jatropha is widely grown as a living hedge, since it can be planted easily and densely from cuttings, helps to reduce soil erosion, and is not grazed by animals. It has a variety of medicinal uses, many related to the plant's toxicity. Heller (1996) describes how the oil has been used to treat skin diseases and relieve pain; the leaves processed and used as an antiseptic after childbirth as well as to treat coughs; and the sap used to treat wounds due to its antimicrobial and blood-clotting properties. Orwa et al. (2009) add that Jatropha seeds are used as a purgative and its branches as a chewing stick, while parts of the plant have also been used to treat conditions as wide-ranging as fevers, baldness, jaundice, syphilis and hemorrhoids. Preparations made from the seeds have been deployed as a rat poison, while tannins from the leaves, roots and seeds have been used for inks and dyes (Orwa et al. 2009). Jongschaap et al. (2007, p. 27) summarize: "The traditional and successful application of J. curcas includes functions like soil and water 
conservation, soil reclamation, erosion control, living fences, firewood, green manure, lighting fuel and local use in soap production, insecticide and medicinal application."

More recent attention has focused on Jatropha's potential to produce biofuel. Straight vegetable oil (SVO) from the plant, obtained by simply crushing the seeds, can be used in modified lamps that preheat the oil to help it travel up the lamp's wick. Jongschaap et al. (2007) report that the toxins present in Jatropha oil do not pollute when burned, and thus do not pose a health risk if used indoors. SVO can also be used directly in some types of diesel engines (such as electricity generators or grain mills) using a twotank system where fossil fuel diesel is used for the first few minutes to warm up the engine, Jatropha oil is used for the main period of operation, and then diesel is used again for the last few minutes before shutting off the engine.

Because of its high viscosity (20-25 times higher than fossil fuel diesel), Jatropha SVO can cause problems in some engines such as sticking and gum buildup; thus, further processing is needed to turn it into biodiesel that can be easily blended with fossil fuel diesel or used directly in a wider range of engines such as automobiles (Jain and Sharma 2010). This process involves transesterification, a chemical reaction achieved by exposing SVO to a base. Glycerol can be produced as a marketable byproduct of this process, improving the economic prospects of Jatropha processing (Weyerhaeuser et al. 2007).

After the seeds have been pressed to extract oil, the leftover seed cake (or press cake) can be used directly as a fertilizer rich in nitrogen, or compressed into briquettes to be burned as cooking fuel. The seed cake can also be fermented to produce biogas; the residue resulting from this process retains enough nutrients to also be applied as a 
fertilizer (Jongschaap et al. 2007). While press cake from other oilseeds is often used as livestock feed, this is not realistic for Jatropha unless it can be detoxified, a process which Jongschaap et al. (2007) consider too complex to be practical.

\section{Agronomy}

Enthusiasm over Jatropha as a source of biofuel hinges on several beliefs about its agronomic qualities: that the plant produces abundant oil, thrives in dry conditions with poor soils, requires few agricultural inputs and is largely resistant to pests and diseases. These claims have driven the influential arguments that Jatropha can be productively grown in "marginal" areas with few input costs, thus offering economic opportunities or access to energy in remote areas without threatening food production. Perspectives from the scholarly literature on these agronomic themes are presented here, drawing particularly on Jongschaap et al.'s (2007) systematic evaluation of the extent to which scientific research supports these perceptions about Jatropha.

Oil production per plant is a function of seed yield, seed size and oil content. Whitaker and Heath (2010) identify seed yield and oil content as two of the three most important factors (along with biodiesel consumption efficiency) in achieving sustainability outcomes from producing Jatropha for energy. But reports of Jatropha's oil production potential vary tremendously.

Major problems have been reported with calculating Jatropha seed yields, for example due to extrapolating from individual, mature trees instead of tracking the yield of a stand of trees grown under similar conditions. Seed yields are frequently presented in terms of weight, ranging from less than 0.4 to more than 4.0 tonnes of seed per hectare, 
without specifying the tree spacing, or whether the seed husks were included in the calculation (Jongschaap et al., 2007). Projected seed yields of up to 12 tonnes of seed per hectare are reported without supporting evidence. Even though genetic variation within a plantation is usually low, the seed yield per tree can vary widely, e.g. from 0.2 to more than $2 \mathrm{~kg} /$ tree in the same plantation (Francis et al. 2005). Jongschaap et al. (2007) warn that it is easy to overestimate the oil yield of a plantation if seed yield is measured but an incorrect value for oil content is assumed. Reports of the oil content of Jatropha seeds range from $23-45 \%$.

Data are particularly lacking for Jatropha yields under dry and low-nutrient growing conditions, even though these are the very conditions under which Jatropha should be grown if it is to avoid competing with cultivation for food production (Jongschaap et al. 2007). Numerous authors repeat Jatropha's reputation for drought tolerance without citing supporting evidence. Some state, for example, that Jatropha can grow in arid zones with only $200 \mathrm{~mm}$ annual rainfall (Jain and Sharma 2010), while others argue that Jatropha needs at least $600 \mathrm{~mm}$ or even $900 \mathrm{~mm}$ annual precipitation to grow well (Francis et al. 2005). Some have suggested that Jatropha can produce a positive water balance by breaking up soil with its roots, increasing infiltration, and creating a cooler microclimate using its shade. However, Bekunda et al. (2009) question whether these gains would outweigh water losses via transpiration from Jatropha's canopy. Jongschaap et al. (2007) found that in most places where data were available, Jatropha's "water request" was going unfulfilled: that is, Jatropha's potential transpiration was higher than its actual transpiration, meaning that it would have used more water if it were available. Jatropha does exhibit some features that allow it to 
withstand periods of dryness, such as the ability to produce leaves with a different anatomy when drought conditions begin (Maes et al. 2009). But Jongschaap et al. (2007) point out that such studies on Jatropha's ability to survive say nothing about its ability to produce oil while experiencing water stress.

As for Jatropha's ability to exploit nutrient-poor soils, Jongschaap et al. (2007) indicate that Jatropha's root system does enable it to access nutrients from deeper soil layers. However, since Jatropha is not nitrogen fixing, it eventually needs to be fertilized itself (Openshaw 2000). Studies from India show that applying organic fertilizer to Jatropha significantly and positively affected Jatropha's growth rate, seed production and oil content (in Jongschaap et al. 2007). Together with the Jongschaap et al.'s (2007) observation that flowering - the stage that crucially determines seed production - ends when nutrients become limiting, these findings suggest that although Jatropha appears able to survive in low-nutrient conditions, its oil yield is strongly enhanced by the application of fertilizers.

\section{Jatropha and land use}

Based on the evidence above, it appears that in order to produce abundant oil (i.e. perform as an energy crop), existing varieties of Jatropha need water supplies and nutrient levels beyond those that are usually found in the semi-arid areas where many have recommended planting it. Weyerhaeuser et al. (2007) described this problem in Southwest China, where much of the land designated as 'marginal' has proven to be unsuitable for Jatropha cultivation. Such a situation leads to two obvious strategies for producing commercial quantities of Jatropha oil: 1) irrigating and fertilizing semi-arid 
land in order to make it more suitable for Jatropha; and 2) planting Jatropha on land with higher rainfall and soil nutrient levels, i.e. arable land. Growing Jatropha at a smaller scale (as fencing, for example) with the intent of meeting household energy needs has different implications for land use and will be discussed later.

If one were to plant Jatropha on semi-arid land and then provide irrigation and fertilizers to encourage it to produce more oil, this would have the effect of increasing the overall production potential of the land, creating conditions that would make it possible to grow other types of crops instead of Jatropha, including food. Although this approach would technically satisfy the claim that Jatropha was not displacing existing food crop production, it would raise other questions related to competition with the cultivation of edible crops. Presenting Jatropha as a crop that can thrive in environments that are too harsh to grow food crops seems misguided if it is necessary to alter those harsh conditions to produce ones that could also support food production in order to successfully grow Jatropha. In other words, Jatropha would take up the same agricultural production potential (in terms of land area, water and nutrient inputs) as food crops would if one were to make the effort to grow them in the same semi-arid areas. It is to this type of situation that Bekunda et al. (2009) refer when they conclude: "The bottom line is that consideration of the use of so-called 'degraded' or 'waste' lands in Africa and elsewhere for production of biofuel feedstock cannot be de-linked from the need for increased food production" (251).

A second strategy for growing Jatropha to produce large quantities of oil would be to simply grow it on land with sufficient rainfall and favourable soils; in other words, arable land. Provided that one could secure such land for this purpose, this would be 
easier and likely much more profitable than irrigating and fertilizing lower productivity land. Several have raised concerns that investors may reach the same conclusion and look away from semi-arid, nutrient-poor areas, instead seeking to establish Jatropha plantations on land that has higher potential to support agriculture or biodiversity in order to maximize their returns (Achten et al. 2010; Brittaine and Lutaladio 2010). Of course, using prime agricultural land to grow Jatropha would contradict the argument that it does not compete with food production.

\section{Contested discourses of 'marginal' lands}

Even if Jatropha could grow well and produce abundant oil under dry, nutrient-poor conditions, crucial social issues would remain related to the classification of these areas as 'waste' or 'marginal' lands. Two important dimensions of the discussion of Jatropha as a crop suited to so-called 'marginal' lands are that it dismisses the importance of pastoral livelihoods, and often glosses over contentious issues of land rights. Because the discourse of growing Jatropha in 'marginal' lands persists despite the agronomic evidence presented above, this section briefly discusses these issues and explores their implications for food security and livelihoods.

Francis et al. (2005) make a statement that is not atypical in the literature on Jatropha, in this case referring to India: “...the land foreseen for this purpose [growing Jatropha] is currently not in use. Thus planting these areas to Jatropha would not take away any land from producing food crops" (p. 21). This overlooks the fact that people often use land that is perceived as empty in a variety of ways that sustain or supplement their livelihoods but do not involve cultivating crops. Particularly in East Africa, 
pastoralism is the dominant way of life for people inhabiting large areas of exactly the type of semi-arid land that Jatropha's proponents describe as suitable for plantations. Grazing cattle, goats and sheep not only produces a subsistence food supply, but is central to the culture and identity of pastoralists. By suggesting that only land that is used to grow crops is "in use," the discussion about how well Jatropha can grow on semi-arid or otherwise non-arable lands privileges crop-based agriculture over other food production systems and livelihoods. I will return to this topic in relation to the case study of Nguruman, where pastoralists and farmers experience differing land use needs within a group ranch system of land ownership.

Land classification systems that use terms such as 'marginal' or 'waste' lands were in many cases colonially imposed. For example, Ariza-Montobbio et al. (2010) describe how India's biofuel policy, which prioritizes cultivating Jatropha and other oilseed plants on 'wastelands,' draws on a definition of 'wasteland' that originated during the colonial period and was applied to land that "did not generate revenue for the British government" (p. 879). Emphasizing this point, Baka (2011) points out that land classification tends to be based on economic value, overlooking "ecological, cultural or livelihood benefits" that a given plot of land may have (p. 2). Clearly, a policy such as India's to focus on cultivating 'wastelands' would have strong implications for those who may already be using the land for non-economic purposes.

Closely related to these issues are questions of land tenure and land rights. Land that is perceived as empty is often occupied, a situation that is complicated where land tenure and rights of access are unclear or simply not respected. Friends of the Earth (2010) suggest that tensions over access to land in Africa appear to be occurring just as 
much for Jatropha plantations as they are for other biofuel crops, with the result that the loss of traditional land gives rise to "growing food insecurity and hunger" (p. 4). Land tenure issues related to the two Kenyan case study areas (Nguruman and Mpeketoni) will be discussed in the next chapter.

\section{Labour}

Paradoxically, claims of both high and low labour requirements have been used to promote (and critique) Jatropha. Estimates of the amount of labour required to establish and maintain a one-hectare plantation vary widely, ranging between $75-200$ person days for the first year, and 40-110 person days per year from the third year onward (Grass 2009). Some have portrayed high labour intensity as a positive feature of Jatropha, seeing it as a means of creating rural employment (Achten et al. 2007; Brittaine and Lutaladio 2010), even to the extent that this might contribute to a reduction in rural-urban migration (Muok and Källbäck 2008).

On the other hand, Jatropha has also been promoted as a low-labour crop that can bring economic or livelihood benefits with little trade-off in the form of time and energy that must be invested in cultivating it. Jongschaap et al. (2007) contest this claim and the arguments that it has been used to support, stating:

It is unverified that $\mathrm{J}$. curcas oil production requires minimum amounts of labour input. The claim that it would be an excellent choice in areas that have low labour capacity should therefore be strongly defied. Also, the noble thought of generating income in HIV-affected communities by planting J. curcas as a low labour input crop, cannot be sustained. (p. 23)

The perception that Jatropha is a low-labour crop has also formed the basis of claims that growing it can benefit women in particular by reducing their workload, for example: 
"Women especially can benefit [from Jatropha production], because milling machines powered by diesel engines fuelled with Jatropha oil reduce the amount of tedious work they must do" (Brittaine and Lutaladio 2010: 82). For this to be true, cultivating Jatropha must not create more "tedious work" for women ${ }^{16}$. In addition to the critique of Jatropha's overall labour requirements just presented, the case studies of Nguruman and Mpeketoni will return to the question of whether women (and children) in these locations performed a disproportionate share of the work put into planting and tending Jatropha.

Logically, the claim of high labour requirements fits with a model of growing Jatropha in plantations where the resulting energy might be used elsewhere and the main local benefit would be the potential for employment creation. By contrast, the claim of low labour requirements fits with a model of small scale cultivation where farmers could theoretically harvest 'something from nothing' by planting Jatropha as fencing, using the resulting oil for household lighting or selling it to generate small amounts of income. The issue of Jatropha's labour intensity thus illustrates a case where unclear or differing research results can allow actors to choose and repeat whichever interpretation supports the strategies, goals or discourses to which they subscribe.

\footnotetext{
${ }^{16}$ For Jatropha powered milling machines to save women time and labour, the availability of Jatropha oil must also make it possible for milling machines to operate where they previously did not, or make it significantly less expensive to run mills than if they used fossil fuels. It is beyond the scope of this research to assess the availability of rural milling infrastructure across a broad geographic area, but in both of the case study areas visited for this research where the production of Jatropha oil was being discussed, diesel powered grain mills already existed and were widely used. In Mpeketoni in particular, electricity produced at a large diesel generating station was available at nationally standardized rates, weakening arguments that Jatropha oil could provide electricity for small businesses such as grain mills that could not be supplied in another way.
} 


\section{Energy and greenhouse gas balance}

Achten et al. (2007) report that initial assessments of Jatropha's energy balance and greenhouse gas balance are positive, meaning that Jatropha yields more energy than it takes to produce it and emits fewer greenhouse gas emissions throughout its life cycle than fossil fuel diesel. However, they note that these outcomes depend heavily on the type of land on which Jatropha is cultivated as well as the production intensity and distance to market. In a study sponsored by Daimler, Reinhardt et al. (2007: 47) conclude that Jatropha biodiesel has "considerable potential" to reduce greenhouse gas emissions, but warn that these benefits come with other environmental costs such as acidification and eutrophication.

Ndong et al. (2009) conducted a life cycle analysis of Jatropha grown in smallholder plantations in West Africa (Ivory Coast and Mali) and shipped to France for processing into biodiesel. They conclude that under these conditions, Jatropha biodiesel achieves a $72 \%$ savings in greenhouse gas emissions compared to fossil fuels, and produces a net energy ratio (biodiesel output to fossil fuel input) of 4.7. A life cycle study from Thailand (Prueksakorn and Gheewala 2008) also finds that under a range of scenarios, Jatropha's net energy ratio remains higher than 1 . These findings support the idea that biodiesel produced from Jatropha, at least under some conditions, can offer climate change mitigation benefits compared to fossil fuel diesel.

Whitaker and Heath (2010) provide an alternate perspective, questioning the carbon balance of Jatropha-based biodiesel. They conclude from their model that even without taking land use conversion into account, Jatropha biodiesel would fail to produce a reduction in GHG emissions compared to fossil fuel biodiesel if seed yields fell below 
1.25 tha annually, a very real possibility given the wide range of yields reported above. Bailis and Baka (2010) conclude that jet fuel derived from Jatropha grown in Brazil can result in GHG reductions of $86 \%$ compared to a fossil fuel reference scenario, or GHG increases of up to $60 \%$ depending on the role played by land use change.

Jatropha's carbon balance has major implications for its perceived status as a "clean" alternative to fossil fuels. This is particularly relevant to the question of whether Jatropha projects deserve to qualify for carbon credits through the Clean Development Mechanism, or other forms of compensation through voluntary carbon offset programs, a topic that will be revisited as part of the Mpeketoni case study.

\section{Summary of literature perspectives}

This section has surveyed existing literature on Jatropha, drawing on academic journal articles as well as reports prepared by NGOs, research institutes, and international organizations. These publications each investigate one or more selected aspects of Jatropha's performance and potential, but several also draw general conclusions about Jatropha's potential to contribute to environmental, economic and social goals. It is worth considering the nature and tone of the overall conclusions drawn by the authors whose work is discussed above. Table 4.1 summarizes the overall stances on Jatropha, where one could be found, of this diverse group of researchers as a way to "take the pulse" of researchers' opinions about how recommendable different types of Jatropha initiatives might be. 
Table 4.1: Summary of overall positions on Jatropha from key literature sources

\begin{tabular}{|c|c|c|}
\hline Source & Stance & Conclusion \\
\hline $\begin{array}{l}\text { Francis et al. (2005) } \\
\text { Journal article }\end{array}$ & Positive & $\begin{array}{l}\text { "Large-scale Jatropha bio-diesel production on barren lands is one of the most practical options } \\
\text { for increasing the share of biofuels in transportation energy in India." (p. 23) }\end{array}$ \\
\hline $\begin{array}{l}\text { Henning (2004) } \\
\text { Conference paper }\end{array}$ & Positive & $\begin{array}{l}\text { "The more seeds/oil Jatropha produces, the more food crops are protected from animals and } \\
\text { erosion. Also additional income is created, mostly for women." (p. 7) }\end{array}$ \\
\hline $\begin{array}{l}\text { Grass (2009) } \\
\text { Journal article }\end{array}$ & Positive & $\begin{array}{l}\text { "I strongly believe that the propagation of Jatropha can be seen as a possible option for rural } \\
\text { development." (p. 37) }\end{array}$ \\
\hline $\begin{array}{l}\text { Openshaw (2000) } \\
\text { Journal article }\end{array}$ & $\begin{array}{l}\text { Negative: } \\
\text { energy }\end{array}$ & $\begin{array}{l}\text { "Several agencies are promoting Jatropha oil as an energy source, to the detriment of other } \\
\text { uses... Promoting plant oil for these [energy] uses may deter sustained economic growth, hinder } \\
\text { improvements to the quality of life and delay poverty alleviation." (p. 3) }\end{array}$ \\
\hline $\begin{array}{l}\text { Jongschaap et al. } \\
\text { (2007) } \\
\text { Plant Research } \\
\text { International report }\end{array}$ & $\begin{array}{l}\text { Negative: } \\
\text { energy }\end{array}$ & $\begin{array}{l}\text { "Claims of low nutrient requirements, low water use, low labour inputs, the non existence of } \\
\text { competition with food production, and tolerance to pests and diseases are definitely not true in } \\
\text { combination with high oil yield production." (p. 27) }\end{array}$ \\
\hline $\begin{array}{l}\text { Achten et al. (2010) } \\
\text { Journal article }\end{array}$ & $\begin{array}{l}\text { Positive: } \\
\text { small-scale }\end{array}$ & $\begin{array}{l}\text { Community-based initiatives must give "correct information on land suitability including } \\
\text { potential yield range, risk of yield loss, management practices and possible water competition, as } \\
\text { Jatropha will not yield well on all sites for which its suitability has been claimed." (p. 165). }\end{array}$ \\
\hline $\begin{array}{l}\text { Bekunda et al. } \\
(2009) \\
\text { SCOPE report }\end{array}$ & Cautious & $\begin{array}{l}\text { "Even for well recognized biofuel crops such as Jatropha, there is surprisingly little information } \\
\text { on the yield potential under different agro-climatic zones. The great potential currently being } \\
\text { touted for Jatropha is based on scanty evidence..." (p. 246) }\end{array}$ \\
\hline $\begin{array}{l}\text { Weyerhaeuser et al. } \\
\text { (2007) } \\
\text { ICRAF report }\end{array}$ & Cautious & $\begin{array}{l}\text { Establishing large-scale, monoculture plantations in China using existing seed stock would } \\
\text { reduce biodiversity, increase financial risk for farmers and increase the risk of a pest outbreak, } \\
\text { while providing only a slight contribution to energy security and GHG emissions reduction. }\end{array}$ \\
\hline $\begin{array}{l}\text { Brittaine and } \\
\text { Lutaladio }(2010) \\
\text { FAO report }\end{array}$ & $\begin{array}{l}\text { Positive: } \\
\text { small-scale }\end{array}$ & $\begin{array}{l}\text { "For the present, the main pro-poor potential of Jatropha is within a strategy for the reclamation } \\
\text { of degraded farmland along with local processing and utilization of the oil and by-products." (p. } \\
\text { xv) }\end{array}$ \\
\hline $\begin{array}{l}\text { Friends of the Earth } \\
(2010) \\
\text { NGO report }\end{array}$ & Negative & $\begin{array}{l}\text { "The much vaunted wonder crop Jatropha, rather than bringing a guaranteed income, in fact } \\
\text { takes valuable water resources and needs expensive pesticides. In some cases, food crops have } \\
\text { been cleared to plant Jatropha, leaving farmers with no income and no source of food." (p. 4) }\end{array}$ \\
\hline
\end{tabular}


In general, these studies recognize that positive claims (only some substantiated) have accompanied Jatropha, while different authors are swayed or unmoved by these claims to varying extents. Several of the studies cited here conclude that Jatropha projects are more likely to benefit farmers if they involve multiple and non-energy uses of Jatropha (e.g. Grass 2009, Openshaw 2000, Jongschaap et al. 2007), and follow small-scale production approaches (e.g. Achten et al. 2010), as compared to plantations that are intended to produce energy alone. Those who express cautious or negative perspectives on largescale plantations base them on several factors, including: concerns over the financial, social and ecological risks involved with a large-scale experiment; doubts that such a production system would or could benefit farmers; skepticism that enough is known about Jatropha's agronomy for such ventures to succeed commercially; or outright disbelief that Jatropha can produce commercial quantities of oil when grown in plantations. Most advocate proceeding slowly and building up more knowledge about the plant before undertaking large projects (Weyerhaeuser et al., 2007, Friends of the Earth 2010, Brittaine and Lutaladio 2010, Achten et al. 2010, Jongschaap et al. 2010).

\section{MEDIA PERSPECTIVES}

Jatropha has been the subject of much - and highly contrasting - media coverage. This section discusses the messages, tone, and some implications of the contested media space that has surrounded Jatropha as a biofuel crop.

The sources considered in this media analysis include newspapers and online media reports published between January 2007 and the end of 2010. These were drawn from a systematic search of major Kenyan newspapers (The Daily Nation, The Standard, 
Business Daily, and The East African) for all stories mentioning "Jatropha," as well as a collection of other media stories that I gathered from email listserves (including Biofuels Digest), recommendations from colleagues, and occasional Internet searches conducted from $2008-2011$. This is not an exhaustive list of media coverage of Jatropha; for example, it is heavily weighted towards African sources and content. However, it draws from many sources and I believe it gives a worthwhile sampling of the media attention given to Jatropha from 2007 to the end of 2010.

\section{Positive claims and media enthusiasm}

Jatropha has received many accolades from many different perspectives. In some cases, enthusiastic claims have been framed in terms of an overall endorsement of the plant. Many news reports on Jatropha have used superlative language, for example referring to the plant as a "wonder shrub" (Mutua 2007), "trophy tree" (Obala 2010), "saviour" (Cheboi 2008), and "resource of dreams" (Thomas 2009). These terms present Jatropha as an agent of transformative change, a theme further exemplified by the headline, "Will the world join [the] Jatropha revolution?" (Ghosh 2007).

As mentioned in the literature review above, Jatropha's potential as an energy source has sometimes served as a focal point and several threads emerge from the media coverage on this topic. Favourable news coverage has highlighted Jatropha's potential as a source of clean energy, expressed through headlines including: "Africa seeks clean, profitable biofuel" (Clayton 2010), and, "Local shrub carries potential for clean fuel" (Sharpe 2006). Other reports emphasize the macroeconomic goals that Jatropha could help to reach, for example by reducing Uganda's fuel import bill ("Uganda to extract 
biodiesel from 'wonder plant' jatropha," Abdallah 2009); or by providing an alternative source of aviation fuels ("Jet test should spark quest for new biofuels," Houston Chronicle 2009). One article, titled, "Endless musing costs Kenya big bucks" (Aron 2010), provides further commentary on Jatropha as a national economic opportunity by alleging that debates over Jatropha have caused investors to bypass Kenya and invest in Mali and Burkina Faso instead, countries which the author states have made stronger and clearer commitments to promoting Jatropha.

On the theme of rural income generation, one news story refers to Jatropha as a "money tree" that can produce a constant stream of income (Obala 2010), while another headline reports: "Study says biofuel crop can improve earnings of farmers in marginal lands" (Mbogo 2010). A further headline proclaims Jatropha to be "An eco-friendly way of growing cash and energy" (Senelwa 2009). Linked to these assurances that Jatropha produces direct income for growers is the idea that planting it leads to job creation, for example: "Could biodiesel solve India's rural job woes?" (Cleantech 2009). Meanwhile, Gakii (2010) spreads the message that Jatropha can provide energy access to rural areas with the phrase, "Green power lights up rural Kenyans' lives."

Finally, positive news reports perpetuate claims that growing Jatropha benefits the environment, including through rehabilitation of 'marginal' areas. Examples include the proclamations: "Tree that holds solution to fuel crisis and environmental conservation" (Njungiri 2008), and "Jatropha offers 'green hope' for arid areas" (Mbogo 2009).

Overall, the positive media portrayals of Jatropha range from sweeping praise to specific claims about its ability to provide clean energy, national economic opportunities, rural income, job creation, and environmental benefits. These examples demonstrate a 
suite of claims about Jatropha that have been perpetuated through newspapers and online media sources. Just as importantly, they show the tone that has accompanied these messages: glowing, optimistic, even triumphant. What meanings can we attach to the use of such strongly positive language about Jatropha? Does it serve to whip up enthusiasm, to persuade, to reassure? On one level, the messages to which these fervent phrases are attached seem harder to dispute because of the strength of conviction with which they are expressed. However, the following section suggests an alternate possibility: that instead of pre-empting criticism, these rhetorical devices may actually invite it.

\section{Critiques and media backlash}

Media coverage that questions or criticizes Jatropha's potential has at times used equally extreme language. The strongly positive claims that were attached to Jatropha above have been countered with dismissive labels such as "blunder crop" (Lane 2009) and "biofuel gone bad" (Time 2009). Several headlines turn positive labels into ironic questions, for example: "Jatropha: not a wonder crop after all?" (Strickland 2009), "How green is the green gold rush?" (Polack 2009), and, "Green gold losing its glitter?" (Sanderson 2009).

A dominant message in negative media stories has been that Jatropha has performed poorly or fallen short of expectations, for example: "wonder weed plans fail to flourish" (Sanderson 2009), "Don't fall for Jatropha plants, warns UN body" (Jagannathan 2010), and "Hailed as a biofuel miracle, Jatropha falls short of hype" (Luoma 2009). Observed or anticipated negative social impacts are expressed through headlines such as: "How a biofuel 'miracle' ruined Kenyan farmers (Wadhams 2009), and "Lack of science means Jatropha "could fail poor"' (Bhattacharyya 2010), while 
negative environmental impacts are described in terms like: "Jatropha biofuels: the true cost to Tanzania" (Mutch 2010), and, in relation to a proposed project in Coast Province, Kenya, "Environmentalists label biofuel project ecological disaster" (Jamah 2010).

An additional story that appears in these critical media perspectives on Jatropha relates to issues of land tenure and land grabs. Headlines on this theme include: "Africa becoming a biofuel battleground" (Knaup 2008), and "African Jatropha boom raises concerns" (Browne 2009). These and other articles (e.g. Gathura 2010) detail land deals for large Jatropha plantations that involve international investors, and argue that under these conditions, Jatropha production disrupts access to land and contributes to food insecurity.

Notably, many of these examples frame their critiques by contrasting some feature of Jatropha with a positive claim. The opening sentence of Mohiuddin's (2010) article illustrates this technique: "To its fans, Jatropha is a miracle crop, an eco-friendly answer to India's growing energy needs, but some experts are starting to question whether the wonder-shrub is too good to be true." The entry point of the critique is a (perhaps exaggerated) restatement of the positive claims about Jatropha.

From the media coverage presented here, it seems that negative portrayals of Jatropha have used words like "miracle" and "wonder" at least as often, if not more so, than positive portrayals. It is interesting to consider how, or how much, actors with a critical perspective on Jatropha may have strategically invoked these extremely positive labels in order to establish or strengthen their own case. Perhaps it is easier to knock something down if one first promotes the perception that it was placed on an undeservedly high pedestal. This tactic lets critics portray themselves as though they are 
unmasking the truth, or debunking myths. Acknowledging opposing positions in a way that makes them appear to be based on emotion rather than 'fact' may be a strategy for fending off rebuttals. All of this raises the question of whether some degree of the perceived "hype" surrounding Jatropha was constructed or perpetuated through the process of critiquing it.

\section{Mixed messages}

Table 4.2 shows a series of headlines about Jatropha in chronological order, with colour coding to show whether each article adopted a broadly positive, critical, or cautious / questioning stance about Jatropha. Green rows represent stories expressing an overall positive stance on Jatropha; orange rows, a negative or critical stance; and yellow rows, an intermediate, cautious, or 'questioning' stance. 
Table 4.2: Headlines about Jatropha from various media sources, 2007-2010

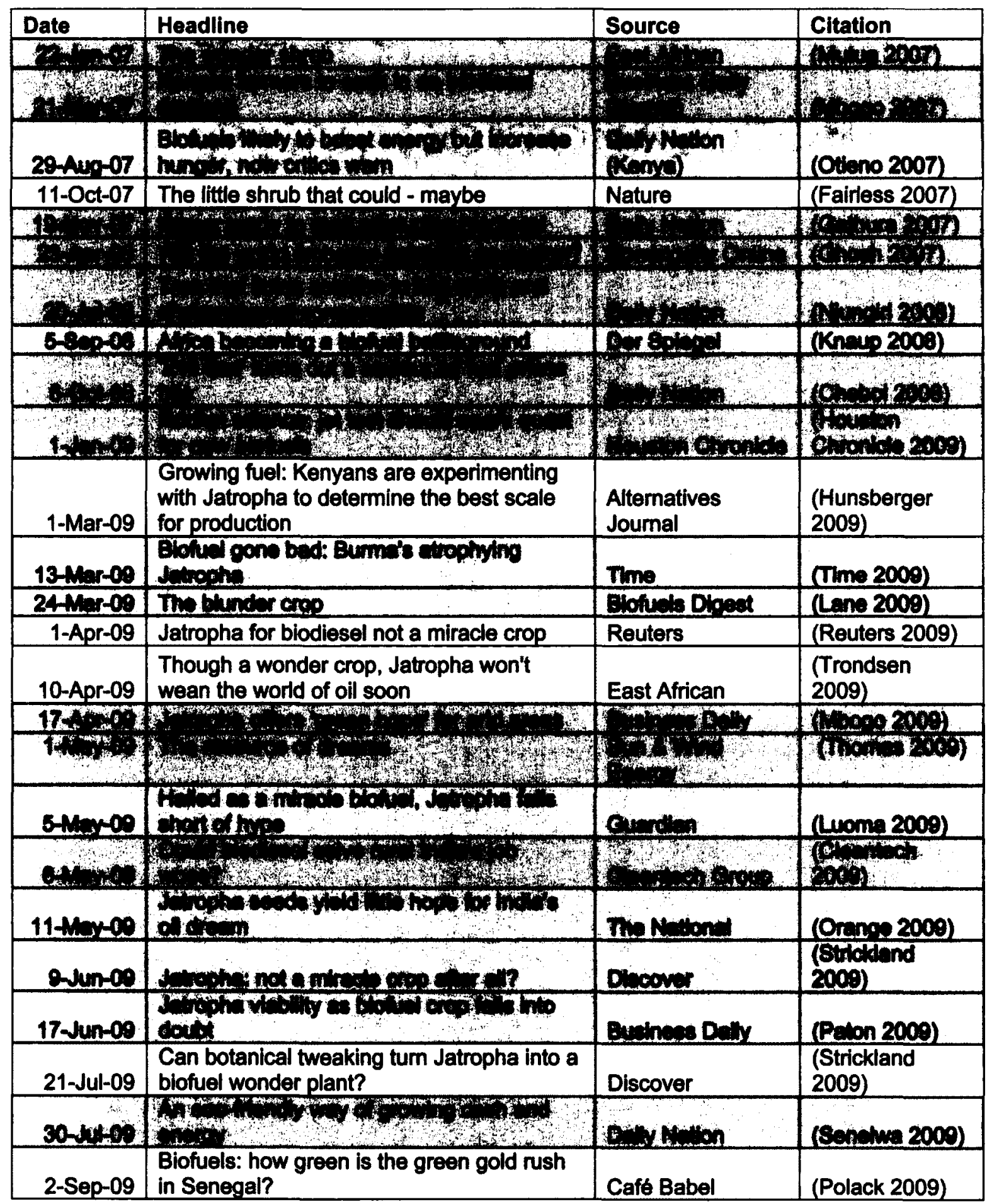




\begin{tabular}{|c|c|c|c|}
\hline Date & Headline & Source & Citation \\
\hline $16-\operatorname{sep}-00$ & Wonder meed plans foll to fouth & Neture Now & $\begin{array}{l}\text { (Sandereon } \\
2009 \text { ) }\end{array}$ \\
\hline $400+09$ & 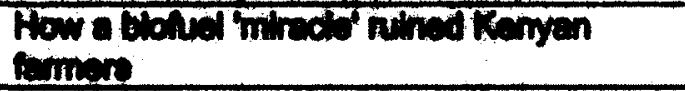 & $\operatorname{Tm}$ & $\begin{array}{l}\text { (Wedhums } \\
\text { 2009) }\end{array}$ \\
\hline $900 t-09$ & Altan detrophe boom renes concems & $\begin{array}{l}\text { Eedt Airican (clioo } \\
\text { Now York Timoe) }\end{array}$ & (Erowne 2009) \\
\hline & (1) & Eutaricen & $\begin{array}{l}\text { (Sandereon } \\
2000)\end{array}$ \\
\hline 11 & It: & & $(0,2,-40,0)$ \\
\hline 26-Jan-10 & Doubts over India's 'miracle' biodiesel crop & AFP & $\begin{array}{l}\text { (Mohiuddin } \\
\text { 2010) }\end{array}$ \\
\hline $3 F C b-10$ & Litroph femere we & Eusiness Dolly & $\begin{array}{l}\text { (Omondi and } \\
\text { No'etich 2010) }\end{array}$ \\
\hline $16-F d-10$ & 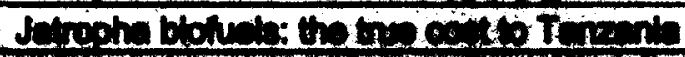 & Eoclogle & (Mutah 2010) \\
\hline & & & $\begin{array}{l}\text { (urnd Chang } \\
\text { Dovo) }\end{array}$ \\
\hline $27+m-10$ & $\begin{array}{l}\text { Mindate } \\
\text { ferled to }\end{array}$ & Daly Nation & (Gethura 2010) \\
\hline 30-May-10 & Jatropha: let us hear views from all sides & Daily Nation & $\begin{array}{l}\text { (Daily Nation } \\
\text { 2010) }\end{array}$ \\
\hline $31+\sin 310$ & 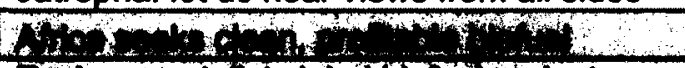 & 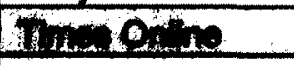 & (Closen 2010) \\
\hline 7 Jun-10 & 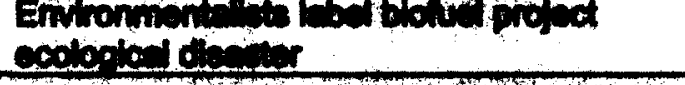 & Sindind (Konya) & (Jamen 2010) \\
\hline 16. & & & $\begin{array}{l}\text { Coming } \\
\text { 2010) }\end{array}$ \\
\hline 16.2 & & & $\operatorname{Asen} 2040$ \\
\hline $21-\sqrt{4 n-10}$ & ci: & Exydution & $(\mathrm{Ke} \cdot \mathrm{me10})$ \\
\hline $24+140$ & & & $(0<-2010)$ \\
\hline $26-\sqrt{2}-10$ & $\begin{array}{l}\text { Donth } \\
\text { bedy }\end{array}$ & $\begin{array}{l}\text { The Economic } \\
\text { Zire }\end{array}$ & $\begin{array}{l}\text { (Jegennethen } \\
2010)\end{array}$ \\
\hline & & & $\frac{(102010)}{(L x h=12010)}$ \\
\hline & 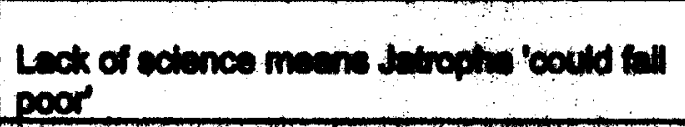 & $\begin{array}{l}\text { Scivonos end } \\
\text { Development } \\
\text { N.wuok }\end{array}$ & $\begin{array}{l}\text { (Bhathacheryya } \\
2010)\end{array}$ \\
\hline $27-0-010$ & 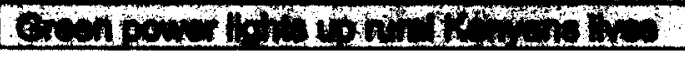 & 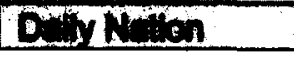 & $($ Cect 2010) \\
\hline
\end{tabular}

The distribution of media headlines in Table 4.2 shows that positive and negative messages about Jatropha coexisted throughout the period from 2007-2010. No clear pattern can be seen whereby either positive or negative messages came to dominate over time, or where rhetoric diminished on one side or the other. For example, the polarized 
headlines "Environmentalists label biofuel project ecological disaster" (Jamah 2010) and "Trophy tree to unlock Kenya's full potential" (Obala 2010) appeared within a few weeks of each other - in the same newspaper - towards the end of the period considered. Some intermediate points of view can be found, for example, "Jatropha: let us hear views from all sides" (Daily Nation 2010), but these do not appear to have noticeably increased over time.

Perhaps the most striking aspect of this media assessment is the extent to which both supportive and critical stances on Jatropha have been expressed using highly provocative language. Of course, news headlines tend to be deliberately sensationalistic in order to attract attention, and are often chosen by editors rather than those who researched and wrote the accompanying articles. Many of the news stories mentioned here tried to achieve some level of journalistic "balance" by including multiple points of view in the full text of the articles, even if their headlines were strongly positive or negative. Still, this set of headlines indicates what a variety of editors thought their audiences wanted or needed to know about Jatropha at the time when each story appeared. In turn, their choice of words has played an important role in shaping perceptions and the boundaries of debate about Jatropha.

Rhetorically extreme labels such as "wonder crop" and "blunder crop" have contributed to setting the terms of discussion in a variety of ways. Powerful and persuasive, at times these terms have been absorbed and repeated by others in ways that reinforce their interpretation of reality, while at other times they have been invoked with irony or criticism in order to strengthen an opposing argument. 
Positive labels attached to Jatropha have occasionally crept into the academic literature. For example, in their research article on engine performance of Jatropha biodiesel, Jain and Sharma (2010) use the normative phrase "Jatropha the wonder plant" (p. 765) not to critique it, but at face value, as part of their introductory description of the plant. In this way, the term "wonder plant" is presented as a piece of received wisdom that in effect provides a normative frame for the study.

By contrast, several of the reports and academic articles about Jatropha that were reviewed in the previous section refer to these glowing descriptions of Jatropha, though in critical ways. Repeating and reemphasizing the most dramatically positive labels can make it seem as though the people who support Jatropha are unreasonable or pie-in-thesky, enabling those with an argument against it to portray themselves as pragmatic realists. Friends of the Earth (2010:4) employs this tactic when it refers to "the much vaunted wonder crop Jatropha" as a way of setting up its critique of Jatropha projects. Report titles such as, "Jatropha reality check" (GTZ 2009), and, "Jatropha: claims and facts" (Jongschaap et al., 2010) fit this pattern. The word "hype" also appears several times in scholarly articles (e.g. Achten et al. 2010, Grass 2009), always attached to the idea that the authors who invoke the term are responsibly working to dispel unsubstantiated rumours.

Thus the existing literature and media coverage of Jatropha are closely entwined, sharing some of the same rhetoric. In some instances, authors writing for very different purposes have invoked the same, highly normative terms, perhaps for similar, strategic purposes. As this thesis moves into the Kenyan context, I will track if and when the actors who I interviewed expressed any of the positive or negative labels presented here. 


\section{GLOBAL CULTIVATION AND SPREAD}

In order to understand how and why Jatropha came to be promoted as a biofuel crop in Kenya, it is important to put this case in a global context. How far and how fast did interest in Jatropha spread, globally? Is it possible to see patterns - perhaps representing waves of donor or investor interest - in particular times and places? If so, do these correspond to events such as oil price fluctuations or the announcement of biofuel policies? The following sections investigate these questions by drawing on a range of information sources, each of which contributes some evidence to an overall picture that remains incomplete. By piecing them together and looking for areas of agreement, this brief analysis seeks to advance the current state of knowledge on spatial and temporal patterns of interest and investment in Jatropha.

\section{General interest}

There are several ways to gauge changes in the level of interest in Jatropha. One starting point is to examine the nature and extent of media coverage on the topic. While I have not undertaken a systematic content analysis of reports about Jatropha, the preceding sections presented and critiqued a variety of messages about Jatropha that have appeared in both academic and media sources. The foregoing analysis shows that optimistic, dismissive and cautionary perspectives on Jatropha have coexisted in the past, and continue to coexist in the present.

Looking at internet search trends is another, albeit rough, way to assess general interest in a topic. The search engine Google reports a rising number of searches for the term "Jatropha" throughout the period from 2005 to mid-2008, followed by a steady 
decline through the first quarter of 2011. In Figure 4.1, the upper line represents an index based on the volume of total searches, while the lower line represents an index of the volume of news references to "Jatropha." Letters correspond to particular news stories, as will be discussed in Figure 4.5. Prominent spikes occurred in August 2007, mid-2008, and December 2008, which I will discuss further on.

Figure 4.1: Google search trends for the term "Jatropha" (Google 2011)

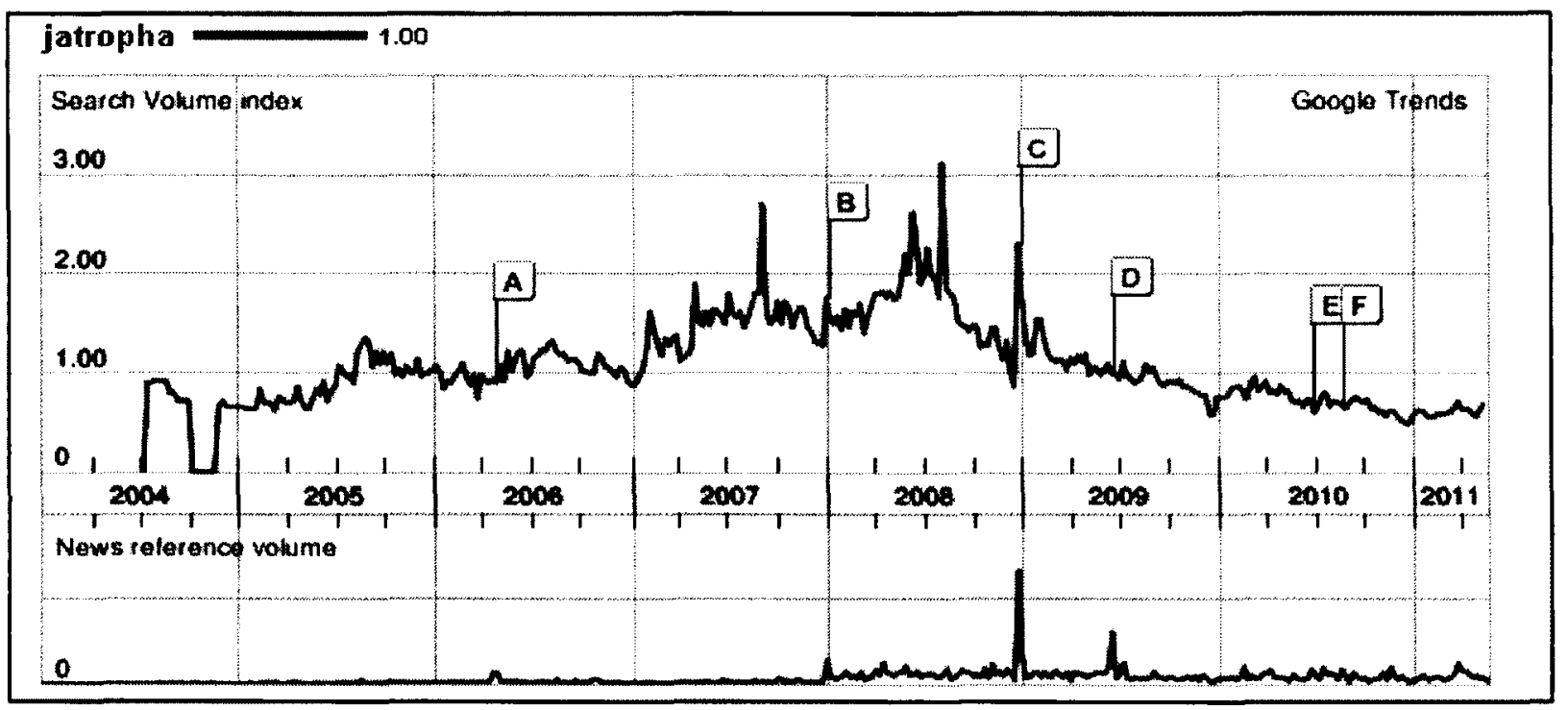

\section{Project listings}

In addition to this general indicator of interest in Jatropha over time, at least two attempts have been made to document the locations and details of Jatropha projects worldwide.

Jatrophabook is a website that was designed to act as a social networking site for those involved with Jatropha projects. Members register their Jatropha activities on the site, which then maps the projects and allows visitors to view a profile of each one. As of May 2011, Jatrophabook listed almost 400 projects, including 171 seed producers, 51 extraction plants, 32 refining plants, 19 energy producers, 58 research centres, 10 final users and 56 suppliers (Jatrophabook 2011). That Jatrophabook includes all of these 
different types of projects is a major strength compared to GEXSI (2008), which focuses solely on Jatropha plantations. One limitation of Jatrophabook is that its reach is limited to the extent that people know about it, take the initiative to register themselves, and provide accurate information. It reports that 246,000 ha are currently under cultivation (Jatrophabook 2011), a much lower figure than GEXSI (2008) provides. As well, the distribution of Jatrophabook's membership and projects by country is strongly skewed towards Italy, where the site is based, suggesting that it is still in the process of expanding its network geographically.

In 2008, a report published by the Global Exchange for Social Investment (GEXSI) compiled actual and forecasted Jatropha plantings in 55 countries, based on interviews with selected stakeholders and online questionnaires conducted in February and March, 2008. GEXSI (2008) provided a country-by-country summary of Jatropha activities, including the number of known projects, hectares under cultivation, an assessment of whether commercial-scale activities were occurring, and predictions about the extent of future plantations.

The report profiled 242 projects covering approximately 900,000 hectares globally. In terms of hectares already planted, $85 \%$ were reported to be in Asia, $13 \%$ in Africa and 2\% in Latin America (GEXSI 2008). However, similar numbers of projects were reported in Asia and Africa (104 and 97 respectively), indicating that the average plantation size was much larger in Asia than in Africa (Figure 4.2).

Crucially, GEXSI $(2008$, p. 5) pointed out that very few of the projects in its inventory were more than two years old, and that "hardly any" were producing significant quantities of Jatropha oil at the time of research. Still, the report estimated that global 
Jatropha cultivation would increase dramatically: to 5 million ha by 2010 , and 13 million ha by 2015 (GEXSI 2008). This speaks to the speed with which Jatropha projects appeared to be multiplying, as well as the very high prevailing level of confidence in Jatropha as a biofuel crop at the time.

Figure 4.2: Jatropha projects and hectares planted by region (GEXSI 2008)

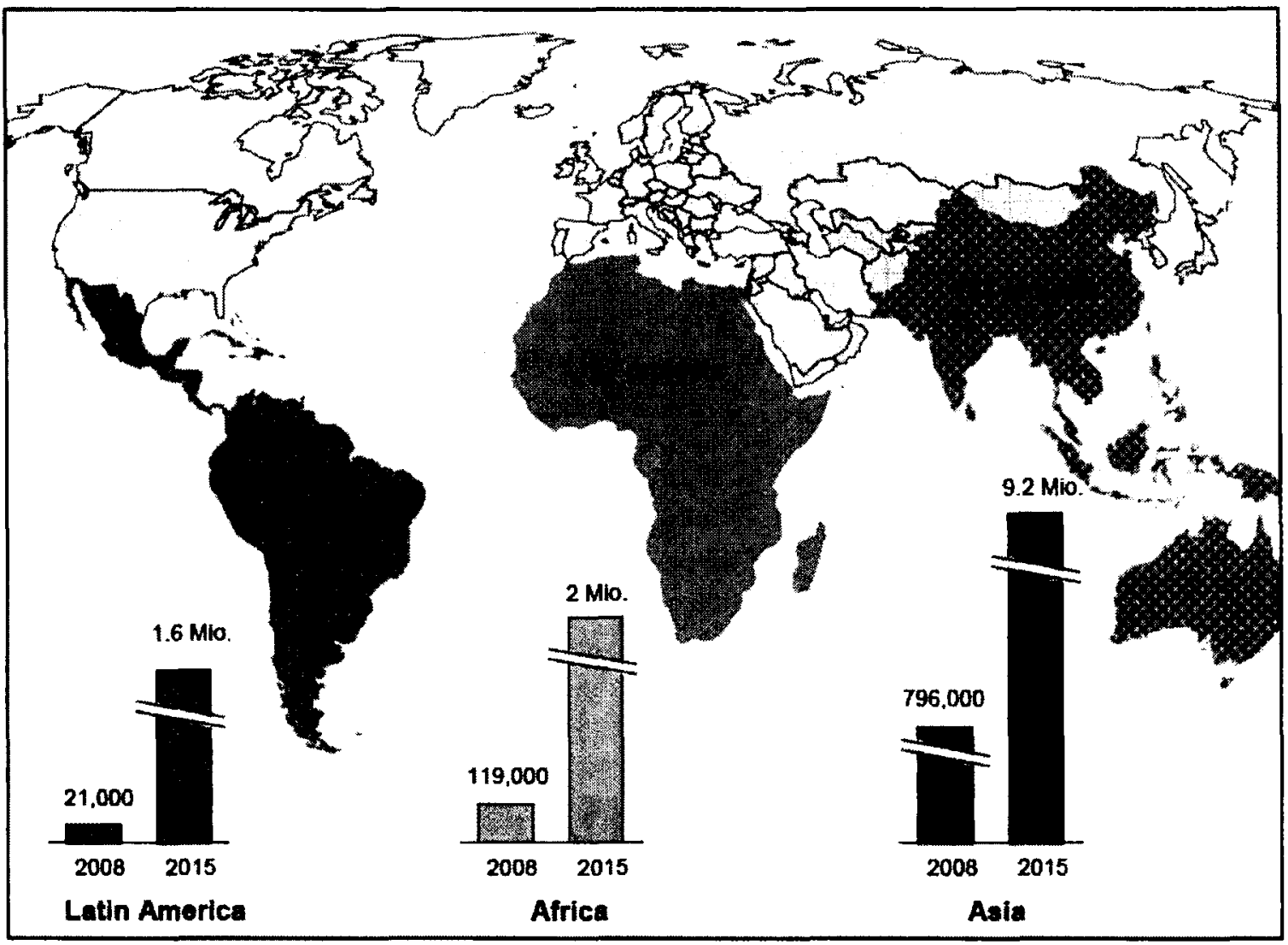

The GEXSI report provides an important snapshot of Jatropha activities that were reported (and anticipated) in early 2008. Numerous other studies have drawn on GEXSI's findings (e.g. Brittaine, 2010), reflecting this report's status as the most complete record of Jatropha projects available at the time. Given how quickly events have progressed in this field, the question remains: how has the spatial scale of Jatropha projects changed since its publication? 


\section{Project announcements}

It would be ideal if one could combine a project inventory like those compiled by Jatrophabook and GEXSI (2008) with the type of time series analysis provided by Google search trends. I attempted to take on this task by sifting through the archives of Biofuels Digest, a daily compilation of industry news related to all types of biofuels. Edited by Jim Lane, Biofuels Digest summarizes press releases and reports, providing links to the original sources, and also occasionally provides its own (pro-biofuel, proprivate sector) editorial pieces.

My plan was to create a spreadsheet of announcements about investments and land deals related to Jatropha, plot these in space and time, and compare them to a timeline of potentially relevant events. Focusing on the time period of July 2008 (soon after GEXSI's report was published) until the end of 2010, I searched Biofuels Digest for all postings that included the word "Jatropha." I reviewed these and selected the ones that reported public announcements of new investments in Jatropha plantations, land deals, processing facilities, or research projects. For the accompanying timeline, I kept a separate list of Digest entries that described newly released research reports, newspaper and magazine coverage, and business news related to Jatropha, as well as policy developments related to biofuels more generally.

For this exercise I focused on tracking the stated intentions of Jatropha actors as a proxy for the level of interest in Jatropha. Of course, not all of these planned investments or land deals will have come to fruition. I considered the level of commitment that it takes to make a public announcement about financing or a planned project sufficient to reflect a certain threshold of buy-in over the idea of Jatropha. This decision - to examine 
expressions of intent, rather than actions - follows from Anna Tsing's (2000) "economy of appearances" concept, where speculative hype is seen to play a major role in building the momentum of an emergent industry.

\section{Results}

Over the 30-month period from July 2008 - December 2010, I identified 84 new Jatropha project announcements. These included 58 proposed plantations, contracts with farmers or land allocations, along with 17 investments in new processing plants. The remainder of the announcements concerned new pilot projects, research initiatives or business startups.

The area that the announcements claimed would be planted with Jatropha totaled over $11,800,000$ hectares, as shown in Table 4.3. Dividing these into the same regions as the GEXSI report, this time Africa had the greatest share of planned hectares, followed closely by Asia, with the Americas (Latin America plus a few projects in the southern United States) trailing behind.

Table 4.3: Hectares to be planted with Jatropha, derived from announcements reported in Biofuels Digest, July 2008 - December 2010

\begin{tabular}{|l|l|}
\hline Region & Area (ha) \\
\hline Africa & $5,119,263$ \\
\hline Asia & $4,900,564^{17}$ \\
\hline Americas & $1,065,674$ \\
\hline Unspecified & 750,000 \\
\hline TOTAL & $\mathbf{1 1 , 8 3 5 , 5 0 1}$ \\
\hline
\end{tabular}

\footnotetext{
${ }^{17}$ This figure for Asia includes a calculation. One company announced that it would contract farmers to establish 5 billion plants; I converted this into 2 million hectares based on a spacing of $2 \mathrm{~m} 2 \mathrm{~m}$, or 2500 plants per hectare. This is the maximum planting density recommended for commercial production by Jatropha World (Jatrophabiodiesel.org); in other words, it gives a conservative estimate of the number of hectares to be covered. However, if the plants were used to establish hedgerows instead of plantations, the number of hectares involved would be lower.
} 
The investment announcements showed no clear temporal trends (Figure 4.3). A peak in March 2009 does not appear to be part of a larger pattern, and can be partly attributed to a single company in the Philippines announcing multiple projects in different areas of the country on the same day.

Figure 4.3: Jatropha project announcements, July 2008-December 2010

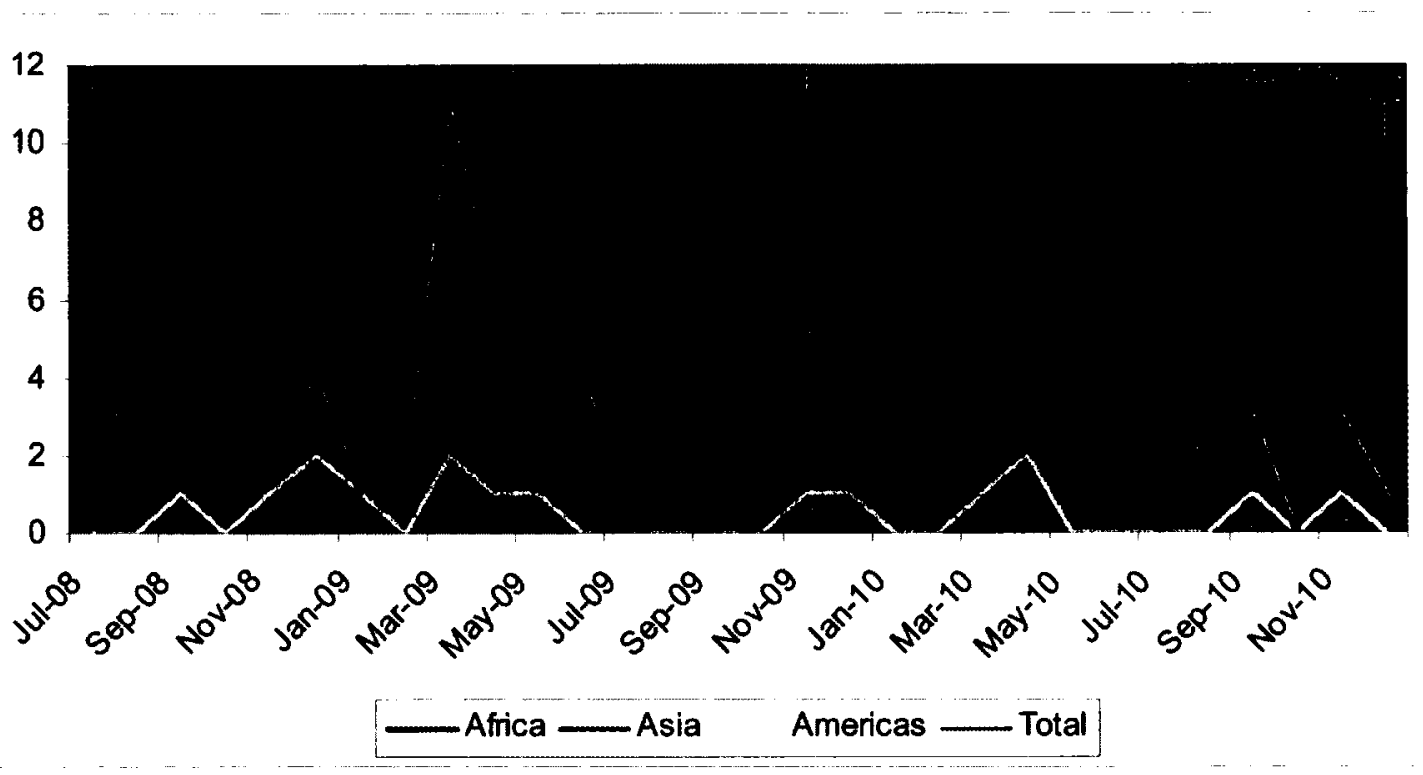

Figure 4.4 overlays the monthly total of Jatropha announcements from my scan with the Google search trend results for the same time period. It is difficult to see correlations, except that both lines are relatively flat from mid-2009 onward. Lining these up with a selection of Jatropha- and biofuel-related events, outlined below, there are few cooccurrences of these events with changes in general or investor interest. Exceptions include events 1 and 2 on the timeline, where world oil prices hit all-time high levels in July 2008 at the same time as the Google searches for Jatropha peaked. During the same month, "food versus fuel" received prominent media attention, for example through 
speculation that biofuels derived from food crops were responsible for a large share of the food price increases that were occurring (e.g. Chakrabortty, 2008). While bad news for biofuels in general, in combination with high oil prices this story likely increased the appeal of Jatropha, a non-food energy crop that was reputed to grow in areas unsuitable for other agricultural production.

Events 4,5 , and 6 correspond to the other prominent spike in Google search trends, in December 2008 (as well as Google's news index, represented by the lower line). Two successful test flights powered by a blend of Jatropha-derived biodiesel coincided with new, biofuel-friendly renewable energy legislation in the EU.

Event 7 coincides with a small peak in news coverage of Jatropha in May 2009, though perhaps for negative reasons. An article in the Guardian newspaper challenging Jatropha's performance could be interpreted as an early example of the kind of media backlash that later became more common.

From this point onward it becomes more difficult to see patterns in the occurrence of key events and shifts of interest in Jatropha, largely because there are no further discernable trends in investor or general interest, as already mentioned. 
Figure 4.4: Overlay of Jatropha project announcements (top graph), Google search trends (bottom graph, upper line), and Google news reference index (bottom graph, lower line), with timeline of key events (vertical lines), July 2008 - December 2010 Events expected to have an enabling effect on Jatropha investments are shown in green; those with an expected negative effect, in red. See numbering scheme below.

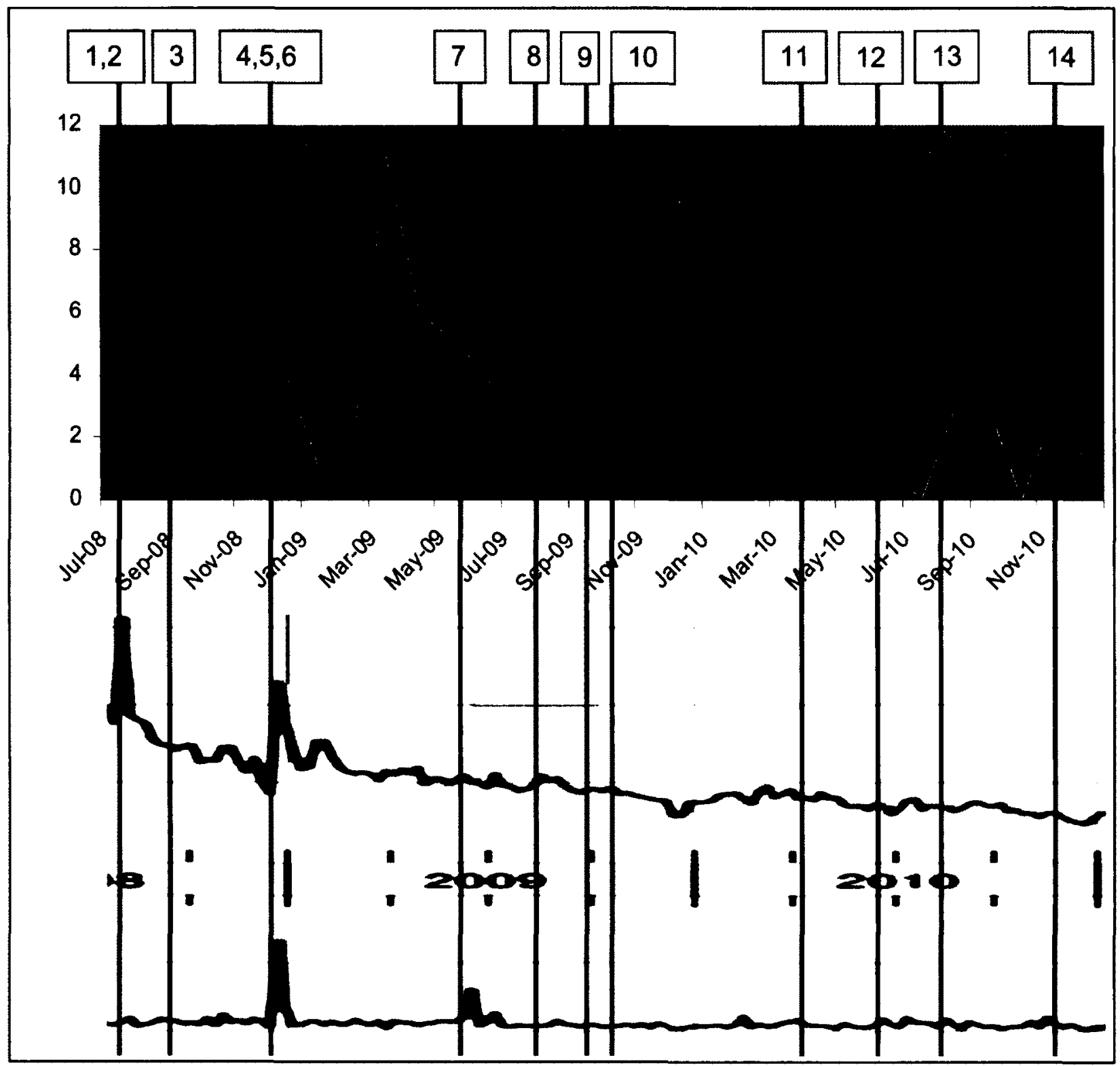




\section{Timeline of key events}

1. July 2008 (energy sector): Price of oil reaches highest level to date

2. July 7, 2008 (media): A "suppressed" World Bank study reportedly blames biofuels for $75 \%$ of food price increases (Chakrabortty 2008)

3. August 19, 2008 (policy): Government of India announces a plan to convert $40 \%$ of all "waste" lands in the country to Jatropha production by 2012

4. December 2008 (policy): EU Parliament approves renewable energy directive including biofuel targets

5. December 30, 2008 (Jatropha industry): Successful test flight in New Zealand using a blend of Jatropha-derived biodiesel

6. January 8, 2009 (Jatropha industry): Successful test flight in United States using a blend of Jatropha-derived biodiesel

7. May 5, 2009 (media): Guardian article: "Hailed as a miracle crop, Jatropha falls short of hype" (Luoma 2009)

8. August 19, 2009 (Jatropha industry): Company called BEI unveils a mechanical harvester for Jatropha

9. October 2009 (media): Negative coverage of Jatropha in Time magazine (Wadhams 2009)

10. October 15, 2009 (policy): Government of Tanzania suspends all investments in biofuels following news of an impending report on the negative impacts of Jatropha investment

11. April onwards, 2009 (energy sector): Deepwater Horizon oil spill in Gulf of Mexico

12. June, 2010 (media): Friends of the Earth releases report, "Africa: up for grabs," criticizing Jatropha plantations in Africa and calling for an end to European biofuel targets (Friends of the Earth 2010)

13. August 24, 2010 (Jatropha industry): Company called SG announces they have sequenced the Jatropha genome - seen as an important step towards producing improved varieties

14. November 24, 2010 (Jatropha industry): Successful test flight in Brazil using a blend of locally produced, Jatropha-derived biodiesel

Google search trends suggest that interest in Jatropha grew more or less steadily from 2005 to a peak in 2008, followed by a gradual decline. Looking at project announcements made between mid-2008 and late 2010 , it is difficult to see a clear pattern of investment from work presented here. Three explanations could help to interpret why there were no obvious surges or crashes of investor ambitions observed over that time period. 
First, the data set undoubtedly has some limitations. The data used here are only as complete as Biofuels Digest's coverage of announcements, drawn from online sources, press releases, and personal contacts (Lane 2009). It is very likely that some announcements were missed if they were not publicized through the channels that Biofuels Digest uses to compile its updates. Still, the scale of proposed projects over the time period considered, in terms of number of hectares, is broadly consistent with GEXSI's projections for the expansion of Jatropha. This suggests that the announcements captured a scale of activity that coincided with what some researchers had previously anticipated.

Second, if we believe that Google search trends say something valid about the level of general interest in Jatropha, then one can conclude that the time period covered in my scan corresponds with a very gradual decline of interest with few pronounced peaks or troughs. In this context, one would not expect major shifts in investor behaviour to occur. It would be illuminating to trace the pattern of investments further back in time to see whether a "bubble" preceded the scan; however, it is more difficult to access and verify stories that were distributed on the Internet the older they become.

Third, as the timeline and the preceding analysis of media coverage show, positive and negative messages about Jatropha coexisted throughout the time period in question. While there were clearly some rhetorically extreme stories about Jatropha's perceived benefits, as well as equally extreme criticisms of its perceived failures, the fact that the negative stories have not replaced the positive ones (and conversely, that positive ones have not trumped the negative ones) matches with a largely consistent pattern of investment. 


\section{Discussion}

Table 4.4 summarizes the sources of information that were presented above in terms of their contributions to understanding the spatial scale and temporal trends of Jatropha activities around the world. Jatrophabook and GEXSI (2008) provide static snapshots of Jatropha activities, including their size and distribution, while Google search trends add a temporal dimension by showing shifts in general interest in Jatropha. My survey of Jatropha investments and project announcements reported in Biofuels Digest attempts to combine a spatial and temporal analysis of buy-in over Jatropha, while my timeline of key events that might reasonably be expected to influence interest or investment in Jatropha provides temporal context to help interpret any patterns (although there was no strong pattern to be found). 
Table 4.4: Strengths, limitations, and contributions of various sources of information on spatial and temporal patterns in Jatropha's spread

\begin{tabular}{|c|c|c|c|c|}
\hline \multirow[t]{2}{*}{ Source } & \multirow[t]{2}{*}{ Strengths } & \multirow[t]{2}{*}{ Limitations } & \multicolumn{2}{|c|}{$\begin{array}{l}\text { Contribution to knowledge } \\
\text { of Jatropha }\end{array}$} \\
\hline & & & Spatial scale & $\begin{array}{l}\text { Temporal } \\
\text { trends }\end{array}$ \\
\hline $\begin{array}{l}\text { Google } \\
\text { search } \\
\text { trends }\end{array}$ & $\begin{array}{l}\text { Relatively long } \\
\text { time series } \\
\text { Sensitive to quick } \\
\text { shifts }\end{array}$ & $\begin{array}{l}\text { Internet searches } \\
\text { proxy for interest; } \\
\text { no signal of how } \\
\text { they translate into } \\
\text { attitudes or action }\end{array}$ & No & $\begin{array}{l}\text { Yes: general } \\
\text { interest and } \\
\text { news } \\
\text { reference } \\
\text { index }\end{array}$ \\
\hline $\begin{array}{l}\text { Jatropha- } \\
\text { book }\end{array}$ & $\begin{array}{l}\text { Details several } \\
\text { types of Jatropha } \\
\text { projects } \\
\text { Members self- } \\
\text { register (no } \\
\text { screening) }\end{array}$ & $\begin{array}{l}\text { Membership skewed } \\
\text { towards Italy } \\
\text { Members self- } \\
\text { register (no } \\
\text { verification) }\end{array}$ & $\begin{array}{l}\text { Yes: scale } \\
\text { and } \\
\text { distribution } \\
\text { of projects }\end{array}$ & No \\
\hline $\begin{array}{l}\text { GEXSI } \\
2008\end{array}$ & $\begin{array}{l}\text { Most complete } \\
\text { global inventory of } \\
\text { Jatropha } \\
\text { plantations up to } \\
\text { early } 2008 \\
\end{array}$ & $\begin{array}{l}\text { Plantations, not } \\
\text { other project types } \\
\text { Snapshot in time }\end{array}$ & $\begin{array}{l}\text { Yes: scale of } \\
\text { plantations } \\
\text { plus country- } \\
\text { by-country } \\
\text { profiles }\end{array}$ & $\begin{array}{l}\text { No, but gives } \\
\text { projections of } \\
\text { future } \\
\text { expansion }\end{array}$ \\
\hline $\begin{array}{l}\text { Survey of } \\
\text { Biofuels } \\
\text { Digest }\end{array}$ & $\begin{array}{l}\text { Public } \\
\text { announcements } \\
\text { (intent) as proxy } \\
\text { for investment } \\
\text { decisions } \\
\text { Spatial and } \\
\text { temporal analysis }\end{array}$ & $\begin{array}{l}\text { Limitations of data } \\
\text { set } \\
\text { No signal of whether } \\
\text { projects went ahead } \\
\text { (measures buy-in, } \\
\text { not outcomes) }\end{array}$ & Yes & Yes \\
\hline $\begin{array}{l}\text { Timeline of } \\
\text { key events }\end{array}$ & $\begin{array}{l}\text { Provides temporal } \\
\text { context for } \\
\text { interpreting trends }\end{array}$ & $\begin{array}{l}\text { Selective } \\
\text { No causal } \\
\text { relationships }\end{array}$ & $\begin{array}{l}\text { No: many } \\
\text { not related to } \\
\text { Jatropha } \\
\text { activities } \\
\end{array}$ & Yes \\
\hline
\end{tabular}

Clearly the state of knowledge that surrounds the spread of Jatropha activities and investments remains partial, with each of these sources contributing a piece to an incomplete puzzle. However, these separate pieces of evidence do corroborate some elements of the same story. GEXSI (2008) exposed the scale of Jatropha plantations, reporting close to 1 million hectares under cultivation at that time, while Biofuels Digest 
announcements show plans for future plantations growing at approximately the same rate as GEXSI's predictions. Google search trends spiked at a time when world oil prices were at their highest, and again when commercial airlines conducted successful test flights on a blend of Jatropha-derived fuel, suggesting that, in 2008 at least, these events may have contributed to heightened interest in Jatropha as an alternative to fossil fuels. The subsequent lack of patterns in both Internet search trends and project announcements suggests that while Jatropha's novelty may have worn off, interest and investment in it remained relatively steady - perhaps related to the persistent coexistence of positive messages about Jatropha alongside the critiques reported in the media analysis.

\section{CHAPTER SYNTHESIS}

This chapter has explored recent trends in the spread of messages and claims about Jatropha, levels of general interest in the crop, and investments in specific projects in several countries. The patterns discussed here provide a crucial link between the general debates and discourses on biofuels highlighted in Chapter 3, and the promotion of Jatropha in Kenya specifically, which will be the focus of the remainder of this thesis. For example, research findings on Jatropha challenge fundamental claims about its ability to grow well and produce abundant oil under harsh agro-climatic conditions - claims which are central to the idea that Jatropha can produce biofuel without competing with food production. This is an important element of international debates over biofuels, and a particularly relevant consideration when attempting to grow Jatropha in Kenya's dry, so-called "marginal" lands where few food crops are cultivated. 
Debates over the relative merits of large-scale and small-scale strategies for growing Jatropha, and the different purposes for which Jatropha could be grown, emerge strongly from the literature review. These evoke the same themes of environmental benefits, energy security, and economic or agricultural development at different scales that were introduced in Chapter 3, and provide a series of reference points for situating discussions about different approaches and types of Jatropha activities in Kenya.

This chapter has also shown that critical and optimistic messages about Jatropha persist and coexist, both in the academic literature and the media. The continued repetition of claims and counter-claims suggests that neither position has become dominant over time, and matches with a relatively steady trend of investment in Jatropha projects. The applicability of this insight to the Kenyan context will be considered in the chapters to come. However, the co-occurrence of a peak of general interest in Jatropha (measured using Google search trends) with a period of high oil prices hints at possible interactions between the promotion of Jatropha and broader economic forces.

A small jump in interest following the first successful test flights that were run partly on Jatropha-derived biodiesel suggests that public curiosity, at least, may have been influenced by hearing a "success story." Crucially, this depends not only on the successful event taking place, but also on dissemination of the story - a theme that will be further examined in Chapters 5, 6 and 7 through discussions about the role of the media, the importance of controlling discourse, and the political economy of knowledge surrounding Jatropha in Kenya. Chapter 5 now moves from general patterns to the specific case of Jatropha in Kenya, introducing the historical and agricultural context, the main actors involved, and some broad features of Jatropha activities in the country. 


\section{CHAPTER 5: JATROPHA IN KENYA: ACTORS AND ACTIVITIES}

This chapter moves from the global status and trends of Jatropha to the Kenyan context, thus setting the scene for a detailed examination of the politics and implications of promoting Jatropha to small farmers in Kenya. It begins by briefly reviewing the country's land politics and past agricultural interventions to provide a historical backdrop for the promotion of Jatropha. The discussion then turns to the story of Jatropha as an energy crop in Kenya, reviewing its history and the extent of its spread. The chapter then introduces key players in Kenya's recent Jatropha activities, delineates their roles, and presents some general features of Jatropha activities in the country - particularly the conspicuous absence of processing and marketing. After drawing on secondary sources to establish the context, key informant interviews provide the main source of information used to document the landscape of Jatropha actors and activities.

\section{KENYAN CONTEXT}

\section{Historical context of land and agriculture issues in Kenya}

Kenya's history has been repeatedly marked by the introduction of new crops and agricultural strategies as well as heated controversy over the distribution of land. During the colonial period these processes were linked as British land policy oversaw the allocation of the country's most fertile land to European settlers who established cash crops such as coffee, which Kenyans were legally prohibited from growing at the time. After independence in 1963, the new government reversed this policy and encouraged both smallholder cash crop production and private foreign investment, with the result that transnational corporations and their subsidiaries played a central role in establishing the 
country's sugar and tea industries, while the government itself encouraged the establishment of other cash crops such as tobacco (Currie and Ray 1987). Experiences with these cash crops continue to condition Kenyans' views about agriculture and perhaps influence their perceptions of Jatropha as a 'new' enterprise, as will be discussed in more detail later.

Land rights have been an ongoing source of tension in the country. Reserves for each colonially recognized ethnic group were established by the British administration in 1926, with the effect of separating and confining Kenyans based on ethnicity. The expropriation of land to establish large farms in the so-called 'white highlands' created severe land pressure, with the Kikuyu alone losing more than 60,000 acres to the expansion of European settlement (Elkins 2005). This was only one part of a string of injustices. The imposition of taxes, combined with restrictions on the types and quantities of crops that Africans were allowed to grow, pushed many from subsistence agriculture into wage labour (Anderson 2005). Colonial officials imposed mandatory participation in 'soil conservation schemes' in the 1940s and 1950s; these demanded hard labour to build agricultural terraces and were so strongly opposed that in one incident, 2,500 women in Central Province jointly rebelled against them in 1948 (Mackenzie 1998). Colonial land, agricultural and tax policies thus combined to create new economic and social pressures.

Control over land was one of the major grievances driving the Mau Mau uprising, which triggered a multi-year conflict in which up to 50,000 Africans died, primarily Kikuyu, Meru and Embu (Blacker 2007). Approximately 100,000 Africans were detained and 'screened' based on suspected involvement with the rebellion, many of them tortured or abused by both colonial officials and African loyalists known as Home Guards (Elkins, 
2005). This conflict caused Kenya's British administrators to declare an Emergency Period from 1952-59, contributed to the erosion of public support in Britain for its colonial foreign policies, and arguably hastened the end of British rule in Kenya (Elkins, 2005).

Subsequent changes to land ownership laws and their (lack of) enforcement have done little to alleviate deep concerns over the inequitable distribution of land. Freehold titles were entrenched in a manner that favoured those who had the resources to purchase land over those who did not (Kenya Land Alliance 2004). Different land ownership systems in different parts of the country (e.g. individual titles vs. group ranches) have each presented their own opportunities and pitfalls, crucially depending on who has the power to allocate others' access to land. A lack of harmonization of land laws and administration has created a situation where multiple deeds are sometimes awarded for the same parcel of land (Agenda 4 Implementation Framework, 2008). Meanwhile, patronage and élite capture (i.e. land grabs) have continued to provoke frustration, with government officials frequently using the privatization of public lands as an instrument of political control (Klopp 2000).

Tensions over access to land have at times erupted in violence. In the 1990s, clashes broke out in several parts of the country, particularly the Rift Valley. The Kenya Land Alliance (KLA) (2004) alleges that political leaders at the time encouraged residents to drive out those from other parts of the country (perceived as "foreigners" to the area) who had gained land titles either through land redistribution initiatives or outright purchase. Many people were displaced and no serious efforts were made to 
resettle them, an issue which the KLA warned could one day lead to further violence or even civil war if left unaddressed (Kenya Land Alliance 2004).

In early 2008, violence and social upheaval after the December 2007 parliamentary and presidential elections killed over 1,100 Kenyans, about three quarters of them in Rift Valley Province (Kenya National Dialogue and Reconciliation 2008). Approximately 500,000 more were internally displaced (Elhawary 2009), many of whom have not returned to the areas where they previously lived. The Waki Commission, the judicial inquiry tasked with documenting the causes and impacts of the violence and making recommendations to avoid similar conflicts in future, described how the violence was overtly linked to ethnicity, particularly Kikuyu versus Luo, the two largest ethnic groups in the country. However, it argued that the violence reflected a lack of political will to address a variety of deep problems (Kenya National Dialogue and Reconciliation 2008: p.36, emphasis added):

... because violence surrounding elections has been ethnically directed, this has increased distrust among different ethnic groups and vastly eroded any sense of national identity... Attempts have been made to crack down on gangs and half heartedly to reform institutions. Neither has been successful because the government has not been serious, has not been willing to address the generic issues or underlying causes of violence.

The Commission went on to identify some of these underlying causes as issues of "land, marginalization and inequality, and youth" (p. 36). The subsequent peace agreement mediated by Kofi Annan also identified the need for land reform as one of the "fundamental root causes of recurrent conflict" in Kenya, which the accord's signatories committed to addressing through a series of institutional changes (Kenya National Dialogue and Reconciliation 2008: 5). Despite the peace accord's emphasis on reforming 
institutions related to land, many of those who were displaced in 2008 still face an uncertain future as fundamental questions about land have remained unaddressed (Elhawary 2009).

The Mau Mau rebellion in the 1950s, clashes in the 1990s, and post-election violence in 2008 suggest that tensions over access to land have contributed to a pattern of recurring conflict in Kenya. This very brief section has shown that the introduction of Jatropha in Kenya is set against a history of contested land rights, insufficient efforts to achieve land reform, and 'top-down' agricultural schemes. The effects of these influences will be revisited throughout the analysis.

\section{Jatropha's spread in Kenya}

As mentioned in Chapter 4, it is believed that Jatropha was spread throughout Africa by Portuguese traders (Heller 1996), a plausible explanation for its arrival in Kenya given the historical trade routes that operated along the Indian Ocean coast. While the year of its introduction is unknown, one informant who I interviewed for this research claimed to have seen botanical records showing that the plant had become naturalized in several parts of Kenya by the 1920s, although some of these pockets of Jatropha were later destroyed (NGO4). ${ }^{18}$

Farmers have grown Jatropha in parts of Kenya for decades, most often as a living fence or grave marker that animals will not graze due to the plant's toxicity (Government of Kenya and GTZ 2008). A few farmers in Western Kenya began to use Jatropha as a

\footnotetext{
${ }^{18}$ To attribute statements to particular (anonymous) interviewees, I use a system of codes that includes the type of organization to which they belong. For key informants, NGO = non-governmental organization; PS = private sector; $\mathrm{GO}=$ government; $\mathrm{RS}=$ researcher; $\mathrm{DN}=$ donor. Interviewees from the case studies are numbered with the prefixes MP for Mpeketoni, and NG for Nguruman.
} 
support plant for vanilla vines in about the year 2000 (GTZ 2009). Farmers who participated in this research reported having used the plant medicinally to treat cuts and stomach complaints. In Nguruman, Kajiado District, which is generally regarded as a seed source area for Jatropha in Kenya, one farmer reported having brought planting material from the Taita area in the 1970s. He used this to establish the oldest fences that were observed in Nguruman during this research. However, some very mature individual trees could also be found, both in Nguruman and Mpeketoni, which clearly predated this movement of seed material.

Starting around the year 2006, several NGOs and a few businesses in Kenya encouraged farmers to plant Jatropha as an income generating strategy based on its potential as an energy crop. The following years saw a busy spread of Jatropha to farmers in many parts of Kenya, largely driven by internationally funded NGOs, as discussed in detail below.

Several reports have attempted to assess the potential for Jatropha to flourish in Kenya. Muok and Källbäck (2008) state that large areas of the country ("abundant idle land" in arid and semi-arid areas) are suitable for growing Jatropha (p. 51). They conclude that if sufficient research and development activities, regulatory measures, and safeguards for rural well-being were put in place, then a Jatropha biodiesel industry in Kenya could supply national energy needs and produce surplus for export, while achieving rural employment gains and environmental benefits. Similarly, in a World Bank-supported report prepared for the Kenyan government, which lists the promotion of smallholder Jatropha production as one of its aims, Ng'ethe (2007) describes Jatropha as providing "remarkable opportunities to smallholder, medium and large-scale farmers," 
particularly in arid and semi-arid lands and "other fragile ecosystems" (p. 3). Both of these reports draw strongly on the idea that Jatropha grows well and produces abundant seeds under semi-arid conditions, a claim that was presented and contested in Chapter 4 .

Tomomatsu and Swallow (2007) present a bleaker picture of Jatropha's ability to benefit farmers in Kenya. Drawing on an analysis of Jatropha activities from 2005-2007, they conclude that under prevailing economic conditions at the time, smallholder Jatropha production was not economically favourable compared to growing other crops. The authors acknowledge a fundamental tension between the desire to produce Jatropha on a large scale, which they state would bring greatest benefits to the country as a whole, and the likelihood that small-scale farmers would not benefit from participating in such arrangements. However, the authors note opportunities for small-scale farmers to benefit by growing Jatropha to be processed locally and used as a substitute for kerosene. As well, Tomomatsu and Swallow point out that the financial outlook for Jatropha-based biodiesel could improve significantly if subsidies or tax incentives were put in place.

In an assessment of all types of biofuels that could be produced in Kenya, the Government of Kenya and GTZ (2008) report that Jatropha's "purported strengths" of being able to thrive in poor soils and semi-arid conditions "may have been exaggerated" (p. 35), though they acknowledge benefits such as the ability to help control soil erosion. In a more specific follow-up report titled, "Jatropha reality check," GTZ (2009) presents a much more critical view of Jatropha in Kenya. Based on a survey of Jatropha growers in several parts of the country, the report concludes that growing Jatropha is not economically viable using either monocrop or intercrop strategies, and recommends that all actors "for the time being cease promoting the crop among smallholder farmers for 
any plantation other than a fence" (p. 2). In an example of highly evocative language applied to Jatropha, the report's executive summary continues (GTZ 2009, p. 2): "These conclusions provide a sobering retort to some of the unbridled hype that has swirled around Jatropha over the past few years..." While the content of this report is generally consistent with the findings of Tomomatsu and Swallow (2007), its tone is more confrontational. It appears that GTZ (2009) has attempted to counterbalance what it perceives as inappropriately positive claims that have been made by others.

In a specific study on Jatropha grown as fencing, Boerstler (2010) evaluates the potential for Jatropha to provide energy for household use, calculating that after two years of growth in a particular coastal area, a hedge $369.5 \mathrm{~m}$ in length would be able to supply an average rural household's lighting needs on an ongoing basis. A much shorter hedge (108.8 $\mathrm{m}$ after five years of growth in the study area) could supply enough Jatropha oil to substitute for kerosene during the five months of the year when income is lowest due to the planting and harvest schedule (p. 220). These findings are consistent with GTZ's (2009) conclusion that growing Jatropha as a fence would be most economically beneficial for farmers.

There is no central record of how many farmers in Kenya have planted Jatropha; different sources report wildly different numbers. On the low end, GTZ (2009) estimated that only 472 farmers were actively growing Jatropha in 2009. This number was based on the assumption that their baseline survey comprised $60 \%$ of Jatropha farmers in the regions they visited, informed by discussions with local officials. GTZ did not count farmers who once planted Jatropha but later abandoned it, nor farmers in areas that were 
not part of their survey - including, significantly, Mpeketoni, where a project reportedly involving over 1,400 farmers was well underway at the time of the GTZ survey.

A much higher estimate comes from Jatropha's most vocal promoters. Leaders of Kenya's three largest Jatropha NGOs (Green Africa Foundation, Vanilla-Jatropha Foundation, and Vanilla-Jatropha Development Foundation) each reported during interviews that their organization worked with "thousands" of farmers. Combining these with the 1,470 farmers reportedly enrolled in the Mpeketoni project would yield at least 8,000 small farmers ${ }^{19}$, not including those who were unaffiliated with any of these organizations, such as in Nguruman, Shimba Hills or Kwale / Kilifi. Of course, even if accurate, these numbers presumably include all farmers who have been 'reached' by Jatropha promoters and not necessarily those who continued to grow the crop, or indeed followed through with planting it at all. GTZ (2009) documents one such drop-off in farmer participation, reporting that a project run by the private company Energy Africa in Shimba Hills, Coast Province, initially distributed planting material to 800 farmers and later signed contracts with 200 of them, but by the time of the GTZ survey, only 75 farmers in the area who were still growing Jatropha could be found.

Sources agreed, however, that in 2009 commercial cultivation on large plantations had not yet begun (GTZ 2009, NGO7, PS1, PS3). Rumours abounded about investors negotiating access to large tracts of land to establish commercial plantations, including in the media (e.g. Miriri 2008; Bii 2009). Subsequent debates have intensified over a proposed 50,000 ha Jatropha plantation in the Dakatcha Woodlands, Coast Province (Ross 2011). However, at the time of this research, neither this nor any other large-scale Jatropha project had reached the implementation stage.

${ }^{19}$ Out of a rural population of approximately 26 million in 2009 (Kenya National Bureau of Statistics 2010) 
Many farmers who planted Jatropha in Kenya report that far from being a highyielding crop, it has grown slowly and produced fewer seeds than they were led to believe (GTZ 2009; Hunsberger 2009; Wadhams 2009). Their observations are affirmed by the numerous studies reviewed in Chapter 4 that question the optimistic claims about Jatropha's agronomic potential and call for caution until more is known about its performance under different ecological conditions and management practices (e.g. Achten et al. 2007; Jongschaap et al. 2007; Achten et al. 2008). Meanwhile, Jatropha's potential competition with food crops for arable land, water, nutrients and labour, as well as with livelihood activities such as livestock grazing, remains largely unresearched.

\section{Key informant perspectives on Jatropha in Kenya}

Numerous participants in this study argued that up to the time of research, Jatropha had dominated discussions about biofuels in Kenya. For example, in strong terms, one NGO representative stated: "The [government's] biofuel strategy is basically the Jatropha strategy. There's no other oil that's seen to come close" (NGO4). Another said, "A name comes with a brand. Jatropha will initially be the brand of biodiesel" (NGO2). A third commented with some irony, "Jatropha is a bandwagon. We're on it; even you are on it now. We don't know where the wagon is going, but the band is playing" (NGO8). Using more moderate language, government representatives described Jatropha as a "lead crop," "flagship crop" or simply "the feedstock" for biofuel production in Kenya (GO1, GO2).

These phrases align with the government's 2008 position that Jatropha was the top priority in its draft renewable energy strategy (Government of Kenya 2008). Implicitly, acceptance of Jatropha's dominant status could be observed at a June 2009 forum that 
was inclusively called the Kenya Biodiesel Workshop, ${ }^{20}$ though its presentations and discussions focused almost entirely on Jatropha (Government of Kenya 2009). While these are selected examples, the breadth of actors who expressed that Jatropha was the most important biodiesel crop in Kenya, along with the variety of ways in which this perspective was put forward, demonstrate that this was a widely held view at the time of research. Together, the written, verbal and implied messages just presented reinforce the interpretation that Jatropha was seen to deserve special attention within Kenya's renewable energy landscape.

\section{MAJOR PLAYERS IN KENYA'S JATROPHA ACTIVITIES}

How did Jatropha assume this privileged position, and what kept it there? Answering this question involves delving into a tangle of actors, motivations and influences operating across sectors and scales. Key informants in this research expressed that a small number of NGOs (and by extension, their donors) played a leading role in promoting Jatropha in Kenya, while government agencies, private investors and researchers supported (and at times contested) this trend. This section explores the roles and activities of this group of actors, drawing on interviews with 22 individuals conducted between February and July 2009. As mentioned in Chapter 2, these included representatives of government agencies, non-governmental organizations, private companies, research organizations and donors.

These categories are not internally uniform nor are they mutually exclusive. Each group includes multiple perspectives and strategies, while some interviewees acted in

${ }^{20}$ Organized by the research subcommittee of the National Biofuel Committee 
more than one capacity. ${ }^{21}$ As Lewis (2003: 220) wisely observes, "Organizations are filled with internal contradictions and conflicts and cannot be regarded as either unitary or predictable structures." Recognizing this diversity within and between organizations, the interviewees are nonetheless grouped here based on their primary roles to look for common perspectives between members of each group as well as to consider the perceptions of each group held by other actors. Bernstein's (2010) four key questions for agrarian political economy are used as a guiding framework: Who does what? Who owns what? Who gets what? And what do they do with accumulated surplus? Here the question of who 'does' what is addressed through the description of the actors' activities, while the most relevant of the three other questions are raised at the end of each subsection.

For the remainder of this chapter, the discussion is primarily based on how each group was perceived and described by members of other groups. Chapter 6 will delve into key informants' explanations of their own motivations, decisions and actions.

\section{NGOs}

A handful of NGOs conducted Jatropha-related activities among their main undertakings in 2009. All of these organizations were based in Kenya and most were at least partially supported by international, non-governmental donors. ${ }^{22}$ The most prominent of these were the Green Africa Foundation (GAF), Vanilla Development Foundation (VDF), and the Vanilla-Jatropha Development Foundation (VJDF), ${ }^{23}$ each of which actively

\footnotetext{
${ }^{21}$ Some of these combinations of roles include researcher / private sector, researcher / government and $\mathrm{NGO}$ / government.

${ }^{22}$ Including the World Bank, Prince Albert of Monaco Foundation, Norwegian Church Aid and the Global Environment Facility

${ }^{23}$ The Vanilla Development Foundation and the Vanilla-Jatropha Development Foundation initially formed as a single organization which later split into two.
} 
promoted Jatropha to small-scale farmers in multiple areas, and publicly championed Jatropha, for example at meetings, in workshops, and through the media. Their official mandates and priorities ranged from environmental conservation to rural poverty alleviation. The nature, scope and scale of their activities varied considerably. Some focused on distributing seeds or seedlings to smallholder farmers, encouraging them to plant Jatropha and providing technical advice (e.g. GAF, VDF, VJDF). Some also liaised with investors who wished to establish large plantations (e.g. GAF). Other organizations focused on coordinating the formation of farmer groups in order to grow and process Jatropha for household lighting or local value addition projects (e.g. Norwegian Church Aid, UNDP/DED/WWF). These generally focused on only one or two projects, and were less active in national committee meetings and workshops. Still other NGOs (e.g. Help Self Help Centre, COPSO) were interested in biodiesel and rural energy more broadly, but were not directly engaged in Jatropha activities in 2009. NGOs thus represented a highly heterogeneous collection of actors. Participants in this study identified three of these organizations - GAF, VDF, and VJDF - as the most vocal and influential promoters of Jatropha in the country.

Several actors who were interviewed for this project described how NGOs were the first to popularize the idea of growing Jatropha in the country and remained "at the forefront" of its spread (RS4, PS1). A recurring theme was the role that NGOs had played in building farmers' perceptions and expectations of the crop. Some expressed this with disapproval in relation to raising false hopes, as discussed in Chapter 6.

Several interviewees discussed the link between NGOs' commitment to Jatropha and their ability to attract funding. A representative from one of the smaller NGOs 
directly attributed sustained "hype" over Jatropha to NGOs' ability to quickly adopt new ideas that can attract a funding base (NGO1). A private sector representative commented, "I think some of these [NGOs] are seriously concerned that in the countryside people are very poor, so they have invested some of their survival capital in this Jatropha idea, so they cannot give it up" (PS3). These statements attest to the early adoption and persistence of particular NGOs in promoting Jatropha, and link these characteristics to the availability of donor funds.

Other actors expressed the opinion that NGOs had provided significant input into the policy development process. A representative of one NGO that was not involved in this process felt that another NGO had strongly influenced the 2008 biodiesel strategy prepared by the Ministry of Energy (NGO6). A researcher (RS1) went further, observing:

The early proponents of Jatropha were loud and organized... and they had a lot at stake in Jatropha because they had put so much into it. They had told all their donors that this was going to work... they needed to keep the confidence up, and the way to do that was to influence every decision to support Jatropha.

A government representative echoed these sentiments, stating that "NGO advocacy on biodiesel has been quite strong," going on to suggest that if NGOs can attract funding by promoting an activity that is in line with global thinking, they will do what they can to promote the idea to policy makers (GO1).

These comments suggest that some NGOs aligned themselves with international donors' objectives to attain operating funds for Jatropha activities, and worked to maintain this arrangement by promoting Jatropha through the policy development process. This strategic positioning aligns with Mosse's proposition that the primary function of policy is "to legitimize rather than to orientate practice" (2005: 14). In this 
case, several interviewees advanced the interpretation that some NGOs sought to consolidate interest in Jatropha by participating in the policy process - in other words, seeing policy formation as an opportunity to add legitimacy to activities that were already underway. In response to Bernstein's question of who 'gets' what, NGOs who have harnessed external resources appear to have been the main beneficiaries of Jatropha activities in Kenya so far. This theme is explored in more detail in Chapter 6.

\section{Donors}

International donors were seen as a driving force behind the spread of Jatropha in Kenya, primarily by providing financial support that enabled NGOs' activities. The donors referred to here all represent nongovernmental bodies; some are multilateral donors while others are bilateral. ${ }^{24} \mathrm{~A}$ member of the private sector underlined the importance of donors' contribution by commenting, "All the NGOs in the forefront, they're getting their funding from outside. If they're not funded, they're not going to promote [Jatropha]" (PS1). The relationship between a particular donor organization and a Jatropha project involving forms of capacity building that go far beyond financial support - is examined in detail in the case study on Mpeketoni in Chapter 6.

In addition to funding program activities, donors were credited with enabling research that otherwise would not have taken place. For example, one NGO representative described how attracting international funds opened up new possibilities "where we could now do research in a proper way" (NGO4) and thus improve the information on which the expansion of Jatropha was based. A private sector actor

\footnotetext{
${ }^{24}$ Specific donor organizations included the World Bank, Prince Albert of Monaco Foundation, Norwegian Church Aid, and United Nations Development Programme - Small Grants Programme. Some interviewees declined to disclose the sources of their funding.
} 
summarized: "For us to have a better variety or a better provenance [of Jatropha], we cannot afford research locally funded. We have to wait for funding from outside." (PS1) A researcher responsible for coordinating an internationally funded grant praised the donor for providing support without imposing a particular agenda on the work (GO3). In these ways donors were seen to provide indispensable backing for the Jatropha projects and research that were already underway.

At the same time, interviewees acknowledged that these activities were vulnerable to a shift in donor priorities - particularly if regulatory decisions within Kenya did not match these priorities. For example, one researcher (RS2) commented:

Outside donors, they usually don't do things for the sake of it. They also do it for the sake of benefiting from it. But if Kenya is going to rule out the possibility of exporting the oil maybe to European Union, then the European Union might find it is not attractive to put more research into biodiesel in Kenya... unless it is a regular organization which has been supporting some research activities in the country.

Some thought that a decline in donor support for Jatropha was already taking place. For example, one NGO representative stated: "Right now the international community, particularly the donors, are not very enthusiastic to support biodiesel or biofuels... the lack of successful case stories is putting on their brakes" (NGO2). A researcher (RS1) described a similar shift in donor priorities:

[with] the high oil prices and all that, there was a lot of money, everyone was thinking biofuel was hot... and then it got a black eye with food, and now oil prices are low, and no one is interested... I think most of the interest globally is in cellulosic ethanol and algae and other things like that. Those are the areas where the big money is.

Collectively, these comments demonstrate that donor interest helped to propel early Jatropha activities in Kenya, and signal that changes in this level of interest could inhibit the further spread of Jatropha. Whether or not they are already occurring, it appears that 
changes to donor priorities and confidence levels could strongly affect the future of Jatropha projects, research and - directly or indirectly - biodiesel policy in Kenya.

Here the most relevant of Bernstein's questions is: who owns what? Donors clearly 'own' the financial resources that have been mobilized to promote Jatropha in Kenya. Like Currie and Ray's (1987) description of transnational corporations in Kenya in the 1970 s and 1980 s, these donors are a step removed from the farmers who implement their projects, in this case because NGOs (as opposed to subsidiaries) act as intermediaries. A two-way relationship ensues in which donors rely on NGOs to carry out their mandates, and NGOs rely on donors to continue their activities. Harsh et al. (2010) point out that organizations have an advantage in attracting funding if they can provide accounts of their activities that donors find satisfactory, with two outcomes: first, that funds tend to 'lodge' within organizations that are better placed to provide these accounts, including those in capital cities; and second, that the discourse employed by NGOs in meetings and workshops can be quite different from that employed in the field, the former reflecting attempts to achieve convergence with donor priorities. Several NGOs working with Jatropha in Kenya appear to have successfully tailored their activities - and their discourses - to tap into these donor resources. As a result, they have an incentive to keep providing optimistic accounts of Jatropha in order to safeguard against a shift in donor priorities, as will be discussed further in Chapter 6 .

\section{Government}

As mentioned, the Government of Kenya listed Jatropha as the top priority in its 2008 draft strategy paper on biodiesel (Government of Kenya 2008). This represents a strong 
official endorsement; however, in 2009 the government's stated support for Jatropha had yet to be consolidated through policy. At the time of this research the government was drafting a biodiesel policy as well as a regulatory framework that would, when implemented, have major impacts on the economic conditions surrounding the crop. These documents will likely clarify how biodiesel and crude Jatropha oil will be taxed and/or subsidized, specify conditions for exporting biofuels, and possibly establish a national fuel-blending mandate. A government representative stated: "the initial focus in development of the biodiesel industry was Jatropha. However, through various stakeholder interactions it has come out that there is need to explore the potential of other oil crops" (GO1), showing some readiness to consider alternative biofuel crops alongside Jatropha.

Several ministries were involved in this policy development process, with the Ministry of Energy playing a lead role. To produce the biodiesel strategy paper and the eventual policy, in 2006 the Ministry of Energy convened a National Biofuels Committee comprising representatives of government ministries ${ }^{25}$, research institutes, NGOs and private companies whose mandates relate to biofuels. The National Biofuels Committee has subcommittees that include a Policy Committee and a Research Committee. Another body, the Kenya Biodiesel Association (KBDA), was created in 2008 out of the committee's recommendations with the aim of bringing together actors from across the value chain, coordinating and overseeing the implementation of Jatropha activities in the country, and incorporating members' perspectives into the policy development process.

${ }^{25}$ Including the Ministries of Energy, Agriculture, Cooperative Development and Marketing, Environment and Natural Resources, Finance, Gender, Sports, Culture and Social Services, Higher Education, Science and Technology, Lands, Local Government, Regional Development Authorities, Trade, Transportation, Water and Irrigation, and Youth and Sports. 
In this way both the policy process and the primary body for overseeing Jatropha activities in the country have been designed to include input from NGOs and the private sector in addition to government actors.

In addition to developing policies directly related to biofuels and Jatropha, the Government has further potential to influence Jatropha activities through its network of extension officers affiliated with the Ministry of Agriculture. These officers could play a major role in informing and supporting farmers with respect to Jatropha growing - or discouraging them, depending on the Ministry's position. Local agriculture officers are in direct contact with farmers, and could serve to either enhance or counterbalance the influences of NGOs who were promoting Jatropha in rural areas. At the time of research, local agriculture officers were not actively promoting or discouraging Jatropha, although a Ministry of Agriculture representative emphasized that the Ministry held a favourable view of Jatropha and was working on an information pamphlet on the subject.

Those interviewed for this research varied widely in their opinions about government's role, approach and achievements. Some held the view that government was acting with appropriate leadership; for example, one was impressed by a presentation in which a government representative articulated the government's accomplishments, plans and challenges to date with respect to Jatropha and biodiesel (PS3). Others felt that the government was neither leading nor following, for example citing a high number of workshops and meetings as evidence that the process was marked by much talk and little action (RS1, NGO2). Still others were critical, for example stating that government was "not owning the process," but being led by others (PS1). These opinions show a range of views about whether the government was wielding or sharing power; whether it was 
taking decisive action on the issue of Jatropha, stalling, or allowing itself to be pushed by interested parties.

At the time of research, the Kenyan government had endorsed Jatropha and was taking steps to regulate it. But because the government, particularly the Ministry of Energy, had the official authority and mandate to perform these roles, its actions can also be viewed as a form of ownership. In this sense, the government 'owns' the process of policy formation, which has major implications for all other actors. Crucially, the government appeared willing to share its ownership of this process with other interested parties through the 'multi-stakeholder' National Biofuels Committee and the KBDA, creating space for direct input and lobbying. Issues of inclusion and exclusion in this process will be discussed in Chapter 6 .

\section{Private sector}

A few private companies had initiated Jatropha projects in Kenya in 2009. For example, Better Globe Forestry had established a pilot plantation in Kiambere with the aim of expanding this into a larger operation involving a nucleus plantation surrounded by outgrowers (farmers who grow a crop under contract with a central buyer). In Shimba Hills, Coast Province, the company Energy Africa had established a network of outgrowers, although as mentioned earlier in this chapter, at the time of research the number of participating farmers had dwindled from a high point of 200 to about 75 (GTZ 2009). Using a different business model, Pipal Limited was in the early stages of coordinating a public-private partnership between the German Ministry of Cooperation and Development (administered by the development bank DEG), and nine commercial 
farmers in East Africa. In the hope that it would eventually strengthen their business, each of these farmers made a financial contribution and invested their own labour to participate in a set of field trials designed to address significant unknowns about Jatropha before attempting to produce it on a commercial scale.

As mentioned earlier, media stories about investors planning to establish largescale commercial plantations at that time were regarded as premature. One private sector actor (PS2) described the pattern of private investment to date:

The private investors as a group have really been reluctant to invest largescale as of now. Small pockets here and there. For Jatropha to be viable for a private enterprise it probably needs a 10,000 hectare-plus scheme, and we haven't seen any of that. We just hear stories of potential ones but nothing has really come through.

Another stated that without a clear government policy, investors were reluctant to pursue Jatropha because of uncertainty surrounding how its products would be subsidized or taxed: "Private investors always want to see what government is intending to do. If government gives mixed signals, these people won't invest, they hold onto their investment, they wait" (PS1). This is consistent with Tomomatsu and Swallow's (2007) assertion that government subsidies or tax incentives could have a major impact on the price competitiveness of biodiesel compared with fossil fuel diesel. Meanwhile, several mentioned that securing access to land remained a key obstacle to large-scale Jatropha farming (e.g. PS3).

A government representative stated that private actors had played a minimal role in the policy process at its early stages (GO1). While large-scale investment may yet come, for now most actors agreed that the private sector was playing a limited role in promoting Jatropha in Kenya. In January 2010, one of these businesses reported that it 
was pulling out of major Jatropha efforts because of high costs and an unfavourable market.

Usually one would expect private sector actors to accumulate a surplus from their business activities. However, in this case (aside from private nursery operators who sell seedlings) the companies that have invested the resources to create Jatropha growing schemes have not profited from doing so. The fact that Jatropha seeds are not yet being processed into end products on any significant scale goes against market logic and will be discussed in the section on Jatropha's incomplete value chain.

\section{Researchers}

The reports reviewed earlier in this chapter show that significant research attention has been devoted to assessing Jatropha's potential in Kenya. This level of interest, and the associated allocation of resources, can be linked to the priorities of the institutions that provide research funds. For government research institutions such as the Kenya Forest Research Institute and the Kenya Agricultural Research Institute, this emphasis aligns with the draft biodiesel strategy's focus on Jatropha, and is thus a strategic decision. Initiatives run by other research centres, NGOs or consultants have been enabled by the availability of funds from international or private sources (e.g. World Bank, GTZ, CGIAR, DED, commercial farmers; in my own case, SSHRC and IDRC). Agronomy, economic cost-benefit analysis, and strategies for developing a value chain for Jatropha have formed the core of most studies (Ng'ethe 2007; Tomomatsu and Swallow 2007; Government of Kenya and GTZ 2008; Muok and Källbäck 2008; GTZ 2009). Much less 
attention has been given to the social implications of Jatropha cultivation for farmers and rural households.

Research efforts were beginning to be coordinated through a Biodiesel Research Committee, a subcommittee of the National Biodiesel Committee tasked with keeping track of research that is taking place, avoiding duplication and channelling funds toward appropriate institutions. Some actors expressed frustration over the slow pace of research (e.g. NGO2). For their part, researchers expressed that it was inevitable that field trials would be slow to produce results given that Jatropha plants take several years to mature (e.g. RS3).

Returning to Bernstein's framework, researchers 'do' knowledge production, resulting in their 'ownership' of knowledge that is highly useful to other actors (including, for instance, this thesis). Sometimes this knowledge is freely shared, for example through publications that are made available online, or presentations at events such as the National Biodiesel Workshop in June 2009. Other times, actors allege that knowledge has been strategically withheld, as will be discussed further in Chapter 7 . Even when results have been released, proponents' responses to unfavourable research outcomes have not always been well received. This is discussed further in the section "Responses to dissent" as well as the section on the political economy of knowledge in Chapter 7. 


\section{Media}

Chapter 4 discussed patterns in media portrayals of Jatropha in several countries. As the headlines and analysis in Chapter 4 show, Kenyan newspapers used both strongly positive and strongly negative language about Jatropha, with no clear pattern in time: seemingly contradictory messages on the subject seemed to coexist in the Kenyan print media.

In several instances, key informants referred to the role that the media played in influencing public opinion about Jatropha (PS1, PS2, RS1, RS4, GO3, NGO6, DN1). Two stated directly that the media had been too enthusiastic, contributing to raised hopes and false impressions (NGO6, DN1). One accused the media of providing "misinformation" and called for a "more sober attitude" on the subject (PS2). Another described how the media had perpetuated rumours of large land deals for Jatropha that had not materialized, and expressed that if more negative experiences with Jatropha were reported in the media, this would have a dampening effect on Jatropha activities (RS1).

At times, the Kenyan media has served as a platform for actors who were heavily involved with Jatropha to publicly share their views. Some of the individuals interviewed for this research wrote opinion pieces published under their own name, or were quoted extensively in stories written by reporters. Taking this approach further, one NGO representative described plans to start a TV and radio station in order to spread "proper information" throughout Africa, and presumably to have greater control over the messages that were being spread.

While I was not able to track the radio coverage that Jatropha received in Kenya, seven different farmers in Mpeketoni mentioned that hearing about Jatropha on the radio 
(perhaps on Tanzanian stations, given their location) had helped them to form their impressions of the crop. In a similar vein as the comments about newspapers, one key informant critiqued the way Jatropha had been portrayed on the radio: "the media is very strong in disseminating information, but they have also been disseminating information that is not very correct through FM stations. ... So the media has got a strong role to play in terms of dissemination of information, but it has to be correct information" (RS4).

That the media 'own' widely accessed distribution channels for information about Jatropha, both in the sense of financial ownership and control, speaks to their important role in influencing opinions and decisions about Jatropha activities. The political economy of knowledge surrounding Jatropha in Kenya, and its implications, will be discussed further in Chapter 7.

\section{Farmers}

Farmers represent a special category of actors in relation to the research questions. Their experiences and perspectives will be explored in detail through the case studies in the following two chapters. For now, it is enough to say that farmers' exposure to Jatropha has been mediated by the other groups just described. NGOs have in many, though not all cases, provided the most direct link between farmers and Jatropha. The combined influence of NGOs, donors, government officials (including local agriculture officers), researchers, and the media produces enabling and/or constraining conditions under which farmers form an impression of Jatropha and may begin to experiment with it. Ultimately, however, farmers make their own decisions about whether to plant Jatropha, and once planted, whether to continue to grow it or abandon it in favour of another crop. 


\section{Actors revisited}

The preceding sections have introduced the main groups of actors involved with Jatropha in Kenya and examined their activities in light of Bernstein's questions. NGOs, donors, government officials, businesses, and researchers all 'do' things that affect the ways in which Jatropha has been introduced and regulated. What they 'own' and what they 'get' vary widely, both within and between groups. While donors provide the financial resources that have enabled NGO-led projects to occur, government officials 'own' (in the sense of controlling) the policy development process. Researchers 'own' the process of knowledge production, while the media 'owns' some of the main channels through which information is publicly disseminated. The prevailing view among those interviewed for this study is that a small number of NGOs have so far been able to 'get' the most out of the production of Jatropha by way of donor funds needed to sustain themselves, while there has been no appreciable financial surplus to distribute. Table 5.1 summarizes the foregoing discussion of activities and forms of influence for each of the main groups of actors. 
Table 5.1: Who controls what with respect to Jatropha in Kenya?

\begin{tabular}{|l|l|l|}
\hline Who? & Controls what? & How? \\
\hline NGOs & $\begin{array}{l}\text { - Strongly influence farmer } \\
\text { expectations of Jatropha } \\
\text { - Influence policy development }\end{array}$ & $\begin{array}{l}\text { - Directly mediate relationship } \\
\text { between farmers and Jatropha; } \\
\text { control farmers' access to knowledge, } \\
\text { resources } \\
\text { - Take part in multi-stakeholder fora }\end{array}$ \\
\hline Donors & $\begin{array}{l}\text { - Enable NGO activities and } \\
\text { research }\end{array}$ & - Provide funding, capacity building \\
\hline Government & $\begin{array}{l}\text { - Controls policy process: can } \\
\text { set economic and legal } \\
\text { boundaries on Jatropha } \\
\text { - Could enable or inhibit spread } \\
\text { of Jatropha through agricultural } \\
\text { extension officers }\end{array}$ & $\begin{array}{l}\text { - Policy could include subsidies, tax } \\
\text { incentives, quotas, limits on access to } \\
\text { land; for now, sharing control over } \\
\text { policy with other actors } \\
\text { - Min. of Agriculture not actively } \\
\text { promoting or discouraging Jatropha }\end{array}$ \\
\hline $\begin{array}{l}\text { Private } \\
\text { sector }\end{array}$ & $\begin{array}{l}\text { - Potential to invest in Jatropha } \\
\text { projects, especially large-scale }\end{array}$ & $\begin{array}{l}\text { - Limited deployment of this potential } \\
\text { so far }\end{array}$ \\
\hline Researchers & $\begin{array}{l}\text { - Influence what is considered } \\
\text { possible or feasible with respect } \\
\text { to Jatropha }\end{array}$ & $\begin{array}{l}\text { - Produce knowledge } \\
\text { - Priorities influenced by availability } \\
\text { of funds or mandate of institution }\end{array}$ \\
\hline Media & $\begin{array}{l}\text { - Influences public perceptions } \\
\text { of Jatropha }\end{array}$ & $\begin{array}{l}\text { - Broadcasts information / claims } \\
\text { (may use sensational language) }\end{array}$ \\
\hline Farmers & $\begin{array}{l}\text { - Ultimately make own } \\
\text { decisions about whether to plant }\end{array}$ & $\begin{array}{l}\text { - Conditioned by these influences as } \\
\text { well as their own experiences }\end{array}$ \\
\hline
\end{tabular}

\section{JATROPHA'S VALUE CHAIN}

Before delving into the motivations and influences that have affected the spread of Jatropha in Kenya in Chapter 6, it is worth describing an unusual feature of Jatropha activities in the country. In spite of the considerable attention and resources that are focused on promoting Jatropha to farmers, designing studies to improve its agronomic potential, and building a biodiesel policy around it, there is a crucial step missing in the development of a Jatropha value chain: that of processing the seeds into usable energy.

Figure 5.1 presents a general value chain for Jatropha, showing several different pathways of activities and products that are possible. The upper part of the diagram shows activities (represented by yellow boxes) related to the production of Jatropha 
seeds. The arrows show outputs from one activity providing inputs to another. Here nursery cultivation provides seeds and seedlings to Jatropha farming. Seeds that are harvested from farms and gathered from fences are fed into the "collection" process, where intermediate buyers or processors purchase seeds to be processed. Activities in the processing stage of the value chain, represented by the middle layer of the diagram, include oil extraction, biodiesel and soap production, and seed cake processing. These activities in turn generate a suite of products, represented by orange boxes. Each of these follows its own path through the marketing stage of the value chain, where distribution, retail and consumption activities take place. 
Figure 5.1: General value chain for Jatropha products (adapted from Messemaker 2008)

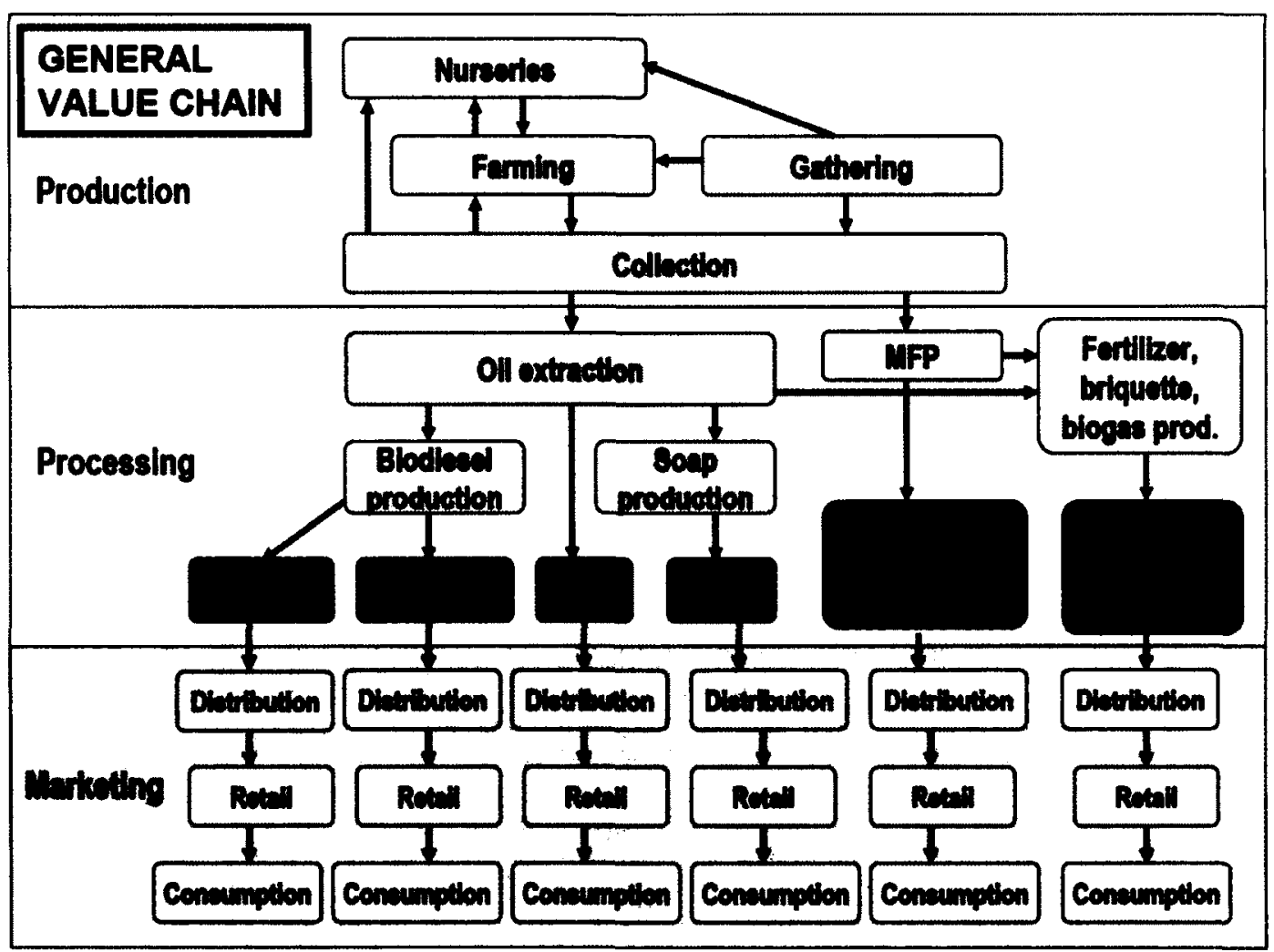

This generalized model shows a diverse set of products and outcomes that can theoretically be derived from Jatropha. In practice, most examples of Jatropha production in other countries (e.g. India, Mali, Tanzania) reflect efforts to develop all stages in the value chain for one or more particular pathways rather than to achieve all of the possible ends at once. For example, Figure 5.2 shows how Jatropha activities in northern Tanzania were focused on producing SVO, soap, and energy services such as electricity and grain hulling, based on Messemaker's (2008) account. Here the faded boxes represent inactive areas, while the brighter boxes represent active ones. Although there are discontinuities in the later stages of the value chain (represented by dashed arrows), Messemaker (2008) describes how Jatropha seeds in northern Tanzania were being converted into SVO and soap, and used to some extent in multifunctional platforms. 
Figure 5.2: Jatropha value chain, Tanzania (adapted from Messemaker 2008)

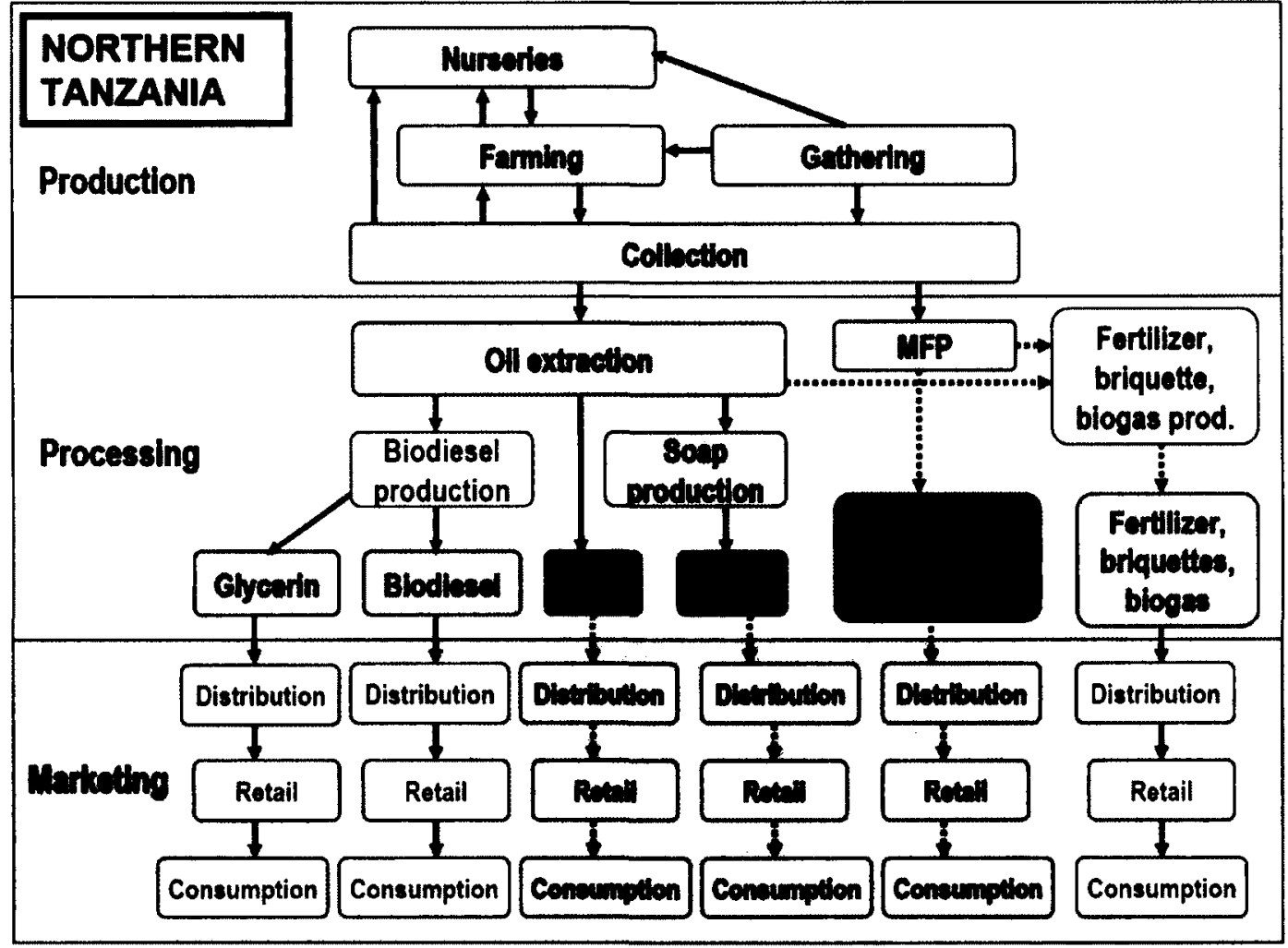

Figure 5.3: Jatropha value chain, Kenya

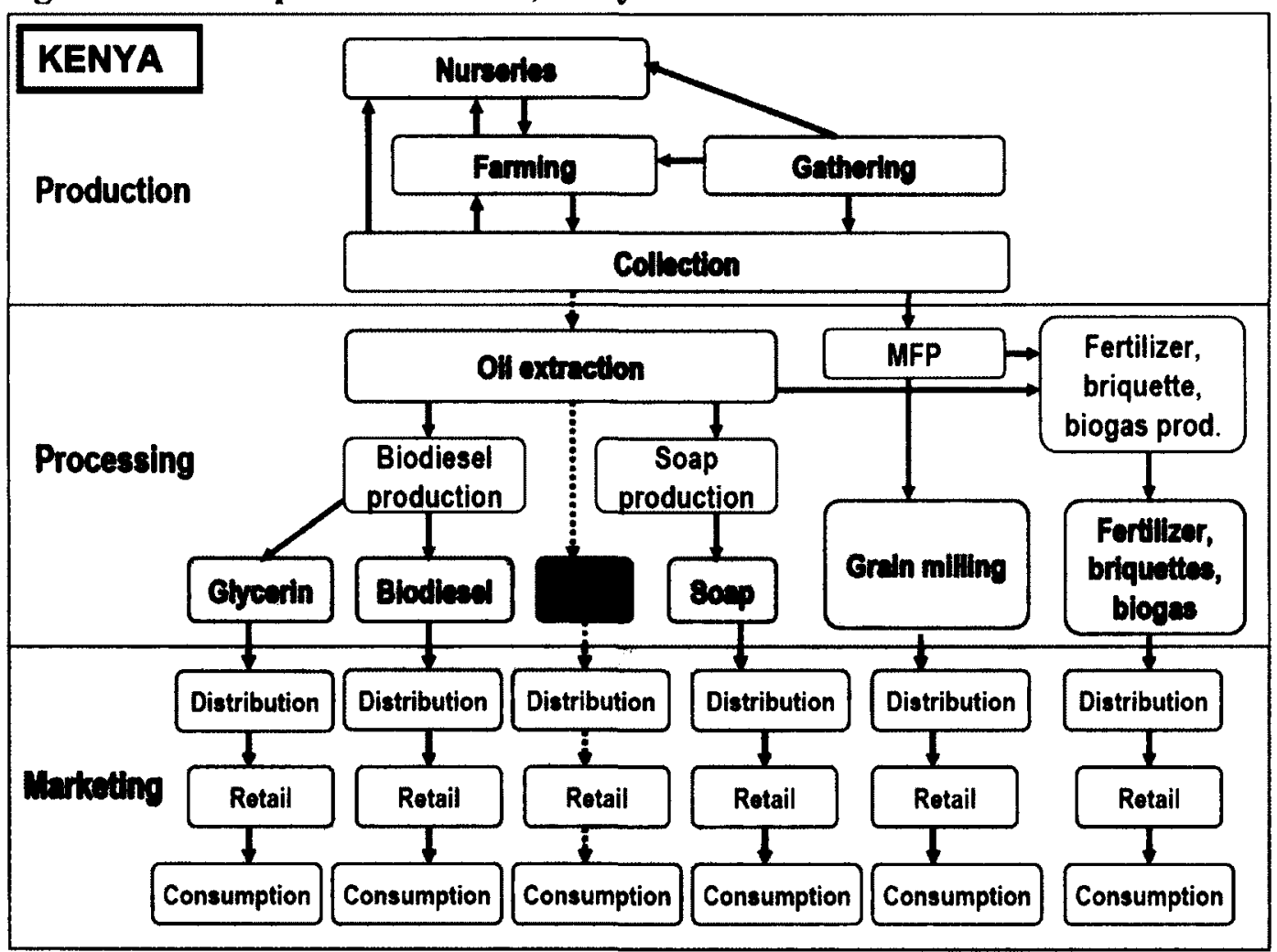


The picture looks quite different in Kenya (Figure 5.3), where nearly all on-theground Jatropha activities at the time of this research focused on distributing seeds and seedlings to farmers and providing training on how to manage the crop. Very little processing and virtually no marketing and use of Jatropha products was taking place (Tomomatsu and Swallow 2007; GTZ, 2009). While some interviewees in this project expressed that there was an insufficient supply of seeds to support commercial processing, others (including many farmers) described having nowhere to sell harvested seeds, i.e. no opportunities for processing. The few projects that were extracting straight vegetable oil from Jatropha at the time of research were either doing so on an experimental basis or were at such a nascent stage that it was too early to tell whether lasting markets or local consumption patterns will become established. As one participant lamented, "If you get oil, what will you do with it? There's no market" (NGO9). Another affirmed this view of the market by saying, "NGOs should invest in machines where they're supplying seedlings. They should focus on particular areas where they've been working and get good [oil] volumes instead of running around distributing more and more" (GO2).

Without processors, the market for Jatropha resembled a cycle where seeds were being sold as planting stock rather than as feedstock for extracting Jatropha oil. This created a situation where the propagation of Jatropha appeared to be treated as an end in itself, rather than as a means to the end of energy production. This phenomenon will be discussed further in Chapters 6 and 7. This pattern is highly unusual when compared to cash crops such as coffee, tea and sugar, all of which were introduced in Kenya to feed into existing markets. 
With few exceptions, Jatropha's proponents have so far not found it possible or necessary to complete the production cycle. It is interesting to speculate on whether such a scenario would be likely to occur if Jatropha activities were dominated by the private sector, or if a market-based approach to development occupied a position of clear priority. Under these circumstances, if no products were produced to generate revenues, it seems unlikely that investment would continue for long. In this sense, NGO activities may have been able to persist in the absence of markets and financial incentives since their funding did not need to be repaid to investors, nor was it generally tied to achieving outcomes measured in economic terms. Messemaker (2008) identifies a similar phenomenon surrounding Jatropha in Tanzania, reporting that NGOs distorted markets in such a way that businesses were unable to compete.

\section{Experiences from Tanzania}

Why do the Kenyan and Tanzanian value chains for Jatropha look so different? What features do these two countries share in terms of a nascent Jatropha industry? Because of their close proximity and the high level of connection between these neighbours, including direct visits as well as overlapping media exposure, it is useful to examine Tanzania's experiences with Jatropha in more detail. Identifying similarities, differences and points of contact between these two countries with respect to Jatropha will also help to generate insights into how Kenya's Jatropha activities have interacted with broader forces or events.

Jatropha activities in Tanzania appear to have followed two periods of growth. The first, up to the year 2005, consisted of a small number of projects initiated mainly by 
one NGO (Kakute) and one private company (Diligent), each involving smallholder farmers with the aim of producing Jatropha oil either for local use or for export (Caniëls and Romjin 2010). In a survey of Jatropha activities in northern Tanzania during this period, Messemaker (2008) portrayed a situation where the propagation of Jatropha outpaced the development of markets for end products, describing a "tense" market for seeds, a "substantial" market for straight vegetable oil (SVO), a "limited" market for soap, and "no" price-competitive market for biodiesel derived from Jatropha. One enterprise used some Jatropha oil to power vehicles for an eco-safari company, while Jatropha soap production also apparently enjoyed some success. However, Messemaker (2008) reported problems with the marketing and consumption stages for all other Jatropha products. For example, household lamps were not being used because they did not function properly, while multifunctional platforms (MFPs) intended to provide household electricity or milling were running on diesel instead of Jatropha oil - or were not running at all (Messemaker 2008). Biogas and briquette production from Jatropha seed cake were occurring only on an experimental level. Two commercial farmers who had previously established large, monoculture plantations of Jatropha had abandoned these in favour of other crops because of poor economic returns (Messemaker 2008). Cultural factors also came into play: Maasai women were generally not able to plant Jatropha because they did not own land, while some farmers may have been suspicious of growing Jatropha commercially because of its traditional use as a grave marker (van Eijck and Romjin 2008).

Nonetheless, between 2005 and 2008 "a virtual deluge of foreign investment" ushered in a second phase of expansion in Tanzania's Jatropha sector, encouraged by 
heightened international concerns over climate change and the establishment of fuel blending mandates in several countries in Europe and North America (Caniëls and Romjin 2010: 11). Jatropha initiatives took several forms, ranging from multifunctional platforms meant to provide local grain milling, to large plantations of over 50,000 ha that were intended to produce raw Jatropha seeds for processing elsewhere. These were concentrated in Tanzania's coastal province to facilitate export. In one such case an investor reportedly planned to lease 80,000 ha of land, clear the original vegetation, plant a monoculture of Jatropha, and harvest it mechanically (Caniëls and Romjin 2010), illustrating the scale of investment and production that was envisioned. Medium-sized projects included outgrower schemes where farmers were encouraged to grow Jatropha on their own land for centralized oil processing, but the byproducts such as seed cake were intended for local use. One shipment of Jatropha oil had been exported (by air) to be used in a test flight in New Zealand (Caniëls and Romjin 2010).

By late 2008, Caniëls and Romjin (2010) concluded that none of these business models had become dominant, though high food prices had heightened many observers' concerns over competition between food and Jatropha production, while research on the carbon impacts of land use conversion cast doubt on Jatropha's potential to reduce GHG emissions when produced on previously uncultivated land. Both of these tendencies put pressure on the plantation production model. NGO reports were especially critical of large-scale investments in Jatropha plantations, pointing to low land prices, ecological impacts, lack of public consultation, and scanty compensation (if any) paid to communities as evidence that local residents were not benefiting from these projects (Oxfam International 2008; WWF 2009). At least two foreign investors withdrew from 
large plantation projects in Tanzania in 2009, both accused of establishing or planning to replace biodiverse forests with Jatropha monocultures (Mutch 2010).

Economic studies suggest that growing Jatropha in Tanzania is unlikely to be profitable under most scenarios (Loos, 2009; Wahl, Jamnadass, Baur, Munster, \& liyama, 2009). Seed yields have turned out to be lower than predicted, particularly under harsh growing conditions, leading some to describe actors' early positive expectations for Jatropha as being "driven by subjective beliefs and wishful thinking" rather than evidence (van Eijck \& Romjin, 2008, p. 321). Even using yield estimates that were higher than those observed, Loos (2009) concludes that a Jatropha plantation could only become profitable from the fifth year onwards; similarly, Wahl et al. (2009) find that a five-year investment is likely to produce negative financial results, and that unless yields increase substantially, only Jatropha grown as hedges can be expected to provide small but steady income for growers.

Throughout this period, no national policy existed in Tanzania governing fuel blending, exports or taxation of biofuels, creating a level of uncertainty which some have described as the biggest obstacle to the development of a Jatropha industry in the country (van Eijck and Romjin 2008). While the Tanzanian government created a National Biodiesel Taskforce and passed its draft guidelines for sustainable biofuel production in 2008, this document remained unapproved by the Cabinet in early 2010. The government has been criticized for failing to enforce existing laws over access to land (Caniëls and Romjin 2010), while some have questioned whether Tanzania's land laws are adequate to handle the challenges posed by large-scale investment interest in biofuels (Sulle and Nelson 2009). In October 2009, the Government of Tanzania suspended all new biofuel 
investments and land deals "until it had reviewed the selection criteria for each investment and drawn up clear policies and procedures" (Caniëls and Romjin 2010: 20).

The story of Jatropha in Tanzania provides several salient insights. The mix of strategies and dramatic swings in foreign investment show how changing priorities among external players have played a key role in determining the trajectory of Jatropha in the country. Meanwhile, a lack of government regulation seems to have enhanced a 'freefor-all' setting where multiple approaches could be pursued simultaneously. In terms of approaches to development, large-scale commercial production for export has been pursued at the same time as smaller-scale, livelihood-oriented approaches focused on supporting small enterprise and household lighting.

As a neighbouring country to Kenya, Tanzania's experiences are particularly important to this research. Jatropha actors in Kenya who were interviewed for this project often referred to experiences they had heard about or even witnessed in Tanzania. These individuals included farmers who had first learned about Jatropha from Tanzanian radio programs, a private sector actor who had worked in Tanzania collecting germ plasm, and a youth in Nguruman who had travelled to Tanzania on an organized tour of Jatropha projects. Direct and indirect exposure to Jatropha activities and debates in Tanzania thus helped to influence some actors' perspectives on Jatropha in Kenya; at the same time, existing scholarly analysis of the Tanzanian case can provide insights into interpreting patterns of activity in Kenya. 


\section{CHAPTER SYNTHESIS}

This chapter has described the spread of Jatropha in Kenya, introduced the main groups of actors involved, and begun to scrutinize their activities and relative influence. The resulting analysis provides some early insights into the research questions posed in Chapter 2.

A variety of NGO and government actors expressed the view that Jatropha was the most important biodiesel crop in the country, a message that was also presented in government documents, a national research workshop, and numerous media stories at the time. In response to the question, Is there a dominant discourse attached to Jatropha in Kenya?, evidence presented in this chapter suggests a general consensus that Jatropha occupied a prominent, if not dominant, position in discussions about biofuels within the country in 2009. Although different actors clearly had different interpretations of how Jatropha activities in the country should proceed and which outcomes should be prioritized - a topic which will be more fully explored in Chapter 6 - the vast majority of interviewees agreed that Jatropha was receiving a special amount of attention from government, donor, NGO, research, and media actors. In other words, while they may have disagreed about whether Jatropha deserved this attention, and whether and how it should be pursued in support of a wide variety of goals, actors with many different affiliations converged on the belief that Jatropha was too important to ignore. The centrality of Jatropha to discussions of biofuels in Kenya thus represented a common thread in the discourses surrounding it.

The preceding discussion also sheds light on the question, What power relations characterize the funding, introduction and governance of Jatropha in Kenya? Research 
participants identified a few NGOs (and by extension, their donors) as the most influential players driving a pro-Jatropha agenda forward in the country. In terms of the power that can be ascribed to knowledge production and dissemination, researchers with a variety of affiliations (e.g. government, private sector, and international institutions) had the most control over knowledge production. The media and NGOs played important roles in controlling the spread of information - the media through broad distribution to the public, often using highly evocative language, and NGOs by directly mediating the relationship between farmers and Jatropha. Meanwhile, the Government of Kenya held considerable power to direct the course of future Jatropha activities, primarily in the form of authority over the policy development process.

At the time of research, the government showed willingness to share its control over policy formation with members of other actor groups, through formal committees (e.g. the National Biodiesel Committee and its Research Subcommittee) as well as a multi-stakeholder association (the KBDA). The question of what factors may have enabled or served as barriers to participation in these groups will be revisited later on. For now, in the context of the question, To what extent have powerful actors enabled participatory decision-making or benefit sharing?, the government's openness to including multiple stakeholders in the policy process provides one example of such power sharing.

This chapter pointed out a curious feature of Kenya's Jatropha activities: that in spite of the attention given to propagating the crop, almost no one was processing Jatropha seeds into usable products. At the time of research, Jatropha had been taken up by hundreds (and possibly even thousands) of small farmers in several regions of the 
country, although its seeds were being processed into oil on a pilot scale only. This truncated value chain is counter-intuitive; some actors appeared to be treating Jatropha as an end in itself rather than as a means to other ends such as the production of renewable energy. However, some parallel experiences can be observed in neighbouring Tanzania. This counter-intuitive arrangement sets up the question, Who has benefited from Jatropha, in what ways, and who has not? In order to understand the origins and implications of this peculiar state of affairs, Chapter 6 will examine the stated agendas, objectives and influences that have motivated the various players introduced here. 


\section{CHAPTER 6: MOTIVATIONS, INFLUENCES, AND DISCOURSES OF DEVELOPMENT}

Chapter 5 introduced the key players involved with Jatropha in Kenya. It described their activities and discussed their areas of relative influence in the context of 'ownership' over knowledge, resources and decision-making authority. Chapter 5 also highlighted some counterintuitive outcomes of Jatropha activities at the time of research, significantly that the value chain for Jatropha in Kenya remained incomplete, with very little processing of Jatropha oil and no marketing of end products taking place. This chapter uses these observations as a starting point for a deeper exploration of the political economy of Jatropha in Kenya. Here the motivations, influences and perceptions of the various actors are treated as centrally important in order to understand what has driven and guided the promotion of Jatropha, particularly as it has unfolded in some unpredictable ways. This chapter explores the possibility that multiple agendas associated with Jatropha represent different discourses of development, and considers the implications of such a plurality of perspectives.

The first part of the chapter draws on interviews with key actors to explore the motivations and influences that shaped their positions and decisions on Jatropha, and groups these into broad discourses of development. The second part examines apparently contradictory phenomena: on one hand, evidence of competition and manoeuvring between the actors who held divergent discourses; and on the other, evidence of continued coexistence of the discourses coupled in some situations with a belief that these different approaches can complement and enhance one another. Finally, a case study of the Jatropha Integrated Energy Project (JIEP) in Mpeketoni, Coast Province 
illustrates what was happening in a particular place where donors, coordinators and farmers approached the same project with different initial objectives.

\section{MOTIVATIONS}

I begin by considering actors' statements about their own priorities and goals related to Jatropha. A useful starting point here is to examine their comments on what benefits they hoped Jatropha would bring - and to whom. When asked who should benefit from Jatropha, interviewees collectively gave three main answers: farmers, "all players in the value chain," and the country. The scale of their ambitions for Jatropha ranged widely, from the household to the international level. When asked what it was about Jatropha that made them decide to become involved with it themselves, actors identified a range of reasons, grouped here into the categories of environmental, humanitarian, economic, personal and institutional. While I have used these emergent themes for organizational purposes, it is possible to find considerable overlap and convergence between them. Indeed, most actors expressed multiple priorities and acknowledged links between the areas described here. The following sections explore these stated motivations in some detail and consider how the agendas that they represent may complement and/or contradict one another.

\section{Environmental motivations}

Non-farmer actors, including NGO, government, private sector, and research representatives, linked Jatropha to a two-pronged environmental agenda. First, climate change mitigation featured strongly as a motivation for supporting Jatropha, with several 
actors using terms such as 'clean,' 'renewable' and 'sustainable' energy to describe it. One private sector representative spoke in urgent terms about the importance of biofuels as an environmentally preferable energy source: "The issue of environment and energy, it's a serious issue. Either way we have to turn to biofuels to save our environment or our planet. There's no option; we need to go to a fuel that will not mess up the environment" (PS1). Others explicitly mentioned climate change mitigation and emissions reduction as reasons to substitute Jatropha-based energy for fossil fuels, one even referring to fuel from Jatropha as "carbon free" (PS4). While many of these climate-related comments were based on the belief that fuel from Jatropha releases less carbon than fossil fuels when burned, some also referred to the role that the Jatropha plant could play by storing carbon as it grows. One NGO representative drew on this reasoning to contrast biofuel from Jatropha with biomass energy, saying that biomass from fuelwood or charcoal "is a very extractive and destructive source of energy. But clean energy, which has got the attention of people globally, is, like biodiesel, where you only get the seed, you produce the biodiesel, and the plant continues to grow and capture carbon" (NGO2). Others echoed this hope that Jatropha would store carbon throughout its life.

Much enthusiasm therefore focused on Jatropha as a means of advancing a climate change mitigation agenda, based on perceptions that Jatropha-as-energy would emit less carbon than fossil fuels, while Jatropha-as-plant would act as a carbon sink. Whether these views were put forward out of sincere dedication to a climate change mitigation agenda, instrumentally in order to access climate-related funds, or a combination of the two, is impossible to discern from this analysis. 
Looking beyond climate issues, actors linked Jatropha to a second set of environmental motivations related to conservation. Interviewees stated that it could increase forest cover, prevent soil erosion and rehabilitate 'marginal' lands. One NGO representative stated, "I am coming in as an environmentalist - that's number one. Even before you get to the oil, as long as there is a plant surviving and increasing the forest cover, I'm already at home" (NGO7). A government representative further articulated this point of view by saying, "We thought that Jatropha being a crop that does well in marginal areas, would help in rehabilitating some of those areas. It would play a double purpose of rehabilitating those areas as well as producing energy" (GO1). In this way, these interviewees saw environmental value in Jatropha due to its reputation as a hardy and drought tolerant plant.

\section{Economic motivations}

Actors gave economic reasons for promoting Jatropha that included direct economic gains from producing and selling energy as well as spin-off effects related to making cheaper or more reliable energy available to other sectors of the economy. These are elaborated below. In effect, actors talked about producing Jatropha as both a productive activity in its own right and an enabler of economic advancement in other areas. These economic discourses were expressed in relation to several scales: the country, the community and the household or individual.

At a national level, actors expected that producing energy domestically could displace imports of both fossil fuel diesel and kerosene, reducing the need for foreign exchange to buy imported fuel and promoting the national objective of achieving a more 
favourable trade balance (GO1, GO2, RS2). Some mentioned the possibility of exporting Jatropha oil to take advantage of trade opportunities with countries that had adopted more favourable policies toward biodiesel (NGO2, NGO4). However, most actors preferred to focus on developing a domestic market for Jatropha products. Actors anticipated that Jatropha production could create economic benefits for the domestic energy sector, although one also pointed out that the government stood to lose revenue that it currently collects from taxes on imported fuels (NGO7). Some also considered the political dimension of lowering Kenya's reliance on other countries for its energy supply to be significant.

If a market for Jatropha-based biodiesel were to become established in Kenya, actors expected it to benefit the country's agriculture, transport and industrial sectors. Interviewees believed that Jatropha would have a more stable price than conventional oil, a very attractive feature given the turbulence of world oil prices in 2008 (and again in 2011). One private sector actor commented: "Local investors who are in manufacturing... these people are worried about the fossil fuel. Last year when the fuel price went up, they made losses. So they want to be energy sustainable" (PS1). Another identified problems with the reliability of energy supplies as an incentive for experimenting with Jatropha, saying: "The very practical thing is that often there is no diesel" (PS4). This actor saw instability of the fuel supply as an obstacle to carrying out horticultural business activities, an obstacle which could be overcome by producing energy within the country or even right on the farm - instead of relying on existing systems of energy distribution.

Actors talked about producing straight vegetable oil (SVO) as a way to support farmers individually as well as rural economic development objectives more broadly. 
Some thought that farmers could generate direct income by selling seeds, either through contractual arrangements with processors or informal agreements with neighbours who wished to plant Jatropha themselves. However, most thought that farmers and rural communities would gain more significant benefits by using Jatropha-based SVO for household lighting and to support other economic activities.

Several interviewees spoke of the money that rural households could save by growing their own fuel for lighting instead of buying kerosene. For example, a donor described how this served as a motivation: "For us, it was replacing, being able to substitute a product that you buy for one that you pick from your own farm.... It was directly related to the poverty aspect, not having to spend money to meet your energy needs" (DN1). ${ }^{26}$ Others said they were driven by a desire to see farmers increase their food production or incomes by using SVO to run small machines that could boost their agricultural output (e.g. irrigation pumps) or add value to their other crops (e.g. grain mills, cold storage facilities). One described these economic advantages: "If [small-scale farmer groups] can be assisted technically to use Jatropha fuel to increase their food production, to process their food crops, to earn more money and change their way of living for the better, then that will be a model village... it can be an example" (PS1). Actors also spoke of the possibility of using SVO to generate electricity and in turn run other machines, thus enabling rural people to undertake income-generating activities that were not previously possible in places without access to electricity. In these ways, interviewees associated Jatropha SVO with the perceived economic benefits of saving

\footnotetext{
${ }^{26}$ See Boerstler (2010) for a detailed analysis of Jatropha's potential to replace kerosene for household use in a case study conducted in Coast Province, Kenya.
} 
household expenses, increasing agricultural income and supporting other productive activities.

Actors thus spoke of Jatropha contributing to an economic agenda via improved energy security in several ways: by providing better price stability than conventional oil, improving the reliability of the energy supply, lessening the need for foreign exchange to import fossil fuels, and making energy accessible to rural people. These goals are consistent with an interpretation of energy security that includes both improved availability and access.

\section{Humanitarian or social motivations}

Numerous actors said they became involved with Jatropha for reasons of social wellbeing, saying it could improve lives, benefit farmers or reduce poverty. As one private sector actor put it: "The opportunity of combining poverty reduction with producing renewable fuel, to me, it makes so much sense. I thought maybe this was the solution. We can work in rural areas, provide employment and improve the environment at the same time" (PS2). While the direct and indirect opportunities for farmers to increase their income from Jatropha activities have been discussed above in relation to rural economic development, livelihood benefits and food security emerged as two other themes that can be associated with a broadly humanitarian agenda.

\section{Livelihood benefits}

Interviewees identified education and health benefits as livelihood improvements that they believed would accompany the use of Jatropha SVO for household lighting or 
cooking. Some described how in rural households that could not afford to buy kerosene on a regular basis, children had little opportunity to study in the evenings. In these cases, their educational opportunities would improve if households could grow Jatropha to produce their own lamp oil (see Mpeketoni case study later in this chapter for quotations). Some pointed to health benefits that they expected to come from using Jatropha oil as an alternative source of energy in the home, claiming that Jatropha oil produces less smoke than kerosene, firewood or charcoal, and therefore would cause fewer lung problems associated with indoor air pollution (GO1, DN1).

\section{Food security}

Food security refers to physical and economic access to food as well as its availability (FAO 2008). In describing their motivations for working with Jatropha, numerous actors identified priorities that were consistent with the concepts of promoting availability and access to food, even if they did not use these exact terms. Several stated that Jatropha could provide energy without directly or indirectly threatening the availability of food, pointing out that because Jatropha is inedible it would not divert a food crop to produce fuel. Meanwhile, its ability to survive in dry conditions meant that it could be grown in so-called 'marginal' lands where no other cultivation was taking place. A government representative (GO2) summarized both of these arguments:

We didn't want a feedstock that would be competing with human beings for food, so we didn't want to go into staple foods like maize, to use them for biodiesel production. We also didn't want a feedstock that would compete with resources for food crop production, for example land... the high potential areas for food production, the areas that have enough rainfall, have fertile soils, we didn't want to touch on that because then you compete. Because if you plant Jatropha and then it turns out to be more economical in terms of what the farmer would get by selling or 
producing, they might opt to produce Jatropha and leave maize. That would be very risky for this country.

The speaker acknowledges that if it were profitable, biofuel production could potentially displace the production of food crops on highly productive land, and associates this scenario with strongly negative consequences. Thus, in relation to both food production and environmental conservation, Jatropha's reputation for being drought tolerant and able to grow in harsh environments made it appear attractive. ${ }^{27}$

Some went further, stating that Jatropha could increase the availability of food by enhancing agricultural productivity in two ways. First, when grown as a fence around existing fields, Jatropha could protect other crops from being grazed or trampled by animals (NGO7). Second, when grown in very hot, dry environments, Jatropha's root system and shade could create a micro-climate that could enable food crops such as sesame or beans to grow between the rows where this had previously been impossible (NGO4).

Finally, some used the argument that Jatropha could build households' capacity to access food by reducing the expense of buying kerosene or increasing their incomes from other agricultural activities, thus enabling them to purchase additional food. One way of achieving this outcome was through value addition, i.e. processing or cold storage of other crops made possible by the access to energy that Jatropha would provide (see Mpeketoni case study for quotations). Another way that actors identified was to grow Jatropha as a companion to vanilla, a cash crop that requires a 'scaffolding' plant on which its vines can climb.

\footnotetext{
${ }^{27}$ However, the extent to which Jatropha was actually being grown on land that was previously uncultivated or characterized as 'marginal' did not match this ideal picture. This is discussed in the Mpeketoni case study.
} 
Jatropha was therefore linked to a food security agenda in several ways: as an inedible energy crop that would not directly divert food to fuel; as a hardy plant that could grow in areas unsuitable for cultivating other crops; by protecting food crops as a fence; by creating a micro-climate enabling food crops to grow in harsh areas; and by increasing household incomes and therefore improving access to food. Interviewees linked all of these hoped-for outcomes to broader humanitarian goals of improving the quality of life of rural households.

\section{Personal and institutional motivations}

Finally, personal and institutional interests contributed to actors' decisions about Jatropha. On an individual level, some said they were drawn to Jatropha because of a thematic interest in science, agriculture or renewable energy. Others saw opportunities to advance their careers through business or job opportunities connected to Jatropha, either on its own or as a companion to vanilla. One NGO representative (NGO4) described the decision to start an NGO that promotes Jatropha:

Instead of coming up and looking for another good job, because there were a lot of office jobs, and do work that after a short time you feel is so stereotyped and there's no new opportunities, new ways to do things, it will be a struggle; but if you started an NGO that is local, that is for local solutions, you might go far.

This individual saw the creation of an NGO as an attractive career path, and identified Jatropha as a set of activities that had the potential to support a new organization. While no other actors were as explicit about their desire to access professional gains that seemed possible through Jatropha activities, some freely accused each other of being motivated by the prospect of jobs and salaries. 
On an institutional level, inevitably the mandates and interests of actors' organizations formed a central part of their motivations for working with Jatropha. Any organization must protect the means of sustaining its activities. For NGOs, among other things this means securing ongoing funding - a process that Wallace (2004), Petras and Veltmeyer (2001) conclude often leads NGOs to opportunism, as they design their activities to match donors' priorities. Many actors interviewed for this study commented on NGOs' need to keep donors interested in their work, with implications for how this might affect their decisions and actions. One NGO representative drew a clear line between organizational and altruistic interests among different players, saying that his organization's interest was to ensure that farmers got benefits, in contrast to some companies and other NGOs which he saw as being motivated by profits (NGO6). Conversely, a government researcher (RS2) alleged that donors, like other actors, were prone to acting out of self-interest: "outside donors, they usually don't do things for the sake of it. They also do it for the sake of benefiting from it." This theme of tension between stated humanitarian objectives and pragmatic organizational interests will return in the section on shady business.

For the private sector, profit-making opportunities were identified as a top priority. When asked why he first became involved with Jatropha, one private sector actor replied: "The big boss of the company asked me to write a project about Jatropha... I suppose that the boss thought that it was a good investment opportunity... I had never been very much interested in Jatropha. But of course when the boss makes a request like that, you have to go with it" (PS3). In this case, the company concerned later discontinued its Jatropha activities when it decided the economic outlook had become 
unfavourable. Clearly the likely return on investment played a paramount role in this company's decisions.

For government, the importance of following policy mandates and maintaining public support provided significant guidance and constraints. Government representatives described how policies related to energy, agriculture and poverty reduction had influenced their decisions surrounding biodiesel and Jatropha. For example, one explained: "we're mainly guided by the energy policy in making these decisions... We look at the policy and see, what are the provisions in the policy? What are we able to do regarding this?" (GO1). Meanwhile, a researcher at a government institute spoke about how public pressure had helped to push Jatropha onto the agenda: "I can say that Jatropha came to [our organization], not [our organization] went to Jatropha, in that Jatropha was actually started by the private sector and the farmers who were demanding it. That means [we] as a research organization had to follow the demand of the public" (RS2). These comments speak to two perceived limitations on the government's freedom to determine its own course of action.

These personal and institutional interests undoubtedly influenced actors' choices, although it is difficult to tell exactly how much they may have outweighed or remained subservient to the economic, environmental and social motivations outlined above.

\section{Synthesis of motivations}

To summarize, interviewees envisioned a wide variety of positive outcomes from Jatropha projects at a number of different scales. At a household level, some espoused providing fuel for lighting, reducing dependence on fuelwood and charcoal, and 
increasing incomes by selling seeds or substituting the expense of buying kerosene. At a village level, they envisioned creating access to electricity for small businesses in areas that were not served by the national power grid. Regionally, some endorsed a model of producing Jatropha commercially (either through an outgrower model or nucleus plantation surrounded by outgrowers) that could sell energy products to large companies or power stations. At a national level, they mentioned increasing the country's Gross Domestic Product (GDP), reducing its foreign exchange spending and buffering against fluctuating world oil prices by using energy that was domestically produced instead of imported. An additional stated goal was to increase food security through a combination of increased rural purchasing power, expansion of agriculture into semi-arid lands and reduced damage to crops by animals. Several also identified international objectives related to reducing carbon emissions in order to combat climate change.

As explored in the next section, some actors spoke of achieving benefits at all of these scales simultaneously and pictured a biodiesel sector in which large- and smallscale activities would complement and stimulate one another. The government's draft national biodiesel strategy (Government of Kenya 2008) notably expressed this position, along with some NGO and private sector actors. Others argued that the most promising potential benefits from Jatropha would be realized through small-scale cultivation coupled with local processing and use of the end products, with goals ranging from providing household lighting to running a generator 12 hours a day for community electricity provision. 


\section{INFLUENCES}

In addition to their individual motivations, I asked key actors what factors they thought had influenced the spread of Jatropha in the country. Many said that the initial idea and much of the drive for Jatropha had come from outside Kenya. Since the most vigorous promoters of Jatropha were NGOs with international funding, many of the outside motivations and influences that actors have cited as creating momentum in the industry can be linked to development objectives that were attached to the availability of donor funds. But why were donor funds available? What made Jatropha appear to be a good idea to people both inside and outside the country? Conversely, what may have slowed or discouraged action on Jatropha in Kenya? Table 6.1 presents a summary of the international and domestic influences that actors in this study identified as having facilitated or inhibited the spread of Jatropha in Kenya. 
Table 6.1: Summary of perceived influences on Jatropha activities in Kenya

\begin{tabular}{|l|l|l|}
\hline Motivators & International & Domestic \\
& - Concern with climate change, & - Desire for poverty reduction \\
emissions reduction, clean energy, & - Desire for import substitution \\
carbon offsets & - Policy objectives on renewable \\
- Food vs. fuel concerns (promote & energy, agricultural development \\
interest in Jatropha specifically) & - Biodiversity, land rehabilitation as \\
donor priorities & - Growing domestic energy market \\
- High oil prices (2007-8) & - EU fuel blending mandates \\
- Large export market & - Exposure to experience in other \\
countries & \\
\hline Inhibitors & $\begin{array}{l}\text { - Food vs. fuel concerns (dampen } \\
\text { interest in biofuels generally) } \\
\text { - Declining oil prices (2009) } \\
\text { - Perceived interference from } \\
\text { international oil producers }\end{array}$ & $\begin{array}{l}\text { - Energy policy unclear on biofuels } \\
\text { - Limitations in education system, } \\
\text { domestic knowledge, research } \\
\text { capacity } \\
\text { - Perceived resistance from } \\
\text { petroleum industry }\end{array}$ \\
\hline
\end{tabular}

Table 6.1 suggests that some international phenomena have had a consistent or predictable influence on levels of interest in biofuels in Kenya; for example, pressure to reduce greenhouse gas emissions in order to mitigate climate change. To the extent that this objective is formalized through measures such as fuel blending mandates in countries that could potentially import biofuels from Kenya, interest in producing Jatropha in Kenya could be expected to increase. In the same way, a general increase in energy demand globally appeared to ensure that the market for energy products, fossil fuel or otherwise, would continue to grow, making biofuel production appear attractive. Two interviewees speculated that petroleum producers might seek to interfere with the development of a biofuel industry in order to protect their commercial interests. 
Other international phenomena were seen to have conditional influence that depended on timing or other variables. For example, oil price fluctuations meant that in 2007-8, high prices stimulated interest in alternatives to fossil fuels, while declining prices in 2009 may have cooled off investor interest in biofuels. Food security concerns represent another area of conditional influence; concerns that biofuel and food production were in direct competition with each other was seen to have discouraged interest in biofuels generally, but boosted interest in Jatropha specifically, because of its reputation for growing in semi-arid lands. Environmental conservation was also mentioned as a high priority for international donors. This is another topic that would seem to dampen interest in biofuels generally because of the possibility that uncultivated lands could be converted to monoculture plantations of biofuel crops, but perhaps promote interest in Jatropha specifically due to the perception that Jatropha could assist with "reforestation," soil and water conservation.

At a national level, Jatropha was seen to fit with existing policy objectives on poverty reduction, renewable energy, and agricultural development. Recent and projected growth in Kenya's domestic energy market, together with a desire to meet this rising demand through domestic production rather than costly imports, appeared to stimulate interest in Jatropha activities. Meanwhile, the lack of a clear policy on biofuels was seen to inhibit Jatropha projects, though as discussed in Chapter 5, a policy development process for biofuels was well underway at the time of research. Longer-term obstacles to the development of successful Jatropha projects included perceived weaknesses in Kenya's education system, a lack of country-specific knowledge about Jatropha, and low research capacity to expand this knowledge. Finally, just as interviewees suspected that 
petroleum producers could play a role in swaying interest in Jatropha internationally, some felt that the petroleum processors and distributors within Kenya had a vested interest in discouraging the expansion of biofuels.

\section{Discourses of development}

These influences speak to at least two discourses of development that differ greatly in their scale and form. On one hand, the desire to achieve import substitution, commercial production for export or major reductions in carbon emissions motivate a model of national economic development through large-scale plantations, centrally coordinated biofuel production or international partnerships. This approach, based on markets, production and value chains, is more likely to be of interest to private investors who see potential for an economically robust sector to emerge, particularly if oil prices rise again in future. Theoretically, it fits with a neoliberal interpretation of development, in which private enterprise provides an engine for economic growth, which in turn stimulates "trickle-down" benefits for the general population.

On the other hand, objectives related to poverty reduction and agricultural development through value addition motivate an approach to economic and social development that includes local processing and smaller scale applications, such as using Jatropha oil to power decentralized electricity production, tractors and irrigation pumps. This is rural development in a broader sense, where there is room to consider the health and cost-saving benefits of replacing kerosene with Jatropha for household lighting, as well as the possibility of increased food security on individual farms by using Jatropha fences to protect crops from wildlife and livestock. This scenario, advocated for biofuels 
in general by Milder et al. (2008) and for Jatropha more specifically by Achten et al. (2010), is perhaps better suited to NGO-run projects that have few economies of scale, can use donor money to absorb start-up costs, and are less profit-oriented than commercial operations. This approach is more consistent with a capabilities approach to development, where interventions are targeted at expanding the range of options available to individuals and households in a way that enhances their potential to make choices that are both beneficial and meaningful to them.

Thus, broadly competing discourses for Jatropha-led development in Kenya were articulated by the people who have been responsible for promoting and regulating such a process, evoking Grillo's (1997) view that development knowledge consists of multiple ideas that reflect diversity within as well as between groups. One of these discourses advocates large-scale production of Jatropha as a cash crop to meet national objectives, while the other promotes small-scale cultivation to support household or farmer group objectives. That Jatropha can be seen as an instrument of both market-led national economic growth and community-led rural development helps to explain why it appeals to actors with widely varying priorities. This "duality of discourse" (Hilhorst 2001) can also add confusion and tension to discussions about how to proceed, perhaps helping to explain the unusual features of Kenya's Jatropha activities noted in Chapter 5 and below.

\section{Coexistence of discourses}

Some actors felt that large-scale, commercial interests already had the upper hand or would be catered to more than small farmers (NGO5, PS1); others felt that investors had no incentive to move with Jatropha at the time (PS3). Although stories about impending 
large plantations often circulated in the media, the fact that none had yet been established (and that the one company that had been running a test plantation for several years opted to discontinue its Jatropha activities) suggested that large-scale ambitions had not yet been realized. A number of interviewees expressed the view that there was insufficient knowledge, experience or technical capacity in Kenya to support commercial scale Jatropha production in the near future (RS1, GO1). Also relevant here are informal comments from several interviewees suggesting that the draft biofuel policy would contain language discouraging the export of Jatropha seeds or oil in favour of supporting a domestic market. Nonetheless, some actors continued to actively pursue partnerships with foreign investors (Green Africa Foundation, Biogreen Technologies), suggesting that the large-scale discourse of Jatropha remained viable in the minds of at least some of the actors interviewed for this research. Another (Pipal Ltd.) was launching a research project that investigated the potential for large horticultural operations to produce their own fuel using Jatropha, perhaps representing an intermediate position in terms of the scale and intended uses of Jatropha.

At the same time, as noted in Chapter 5, the fact that smallholder activities had not yet yielded many seeds or resulted in much processing or use of Jatropha products suggests that small-scale planting of Jatropha for community-based objectives had not yet become comfortably established either. The preliminary outcomes of the Jatropha Integrated Energy Project in Mpeketoni illustrate some of the struggles associated with this discourse of development and are discussed later in this chapter. 


\section{Competition between discourses}

With so many different motivations and objectives at play, it is not surprising that there would be competition between actors and perspectives. Jatropha activities in Kenya included some tense interactions that demonstrate such competition. These include claims by some actors that others had engaged in shady business and suppressed dissenting views in the course of promoting Jatropha. The following sections examine these phenomena.

\section{Shady business}

When asked whether anyone had benefited from Jatropha in Kenya so far, several actors from different sectors responded that particular NGOs had benefited more than anyone else, for financial reasons: they had attracted international funding and sold seeds to farmers for high prices (RS1, PS1, PS3, NGO6). Some said that shady business practices had allowed some NGOs and seed brokers to benefit from the spread of Jatropha in Kenya while farmers had not. As the following comments show, their critiques focused on NGOs making false promises, selling seeds to farmers for disproportionately high prices, failing to provide farmers with ongoing support, and generally acting out of personal or organizational interests where these were are at odds with farmers' interests.

Some criticized NGOs for raising farmers' hopes about Jatropha without having adequate knowledge about it. One NGO representative stated, "There are a number of people, NGOs, foundations, who are very ignorant, but they will talk as though they are seed scientists or seed technologists. Sometimes we are not honest with ourselves. We want to promote Jatropha at whatever cost..." (NGO2). A private sector actor echoed 
these views: "There's somebody who has no experience in crop or plant science, then they decide to promote a crop... even before doing any research on it. They have made money; they could earn salaries, allowances" (PS1). In this way donor funds were seen to motivate some NGOs to prematurely push Jatropha. The incomplete state of information surrounding Jatropha is discussed in more detail in Chapter 7.

Others had even harsher words for the dominant NGOs and their motives, including one researcher: "The people who have benefited are the ones who have been able to raise some donor dollars to hold a conference or sell seeds for 2,000 KSh ( 26 USD) a kilo to farmers... They've gamed the system. They've taken advantage of people" (RS1). One NGO actor (NGO1) saw this behaviour as part of a broader pattern:

People are promoting Jatropha only because they have donor money to do it, with the result that farmers suffer. It happens everywhere - NGOs get money and promote an idea without considering the impacts on the farmers they work with. In the end, they just close their books and leave.

An NGO actor sharply criticized others for making false promises: "There are some quacks, I say, who want to tell farmers to grow Jatropha, and they're giving them the impression [the farmers] will sell the seed at a very high price. That is cheating. That is not being honest" (NGO2). While interpersonal conflicts may have influenced some of these comments, the frequency with which this theme emerged during interviews, and the breadth of actors who expressed such views, took me by surprise.

Actors' critical portrayal of NGOs took several forms: that of nimble and astute organizations who spotted an opportunity, attracted funding and contributed to shaping relevant policies; of unscrupulous players who misled and even exploited farmers for financial gain; and of benevolent development workers who sincerely wished to help farmers and were learning from mistakes along the way. For their part, NGOs were not 
the only ones to come under attack. Some actors also made allegations concerning lack of fairness and representation in government processes, researchers guarding information, and private investors engaging in bribery. A feeling of general discontent was summarized by one NGO actor (NGO6): "Ugly things have happened. Everybody sees money in Jatropha; that's the problem."

\section{Responses to dissent}

Those who have most actively promoted Jatropha almost certainly did not anticipate the problems farmers would encounter with production and yields. But knowing what they know now, some of them continue to act as they did before. At times, evidence that counters the narrative of Jatropha as a "wonder crop" has emerged and been vigorously suppressed. For example, at a National Workshop on Biodiesel convened by the Ministry of Energy in June 2009, actors gathered in Nairobi to share and discuss recent research findings about Jatropha. When one speaker presented an unfavourable economic outlook for farmers based on an extensive survey carried out across the country, some delegates argued fervently during the ensuing discussion period that it was essential not to discourage farmers by sharing these results with them - to "crush their hopes," even in the face of decidedly discouraging evidence. Those who made this argument presumably felt that maintaining a positive image for Jatropha, and thus keeping momentum for their projects, was more important than questioning or scrutinizing the information on which this image was based.

This behaviour evokes Mosse's (2005: 2) question: "What if, instead of policy producing practice, practices produce policy, in the sense that actors in development 
devote their energies to maintaining coherent representations regardless of events?" This observation applies to this situation in more than one way. First, government representatives were in the room at the time; thus, there was the possibility of influencing government policy, and therefore the future economic and regulatory circumstances surrounding Jatropha, through what was said in the forum. Perhaps this was part of the reason why NGO representatives who argued against sharing negative research findings with farmers felt compelled to immediately counter the contributions of researchers whose findings threatened the basis of their activities. At the same time, Mosse's question can be considered in relation to a broader interpretation of institutional policy. In this sense, NGOs that depended heavily on outside funding to continue their activities - their existing practice - could be expected to have a strong interest in preserving the idea that Jatropha was economically viable. Recalling Vivian's (1994) ideas presented in Chapter 2 - namely, that donors' emphasis on "success stories" as a condition for continued funding can compel NGOs to cover up problems in favour of perpetuating optimistic messages about their work - it is reasonable to suspect that these NGO actors may have worried about losing funding support if farmers lost interesting growing Jatropha. In these ways, the question of who controlled the discourse of Jatropha could have concrete implications for NGOs who promoted it (let alone farmers who may have planted it).

In addition to such overt suppression of dissenting views, some suspected that covert forms of exclusion were taking place. One NGO representative questioned how the government's steering committee was chosen, noting that some views were not represented and some actors were not included despite having actively taken part in 
workshops. Despite assurances from the Ministry of Energy that no one was prohibited from participating in the Kenya Biodiesel Association, one NGO representative (NGO5) who used to participate in the group stated:

There was an exclusion, slowly by slowly, with no word.... You're not called for meetings, and when they happen you don't even know. You just get to meet with other committee members and they ask you, you were not in the meeting? ... Only some of the stakeholders had the most correct and up-to-date information.

Finally, a private sector actor felt that the amount of time required to take part in the KBDA was too much to justify, saying, "I'm not funded to attend those meetings. So I can't be attending things where other people are earning salary" (PS1). This interviewee drew a distinction between those who were paid only to complete specific contracts, and those whose employers paid salaries that included time spent at external meetings. These interviewees thus identified several barriers to participation in committees and meetings, including connectedness to key individuals, communication about the committee's activities, and availability to spend time attending meetings.

Whether overt, covert or merely suspected, these anecdotes of exclusion and suppression of particular points of view raise questions about the supposedly participatory nature of decision-making around Jatropha in Kenya. As Gaventa (2006) points out, 'participatory' processes, structures and language can sometimes mask rather than opening up power relations. In this case, those who participated in workshops and meetings - and made use of such occasions to argue persuasively for their institutional positions - were able to wield a form of power by influencing dominant narratives about Jatropha. Control over the production and distribution of knowledge thus represented an 
important link to control over government and institutional policies toward Jatropha, a theme that will be re-examined in Chapter 7 .

\section{Perceived complementarity of discourses}

Several interviewees expressed the belief that small- and large-scale strategies for growing Jatropha would stimulate and mutually reinforce each other. Along these lines, some described how large investments could build processing capacity, raise interest among potential buyers, and encourage more farmers to plant Jatropha, thus building momentum toward some sort of critical mass which could in turn help to enable smaller projects. For example, one researcher (RS4) expressed that large-scale projects, if successful, could provide examples to motivate and support small-scale initiatives. Going further an NGO representative (NGO3) said this when asked what would be the best approach to growing Jatropha in Kenya:

I would say the hybrid. Whoever is able to plant more, let him plant because until we get a critical mass we cannot talk about Jatropha as a business. When we get, you know, sizable quantity, that's the time you will find probably investors bringing crushing machines, investing in an industry of transesterification and all that. But until we get to that point we cannot. At the same time, the villager there who can get a few kilos, extract oil, she can use them for local lighting, for the stove and all that. So to me, a hybrid would work very well. The commercial would assist, would be a link to the small-scale. The small-scale can really ride on the large-scale, for machinery and all that. ... You cannot say the small-scale can survive on their own; neither can the large-scale survive on its own.

This actor saw it as not only possible, but necessary that small- and large-scale production occur side by side. In other words, the two discourses of development clearly articulated in this quotation as commercial production led by the private sector, 
and livelihood-oriented production for local use - were seen to be not only compatible, but mutually dependent.

Several interviewees drew parallels between a potential Jatropha industry and existing systems of coffee, tea, sugar, and wheat production, presenting these as examples of how large and small farms could successfully coexist. For example:

We're looking at a combination of approaches. We have a model like for sugar, coffee and tea with a nucleus plantation and outgrowers, and those would be smallholders. Another option is the cooperative model if there is no nucleus plantation and farmers group together to grow Jatropha and have their own processing plant. (GO2)

This actor envisioned two roles for small-scale producers: that of supplementing nucleus plantations controlled by large investors in the style of existing cash crops, and acting collectively to process their own Jatropha oil without the involvement of such investors. Other interviewees described how small-scale farmers could participate in presumably centralized production systems:

Kenya is the largest producer of tea. Now that tea crop... the company grow more or less monoculture, but when you go to the small-scale farmers, you will find there's a plot of tea here, a plot of maize, a plot of trees here and all these things. That is what we see with Jatropha and other biofuel crops. It's not going to be all monoculture. (NGO2)

Another stated:

In the coffee and tea industry, the large-scale and small-scale players are able to benefit in such a way that the large-scale have their take and the small-scale also... So if we get organized [for Jatropha] such that the large-scale will be given a certain percentage of the crop to feed in and the small-scale also will be given a certain percentage, or an incentive to grow it, there will be a maintaining of the balance between how much the large-scale should produce, and how much the small produce. (NGO5)

These actors clearly felt that small-scale growers could benefit within a system that included (and was perhaps driven by) large-scale production. However, in these last two 
quotations it is less clear what form of small-scale production the interviewees pictured. For small-scale farmers, growing a cash crop under contract for a company would presumably mean selling Jatropha seeds for direct income, rather than generating energy that could be applied to local uses. A donor (DN1) expressed reservations about the likelihood that such an outgrower approach would benefit small-scale farmers:

No one wants to set up a plantation where he'll have to spend so much money and receive so little yield. So what they'll opt to do is have outgrowers grow it for them, and then they'll source it from the outgrowers, and then put punitive measures to make sure they receive the maximum out of that.... How long will it take for a farmer to pay off his debt? It's a very risky thing.

Thus, several actors subscribed to a "hybrid" discourse of Jatropha production, where large-scale commercial production and small-scale production could coexist and reinforce one another. In at least one case, this was explicitly tied to the contrasting discourses of development described above, where small-scale farmers would produce energy for local use. In other cases, actors envisioned small-scale farmers as participants in a cash crop model of production where they would participate by feeding their produce into a centralized, commercially oriented value chain in exchange for cash. These different interpretations of the roles available to small-scale farmers in an emerging Jatropha economy in Kenya have important implications for the power dynamics involved in Jatropha's promotion and spread. Meanwhile, in response to the research question, Is there a dominant discourse of development attached to Jatropha in Kenya?, these comments provide evidence that multiple discourses of development not only existed among different actors, but that in some cases, individual actors espoused multiple discourses simultaneously. The resulting tensions and opportunities are explored in more detail below. 


\section{Divergence and convergence}

The actors involved with Jatropha in Kenya represent a plurality of goals and strategic interests. The foregoing discussion has broadly linked these to two discourses of development: one focused on markets, national and international objectives; the other on rural development and community-based objectives. These dual expectations simultaneously broaden Jatropha's appeal and confuse its implementation. While some actors have wielded various forms of influence, including input to policy processes and suppression of dissent, to try to establish a dominant view of Jatropha, a plurality of discourses and critiques persists. The continued existence of multiple discourses enables a strategic flexibility that different actors have used to pursue different ends (Hilhorst 2001). Taken together, the strength of particular NGOs who have mobilized donor resources, the malleability of a policy process that explicitly seeks 'stakeholder' input, and the vagaries of a market that has not yet materialized, create a situation where Jatropha can be grown widely but processed nowhere, and where exclusion and shady business have the potential to go unchecked.

But these outcomes are far from inevitable. As Tsing (2005) observes, a creative friction can also occur where apparently disconnected viewpoints come into contact with one another. The Mpeketoni case study examines how these dynamics play out in relation to a specific Jatropha project and considers the potential for diverse actors to achieve multiple goals. 


\section{INSIGHTS FROM MPEKETONI}

The Jatropha Integrated Energy Project (JIEP) in Coast Province, Kenya provides an opportunity to examine a practical case where the objectives of international donors, local coordinators and farmers meet. Headquartered in the town of Mpeketoni, Lamu District, JIEP encourages small farmers to grow Jatropha using an outgrower model. The project aims to produce straight vegetable oil (SVO) for household lighting as well as to support value addition enterprises for locally produced crops.

Figure 6.1: Map of Mpeketoni area (Aerospace Center (U.S.) 1969 (rev. 1994): Mpeketoni area added by author)

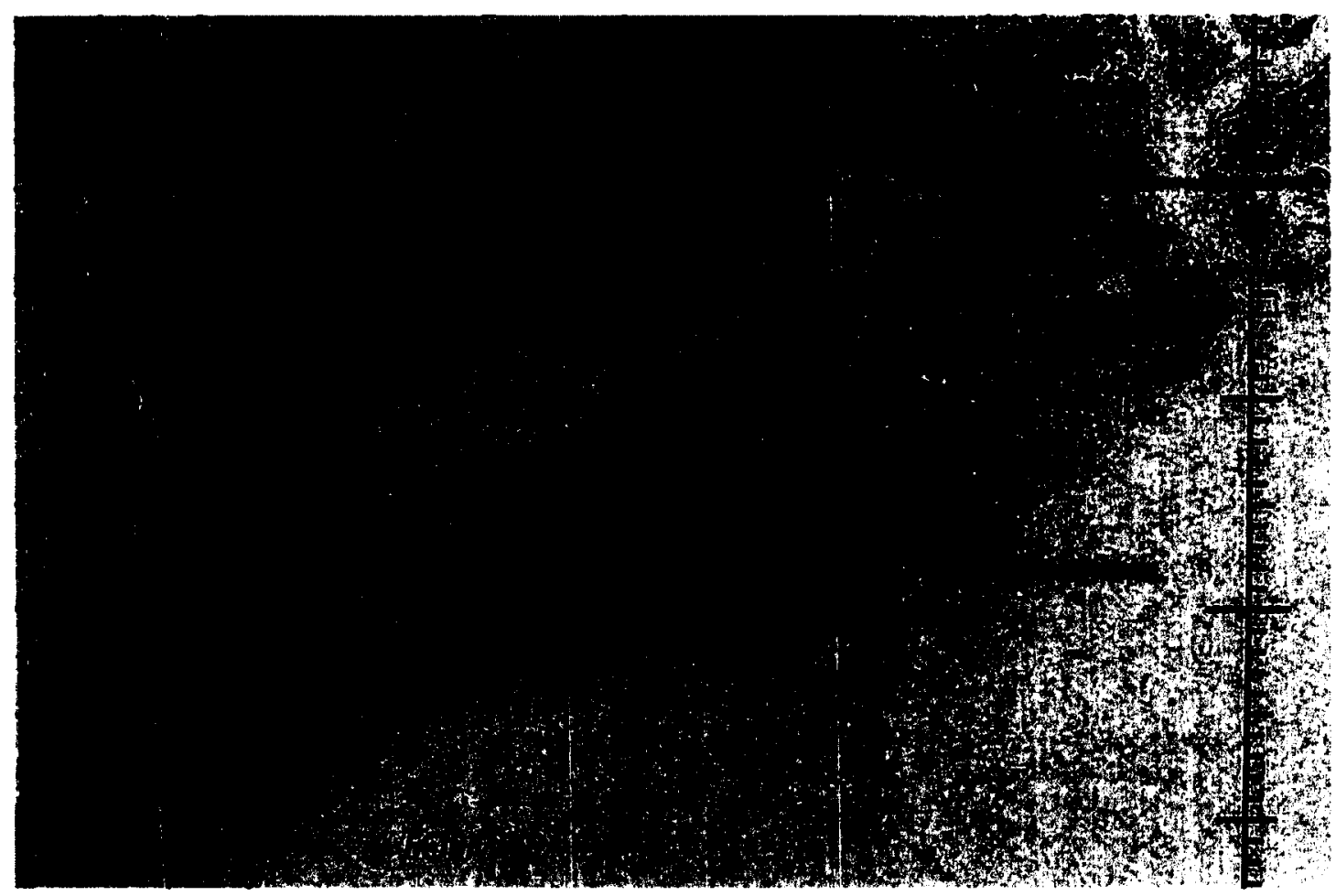

The population of the project area (about 30,000 in 2004) comprises a mix of coastal (Swahili) inhabitants and farmers from other communities who arrived as part of the

Lake Kenyatta Settlement Scheme from the 1970s onward. The Kenyan government actively promoted cotton production in the area and collaborated with German Technical 
Cooperation (GTZ/GASP) to establish the settlement's infrastructure (Kirubi 2009). Several international NGOs continue to be involved in providing public services such as health care and education. A diesel generating station run by the Kenya Power and Lighting Company has provided electricity at a nationally standardized rate since October 2008 , though the cost of connecting to the grid remains prohibitive to most residents. Most settlers were allocated 10-acre plots, and population growth in the area is still mainly accommodated by expanding the settlement rather than subdividing existing plots. Major crops include maize, beans, mangoes, cashew nuts, citrus fruits, cowpeas, coconut, chilli peppers and bixa (a cash crop used to produce dye).

Agricultural challenges in the area include poor access to markets, declining soil fertility, and crop damage caused by wildlife. Many farmers stopped growing cotton after the consolidation of ownership at nearby processing facilities drove prices down, drastically reducing farmers' profits on what had previously been the area's most profitable cash crop. Other cash crops, such as cashew nuts, are sold raw for processing elsewhere, with the result that local residents do not benefit from related employment or value added. Middle buyers with trucks control access to markets and effectively set the prices for perishable crops such as mangoes, which further limits farmers' incomes. Keeping the land productive is another challenge; after clearing new land by burning, soil fertility is high for the first few seasons but declines over time. Some farmers compensate by using fertilizers while others practice crop rotation. Meanwhile, wildlife such as baboons, buffaloes and zebras continually trouble farmers by damaging crops.

JEP was established in 2007 by Norwegian Church Aid (NCA) and an existing farmer group called the Lamu Cotton Growers' and Industrial Association. The project 
has since evolved into an organization in its own right. JIEP plans to buy Jatropha seeds and raw agricultural produce from farmers, extract SVO from the Jatropha and use the resulting energy to add value to the other crops through processing or cold storage. Finally, the project plans to sell the finished products, thus taking responsibility for the processing and marketing stages of the value chain. A second strategy of the project is for farmers to exchange Jatropha seeds for SVO and compatible lamps.

Norwegian Church Aid is the sole sponsor of the project, providing financial support as well as training and capacity building. Its funds have been used to establish an office, provide Jatropha seeds, hire trainers, purchase equipment, and establish a revolving loan fund for the project to buy Jatropha seeds back from farmers. At the time of research, one of NCA's staff members continued to actively facilitate JIEP committee meetings while visiting from Nairobi on a periodic basis, working with project coordinators to develop business plans and administer the budget. Clearly, the project would not have taken flight without NCA's financial and human resources.

By July 2009 , approximately 1,470 farmers had reportedly registered with the project and planted Jatropha in on-farm plots ranging from $1 / 4$ acre to 2 acres in size. The farmers were organized into 8 zones and 57 smaller committees across an area approximately $75 \mathrm{~km}$ in diameter. An NGO contracted by the donor provided training on how to establish nurseries and plant Jatropha. Most farmers planted between May and July 2008. I first visited Mpeketoni in May 2009 and returned for a follow-up visit in July the same year. In a January 2010 update, the project coordinator reported that the project began to purchase Jatropha seeds from farmers in December 2009 and had by that time 
acquired about $1 / 2$ tonne, although a delay in securing funds to buy the seeds meant that many farmers had sold their seeds to other brokers by the time the project began to buy.

A multifunctional platform worth 1 million Kenyan shillings (KSh) $(13,700$ USD), purchased by NCA, arrived in Mpeketoni in March 2009. This machine is designed to extract straight vegetable oil from Jatropha seeds, produce electricity, and power a mill for grinding grain amaranth. During a visit in July 2009, the machine was not yet operating as no Jatropha seeds had been collected from area farmers. By January 2010, it was reportedly producing some SVO, but due to a technical problem with the milling attachment, amaranth processing had not yet begun.

Interviewees in Mpeketoni included 26 farmers who had planted Jatropha, two farmers who knew of Jatropha but had decided not to plant it, and two coordinators of JIEP. All were interviewed in May 2009 and most were revisited in July 2009. An extended interview with a Norwegian Church Aid official in Nairobi provided a donor perspective on the initiative.

\section{Motivations and expectations}

Donors, coordinators and farmers expressed a range of motivations and initial hopes for the Jatropha project. An NCA representative explained how the organization started from a position of concern over climate change that was focused on reducing greenhouse gas emissions:

We were struggling with this whole issue of climate change.... We as NCA were struggling to find what would be the appropriate response to climate change from the perspective of communities, while feeding into the big debates and the big discussions and the big responses that were being driven from a Western point of view. 
In other words, NCA approached the project with an interest in participating in "big" (i.e. international, high-level) responses to climate change, together with a mandate to promote community development. This position presented the immediate challenge of linking a Western desire for emissions reduction with a locally relevant social development agenda in rural Kenya - perspectives that reflected not only different scales of activity, but perhaps different issues and themes altogether. NCA resolved this by connecting local, plant-based energy production with poverty alleviation, saying: "The motivation we saw was more to give farmers a way to reach their energy needs without dipping their hands into their little cash resources... being able to substitute a product that you buy for one that you pick from your own farm... So it was directly related to the poverty aspect, not having to spend money to meet your energy needs." NCA's approach to the project was thus focused on the goal of producing renewable, accessible energy for development.

A JIEP coordinator used similar language to frame the project's objectives, identifying a dual focus on climate change and poverty alleviation: “... the main objective of the project [was] to fight poverty and the effects of climate change, and at the same time to increase farmers' income as part of poverty reduction." Using fuel derived from Jatropha to process or preserve other crops was this individual's top priority: "The benefits of Jatropha oil are not in selling the oil, but in using the oil to add value or to support our other farm activities." Coordinators described how Jatropha oil could add value by producing electricity or directly fueling equipment that would mill grain, juice mangoes, shell cashew nuts, separate cotton lint from seeds, or run a cold storage facility. All these activities would yield finished products with higher profits than 
farmers currently earned by selling raw produce. In this way, the Jatropha project appeared to have the potential to satisfy a longstanding desire in Lamu District. A coordinator described how the pre-existing Cotton Growers' Association had been seeking ways to add value to local crops for several years, stating:

The objectives of value addition did not start recently, because we wanted to add value to our mangoes. We also wanted to add value to our cashew nuts... the idea of value addition has been there all along. The biggest problem was that it was very difficult for the association to find sponsors, or the required funding. We looked around and made a lot of applications... It took us a long time, and thanks to NCA who came to our aid some two years ago.

In other words, the Cotton Growers lacked funds to put their value addition plans into action, and NCA appeared able to provide these funds through the Jatropha project. From the Cotton Growers' point of view, this partnership offered an opportunity to realize one of their long-standing ambitions. Combining this perspective with NCA's initial interest in climate change mitigation, it appears that $\mathrm{NCA}$ and the Cotton Growers approached the project from different directions; in the Jatropha project, both saw potential to achieve their primary objectives.

NCA and JEP representatives also spoke of the importance of using Jatropha oil in household lamps instead of kerosene. Both made an explicit link between household use of Jatropha for lighting and improved educational opportunities for children who would be able to study longer in the evenings. One explained, "The farmers are keen on household use because they are poor, they cannot afford kerosene to light their lamps in the evening... Illiteracy levels are very high because children cannot study in the evening. They lack light. Now the farmers feel that if they can get a source of light, that will be very welcome." 
Project leaders also hoped the initiative would provide electricity generation, fuel for boats and buses, and eventually qualify for carbon credits under the Clean Development Mechanism. One stated, "As [Jatropha] grows it will serve as a carbon sink. It stores carbon in its roots, and when it burns it also produces very little carbon dioxide... So this will help us generate more income and at the same time, fight the effects of climate change." Donors and local coordinators thus spoke of anticipated benefits that ranged from improving household-level access to light in the evenings to combating the global challenge of climate change.

Farmers expressed high hopes for what Jatropha would bring them. When asked how they hoped to benefit from it, the majority (19/26) wanted to use Jatropha oil for household purposes (lighting and/or cooking). An equal number mentioned wanting to gain income from selling either seeds or oil products. Their specific goals were ambitious. One farmer said he was waiting for Jatropha to provide enough income that he could buy a motorbike and a solar panel - both major purchases. One woman hoped it would support her in her old age so that she would no longer have to cultivate more labour-intensive crops, explaining, "I am old and I don't have the energy to look after things like maize. Jatropha is less work." A man expressed similar views, saying Jatropha would allow him to trade oil and get money in his old age, without giving him backaches: "It can increase my years and I will live longer." Seven specifically described their plans to use Jatropha oil for lighting to save the expense of buying kerosene, for example, "We will minimize buying kerosene - instead of buying from somewhere else, we will buy from the people here. Everybody will bring 5 kilos [of seed] and get their own oil; if there is extra, then [we will] sell it to neighbours." One mentioned wanting to run an irrigation 
pump on fuel derived from Jatropha. Their spirit of overall optimism was captured by one farmer's statement that "this plant can change lives." These comments reflect a range of personal benefits related to income and health that farmers anticipated Jatropha would bring at the household level.

Two farmers also hoped Jatropha would allow them to avoid crop damage from wildlife. For example, one whose farm was at the edge of the settlement described how difficult it was for her to grow food crops because "all manner of animals are around the farm - so many buffaloes and zebras." She explained that she had planted Jatropha on much of her land - more than any other farmer interviewed for this research - because "Jatropha can't be eaten by wild animals." Crop protection was therefore another benefit that some farmers linked to Jatropha, in addition to the household energy and income just described.

Four farmers mentioned environmental benefits that they hoped would come from planting Jatropha, using phrases such as "it will purify the air" or "it enriches the soil." Three explicitly talked about climate change, for example: "[Jatropha] helps with climate change... Trees have been cut all around. The rains are no longer coming as they used to. I hope and believe that Jatropha will clean the air - it will fight with the smoke emitted by factories." While some of the farmers who spoke about climate change were closely linked to the project leadership (for example, as zone leaders), their views nonetheless show that environmental messages about Jatropha were being disseminated by the project to some extent.

These statements reflect different but overlapping expectations on the part of donors, coordinators and farmers. Each hoped that the Jatropha project would achieve a 
different primary objective: farmers focused on household use and income generation; project leaders prioritized value addition; and donors emphasized the potential for emissions reduction and carbon offsets. These goals represent a suite of benefits to be realized by different people across a range of scales and activities. They also fit within each type of actor's perceived sphere of influence: individual farmers were most attached to farm-level strategies; project coordinators (who had previously led the area's Cotton Growers association) envisioned uniting farmers to leverage economic gains through collective action; and the donor organization moved in the realm of international commitments to address the global problem of climate change. This plurality of discourses for Jatropha fits with Hilhorst's (2001) concept of multiple and coexisting discourses. In this case, the range of views expressed by donors, coordinators and farmers reinforced the idea that Jatropha offered something - and perhaps, something different for everyone. The tensions associated with this scenario and the extent to which donors, coordinators and farmers have adopted each other's objectives will now be explored.

\section{Tensions and disconnects}

As mentioned, the different actors involved with Jatropha in Mpeketoni were attempting to use the same project to achieve a variety of objectives. At times it appeared that they held incongruent positions on the topics of energy overuse vs. energy poverty; the relative importance of value addition to the project; and competition between Jatropha and food production. Each of these themes is discussed in turn. 
The energy paradox: reducing emissions vs. increasing access

Donors, project coordinators and farmers expressed very different initial goals and hopes for the Jatropha project. The NCA representative described a growing awareness of these differences and a process of mutual learning that unfolded as the various actors met to design and implement the project. From NCA's point of view,

...[We] realize[d] that communities can describe issues that we are dealing with, for instance climate change, in their own vocabulary, using their own symbols, relating to their own needs. That for us was a great learning... It forced us to say, the issue here is not just about emissions. Emissions are critical but that's only a Western perspective. But this lady, if she can't afford even an hour of lighting, it has serious consequences... The issue was about affordability and access [to energy].

This central tension between reducing emissions and increasing rural access to energy became increasingly clear to the NCA representative through discussions with residents of Mpeketoni:

It was in the process of interacting that energy poverty became evident to us. Then we realized that they are crying to use more energy, yes? While we are struggling to reduce our emissions because of the energy that we are misusing. So there's a kind of disconnect in this whole debate. That was for us very humbling.

The interactive process of establishing the project thus exposed a fundamental tension between the donor's officially declared desire to reduce emissions from energy use and the farmers' desire to improve their economic opportunities and well-being through increased access to energy. In this sense, different discourses of development came into contact with each other: NCA's initial concern with reducing greenhouse gas emissions perhaps grounded in a sustainable development perspective with a broad view of global environmental sustainability, and farmers' concern with increasing their own well-being 
(including through increased energy use) perhaps based in a capabilities perspective focused on expanding the range of livelihood options available to them.

\section{Whose goals?}

A second disconnect concerned the relative emphasis that different actors placed on using Jatropha oil to provide energy for value addition projects such as cold storage and grain processing. Only three farmers mentioned value addition among their priorities for the project, and two of these held leadership positions within the project. This contrasted with the emphasis placed on value addition by local coordinators, as well as the "popular consensus around the issue of energy and a focus on value addition using clean energy" that the donor representative described. A coordinator explained this difference by saying that farmers involved with the project were overwhelmingly concerned with securing their daily fundamental needs rather than with strategic thinking that could help to improve their livelihoods in more lasting ways: "Most of the farmers are focused on household satisfaction before venturing into factories and agroprocessing. But we are using the committees on the ground to sensitize the communities and the farmers, [so that they] know that we are going to do value addition." The current situation suggests that project leaders prioritized value addition more highly than farmers did.

This difference in perspectives about the importance of value addition highlights the diversity of objectives, strategies and priorities attached to the project. One could interpret coordinators' and farmers' views on value addition as emphasis on different scales of economic activity. Project coordinators, who had worked for years to coordinate farmers and achieve collective gains through the Cotton Growers' Association, 
prioritized a similar style of organizing in order to help farmers collectively benefit from economies of scale and enhanced participation in regional markets. Meanwhile, farmers appeared to focus on their individual and household opportunities without necessarily connecting these to a mechanism for leveraging greater participation in markets outside Mpeketoni.

\section{Food security}

A third disconnect between donor, coordinator and farmer goals could be observed on the topic of food security. Officially the project discouraged farmers from planting Jatropha on land that had already been cleared for cultivation. A coordinator explained:

Because we knew we could get out of the climate change problems and get into worse, hunger, problems..., we don't encourage people to convert land that they were using on food production.... We want farmers to open those areas that are just bushy with nothing, and not to replace the areas with food crops.

However, some of the farmers visited for this study had uprooted tomatoes, vegetables, maize or beans to plant Jatropha. Four of the farmers had converted food or cash crop areas to monoculture plantations of Jatropha, while others had reduced their production of other crops to intercrop with Jatropha. Only two had planted Jatropha on formerly unused land, while one had converted an area formerly used for grazing goats. Most (19/25) were intercropping Jatropha with other crops, although this strategy may become less feasible in 2-3 years' time when the Jatropha canopy fills out and produces more shade.

Thus, in at least a few instances, farmers had already sacrificed some food production in order to establish Jatropha on their farms, with further reductions likely to 
occur in the future. In one sense these farmers took a risk, anticipating that the net benefits would outweigh their losses. However, it is also reasonable to expect that farmers would try to minimize their expenses when experimenting with a new crop. In this case it could be seen as a risk-averse - and economically rational - decision for farmers to avoid incurring the expense of clearing new land if they were unsure whether Jatropha would bring worthwhile returns. In this way, the desire of donors and coordinators to avoid competition with other crops sat uneasily with farmers' desire to minimize their own costs in experimenting with this new venture.

\section{Investments and outcomes}

What resources did farmers invest in planting and tending Jatropha in Mpeketoni, and what did they get back for their efforts? The following sections examine the themes of investments and outcomes.

\section{Investments}

Mpeketoni farmers had invested substantial resources into establishing their Jatropha crops in the form of cash, foregone income and labour, even though the project provided support in the form of training and free seeds for planting. Those who kept records reported making cash investments of between 6,000-8,000 KSh/acre (approx. 85-115 USD) to hire labour and to buy insecticides, water for irrigation, and/or petrol for an irrigation pump. Those who cleared uncultivated land specifically to plant Jatropha would have had to spend considerably more, although no farmers were able to provide exact figures on this. 
A minority had experienced losses from foregone income where they replaced existing crops with Jatropha. In one example, a farmer uprooted bixa to plant a monoculture of Jatropha, resulting in losses of approximately $6,650 \mathrm{KSh} /$ acre (95 USD) in the first year. As mentioned, others had uprooted tomatoes, vegetables, maize, beans and cotton to plant Jatropha.

Intercropping Jatropha with either food or cash crops helped ease the transition to growing Jatropha in the early years but may only work for a limited time. When the Jatropha canopy fills out after 2-3 years, it may cast too much shade to grow other crops between the rows. As well, it is not well known which crops grow best in combination with Jatropha. Numerous farmers were intercropping Jatropha with maize, neither of which fixes nitrogen. This combination could be expected to deplete soil nutrients faster than Jatropha coupled with beans, for example.

Finally, farmers who did not hire labourers had invested their own labour in preparing the land, planting, weeding, irrigating, pruning and harvesting their Jatropha. While most did not keep records of the time spent by different family members on these tasks, it is reasonable to expect that the time invested was comparable to that reported by those who did hire labourers, ranging from 14-30 person-days of labour per acre in the first year.

\section{Outcomes}

In May 2009 farmers in Mpeketoni overwhelmingly expressed that they had not benefited from growing Jatropha to date. Most had harvested few if any seeds in the first year. Only two said that they had benefited directly from growing Jatropha so far. One had sold 
seeds to her neighbours for planting, while the other had fashioned a candle-like light out of Jatropha seeds which demonstrated to his children that the seeds can provide light: "The kids were excited. They now believe that it's true; Jatropha is oil." Some had tempered their original expectations, for example: "[At first] I was excited about not having to buy kerosene anymore if I could produce it in the farm. But I'm realizing that it is slow in coming."

Most farmers accepted that it was too early to benefit from Jatropha because the project was still in its initial stages and remained optimistic about receiving benefits in the future. They expressed this hope through statements such as "when everybody plants, we shall be benefiting" and "when there's a ready market, it will really benefit me." One said the project was "like a pregnant woman," expressing a sense of hopeful anticipation. Some whose plants had suffered heavily in drought conditions or been attacked by pests planned to replant their damaged Jatropha plants. Perhaps this patience can be linked to these farmers' experience with tending other tree crops, which take several years to start producing fruits. Interestingly, when asked to identify the three most important crops on their farms, a minority of farmers included Jatropha - even those who said it had not benefited them whatsoever to date. ${ }^{28}$

However, three farmers expressed frustration or negative views about the project. One stated that Jatropha was wasting his time; it was taking up his farm and his money without benefiting him in any way. Another said, "I have used strength and put energy into it but haven't benefited yet. Like any other business, if this one doesn't bring profits then it should raise questions." These farmers showed a pragmatic attitude towards

\footnotetext{
${ }^{28}$ It is highly possible that knowing I was there to study jatropha influenced participants' answers. The issue of how, and how much, I may have unwittingly contributed to the "hype" over jatropha by conducting this research project is explored further in Chapter 8.
} 
evaluating how important Jatropha was to them, and a willingness to abandon it if it did not bring satisfactory returns on their time, money and efforts. Recalling the events of the National Biodiesel Workshop (in Nairobi, June 2009) mentioned earlier in this chapter, where one of Jatropha's promoters argued that it was crucial not to "crush farmers" hopes" by sharing research findings that showed a negative economic outlook for Jatropha, these farmers' comments suggest that whether or not such messages reached them, they were prepared to make their own decisions about whether to keep growing Jatropha based on their own experience and judgment.

These frustrations were linked to several challenges associated with the project. At the time of this research, JIEP had not yet started to buy and process seeds from farmers as planned, which was a source of impatience. Farmers felt there was no market or they did not know where to take any seeds they produced. Coordinators gave several reasons for this delay, including waiting for approval from the funding agency to establish a revolving loan fund for purchasing seeds and other raw produce from farmers, needing to build a special structure to house the multifunctional platform, and deciding whether this machine should ultimately be located at the site of its current offices or on another piece of land owned by the project. Communication with farmers spread over such a large project area presented another challenge. One farmer thought the project had been discontinued because he had not heard any news from it in such a long time, while others felt that their farms were far from the central point where workshops were held. Finally, some farmers expressed worries that this project would fail "like others" that had promoted particular crops before it, or that Jatropha would end up having an unstable market like other cash crops in the area such as mangoes, cotton and bixa. 
Donor and coordinator representatives were positive about the progress the project had made, while acknowledging that challenges lay ahead. The NCA representative identified the main accomplishment as the contribution JIEP had made to building community capacity: "The social capital not only benefits Jatropha... It benefits the politics of the area, it benefits maize - because the same structure, the same trust can be used to reduce the barriers of transacting business as a community." NCA saw this capacity building as crucial in order for the project to achieve self-sufficiency and to move beyond the resources and capabilities that were open to it in its current form:

[If the community can] address issues of climate, issues of livelihoods, issues of social development, then for us that would be the most critical input that we could have made. Because it will have acquired its own life, it will be able to even draw in its own resources, and even engage local structures and secure inputs that we as an organization may never be able to give to that group.

Thus, the donor organization saw its main function as initiating not a single project, but a process of capacity building that could enable the community to further its goals in a variety of areas.

The JIEP coordinator summarized the project's rationale by casting its aims in both local and global terms, saying:

This project is based in Mpeketoni, but it is a global project because we are working on a global issue, and we are tackling climate change head on. Most people just talk about climate change. They read about climate change and they argue about climate change, but they have not seen its effects. We are the sufferers... We are the ones who know its effects, and we challenge [the world] to support us to do two things: grow and produce more clean energy, and establish clean energy industries at the local level.

Here the speaker appeals for international cooperation and implies that countries with means have a responsibility to assist those who are most affected by the effects of climate 
change. He also expresses hope that in taking such a course of action, diverse actors can achieve goals at multiple scales.

The Mpeketoni project enjoys considerable support from NCA in terms of capacity building and finances, and the donor organization has shown responsiveness to farmers' priorities. These features place the project in a position to demonstrate the best that is possible from such an attempt to organize farmers in Kenya to grow Jatropha for local processing and use. How the project handles the challenges of achieving good yields of Jatropha, developing and executing a focused business plan, and making the transition to a self-sufficient enterprise will be instructive for others who are considering or already working with Jatropha on small farms. This case shows how donors, local coordinators and farmers have attempted to leverage the same resources to satisfy different objectives through a particular project. These actors have to varying extents adopted each other's language in discussing the project and its potential to address a variety of problems, demonstrating the creative flexibility associated with multiple discourses of development.

\section{CHAPTER SYNTHESIS}

This chapter has explored the question, How do the goals and motivations of key actors relate to development discourses? in ways that cut across the themes of development and scale. In terms of the history of top-down, cash crop introductions in Kenya, Jatropha stands out because it has been introduced not as an economic development strategy linked to existing demand for a product, but as an agent of multiple objectives spanning multiple scales. Globally, actors interviewed for this research identified Jatropha as a 
response to climate politics and the performance of oil on world markets; nationally, as a means of reducing imports and alleviating poverty; and locally, as a way to promote rural electrification and household-level energy sufficiency. These varied expectations for Jatropha speak to coexisting discourses of development (Grillo 1997): one broadly market-oriented, another community-based. These broadly match the market-based and ecoagriculture discourses attached to biofuels that were discussed in Chapter 3.

Is there a dominant discourse of development attached to Jatropha in Kenya? Unlike some situations where it appears that one such discourse has achieved dominant or hegemonic status (e.g. ethanol in Brazil, as described by Hall et al. 2008), I argue that in Kenya, these two discourses of development have persisted in relation to the promotion of Jatropha with neither one achieving a dominant position. Several actors expressed a preference for concentrating on a national market for biodiesel rather than exporting, but at the same time, some remained committed to pursuing both discourses at once, or felt that they were mutually dependent for success.

This simultaneous advancement of two discourses occurs in a manner consistent with the "duality of discourse" described by Hilhorst (2001), where a coexistence of discourses is characterized by competition between perspectives as well as a flexibility that allows actors to pursue different ends using the same means. As a biofuel, Jatropha's multiplicity of aims also encourages the involvement of energy and environment actors in addition to agriculture and development ones. This combination of diverse agendas and actors creates some deep tensions and uncertainties that are manifested through allegations of exclusion and exploitation. The struggle to control the discourse surrounding Jatropha represents a form of power - power to influence biofuel policies 
and project funding as well as public perceptions. However, the coexistence of discourses also grants actors a degree of manoeuvrability (Hilhorst 2001) to invoke Jatropha as a means to achieve a variety of (not necessarily compatible) ends.

In response to the question, Who has benefited from Jatropha and how?, interviewees responded very differently in relation to the national and Mpeketoni situations. Nationally, several actors from different sectors said that particular NGOs had benefited the most, largely because of the financial support they had received to pursue Jatropha-related projects. In Mpeketoni, the majority of those interviewed believed that everyone involved in the project would benefit, though the project was still at too early a stage for these benefits to be realized.

The Jatropha Integrated Energy Project in Mpeketoni provides a case of multiple actors working to apply the same set of resources to a variety of goals, showing how farmers' priorities for development compared to those of other actors. Different actors initially approached the project with fundamentally different initial motivations: climate change mitigation by offsetting carbon emissions provided a major motivation for the donors, while community leaders focused on the potential to add value to agricultural activities already taking place in the area. Farmers largely focused on household-level benefits such as using Jatropha oil for lighting, or earning some income from producing it. Farmers ultimately adopted a pragmatic approach to Jatropha, stating that like any other crop, if it did not bring benefits, they would discontinue it. The project exposed tensions between goals that were directed at different scales. Global climate change debates turned out to be less than completely compatible with local development initiatives, in the sense that climate change mitigation objectives relied on reducing 
emissions from energy overuse, while at the local level, project participants wanted access to more energy to do more things.

Despite these differences, the achievement of all of their goals depends on the same outcomes: Jatropha must grow and produce useful yields; the seeds must be processed into oil; and the means of using this oil for household or value addition purposes must be put into place. As Tsing $(2005,13)$ notes: "There is no reason to assume that collaborators share common goals. In transnational collaborations, overlapping but discrepant forms of cosmopolitanism may inform contributors, allowing them to converse - but across difference." In this case, the mutual learning that all three groups expressed suggests that each had heard, and to some degree taken up, the others' priorities through such a conversation across difference. This opens the possibility that in Mpeketoni, international resources that were allocated for one set of goals could be mobilized in a way that also meets others.

The power relations characterizing the enrolment of small-scale farmers in the Mpeketoni project were conditioned by their ability to free up the land, labour, expenses and/or foregone income required to participate. Some felt that their involvement had been hampered by their location, in that they felt far away from the project's main hub and not well connected to it. Clearly, NCA had considerable power in determining the course of the project due to its provision of financial and capacity building resources, although it showed willingness to share - and ideally, transfer - this power in two ways: first, by modifying its plans based on the outcome of community consultations; and second, by working toward a transition where the local project leadership would manage its money, create its own business plan and function as an organization without NCA's help. In these 
ways, the project also provides two examples of powerful actors enabling participatory decision-making.

This chapter has identified and compared multiple discourses of development that different actors have attached to Jatropha, both at the national level and in relation to one specific project. These discourses correspond with perceived benefits in a variety of domains and scales. The theme of control over the production and dissemination of information as a form of power to influence policy formation, funding, and participation in Jatropha-related activities has emerged in this chapter. Chapter 7 will scrutinize in more detail the relationship between the state of information, economic influences, and farmer expectations of Jatropha as an economic activity. 


\section{CHAPTER 7: JATROPHA'S ECONOMY OF APPEARANCES}

Chapter 6 argued that the promotion of Jatropha in Kenya was influenced by a plurality of motivations or agendas linked to fundamentally different discourses of development. This chapter explores the role that the state of information and political economy of knowledge surrounding Jatropha have contributed to its relatively widespread endorsement and rapid promotion in Kenya. The chapter begins by presenting key informants' views on the availability and quality of information about Jatropha and how these have changed over time, and identifies some power issues related to the ability to control information. It then explores the ways in which research participants drew on experiences with other crops in order to help interpret and explain various features of Jatropha, asking to what extent this particular form of knowledge influenced actors' perceptions of the crop. The discussion then considers whether the patterns of information and knowledge that emerge match with Anna Tsing's concept of an "economy of appearances." Case study insights from Nguruman, Rift Valley Province introduce farmer perceptions and expectations of Jatropha, providing an opportunity to explore the interactions between empirical and theoretical perspectives on information, knowledge and a "boom" of interest in Jatropha.

\section{STATE OF INFORMATION ABOUT JATROPHA IN KENYA}

As discussed in Chapter 4, a wide variety of documents and media reports have provided different perspectives on Jatropha over the past several years, ranging in their outlook from staunchly optimistic to cautious and even dismissive. Early in the research process, I decided that in order to understand how and why Jatropha had been promoted in Kenya, 
it was crucial to discuss with participants how they had formed their impressions of Jatropha and whether these had changed over time. Because these perceptions formed the basis upon which actors made their decisions about whether and how to engage with Jatropha, it was important to understand what sources and types of information had proved most influential. I asked research participants how they were first exposed to Jatropha, what sources of information they drew on in deciding whether or not to become involved with it, and how they perceived the quality of available information about Jatropha. Two themes emerged from this line of questioning. Specifically, interviewees felt: that there were many gaps and half-truths in the existing literature and media coverage on Jatropha; and that several barriers inhibited the free circulation of information. Strategies for filling information gaps included: drawing on knowledge and experiences from other settings; advocating a cautious approach to promoting Jatropha until more research could be conducted; and proceeding with a trial-and-error approach to agricultural development. Each of these topics is discussed in turn.

\section{Gaps and weaknesses in knowledge}

A wide range of actors pointed out problems with the state of information about Jatropha. NGO, government, private sector, and research representatives alike described significant gaps in understanding about the crop even as it was being promoted to farmers. Several attributed this lack of knowledge to Jatropha's newness in Kenya. For example, one NGO representative explained, "We don't have improved varieties. We are still talking of a variety in the wild; Jatropha has not been domesticated. And yet, investors and even the development people are promoting it as, I would say, as a 
business, an agrobusiness" (NGO2). A government representative (GO2) concurred, saying, "[Jatropha] is actually new to us. In a sense they have been treated as wild plants growing in the bush. So... which are the right varieties to plant? Which are the agronomic packages that go with these crops? Which we don't have." Others echoed the point that not enough was known about how to grow Jatropha in the Kenyan setting, pointing out specific knowledge gaps related to intercropping (GO3) as well as pests and diseases (RS2). Some actors (e.g. RS4) described how a lack of understanding of Jatropha on the part of farmers who tried to grow it was directly connected to the crop's unpromising early results.

In addition to an absence of information, interviewees had many things to say about the poor quality of existing information about Jatropha, whether it was presented in the form of scientific or media reports. These observations applied to information about Kenya as well as other countries. One (PS3) observed:

What did you find two years ago? You found some experience from India, and then even you had to dig in the information to start knowing, say, what the planting distance is, which is a fundamental fact. ... Then they were saying, this is the yield, et cetera. There was not a single correlation with the local ecology - that was not very useful. And watering, what can you say about watering? They say on an Indian website they water so many litres per week. So what? What is the site? Where is it? What is the evaporation? What is the soil texture? You don't know anything about that... I rarely find a real, scientific article on the internet which gives all the information you need to apply it here.

Another said more simply, "Most of the figures that you see on the website, they are not the type of true figures and it's unfortunate" (NGO7). These comments suggest that, in the years preceding these interviews in 2009 , there was a serious dearth of information about how to effectively grow Jatropha in general, and an even smaller body of information about growing it in Kenya in particular. Actors who worked with Jatropha in 
Kenya during this period used a variety of strategies to fill (or work around) these knowledge gaps, as discussed later in this chapter. First, it is important to discuss interviewees' perspectives on factors that affected the circulation of both information and misinformation about Jatropha.

\section{Access to knowledge}

Different people had different levels of access to information, while various barriers appeared to impede the free circulation of knowledge about Jatropha in Kenya. To begin with, one private sector actor (PS1) pointed out that farmers faced barriers in accessing information held by the few individuals who had experience with Jatropha: "If a smallscale farmer wanted to produce Jatropha and wanted my knowledge from my technical backstopping, they could not afford to pay me as a consultant. So that means there is a gap." This same actor went on to say that studies had been done on Jatropha in Kenya as long ago as the 1980s, but alleged that their findings were not shared, speculating that the desire to secure patents was a possible motivation for secrecy in agronomic research:

People want to patent these varieties. And whoever gets the patent and will be the owner of the seeds, you can imagine, that will be another Monsanto or Syngenta or Dupont. That will be another multinational... People are looking at how they will make money. So that pulls everybody towards Jatropha, and there is a big rush.

Of course, not all research on Jatropha could lead to patents. Nonetheless, some actors expressed doubt that all Jatropha researchers in Kenya were fully prepared to share their findings with others, for example saying, "I've never felt like [those particular researchers] were interested in playing in the sandbox with others" (RS1), or that institutions that were engaged in research "should avail their results" (DN2). Whether or 
not these misgivings were founded, their existence speaks to a climate of unease with regard to information sharing.

As described in Chapter 6, at a research workshop in Nairobi in June 2009 some NGO actors sought to suppress the dissemination of research findings that challenged the discourse of Jatropha as an economically viable cash crop. While this may have been an isolated incident, it showed reluctance on the part of some NGO representatives to adopt new information that was incompatible with their ongoing activities. The vehemence with which one actor in particular spoke out against sharing the results with farmers signalled that the research conclusions were perceived as a serious threat. By defending existing, optimistic messages about Jatropha's potential and suppressing new, critical messages about it, this actor also made an important, though unspoken, statement about the importance of influencing the discourse about Jatropha.

Some actors spoke of problems related to a lack of consolidation of knowledge. One (RS1) described how research efforts were being duplicated, stating that "a lot of people [are] doing the exact same thing in different areas not even knowing that somebody's doing it somewhere else." Another (NGO7) agreed: "The problem also you find is that people on one side, they don't know what the other is doing on the left. Consolidation of all information is not being done... Whether it is deliberate or not, it is something that of course is a missing link." A third (RS4) said that the packaging and delivery of credible information about Jatropha in Kenya needed to improve.

Although research efforts were beginning to be coordinated through the Research Subcommittee of the National Biofuels Committee (introduced in Chapter 5), these comments suggest that much remained to be done in order to bring together research 
findings and practical experiences with Jatropha in Kenya in order to create a more unified, reliable set of information that could be available to a wider range of users. Insufficient coordination of existing research, whether by accident or design, created one barrier to the circulation of existing knowledge, while lack of contact between farmers and 'experts' presented another.

\section{Misinformation}

The gaps in knowledge about Jatropha described above appear to have created conditions of uncertainty where it was possible for inaccurate or wrong information to be spread. A few actors explicitly described how misinformation about Jatropha had been circulated, for example: "There's been complete misinformation in newspapers about the expectations, and there's been misinformation from government... talking about huge schemes and enormous yields" (PS2). Another (PS5) objected to the estimates of seed yields that some of Jatropha's promoters had circulated, saying, "You can't compare a 50-year-old Jatropha tree that's marking a grave in Arusha producing $10 \mathrm{~kg}$ to a plantation of 50,000 hectares. You can't extrapolate like that," and continuing, "I think most of the people who blow it out of proportion don't have the facts and ... they haven't really experienced it on the ground."

In some cases, actors reported that misinformation had resulted in negative impacts on farmers; for example, in reference to a particular project, one NGO representative (NGO6) stated that farmers had uprooted their bananas to plant Jatropha based on bad information and were now disappointed. Another (NGO7) agreed that the dissemination of incorrect information had caused problems, saying: "The biggest thing 
that has been lacking is just education. People don't know, and the wrong information that was given to them was taken like bible truth."

As mentioned in Chapter 5, some blamed the media for disseminating misinformation (RS4, NGO7) and one even expressed a desire to start their own radio and TV stations in order to "give the right information." However, one actor (NGO4) blamed farmers themselves for spreading misinformation about Jatropha, recounting an incident in which a farmer insisted on planting Jatropha seeds in an unsuitable part of the country against the actor's advice. When his seedlings fared poorly, according to the actor, the farmer "sent a very bad word, [that] these things are not viable." The point of the anecdote was that two kinds of faulty information had been spread: first, the misguided idea that Jatropha could grow anywhere (though the actor did not indicate how the farmer might have been exposed to that idea); and second, the counter-idea that Jatropha was not viable at all, based on a failed attempt to grow it under unsuitable conditions. These combined statements show that NGO, private sector and research actors all identified problems with the distribution of inaccurate information, with tangible outcomes for farmers who applied it.

\section{Filling knowledge gaps I: Importing exogenous knowledge}

An obvious way to fill knowledge gaps about Jatropha in Kenya would be to conduct incountry research and consolidate the experiences of farmers who had already grown Jatropha. In addition to the reports on Jatropha specifically in Kenya that already existed at the time of these interviews (Ng'ethe 2007; Tomomatsu and Swallow 2007; Government of Kenya and GTZ 2008; Muok and Källbäck 2008), others followed soon 
afterwards (GTZ 2009; Boerstler 2010), while further research was underway. In the meantime, one of the ways in which actors sought to fill gaps in existing knowledge about Jatropha in Kenya was to import information from other places. Interviewees acknowledged that much of the early information about Jatropha that was disseminated in Kenya at the time of this research had been drawn from experiences in other countries, producing mixed results.

Several interviewees spoke of potential benefits that could be gained by importing knowledge from other settings. For example, some felt it would be more efficient to learn from others' research efforts than to duplicate them. One spoke of opportunities to collaborate with researchers in other countries who were developing new varieties of Jatropha (PS5). A researcher (RS3) expressed similar views, saying that subscribing to journals and learning from experiences in other countries would save a great deal of time: "if we do not use this information we'll basically be trying to do things which other people have; it will be inventing the wheel. Why not just catch the wave the way it is?"

Others pointed out that applying knowledge from other settings often led to dissimilar results. Comments to this effect included: "We never researched Jatropha in the Kenyan situation, instead drawing knowledge from Brazil which is much rainier than Kenya" (NGO1), and "We read a lot about [Jatropha] for other countries, but the local experience is not well documented" (GO1). Several described problems that had arisen from trying to directly apply knowledge from other settings. For example, one private sector actor (PS4) described a specific incident where following advice from a colleague in India led to poor germination rates, until they realized that differences in climatic 
conditions between the two countries meant that the advice had to be modified before it could work. Another actor (RS4) summarized the situation by saying:

You go to the internet, you'll find a lot of information about success stories say in Indonesia, in India and other countries, and so I think [Kenya] might have just borrowed the stories without following the proper systems of introducing new crops whereby you must have certified seeds, you really need to know how to grow it, and all that kind of information was lacking.

One (NGO4) framed the need to adopt knowledge from other countries in terms of limitations in the Kenyan education system. Pointing out that Jatropha was not part of the curriculum, this actor commented that "even the researchers, they are permanently surprised [by Jatropha] because they were not schooled for it," and went on to assert that "maybe for biodiesel people are going overseas for training." These comments imply that this actor felt it was more useful to pursue training on Jatropha outside rather than inside Kenya. However, this same NGO representative also protested that local knowledge was regarded as inferior to knowledge from outside the country, saying: "There is indigenous knowledge [about Jatropha], and that indigenous knowledge is downplayed, such that it looks like a very sophisticated crop that has come from somewhere, that is Portuguese, Orient or something, when for us there's actually a lot of material on the ground at the farmer level" (NGO4). While lamenting this apparent privileging of foreign knowledge over indigenous knowledge, the same actor went on to say: "Even the mamas at home, they know Jatropha. They say, ah, this one! This is just that wild weed we know. But what it can do for them, how it can do anything for their lives, they don't see it." While acknowledging that farmers were already familiar with Jatropha, this actor saw their experience with it as an energy crop as limited and in need of enlightenment from those with outside knowledge. 
Together, these comments suggest that applying knowledge that was gained through research efforts in other countries could, under different circumstances, both accelerate and impede an understanding of how to grow Jatropha effectively in Kenya. Interviewees stated that filling knowledge gaps with experiences from elsewhere could save some of the time and resources it would take to conduct new research, but the comments presented here also raise significant questions about the applicability of this knowledge to the Kenyan setting. This dual - and potentially conflicting - role played by exogenous knowledge was further mediated by issues related to access to knowledge.

\section{Filling knowledge gaps II: Parallels to other crops}

A second way in which actors sought to fill knowledge gaps was by drawing comparisons between Jatropha and other crops that had been introduced to Kenya in the past. Individuals drew on experiences with these other crops, particularly cash crops, to interpret events related to Jatropha, draw strategic insights, and predict what kind of trajectory its future might follow. This section explores both favourable and unfavourable views of Jatropha that actors expressed by comparing it to other crops, and reflects on the role that these comparisons may have played in influencing discourse about Jatropha.

\section{Similarities between Jatropha and other crops}

One of the most frequently mentioned similarities to other crops was simply Jatropha's newness. Interviewees cited coffee and tea as examples of other crops that started slowly, faced skepticism at first, and took time to research and develop, but eventually became 
economically important (NGO2, MCO1). One (PS3) described the painstaking process of developing a new crop:

Jatropha still has the potential to be something... It will just grow slowly. Do you think coffee was just there in one day? Do you know how it started in the beginning of the last century? And now it is there, and still there's coffee institutes that do research - it is very much established, with different strains, with improvement programs, and there was no breakthrough. It was just steady work.

This interviewee refers to the slow growth of the coffee industry in Kenya, which took over 15 years to progress from its introduction by missionaries around 1894 to the point where it was considered a major export crop - and several more decades before it was widely cultivated by smallholders (Waters 1972). On the theme of the "steady work" required to develop a new crop to this level, one NGO representative (NGO2) expressed the view that as an organization, specializing in one crop (Jatropha) instead of working with several at a time could help Jatropha to develop into an "industrial crop" like coffee, tea, wheat, maize, cassava, or sugar cane.

Others pointed out that as a cash crop, not a food crop, Jatropha (like coffee, aloe, vanilla, or Artemisia) needed to be seen in terms of its ability to generate income for farmers to enable them to buy other products (RS3). One stated that like these other crops, Jatropha could potentially enhance food security by improving households' economic access to food (GO2). A farmer in Nguruman (NG 17) said that like coconut or a cow, Jatropha could yield many products or benefits from one thing.

One NGO representative described the struggle to overcome a negative perception that Jatropha would prove to be like mathenge, a shrub that was introduced to arid and semi-arid parts of the country to help control soil erosion but turned out to be highly invasive, with negative impacts on both people and animals (NGO3). This actor cited fear 
of the unknown as the reason why people might make an association between Jatropha and mathenge.

Several actors expressed ideas about which strategies for growing Jatropha would likely work best by drawing on experiences with other crops. Specifically, several described how they pictured smallholder farmers producing Jatropha as part of a system where a centrally owned and managed nucleus plantation ${ }^{29}$ would be surrounded by a network of outgrowers - the same model seen in the sugar, coffee and tea industries (GO2). One described the existence of such a system for these other crops as evidence that small- and large-scale Jatropha production could coexist (NGO5). Another held up the examples of coffee and tea as reasons to believe that small-scale farmers would play an important role in any future Jatropha activities, saying, "any cash crop that liberated Kenya has been done through smallholders" (NGO4).

One private sector interviewee (PS3) expressed confidence that small-scale farmers, such as coffee farmers, tended to experiment with new crops on only a part of their farms, seeing it as unlikely that farmers would convert their entire farm to a new crop and stop growing others. However, another (GO3) expressed concern that sugar cane farmers had pulled up other crops to plant sugar, seeing this as a reason why Jatropha would need to be carefully managed through policies to avoid this outcome. One NGO representative (NGO2) stated that like coffee and tea, Jatropha would probably grow best if intercropped - even though nucleus plantations for these crops were completely monoculture in character.

\footnotetext{
${ }^{29}$ A nucleus plantation is a large, central plantation of a cash crop managed by a company, generally surrounded by a network of smallholder or "outgrower" farms growing the same crop on much smaller pieces of land under contract for the company.
} 


\section{Past experiences with cash crop introductions}

Interviewees drew on a darker series of examples to express uncertainty or scepticism about whether a market for Jatropha would develop in a way that would benefit growers. One NGO representative (NGO8) described how coffee and cotton experienced similar waves of enthusiasm, but at some point prices fell dramatically, even though a market for those products continued to exist. Others (RS1, RS4, NGO3) cited negative experiences with castor - another oilseed crop - where farmers produced seeds only to find there was no market. One described castor and cotton as cases where "people came in; they said, 'oh! Plant! Plant! Plant!' After telling you that 'you plant, we are going to come' - they disappear. The farmer has suffered so much in the cotton industry, in castor" (NGO3). This actor saw this as an instructive story showing what mistakes to avoid repeating with Jatropha.

Another (RS4) reflected on jojoba and castor, saying they were both introduced without any organization, before a value chain or market were developed, with the result that: "famers suffer; they burn their fingers; they lose money; they lose time." This interviewee pointed out that for jojoba in particular, a market never developed, and expressed concern that the same could happen with Jatropha. Finally, a researcher (RS1) expressed that the mismanagement of other crops in Kenya's past such as sugar cane, castor, and coconut did not bode well for Jatropha, saying: "[The managers] take a resource that has a value and they run it into the ground, time and time again."

Specific experiences in Mpeketoni reinforced these examples. Mpeketoni farmers

recounted several cases where "other new plants have been introduced here but lacked markets to sell" (MF 27). For example, "people have been told to plant certain things, 
like bixa and cashews. The prices were good at first, then dropped. They are told the market is like that and there's no negotiating. That's why people here aren't embracing Jatropha - they've been hurt before" (MF 19). One farmer's main worry about Jatropha was that a negative pattern had occurred before: "If brokers will come into the business it will spoil the price control. First they'll come with a high price, then disappear. The farmer will be hopeless and useless" (MF 21). Another (MF 16) echoed these sentiments, saying that with cotton and bixa, middlemen had benefited and farmers had not:

Middlemen come in and control the market. They come between the farmer and buyer and overshadow the buyer. There is a lot of exploitation which causes people to have very little or no hope. You put in so much, and most of your sweat goes to someone who has done nothing. The brokers just sit in town, communicate with people in Nairobi and pack lorries. That's why people have given up on cotton; with bixa it's the same.

Extending this example, one farmer stated that it was crucial to have a Jatropha processing machine locally, or else they risked encountering the same problem they had with bixa (MF 15).

Overall, Mpeketoni farmers stated that crops that bring money were welcome (MF9), but if Jatropha did not bring a good price, they would discontinue it just as they had discontinued cotton growing (MF15). Past experiences had produced a series of cautionary lessons on the risks of experimenting with a new crop. More positively, one farmer in Mpeketoni (MF 18) cited chilies a counterexample of a crop that had been successfully introduced to the area and well-managed by an individual who was wellrespected. 


\section{Unique aspects of Jatropha}

As for features that interviewees saw as being unique or clearly different from other introduced crops, one (GO3) stated that no other crop in Kenya had generated the same kind of early enthusiasm as Jatropha, because of the climate change element associated with interest in Jatropha. Another (PS2) said that unlike other cash crops, the market for fuel was enormous, with the result that even a large increase in production would not be able to flood the market and depress prices. In other words, producers would not be vulnerable to a sudden drop in commodity prices. Even if the price did fall, this actor described how farmers could still benefit by using Jatropha oil for fuel at the domestic level, in contrast to perishable cash crops such as mangoes, which farmers could not consume if they were unable to sell. Thus, some actors felt that the fact that Jatropha represented both an agricultural commodity and a fuel source set it apart from other cash crops, both in terms of the kind of interest that it generated and the likelihood of its exposure to price fluctuations.

\section{Implications of parallels}

Actors supported optimistic as well as pessimistic points of view about Jatropha by drawing on past experiences with other crops. Those who believed that improved varieties of Jatropha could be steadily developed through research and plant breeding bolstered this claim by referring to gradual improvement in the coffee and tea industries over the course of decades. In turn, those who feared that a market for Jatropha might fall through and leave farmers with "burned fingers" likewise presented their case by revisiting experiences with cotton, castor, bixa and other cash crops whose prices had 
dropped at various points in time. The choice of particular other crops - as well as specific aspects of the history of those crops - as a basis of comparison had the effect of guiding discourse on Jatropha. Statements such as "Jatropha is like coffee," "it could turn out like cotton," or, "it's not like mathenge" served as conceptual shortcuts that could quickly communicate a whole set of meanings, implications and emotions to others. While individuals' experiences with other crops clearly influenced their perceptions of Jatropha, given the lack of domestic experience and the murky quality of information that was available about Jatropha at the time, it was also possible for actors to selectively draw on historical examples to support their opinions about Jatropha, and perhaps persuade others to see it in a similar way.

\section{Implications of the state of information}

The preceding sections have illustrated a variety of deficiencies that interviewees identified in the state of information about Jatropha in 2009, as well as strategies for filling or working around these gaps. Several informants described changes in their own understandings of Jatropha, or expressed increasingly cautious views about promoting it directly as a result of these deficiencies. One explained that initially, "People were very excited that we can get diesel and drive a vehicle using seeds from a tree. So there was that excitement, all the excitement. But I think people are now realizing that they need more information" (RS4). Along similar lines, an NGO representative spoke of changing their tactics due to limited knowledge: "We would have said yesterday or last year, just grow it - you will get a buyer. Or, just install the equipment - you will get seeds. This has changed. We must face realities in quite a number of areas" (NGO2). A private sector 
actor affirmed the view that more emphasis needed to be placed on providing highquality information to farmers: "The harm being done by overly promoting, enthusiastically maybe, but knowingly over-promoting the crop has been done, and now it's about being realistic, not just optimistic, in giving the farmers accurate information and the media accurate information" (PS2). All of these remarks speak to a cooling of enthusiasm over Jatropha linked to gaps in knowledge.

Some interviewees spoke even more strongly about what they saw as a need to pause and re-evaluate the wisdom of promoting Jatropha in Kenya in light of information deficiencies. One researcher (RS1) stated that distorted perceptions had strongly influenced Jatropha activities in the country, but that this was beginning to change: "I think people are starting to realize that the reality and the hype are much different from each other, and farmers are becoming disenchanted." This actor went on express hope that people would start to consider a broader set of options and evaluate them objectively, rather than adopting what he saw as a "skewed reflection of reality" offered by overly positive messages about Jatropha.

Another interviewee (DN1) explained how farmer experiences had cast doubt on claims from various sources about Jatropha's potential:

You never could quite put your finger on, what is the actual performance of Jatropha curcas? ... As soon as we started trying it, started planting it and getting a bit more research on it, and getting more feedback from the farmers, it became increasingly clear that it may not be that wonder crop that people present it to be. And for sure we have our own reservations about whether Jatropha can work as a plantation crop.

Finally, a private sector actor (PS4) summarized a cautious position in light of the prevailing state of information about Jatropha: "We've got no idea about a lot of things.

So to go large scale right now, even frankly to give this out to smallholders to say, 'here's 
something that will really benefit you,' I couldn't do that right now." Together, these comments represent a tempering of enthusiasm about Jatropha among several key actors, linked to their recognition that insufficient knowledge and experience with the crop could produce unwanted outcomes.

Despite these cautious words, some actors expressed that enough was known about Jatropha to continue promoting it, and that it would be both possible and productive to learn from trial and error. One (NGO2) strongly endorsed such an approach, saying "let us make mistakes," and continuing: "I am an advocator that we should start growing it despite the problems. We solve those problems along the way." An NGO representative (NGO7) used stronger words to dismiss critics of Jatropha projects, saying:

We are just yapping and not getting anywhere. People are still saying, "oh! You are misleading, oh! You are doing this, oh! This thing is not viable." What is not viable if an airplane has been flown on this oil? And there is land that is available and there are people whom you can create work for them to participate in? I think I can use hard language, let me just say it is doable and we should not be wasting time. We should just be going ahead.

Thus, while some actors advocated slowing down or holding off on Jatropha activities until knowledge about the crop had a chance to catch up, others favoured a trial-and-error approach.

The continued coexistence of these differing perspectives on how to proceed with Jatropha under circumstances of limited knowledge highlights the importance of how discourses are presented and controlled. As introduced in Chapter 2, Vivian's (1994) assertion that NGOs have an interest in overstating success and downplaying failure in order to keep funders interested and maintain their activities is corroborated by some, 
though not all, of the perspectives presented above. The suppression of dissenting research findings and the optimistic endorsement of a trial-and-error approach by some NGO actors appear to be consistent with this view, while those who adopted a more cautious stance in response to growing concern over inadequate knowledge provide counter-examples.

Research on Jatropha in India provides further insight on the topic of how discursive framing can translate into concrete outcomes for farmers. Ariza-Montobbio et al. (2010) conclude that the discourses through which Jatropha was promoted, namely as a 'pro-poor' and 'pro-wasteland' crop, ultimately encouraged patterns of activity that actually reinforced existing patterns of marginalization. In other words, the invocation of particular discourses led to real - and in that case, negative - outcomes for small-scale farmers. A detailed consideration of Anna Tsing's (2000) concept of an "economy of appearances," followed by insights from a case study in Nguruman, provide opportunities to further explore the links between the ability to influence access to information, discourses, and Jatropha activities in Kenya.

\section{JATROPHA AND THE "ECONOMY OF APPEARANCES"}

One of the questions guiding this research is, How did Jatropha come to be promoted as it has been in Kenya? Given the lack of domestic experience with growing Jatropha as a biofuel and the uncertain state of information about it that this chapter has demonstrated, it is not obvious how or why investment in Jatropha in Kenya got very far off the ground. Here, literature on other start-up enterprises can provide some illumination. 
In analyzing the Bre-X mining debacle in Indonesia, Anna Tsing (2000) develops the useful concept of an "economy of appearances." She describes how the Bre-X mining company drew on "myth," "mystery," "drama" and "spectacle" in order to perpetuate a belief that it had discovered large deposits of gold in an area where there was in fact none. The company managed to attract significant investment despite using falsified geological samples. In other words, Bre-X succeeded in constructing a discourse - in this case, a completely fictitious one - of its own potential that was taken up by investors and in turn built further momentum for the company's activities. Reflecting on this case, Tsing writes (2000, p. 118):

The self-conscious making of a spectacle is a necessary aid to gathering investment funds. The dependence on spectacle is not peculiar to Bre-X and other mining scams: It is a regular feature of the search for financial capital. Start-up companies must dramatize their dreams in order to attract the capital they need to operate and expand ... In speculative enterprises, profit must be imagined before it can be extracted; the possibility of economic performance must be conjured like a spirit to draw an audience of potential investors. The more spectacular the conjuring, the more possible an investment frenzy.

The point of Tsing's analysis is not that Bre-X conducted fraudulent business activities; rather, her work helps to explain how start-ups build momentum. The Bre-X example simply isolates and accentuates the role played by discourse and "spectacle" in attracting investment because in this case the company had no other assets to promote. Her insights are equally applicable to legitimate business enterprises and that is the context in which I consider them here.

Although Jatropha's promotion in Kenya appeared to be driven more by donor than investor funding, these observations are still highly relevant. As discussed in Chapter 4 and above, the combination of media coverage, promotional reports, and 
optimistic speculation about Jatropha's performance in its early days as a biofuel crop, both internationally and within Kenya, created a "buzz" that attracted donor, NGO, government and private sector interest. To some extent, in Kenya these messages became mutually reinforcing - for example, through the embedding of NGO perspectives in the policy development process by way of the National Biofuels Committee. Whether wellintentioned or not, behaviour such as suppressing dissent (as seen at the National Biodiesel Workshop), or planning to start a new radio station in order to have more control over the public messaging about Jatropha, seem to be consistent with the kind of "conjuring" Tsing describes. NGOs that were heavily involved in promoting Jatropha had an interest in keeping up appearances that the crop could help to achieve development objectives; as mentioned in Chapter 6, some organizations' revenue streams came to depend on spreading Jatropha more than on actually achieving the goals Jatropha was supposed to make possible. In particular, the lack of a market for Jatropha in Kenya at the time of research contributed to the impression that the triumphant discourse of Jatropha's potential, intermittently presented in the media and by Jatropha's major promoters, resembled an illusion.

Tsing observes that in junior mining companies, geologists have to also act as promoters in order to get funds to continue their work, and stock analysts are supposed to understand geology well enough to evaluate mining companies' claims. In other words, individuals who are trained in geology, finance, or marketing are expected to practice a mixing of roles. She reports that an Indonesian official said this situation created a "stock market rush" rather than an actual "gold rush" in relation to Bre-X. This observation coincides with several of the interviewees' comments about Jatropha described above - 
particularly those who alleged that some of Jatropha's promoters talked about the plant as though they were seed scientists or agronomists, when they lacked the technical knowledge and experience needed to substantiate such a position. Here my analysis aligns with Tsing's: in both cases, under the uncertain conditions that surrounded a new venture, it appears that the promotion of a product was disconnected from technical knowledge. In the case of Jatropha, this knowledge may not have existed, while in the case of Bre-X, it was intentionally fabricated.

For Tsing, the Bre-X story also provides lessons about the social construction of scale. She writes that projects (or "conjurings") that are portrayed as 'global' have a better chance of succeeding if they become tied up with goals at other scales: "It seems likely that successfully conjuring the globe is possible, at least now, only in thick collaboration with regional and national conjurings; certainly financial conjuring has been deeply implicated in promises of making regional and national dreams come true" (2000, p. 121). This observation also resonates with the case of Jatropha in Kenya, even though it was not promoted using the same kind of "financial conjuring" as Bre-X used to create an illusion of gold. As shown in chapter 6, global stories about climate change and clean energy were rolled together with national (government) objectives around import substitution, poverty alleviation and agricultural development; meanwhile, 'local'focused institutions embraced the potential for Jatropha to create rural economic opportunities and livelihood benefits. One could argue these different stories represented 'conjurings' at different scales, with their coexistence and convergence strengthening the overall case for Jatropha. 
Some of the patterns that emerge from the early days of Jatropha's promotion as a biofuel in Kenya thus have much in common with the pattern that Tsing describes: building up an optimistic discourse by communicating, repeating and adopting positive messages, whether or not those who were involved realized that these were only part of the story; guarding (or suspecting that others were guarding) information; and challenging or suppressing dissenting information or views. Certainly Tsing's language about drama and spectacle is consistent with fantastic claims that appeared in the media (e.g. Jatropha as a "trophy tree" or "green gold" - see Chapter 4). The successful attraction of funds that Tsing describes resonates with the "virtual deluge of foreign investment" in Jatropha that Caniëls and Romjin (2010) reported in Tanzania. On the other hand, the Kenyan government appeared to be trying to facilitate an open dialogue about the potential risks as well as challenges of Jatropha, and the national newspapers ran both positive and negative stories.

An interesting question is the extent to which doubts and questions about Jatropha, documented in several vivid quotations earlier in this chapter as well as media reports discussed in Chapter 4 (e.g. "biofuel 'miracle' ruined Kenyan farmers"), reflect the emergence of an equally extreme counter-discourse about Jatropha. Could this negative discourse be interpreted as a spectacle of tragedy? If so, what motivations could be attached to this trend? The Bre-X saga in Indonesia ended abruptly when the simple truth that there was no gold came to light, and the company's story was exposed for what it was: a deliberate fabrication. There is no such simple ending for the story of Jatropha in Kenya. There are still signs of both initial euphoria and an emergent cynicism about Jatropha's potential, as well as intermediate positions such as those expressed in the 
quotations above in which interviewees expressed a desire to continue working with Jatropha and to learn gradually from making mistakes along the way. In the absence of definitive evidence about Jatropha's potential (or lack thereof), the discursive space remains open for continued jostling between these perspectives.

\section{INSIGHTS FROM NGURUMAN}

The second main question guiding this research is, How do the experiences of farmers growing Jatropha compare with the claims of its promoters? A case study of farmers' experiences with Jatropha in Nguruman, Kajiado District helps to approach this question in relation to the themes of information and discourses presented in this chapter. Whereas in Mpeketoni, farmers were part of a centrally organized Jatropha project with a deliberate institutional structure for disseminating information, farmers in Nguruman experienced a much more fluid and unregulated environment with respect to information and knowledge. This section examines how uncertain information, mixed messages, and patterns in the circulation of knowledge helped to shape farmers' perceptions of, and experiences with, Jatropha. In particular, it considers the ways in which the kind of 'jostling in the discursive space' just mentioned in relation to the economy of appearances translated into tangible influences such as price signals.

\section{Background}

The Nguruman area is located $45 \mathrm{~km}$ west of Magadi (Figure 7.1), centred around the towns of Entasopia and Ol Kiramatian. Main crops include maize, bananas, mango, apple mango, papaya and high-value horticulture crops such as tomatoes, chilli peppers, okra, 
eggplant and ravaiya (miniature eggplant). Most of the area's farmers grow a mixture of subsistence and cash crops.

Figure 7.1: Map showing Nguruman area (Aerospace Center (U.S.) 1969 (rev. 1994): Nguruman area added by author)

Residents include pastoralists (Maasai) and agriculturalists (mostly Kikuyu) who share a group ranch system of land ownership over 21,000 ha. Many long-term residents have assigned plots, while newcomers and migrant farmers lease land on contracts as short as 3 months. Migrant workers come from other parts of Kenya as well as from nearby northern Tanzania. Although the group ranch has 1,700 members (NG 14), only the chair of the group ranch has legal title to the land. This makes it difficult for landholders to access loans since they cannot use their land as collateral. Some farmers described how the group ranch owner and his family members controlled large holdings of the most productive land, while those who joined the group ranch later, including offspring of existing members, had been allocated increasingly distant and dry parcels of land. Those 
who were new to the area and leased land from others faced the possibility that they might never be awarded their own plot.

The area has year-round water sources that descend from the Nguruman Escarpment as part of the Ewaso Ngiro river catchment. The group ranch uses a basin irrigation system where water is directed through different canals according to days of the week. However, the surrounding area is semi-arid and places that are outside of the irrigation scheme experience seasonal water shortages. Crop-wildlife and crop-livestock conflicts intensify during the dry season. At very dry times of year, pastoralists are sometimes accused of bringing their cattle or goats to graze on irrigated crops. Although Rift Valley Province was strongly affected by post-election violence and upheaval in early 2008 , residents of Nguruman described the area as peaceful throughout that period. One man who was interviewed for this research had moved to the area to escape from violence elsewhere and make a new start.

The road infrastructure is poor, limiting access to agricultural markets. One resident described the region as "like an island" because it is surrounded by drylands and disconnected from the rest of the country (NG 18). As in Mpeketoni, farmers expressed frustration that middlemen (i.e. those with trucks who could transport their produce to markets) were able to dictate prices for these crops. However, they reported that efforts to unify the farmers to negotiate for better prices in the past had failed.

Communications infrastructure in Nguruman experienced significant expansion in recent years. The construction of a mobile phone network tower in the area greatly improved reception, while the installation of a solar-powered satellite system in early 2009, donated by an American university, provided fairly reliable Internet access at the 
Community Information Centre at the time of research.

Interviewees in Nguruman included 27 individuals. Of these, 14 were farmers growing some Jatropha who did not act as middle agents (buying Jatropha from others in the area and selling to outside buyers); six were middle agents (at least three of whom also grew Jatropha); two were local officers of the Ministry of Agriculture; two were managers of the Community Information Centre; two were involved in discussions about potential future Jatropha projects but were not growing, buying or selling the crop; and two were individuals who had collected Jatropha seeds to sell to middle buyers but did not grow their own plants. One of the middle buyers acted as a central contact who connected me with most of the other research participants. Most interviews were conducted in February-March 2009, with follow-up visits and further discussions in May and July 2009. On my final visit to Nguruman I also conducted informal conversations with shopkeepers who sold diesel or kerosene in order to learn about energy prices and consumption patterns in the area.

\section{Jatropha activities in Nguruman}

By 2009 Jatropha had already been growing in the area for several decades. Nearly all of the residents I interviewed had planted it as fencing, from the 1970s onward. It had also been used as a grave marker as well as medicinally to treat cuts. Growers reported that their plants produced seeds year-round if they were planted in places where they received weekly water from the basin irrigation system, for example fences lining the irrigation channel. Nguruman farmers reported very few pests or diseases on their Jatropha plants.

In about 2006, Nguruman began to attract interest as a source area for Jatropha 
seeds in Kenya. Numerous buyers visited the area to purchase seeds for research and planting in nurseries. Farmers were initially offered prices of up to $100 \mathrm{KSh} / \mathrm{kg}^{30}$, which stimulated their interest in Jatropha. Six had planted more Jatropha hoping to benefit financially from seed sales; two of these had begun to experiment by planting it in small plantation-style field plots, and another had established a nursery for Jatropha seedlings.

Six residents who were interviewed acted as middle agents, buying seeds from those who harvested or gathered them and selling these to outside buyers for up to 250 $\mathrm{KSh} / \mathrm{kg}$. In $2008-9$ the prices offered by these buyers reportedly fell as low as $10 \mathrm{KSh} / \mathrm{kg}$ and the number of buyers ordering seeds from the area had dropped. One of the middle agents in Nguruman (NG 8) described how price fluctuations first created high expectations among farmers, then lowered them: "People realized this was the centre for seeds in Kenya; many came here and the prices went high. They destroyed the market by giving people high prices. Now normal prices seem discouraging. Researchers had lots of money for short-term projects. As a result, the market was spoiled." Another (NG 10) had dealt with only a single buyer, whose price offer had remained constant but over time had become more unreliable about paying when he collected seeds. A third (NG 15), who estimated having bought and sold $700 \mathrm{~kg}$ of Jatropha seeds over the years, thought there was a seasonal cycle to the price changes, with the number of buyers increasing around the rainy season as they sought to take advantage of rains to plant Jatropha in drier parts of the country. This middle agent had sold seeds to outside buyers for prices ranging from $25-200 \mathrm{KSh} / \mathrm{kg}$, and reported having consulted with other middle agents in the area to try to coordinate their orders or stay up to date with recent price offers.

\footnotetext{
${ }^{30}$ Equivalent to $\$ 1.05$ US on November 10, 2011
} 
Nguruman middle agents reported dramatic variation in the seed prices that outside buyers offered, ranging from $10-250 \mathrm{KSh} / \mathrm{kg}$. Early high prices produced initially high expectations among both farmers and middle agents that a commercial seed market would persist under the same conditions. However, the high prices that researchers and nursery owners were initially able to offer represented a small and unsustainable niche market and would be impossible to maintain if Jatropha seeds were being processed into fuels that were price-competitive with diesel or kerosene. For example, a researcher (RS2) reported that nurseries were selling seedlings for 10-20 KSh each, putting nursery managers in a position where they could afford to pay hundreds of shillings for a kilogram of seeds and still earn a profit. On the other hand, approximately $3.5-5 \mathrm{~kg}$ of seeds need to be crushed to produce one litre of straight vegetable oil from Jatropha, depending on the type of press used (Tomomatsu and Swallow 2007; Boerstler 2010). Various actors interviewed for this research offered opinions on what seed prices would support the long-term production of biodiesel from Jatropha without exceeding the price of fossil fuel diesel. Their estimates included: $15-20 \mathrm{KSh} / \mathrm{kg}$ (NGO2); 11-14 KSh/kg (NGO7); $12 \mathrm{KSh} / \mathrm{kg}$ (Mpeketoni project); and as little as 3-4 KSh/kg (NGO6). Clearly there was a major discrepancy between these prices and the initial high prices offered by outside buyers in Nguruman.

One resident (NG 14) summarized the problem of volatile prices from outside buyers by saying:

Too many middlemen are involved. They come at different times. If no one comes for a while, and people have collected seeds but can't sell them, they take the first offer. Then they are fed up, but [then] some other buyer offers someone else $50 \mathrm{KSh}$ and it motivates people to collect again. If they have good luck, they get a buyer with good prices. Bad luck, bad prices. 
A minority of interviewees in Nguruman said that they only bothered to harvest seeds when they heard of a buyer, otherwise letting the seeds fall uncollected. Below a certain price - some said $25 \mathrm{KSh} / \mathrm{kg}$, others 10 - farmers felt it was not worth the effort it took to collect the seeds. One remarked that the sap stains your clothes, and "for 10 shillings you can't afford stains" (NG 17). Storing seeds for long periods of time while waiting for a better price could be problematic; one middle agent (NG 15) recalled, "when we started taking some of our seeds for testing, we were warned that the longer you keep your seeds, they lose quality." When prices dropped, farmers' incentive to collect seeds therefore dropped as well.

Nevertheless, the idea that residents could sell Jatropha seeds for direct income remained strongly present among farmers, perhaps based on their experiences with cash crops such as mangoes, bananas and high-value horticulture crops. A minority of farmers interviewed for this research were interested in how to secure a better market for Jatropha seeds and get into a stronger position with respect to price control. A few thought that a ready market existed somewhere, and that all the price fluctuations had been due to unscrupulous buyers trying to cheat them.

A majority of residents expressed a desire to take advantage of their existing Jatropha and develop it further, either by selling seeds commercially to an outside market, or through local processing and use of Jatropha oil. Residents envisioned using the end products from such a local scheme for lighting, cooking and stationary applications such as water pumps. Three also described how a local processing facility something like a factory - could provide employment for young people. Several said that using Jatropha to get oil or soaps for local use would be better than selling the seeds. 
Still, at the time of research, local processing remained only an idea to most of those who were engaged with Jatropha in Nguruman; very few people were actively considering how it could become a reality. A local agriculture officer had experimented rather unsuccessfully with crushing Jatropha seeds in a manual press meant for lighter oilseeds such as sunflower, leading to the conclusion that a different type of press would be needed instead. A group of at least five people was engaged in discussions on how to develop a viable local Jatropha processing system but these efforts were not well coordinated and were not yet consolidated into an action plan. One described how even occasional visits from outside buyers helped to keep up local interest in Jatropha, which would prove important if new opportunities presented themselves in the future.

Nearly all of the farmers who I interviewed had planted Jatropha many years previously because they considered it a good, strong fence, and any income they had gained from selling seeds in recent years seemed like an unexpected bonus - although they quickly felt disillusioned and let down when prices dropped and that bonus disappeared. Nonetheless, farmers spoke very positively about the possibility of producing and using Jatropha oil in the area and readily identified many types of benefits this could bring. There was a widespread perception among residents that Jatropha had strong potential to benefit people in Nguruman but a lack of clarity about how they could proceed in order to harness this resource.

\section{Patterns in the circulation of knowledge}

An inventory of current Jatropha production in the area was lacking, both from fences and early experiences with field plots. A minority of growers reported that they harvested 
only when they heard of a buyer and did not keep track of their seed yields. Information about present production capacity could help to inform decisions and goal setting about the most appropriate scale and strategy for local oil production if this option were to be pursued.

There seemed to be several different circuits of information. One resident who had moved to Nguruman from another part of the country told me that the area's "opinion leaders" were men who were chosen to lead their age groups based on qualities such as strength, but were not necessarily the most informed people. The need for more education came up repeatedly in interviews, yet information sources that were available were not always well received. For example, a minority of people who I interviewed expressed skepticism of the local agriculture officers' impartiality and transparency, meaning that they were less than fully receptive to learning from them. In another example of information perhaps not being fully shared, during my first stay in Nguruman I was told that a young (very quiet and seemingly shy) resident who had recently traveled to Tanzania to learn about Jatropha's potential was going to give a public demonstration of a Jatropha lamp, but this never occurred. I was left wondering how widely this knowledge would end up being shared.

A resident who had been involved with the Community Information Centre (NG 14) eloquently described general problems with information sharing in the area:

We are selfish with information, which is maybe why some projects like Jatropha don't do well. People don't share information; they work separately instead of working together. Everyone does their job alone. This applies not just to farmer knowledge, but also to sharing knowledge about prices. People are selfish about prices - but trying to maximize benefits may actually maximize their loss. 
In this way, unwillingness to share information and cooperate was seen as a barrier to achieving greater collective benefits, from Jatropha as well as other agricultural ventures.

A counter-example to this assertion was the way in which Nguruman's middle agents began to coordinate with each other to share information about offers they were receiving from outside buyers. One (NG 15) explained:

After some point we were really interacting and talking to each other. [NG 8] would call me and say, 'ok, I've been given an order, and this person is giving a price of $70 \mathrm{KSh}$, do you think that is good?' I would also talk to someone else about it; we were able to keep in touch. And we realized that the prices were not very different from each other.

This interviewee went on to say that although this type of cooperation did not allow Nguruman's middle buyers to actually influence prices, it enabled them to make more informed decisions as well as to help each other clear their stocks of stored seeds.

Residents pointed out some practical obstacles to developing local capacity for processing Jatropha, including a lack of technical knowledge about oil production, market information about equipment, and access to funds for the necessary infrastructure. Those in the group that was discussing plans to develop processing capacity hoped these needs could be met if an external partner or organization became involved. Social barriers also presented challenges including past difficulties in organizing collective efforts among farmers. The land ownership pattern also presented a disincentive to grow trees on leased land: interviewees described how landowners might object to a tenant who wanted to plant trees, while it was also a risky strategy from a tenant's point of view in that there was no guarantee they would still have access to the same land several years later when the trees matured. Still, there was considerable interest among residents in moving forward with a local Jatropha processing system if such issues could be addressed. 


\section{CHAPTER SYNTHESIS}

This chapter has established that access to knowledge and the ability to control the dissemination of messages about Jatropha - i.e. to shape the discourse - represented a form of power to influence its trajectory. Thus, analyzing the patterns of knowledge and perceptions of Jatropha in Nguruman, as well as how those patterns may have influenced farmers' decisions, contributes to answering the sub-question: What power relations characterized Nguruman farmers' involvement in Jatropha growing?

Before Jatropha was promoted as a biofuel crop, farmers in Nguruman were already growing it as fencing for their own reasons. Their perceptions of the plant changed when buyers came in and offered to buy collected seeds at high - but ultimately unstable - prices. In the absence of reliable information about Jatropha activities elsewhere in the country, farmers in Nguruman developed a false sense of how lucrative it would be to grow Jatropha, thinking that the initial high prices represented an established market value for Jatropha rather than a niche market linked to the start-up of research projects and seedling nurseries. Some farmers also acquired a false sense of the scale of Jatropha activities that were already underway in the country, describing how they hoped to link up with a market that they believed already existed, either by establishing a local factory or by forging a contract to produce Jatropha for a large company such as Safaricom.

Unlike in Mpeketoni where a centralized project coordinated the flow of information about Jatropha, in Nguruman there was no focal point for information and discussion. As a result, residents' opinions were scattered and could be contradictory. Nguruman residents had heard different stories from different 'outsiders' who visited the 
area interested in Jatropha, which in turn translated into different price signals, sending confusing messages about the existence and reliability of a market for Jatropha seeds. Without a central information hub, other types of social networks were more important to the spread of information and ideas about Jatropha in Nguruman. Inclusion or exclusion from particular networks influenced individuals' access to information and resources, as well as their ability to earn money from selling seeds. Middle agents, who at first negotiated individually with outside buyers, realized that there were advantages to sharing information with each other.

The question of what views of development were present in Nguruman is closely linked to how this local example interacted with broader forces and discourses. Residents envisioned progress coming from Jatropha in many forms, from increasing the availability of fuel for household lighting and running water pumps, to increasing household income through the sale of seeds, to building a factory that would provide significant local employment. For the most part, these interpretations of development focused on local benefits, though many interviewees connected their ability to gain these benefits to their ability to connect to broader markets. However, one interviewee (NG 14) showed an engagement with processes at an international scale, on one hand saying, "if we invest in Jatropha, maybe global warming will stop" - but on the other, expressing concern that the global food crisis was brought about by biofuels:

The US is making maize into fuel. In sub-Saharan Africa, assume we capitalize on Jatropha. If drought heats this place, will all Africans die? If we only have Jatropha and not food there would be too much shortage of food. If we capitalize on Jatropha as a cash crop, maybe for a start it would bring good income, but if change comes and the demand for Jatropha falls, it will strike on us. 
These links between biofuel production, climate change, and food security reflected a linking of scales that was rarely expressed in the Nguruman interviews. Through involvement with the Community Information Centre, the individual who made these comments had more opportunities than most residents of the area to be exposed to international news and commentary, allowing him to bypass some of the obstacles to information sharing discussed above.

Although most of the influences on Jatropha in Nguruman that research participants identified originated outside of the area, there were few ways in which farmers attempted to influence events at other levels of activity. Up to the time of research, outside buyers had determined the market for Jatropha seeds based on factors that were not connected to an actual market for Jatropha oil. The main drivers of seed prices were the availability of funding for research and NGO activities, and the creation of a seed and seedling market based on optimistic expectations that a biodiesel market would emerge. Nguruman residents attempted to "push back" against price fluctuations in two ways: first, some farmers refused to sell seeds for prices that they considered too low (though they took this action individually rather than collectively); and second, middle buyers began to share information about prices offered by outside buyers (though I did not hear of any buyer raising their offer through resulting negotiations).

Many of those interviewed in Nguruman seemed to be waiting for new opportunities to also come from beyond the local level, whether in the form of funding for an oil extraction machine, knowledge and technical training, or simply access to a more secure and favourable seed market. One interviewee (NG 15) summarized this position, saying: "Even my own people who work closely, I say, 'Carol is coming to do 
research,' and they say, 'she's coming with a machine?' This idea of waiting for somebody to come... I want people to realize that they too can also do." Just as connectedness to outside buyers - and to individuals who were connected to buyers - was an important element in determining who benefited from the collection and sale of Jatropha seeds in Nguruman, many residents of the area saw the ability to connect with potential funding sources as a prerequisite to advancing a local Jatropha project.

The first half of this chapter documented a suite of problems and unique features of the state of information about Jatropha, including incomplete information, poor quality information, misinformation, filling gaps by importing information from other contexts, and drawing parallels with other crops. The Nguruman case illustrates one set of outcomes that came from the combination of a fragmented and incomplete overall state of knowledge about Jatropha, uncoordinated dissemination of that knowledge, and additional filtering and compartmentalization of that knowledge within the community. Returning to Tsing's "economy of appearances," the residents of Nguruman were not witnesses to a coherent staging of a drama about Jatropha's potential. Far from it; with information (including price signals) trickling into the area by way of different individuals at different times, taken up by different residents and circulated through particular networks, the political economy of knowledge in Nguruman was very different from that observed in Mpeketoni, where a centralized approach to information management was in place. In Mpeketoni, a centrally planned project that was developed in broad consultation with participants appeared to overcome many of these challenges to produce a fairly coherent and consistent set of messages about Jatropha, even if farmers' experiences continued to raise new questions, such as how to deal with unanticipated 
pests and diseases. In contrast, Nguruman farmers were exposed to mixed and conflicting messages without the buffering provided by a central organization, leading to widely differing understandings of Jatropha as well as aspirations for its future. 


\section{CHAPTER 8: CONCLUSIONS}

International debates about biofuels have hinged on issues including climate change politics, energy independence, food security, and agricultural development. The range of positions that actors hold on these issues reflect contrasting interpretations of development and progress.

This thesis has examined the international context in which Jatropha came to receive heightened attention as a biofuel crop. Patterns in international discourses about Jatropha, expressed through media reports, scientific literature, NGO reports, government documents, and investor announcements, revealed a coexistence of optimistic and critical stances as well as a plurality of strategies and objectives. In Kenya, alternative discourses of development associated with biofuels have included a market-oriented, commercial approach to achieving national economic growth and emissions reduction goals, and a smaller scale, more community-oriented approach associated with providing livelihood benefits and economic opportunities to rural households. The simultaneous promotion of divergent agendas has produced competition between perspectives as well as flexibility for actors to use Jatropha as a means to approach different ends. Competition was evident in the allegations that those who actively promoted Jatropha engaged in exclusionary behaviour and suppression of dissent, while creative flexibility could be seen in government documents, NGO and private sector activities that espoused a dual focus on empowering small farmers while promoting private investment in large-scale plantations.

This thesis has explored the extent to which Jatropha lived up to the expectations expressed in these discourses of development in the early days of its promotion as a biofuel crop in Kenya, and where it fell short, explored possible reasons for this 
discrepancy. The distribution of Jatropha to small-scale farmers in Kenya outpaced both the development of a market for end products and, more fundamentally, the evolution and spread of knowledge that might have helped it to fulfill some of its potential. A lack of reliable information about Jatropha, compounded by barriers to the free sharing of knowledge, created a situation where unclear or even conflicting claims could continue to circulate. Some actors benefited from perpetuating an optimistic view of Jatropha's potential, while many farmers in the case studies considered here had invested time and resources to cultivate Jatropha but had not yet received any consistent benefits.

This concluding chapter returns to the research questions and analytical framework presented in Chapter 2 and summarizes what has been learned about each major guiding question with respect to issues of power, development and scale. It then discusses contributions that the research can offer to broader discussions and understandings of biofuels. Next, it reflects on key aspects of the research process, such as power relations and subjectivity. It offers ideas about how future research could usefully build on this project, and concludes with a set of final thoughts on the main topics and themes covered throughout this thesis.

\section{RESEARCH QUESTIONS REVISITED}

Many of the questions posed at the outset of this thesis (see Table 2.1) have been answered along the way. Others have not been as clearly addressed, either because it was not possible to determine answers from the research that occurred, there were multiple or conflicting answers, or further interpretation is needed to distill a conclusion. The sets of questions that relate to the concepts of power, development, and scale are revisited here. 


\section{Power}

What power relations characterize the funding, introduction and governance of Jatropha in Kenya, and to what extent have powerful actors enabled participatory decision-making or benefit sharing? NGOs and donors had the financial power to make Jatropha projects happen in Kenya. The national government had the regulatory power to set economic boundaries that might influence Jatropha's viability - but appeared willing to share this power to some extent by inviting other stakeholders to be directly involved in the process of policy formation. The private sector had potential power to bring in investment, but had been cautious so far, perhaps due to lack of regulatory clarity. Researchers and the media had the power to control the production and dissemination of knowledge about Jatropha. An important conclusion on this topic is that the ability to influence perceptions of Jatropha - whether by suppressing inconvenient research findings that questioned its economic viability, or by communicating with farmers directly - became a form of power in itself that helped influence actors' ideas about what was possible (Gaventa and Cornwall 2006). Chapter 7 discussed this idea in relation to Tsing's (2000) 'economy of appearances,' where the perpetuation of an optimistic narrative is seen to build momentum for a new enterprise. There were many parallels between the promotion of Jatropha in Kenya and the patterns of behaviour Tsing associates with other start-up enterprises as they seek to attract investment. These included actors protecting an optimistic discourse, playing multiple roles outside of their own expertise, and linking the enterprise in question to goals at a variety of scales, as discussed below.

What power relations characterize the enrollment of small-scale farmers in growing Jatropha? NGOs and others who had direct contact with farmers (e.g. local 
agriculture officers employed by the Ministry of Agriculture) had considerable power to shape farmers' expectations about how beneficial growing Jatropha was likely to be. In Mpeketoni, as discussed in Chapter 6, the donor organization (NCA) showed signs of having changed its initial plans based on interactions with farmers and residents of the area - an apparent example of voluntary power sharing. However, local coordinators and famers spoke of ways in which they hoped the Jatropha project would help them to reach additional objectives that they had held independently before the project came along. These related both to value addition projects for local agricultural products (favoured by coordinators), and increased household income (favoured by farmers). The co-occurrence of these multiple objectives suggests that in this case, perhaps the relationship between the donor organization and the community was characterized by more complex power relations - after all, NCA 'needed' the support of the community in order to run the project and reach its own initial objective.

In Nguruman, a different set of dynamics governed the spread of information and the experiences of farmers. Without a central hub for information about Jatropha, farmers were exposed to widely varying messages and price signals from seed buyers who visited the area. Because Nguruman was seen as a source area for Jatropha seeds, a variety of buyers from outside the area sought to procure seeds from Nguruman, usually for planting in research projects or nurseries. The high prices that these buyers initially offered was based on a temporary niche market for planting stock, not a long-term price for producing Jatropha-derived fuel that could compete with fossil fuel equivalents. As a result, farmers showed a high level of confusion about the state of the market for Jatropha in Kenya, and voiced a wide array of expectations and aspirations for how they - as 
individuals and as a community - could try to engage with this perceived market. This fragmented state of information made it difficult for farmers to make rational decisions about whether and how to participate in Jatropha growing, and left them feeling dependent on people and events outside of the area to help them achieve positive change.

Who has benefited from Jatropha, in what ways, and who has not? Non-farmer actors overwhelmingly identified NGOs and seed traders as the main beneficiaries of Jatropha projects in Kenya to date because they had attracted funds or earned profit from their activities. In most cases, farmers had yet to benefit from growing Jatropha, although many remained optimistic that this would change. Because those who were promoting or distributing Jatropha were seen to have benefited from it the most, it is possible to interpret Jatropha's introduction in Kenya to date as an intervention that reproduced inequalities, consistent with a critical perspective on NGOs in development (Escobar 1995; Wallace 2004; Harsh et al. 2010). But this interpretation fails to acknowledge more interesting connections and potential outcomes that were also observed, such as the multi-directional influence between donors, local project coordinators and farmers in Mpektoni. These ideas are further explored in the remainder of this chapter.

\section{Development}

How do the goals and motivations of key actors relate to development discourses? Actors discussed Jatropha in Kenya by invoking a variety of motivations and goals that corresponded to international, national and local scales. These clustered around two general discourses: one based on a large-scale, market-led interpretation of development, and the other on a small-scale, community-led one (see Chapter 6). The market-led 
discourse, which some actors expressed in conjunction with hopes that Jatropha would enable Kenya to export fuel, implement a national fuel-blending mandate or achieve major reductions in greenhouse gas emissions, most closely resembled the neoliberal development paradigm discussed in Chapter 2. In particular, the idea that large-scale, probably private sector-led investment in nucleus plantations and processing infrastructure represented a desirable way forward is consistent with the neoliberal view that private enterprise is the main driver of economic growth, which in turn stimulates a cascade of benefits. For example, actors who envisioned a network of smallholder farmers acting as outgrowers focused on the potential of these farmers to earn income, thereby measuring their benefits in terms of their participation in a cash economy.

The community-led discourse of Jatropha in Kenya shared some characteristics with the capabilities approach to development. Actors who focused on Jatropha's potential to provide fuel for household lighting linked it to improving opportunities for education and literacy - one of the central concerns of the Human Development Index as well as to financial savings that could be used for other purchases. As described in the Mpeketoni example below, a focus on encouraging medium-sized enterprise and value addition could turn out to resemble a neoliberal insertion into an existing cash crop economy, or a genuine expansion of local economic opportunities depending on how equitably the project proceeded.

The sustainability paradigm of development most notably appeared in the general categories of motivations that key actors expressed. Chapter 3 concluded that proponents of large-scale and community-based biofuel projects have both framed their potential benefits in terms of environment, energy security, and rural development, although they 
have drawn on different interpretations of these discourses. This research has shown that key actors involved with Jatropha in Kenya also identified their motivations and goals in a way that matched these broad categories.

Is there a dominant discourse of development attached to Jatropha in Kenya? At the time of research both the large-scale, market-led and the small-scale, community-led discourses of Jatropha-led development were very much in circulation, but neither one was well supported by successful activities on the ground. Chapter 5 described the incomplete value chain associated with Jatropha in Kenya: promoters had focused a great deal of effort on propagating the crop and distributing it to ever larger numbers of farmers, but very little production of Jatropha oil was actually taking place. As mentioned, a few actors expressed the belief that these contrasting approaches were complementary and even mutually supporting; in other words, that large-scale investment would stimulate small-scale production, and widespread uptake of Jatropha by smallscale farmers would in turn lend confidence to large-scale investors.

What discourse(s) of development or progress exist in case study areas, and how do farmers' priorities for development compare to those of other actors? In the case study areas, farmers and project coordinators expressed a range of objectives and strategies. In Nguruman, numerous farmers held the idea that they could fit into a larger market for Jatropha that they believed already existed within Kenya. In Mpeketoni, farmers largely hoped to gain direct income or household lighting from a project that focused on local processing of Jatropha for local use. As discussed in Chapters 6 and 7, these goals were not always the same as those of donors or regulators. However, the process of shaping the Mpeketoni project through direct discussions between project 
leaders and participants matched with the 'capabilities' idea that decisions about what constitutes well-being and progress should be undertaken in an open and place-specific way. This process produced a convergence of perspectives that appeared to be unique within the larger set of Jatropha activities in Kenya.

This research also uncovered evidence of overlap between the discourses and blurring between the major development paradigms. In Mpeketoni, actors who endorsed using Jatropha to support small- and medium- sized enterprises such as grain milling and cotton processing sought to expand the range of possible economic activities that were available in the area. It is possible to interpret these efforts as attempts to simply assume new roles within the existing economic system - to capture profit from more stages along the value chain - which fits with a neoliberal view of economic advancement. At the same time, creating new local opportunities would theoretically enhance the options and choices available to residents. As the project matures, a close examination of what types of economic opportunities became available to which people, and any barriers to equitable participation, could help to tease out which of the development paradigms proved to be more applicable.

\section{Scale}

How have broader forces or events elsewhere influenced Jatropha's promotion in Kenya? Actors identified many ways in which broader forces influenced Jatropha's promotion in Kenya (Table 6.1). Rising oil prices in 2008, concerns over climate change, the anticipation of an export market, and a desire to avoid using food crops for fuel were all seen to build interest in Jatropha specifically, while general backlash against biofuels 
and declining oil prices in 2009 may have inhibited interest in Jatropha activities. Biofuel mandates in several countries remain in place, meaning that one of the main drivers of expanded biofuel production is likely to remain influential in the near future. The rise of certification schemes (e.g. Roundtable on Sustainable Biofuels) and addition of sustainability clauses to some biofuel mandates (e.g. EU) suggest that if Jatropha continues to be perceived as a potentially 'sustainable' biofuel crop, these developments could encourage an increase in large-scale Jatropha production for export. It is more difficult to predict future patterns of donor interest in small-scale Jatropha projects.

Is there evidence that lessons from the spread of Jatropha in Kenya have been applied elsewhere? This study provides little evidence to suggest that experiences with Jatropha in Kenya have been taken up elsewhere. It is possible that international media coverage (e.g. Wadhams 2009; Ross 2011) has indirectly influenced events and decisions elsewhere, but this cannot be demonstrated through the research documented here.

How do small-scale biofuel projects interact with broader forces and discourses? This thesis has shown that small-scale biofuel projects such as the one in Mpeketoni interact with broader forces and discourses in several ways. Chapter 6 demonstrated how the global issue of climate change mitigation was an initial motivation for the project's European donor organization, yet as the project evolved the donor organization embraced the need to match this objective with the local concept of clean energy for development. Conversely, at the time of this research some Mpeketoni farmers spoke about how the Jatropha project would address global climate change in addition to more local concerns, when this idea was almost certainly spread by the donors and project coordinators. This mutual uptake of discourses focused on different scales shows engagement between this 
small-scale project and broader ideas. This fits with Tsing's (2000) observation that scale-making projects occur where optimistic discourses about a new enterprise are embedded across different scales - in other words, where an activity is portrayed as being able to achieve aspirations that occur on a number of different levels (see Chapter 7).

Some of the actors interviewed for this research described large-scale and smallscale Jatropha activities as mutually dependent. Others saw small projects like the Jatropha Integrated Energy Project as an alternative to many things that appeared to be wrong with large-scale biofuel production. For example, interviewees stated that local Jatropha production for local use could be done in a more ecologically balanced way and bring more benefits to farmers than enrolment in an outgrower scheme, while potentially enhancing rather than threatening food security. Perhaps this could be seen as a form of resistance to large-scale discourses of biofuel production.

In what ways have farmers attempted to influence events at other levels of activity? In Mpeketoni, project coordinators saw value addition projects as a way to keep the financial benefits from processing crops in the community. In particular, they described how a single owner had bought up several cotton processing facilities in the area over time, until he achieved an effective monopoly and drove down the price paid to farmers. These coordinators saw the Jatropha Integrated Energy Project as providing a pathway to establish a cooperatively operated cotton processing plant that would enable farmers to regain some control over the process - and the economic benefits - of processing cotton. This can be seen as one discourse of resistance against the economic pressure to scale up, consolidate and achieve economies of scale. For their part, Nguruman farmers hoped to attract interest of an NGO or other donor to help them 
establish a Jatropha project or "factory." Although it was more vague, their discourse of progress involved making links to actors outside the community in order to gain financial, technical, and perhaps political leverage. These are the strongest examples of farmers "pushing back" against global or national forces that emerged through this study.

What future trends are likely with respect to biofuel projects and scale? As mentioned, the major drivers of global demand for biofuels remain in place: biofuel mandates remain in place, while oil prices on the global market surged again in 2011. An increase in the number of large-scale land deals suggests a continuing trend in which investors and governments negotiate over access to large tracts of land, usually to produce energy, timber or food crops for export (HLPE 2011). That this trend shows no sign of slowing raises the question of whether large-scale biofuel production, not limited to Jatropha, will continue to expand in sub-Saharan Africa in the coming years. If they come to fruition, the potential large-scale Jatropha interventions that interviewees in this research discussed - some with hope, others apprehension - may show characteristics of these land grabs.

All of this raises more questions: Do the small scale projects described in this thesis represent real alternatives to the model of scaling up and exporting biofuels? Can they continue to resist these pressures? Or do they operate in an entirely different political and economic space, where donors are able to circumvent the pressures that encourage this large-scale model and have the resources to focus on other motives (such as poverty alleviation) instead? This thesis has provided partial answers and starting points for future investigation, which could help to further untangle these dynamics. 


\section{REFLECTIONS ON THE RESEARCH PROCESS}

This section reflects on the research process, returning to the questions of power and reciprocity that were raised in Chapter 2. In the spirit of reflexivity I include aspects of the researcher-participant relationship that went relatively smoothly as well as those which were not so smooth and represent potential limitations on my findings. My initial goals for the research process were to establish a relationship with participants based on a mutual sense of reciprocity, identify and manage power issues appropriately, and give back something worthwhile to the participants. These topics are revisited here in addition to broader ideas about subjectivity and expectations. While my field work was underway I realized that it was necessary to scrutinize the extent to which I may have contributed to the phenomenon I was studying - that is, disproportionate attention to Jatropha - simply by conducting research on it. Here I consider the extent to which the strategies I employed were effective and identify areas where questions remain.

\section{Power relations}

\section{Self-censorship by farmers}

While in the field I often reflected on Scott's (1990) distinction between the "public transcript" and the "hidden transcript" in situations where a power differential exists. In some cases I was able to become aware of differences between what participants told me in a research setting and what they revealed in other situations. For example, my assistant described to me an encounter he had with one participant in the local pub when I was not there. This farmer was disappointed that I had not given him money for taking part in a short follow-up interview - an expectation I would not have been aware of otherwise. By 
chatting with participants informally I was sometimes also able to add nuance to the perspectives they shared during their interviews. However, I must accept that these were exceptions and that most of the views participants presented to me represented the "public transcript" that they were willing to share with a foreign visitor. Particularly in relation to farmers, Kaufmann's (1997: 110) words resonate with my experiences in the field: "My attempts to put people at their ease rarely overcame the formality that the respondents adopted. The efforts I made to relax respondents in the interview were not sufficient to overturn the social hierarchy that framed our meetings."

Nevertheless, some of my efforts did help to establish a positive rapport with participants in Mpeketoni and Nguruman. As mentioned in Chapter 2, I tried to build trust with farmers by visiting them more than once, bringing token gifts, giving them photographs that I had taken of them, and participating in social activities in addition to research interviews. Particularly in Nguruman, on my second visit I discussed my early observations with farmers individually and asked what questions they still wished to learn about or discuss. Their responses helped me structure the public forum which was generally well attended and received. Farmers expressed appreciation for all of these things, with several commenting that it was unusual for visitors to return or to bring back copies of the photos they took. It is my belief and hope that these actions helped participants to feel valued and thus more comfortable sharing their thoughts with me.

To further put these participants at ease, as mentioned in chapter 2 I decided not to audio record my interviews with farmers. The trade-off for trying to help farmers to feel comfortable and share their thoughts more freely was that a degree of detail and nuance was inevitably lost as I relied on real-time translation and handwritten note 
taking. Although the translation process gave me more time to write notes than I had when I conducted interviews in English, I nonetheless recognize that to some extent this decision had the unintended result of privileging the views of interviewees whose interviews I audio recorded and transcribed verbatim, and thus could scrutinize more closely. Farmers also had less control over the research than key actors - in terms of gatekeeping, control over temporal space during interviews, and opportunities to review and suggest revisions to the research outputs.

Another factor that may have contributed to self-censorship was the difficulty I had in approaching farmers without appearing to be affiliated with either a particular social network (in Nguruman) or the JIEP project leadership (in Mpeketoni). I brought a research assistant with me from Nairobi instead of recruiting a local resident to assist me who would inevitably be embedded in the social structure and power relations of each community, hoping that this would emphasize that I was an independent outsider. However, for practical reasons it turned out to be necessary to have a local contact suggest possible farmers to us and then show us where they lived. In both case study areas a well-known local person who was affiliated with Jatropha growing efforts usually accompanied me and my assistant to the farms. This contact person often introduced us to the farmer when we arrived and sometimes remained present during the interview. I recognize that this had the potential to inhibit participants if they wanted to express views that were critical of Jatropha. Interestingly, though, it also gave them an opportunity to address concerns and questions about Jatropha directly to someone who had previously encouraged them to grow it. Several took advantage of the opportunity to direct candid questions or criticism at the contact person. These interactions revealed frustrations, 
grievances and misunderstandings that farmers held which may not have emerged from the interviews otherwise. I am therefore conscious that in terms of the free expression of participants' opinions and feelings, something was given up and something was gained from this arrangement.

\section{Self-censorship by key actors}

I anticipated that the (non-farmer) key informants might be reluctant to share some of their true views about Jatropha and the other players involved in its promotion. I thought they might hold back to avoid conflict, protect their business ideas from competitors, keep early policy ideas confidential, or avoid possible repercussions if they spoke ill of donors or those who controlled access to policy or multi-stakeholder discussions. Although I tried to mitigate these possibilities through the research design, for example by offering not to name interviewees in written outputs of the research, I knew that the Jatropha 'world' in Kenya was small enough that a keen observer might still be able to read between the lines and deduce who said what.

Given these worries I was not prepared for the candour with which some key actors expressed very strong views and ripped into their rivals. I soon realized that the interpersonal dynamics were fractious and began to keep a matrix-like spreadsheet tracking what the key informants said about each other (or each other's organizations). Self-censorship began to seem like less of a problem than the possibility that actors were trying to convince me that their views were more valid, their strategies more sound and their priorities more laudable than those of other actors. This presented an interesting twist to the power dynamics: perhaps some participants saw an opportunity to steer the 
outcomes of my work and end up in a more advantageous position by influencing my views through the interview process.

\section{Suggested revisions}

Another way in which participants could try to influence the research was by asking me to revise parts of the written outputs which I sent for their review. Interviewees from government, NGOs, donors, researchers and the private sector had the opportunity to review these documents while farmers did not, demonstrating another aspect of the power asymmetries between research participants. One government representative rewrote a series of quotations from our interview that I sent for approval, rephrasing the original, candid phrases into ones that sounded formal and qualified - in short, the type of sanitized messages that one often associates with government discourse. Another actor responded to a draft article by suggesting I include reference to specific documents, rephrase certain passages, and use images to portray Jatropha's performance in a more favourable light. A third research participant sent me a long, negative and very stronglyworded email after I shared a paper I had written about this research. I anticipated that not everyone would be happy with what I had written, but I was surprised by the tone and personal nature of this response. A subsequent telephone conversation left both of us feeling much better. Interestingly, although NCA showed strong interest in mediating my activities in Mpeketoni and clearly requested that I share any written outputs with them before they were published, when I did send draft documents for review they never responded with substantive comments. ${ }^{31}$

\footnotetext{
${ }^{31}$ In several instances they confirmed receipt and said they would get back to me with feedback after internal discussions, but never did.
} 
Kaufmann (1997) describes how she initially perceived development actors in her study to be powerful by virtue of their professional status, access to resources, and control of the temporal space during interviews. But by reflecting on certain behaviours, such as the way they sought anonymity and asked her to rewrite a draft paper in more formal language, she realized that these 'powerful' participants also felt vulnerable. I believe that this observation also applies to my key informants, and that those who asked me to modify my written work displayed a degree of vulnerability in addition to concern for 'setting the record straight.'

\section{(How) did I contribute to a disproportionate focus on Jatropha?}

One of my main research objectives was to explore the 'hype' surrounding Jatropha: why and how its proponents came to promote it so enthusiastically over and above other bioenergy alternatives, and the implications of doing so. However, I realize that to some extent I unwittingly contributed to this phenomenon through the process of studying it. I could see this happening in two ways. First, some participants seemed to interpret my presence as an endorsement of Jatropha regardless of the cautious things I said about it. Second, in several cases participants asked or expected me to help them further their proJatropha goals, either directly by bringing them resources or indirectly by connecting them with potential donors.

Although my interviews covered many topics, their primary focus was on Jatropha as I asked participants about their expectations, hopes, experiences and perceptions surrounding it. I tried to distance myself from the positive claims they may have heard and the people who delivered them; I explained to everyone that I was a 
student interested in learning about Jatropha and that I was not affiliated with any NGO, business or other body that was in a position to promote or support Jatropha growing efforts. If participants asked for my opinion about Jatropha I made cautious statements and stressed that I thought certain things would need to change in order for any potential benefits of growing it to be realized. Still, several encounters suggested that instead of receiving the cautious messages that I tried to convey, some participants interpreted my presence and activities in a way that built their hopes over Jatropha. In other words, my efforts to critically examine the excessive positive attention that had been given to Jatropha were at times interpreted as feeding that same attention. This contribution to Jatropha 'hype' could take several forms: focusing too much on Jatropha as opposed to alternatives; feeding optimism over Jatropha; and perpetuating the idea that linking with an NGO or other outside donor was the way to benefit from growing Jatropha.

In Nguruman I struggled to convey to participants that I could not directly advance their desire to establish a Jatropha processing facility. On reflection, although I repeated this message in words every time I met with farmers, it is understandable that they might have thought my actions suggested otherwise. After all, I repeatedly asked them about their expectations and hopes, the challenges they faced, and what strategies they saw for overcoming these challenges. If a visitor were to try to actually implement a development project focused on Jatropha, this type of consultation would be a likely starting point.

The perception that I could bring a processing machine to Nguruman persisted among some participants even up to the time of my final visit. During the public forum, one farmer stood up and asked me whether I had succeeded in finding a machine for 
them. I answered: no, I had not brought a machine and I was never able to. At that point another farmer stood up, spoke animatedly in Kiswahili and then left the forum. I worried that he, too, was frustrated that I had not brought a machine, but my translator conveyed his comments: that everyone should stop asking me about a machine; that finding one was a task for all of them, not for me. While I was heartened to hear this, the first farmer's question showed that some participants had continued to hope that my presence in Nguruman and my interest in Jatropha would stimulate movement on a project.

In Mpeketoni some farmers made comments suggesting that my visit could have both direct and indirect impacts on local opinions about Jatropha. While interviewing one farmer who had voiced skepticism and significant concerns over whether Jatropha would benefit him, I asked what his neighbours and other people he spoke to thought about Jatropha. He replied that his neighbours would see that I had visited to talk about Jatropha, and this would make them more interested in it because someone from so far away was also interested in it. The very distance I had traveled and the effort I had invested to talk with them about Jatropha appeared to bolster its importance regardless of whether I had positive or negative views about what I saw and heard.

Another farmer in Mpeketoni had such negative views about Jatropha and JIEP that he told me he was planning to uproot his plot the same day that I visited. Later in the interview I asked whether his Jatropha would still be there tomorrow. He replied, "that depends on you." Clearly he wanted to hear whether I thought growing Jatropha was worthwhile, and appeared to be prepared to act on my advice. In this case I believe that the farmer was open to hearing positive or negative messages about Jatropha and did not assume that my presence implied endorsement of the crop. Still, it was never my 
intention to give individual farmers direct advice about whether to grow Jatropha, and this interaction reaffirmed my suspicions that my research process was influencing the phenomenon I was trying to examine.

Some non-farmers also hoped that I would help them reach pro-Jatropha goals or made comments to the effect that we were collaborators on the project of advancing Jatropha production. For example, one NGO representative expressed hope that our interactions might one day lead to connections with donors or other partners that could strengthen their activities. Specifically, this actor asked me to act as a link to Canadian universities that could potentially send graduate students to the organization's research stations. Another NGO representative asked in an email after I had returned to Canada whether there was any "Canadian interest" in investing in projects that the organization was involved with. These comments suggest that the actors who made them saw me as an ally in advancing Jatropha projects and a potential link to financial or human resources.

Finally, I wondered how much my written outputs could contribute to a continued overemphasis on Jatropha solely by representing more research dedicated to the topic. I experienced this feeling myself from a different perspective when I attended a meeting in Nairobi with a representative of a European research consortium that had recently received a large grant to study biofuel production in East Africa. His team was now trying to select case study locations and methodological approaches for investigating Jatropha in Kenya according to a predetermined grid of criteria drawn from literature and theory. As I listened to his plans and thought about the challenge of drawing meaningful findings from a new study of Jatropha in Kenya in relation to his team's objectives, I felt a wave of pessimism and found myself wishing they were investigating the potential of 
other, less talked about sources of bioenergy instead. To me, their special interest in Jatropha seemed to perpetuate a disproportionate research focus on Jatropha, which in turn contributed to a sense that 'everyone is talking about it.' Of course I realized my own research was feeding the same buzz in the same way.

In all cases I was left with a lingering question: how well will participants remember my cautionary statements about Jatropha as opposed to the simple fact that I was there, interested in studying it? One interviewee's words rang in my ears: "Jatropha is a bandwagon. We're on it; even you are on it now." My presence, together with the reality that I had research funding from another country to come and learn about people's experiences with Jatropha, signaled a level of international interest that may have appeared to reflect endorsement of Jatropha projects or confidence in their potential, no matter how I tried to explain my role. Participants may have interpreted my verbal messages in which I distanced myself from support for Jatropha as a public transcript, while guessing that a positive position on Jatropha was part of my own hidden transcript.

\section{Subjectivity: on being an 'outsider'}

I was an 'outsider' in two fundamental aspects of this research: as a foreigner studying events in Kenya, and a non-farmer studying agricultural issues. My age and gender distanced me further from some participants, particularly men who held senior professional positions or spoke on behalf of farming households, while bringing me closer to others, such as women and youth.

Of course, not being a Kenyan or resident of Kenya meant that I lacked the detailed knowledge of the country's history, politics, culture and social issues that would 
come from long-term exposure. This undoubtedly impacted my ability to interpret some of my interactions with research participants. However, I also discovered several ways in which being foreign benefited my research.

I found that I was able to "cold call" officials and senior representatives of organizations and successfully set up appointments with little trouble, something that I suspect would be much more difficult for a Kenyan student to do, and which would certainly be much harder for me to do in Canada with Canadian officials. I was given a warm and respectful welcome in several offices where I expected to be ushered in and out as efficiently as possible. Farmers showed special hospitality too: although not completely rare for a foreigner to visit the small towns and villages where I carried out the case studies, it was still fairly unusual for one to visit farms and talk to farmers individually. Although I was conscious of not wanting to take too much time away from busy farmers, my visits were often treated as an event that warranted extensive chatting and cups of tea. In other words, I was able to access people and their time in a more generous way than I would have been able to if I were not from another country.

Often people went out of their way to explain to me 'how things are' or 'how things work' in Kenya, perhaps feeling that they were my first guides to the country, even to Africa. At times I had to fight the feeling that I was being patronized when I thought someone was telling me what I already knew, but I recognized the value of being able to hear people articulate social relations that would otherwise have remained implicit.

Finally, in the wake of the post-election violence that Kenya experienced in early 2008, political and social tensions remained high at the time when I conducted this research. In interviews and casual conversations alike, Kenyans spoke to me about "tribe" 
in more explicit and pervasive ways than I had witnessed during a previous stay in the country in 2004-5. These comments ranged from regretful (that Kenya's politics and society were so fractured along ethnic lines), to suspicious (e.g. that another ethnic group had a hidden agenda), to derogatory (perpetuating negative stereotypes about other ethnic groups). In some ways, I felt that it was easier for me to connect with new people in Kenya as a 'neutral' person from another country than it might have been if I were a Kenyan from a different ethnic group.

\section{RECOMMENDATIONS FOR FURTHER RESEARCH}

Much has happened in the time since I completed the field research for this thesis. In Kenya, some Jatropha projects have ended, others have progressed, and still others have undoubtedly begun. A new national biofuel policy was produced in 2011 and has been working its way through the approval process (USDA Foreign Agricultural Service 2011). The media have also reported announcements about other types of Kenyan biofuel ventures, particularly ethanol derived from sugar cane, as the economic regulations that govern the country's sugar industry are set to change (Xinhua 2011). Further research could begin by updating the work presented in this thesis, for example revisiting Mpeketoni and Nguruman to look for changes in Jatropha project outcomes and participants' perceptions, extending the analysis to consider other Jatropha projects, and examining these in the context of the political and economic changes just described.

Small- and large-scale Jatropha projects in Kenya have received recent attention from researchers and the media, reflecting two of the major discourses documented in this thesis. Boerstler's (2010) study of a community project that involved growing 
Jatropha as fencing and processing it locally to provide household fuel provided a largely optimistic assessment of this process. In contrast, plans for a 10,000 ha Jatropha project in the Dakatcha woodlands, proposed by the Canadian company Bedford Biofuels, drew significant backlash from local people as well as the international media (Ndurya and Kihara 2009; Ross 2011). This debate recently culminated in Kenya's National Environmental Management Authority advising the Kenyan government to stop the project due to environmental concerns (Bird Life International 2011). Overall, GTZ (2009) published a negative economic outlook for growing Jatropha under all scenarios except as fencing. These concurrent developments invite a more thorough discourse analysis and a linking of the discourses of Jatropha at play in Kenya to those already under scrutiny in other settings (Ariza-Montobbio et al. 2010; Baka 2011). The Dakatcha woodlands project drew fire for its environmental as well as social costs, providing an opportunity to link to broader scholarship on the politics of large-scale land deals.

Looking beyond Jatropha and Kenya, the broader themes of this thesis suggest several lines of further investigation related to cross-scale interactions and spatial patterns involving biofuels. Renewed financial turmoil caused oil and food prices to rise dramatically once again in 2011 , raising the question of whether events that appeared to be unique in 2007-8 might be part of a recurring cycle. The answer could have major implications for future investment patterns, whether by improving the economic attractiveness of biofuel production in relation to high oil prices, or perhaps reigniting debates over food-versus-fuel competition. Meanwhile, several high-profile publications have recently reaffirmed the extent of the global land crisis. Growing and compounding demands for commodities (food, feed, fuel, timber) place increasing pressure on a finite 
amount of land that can produce them, while economic globalization often serves to amplify and concentrate the resulting impacts of land use change (DeFries and Rosenzweig 2010; Lambin and Meyfroidt 2011). The dual challenge and responsibility of agriculture - to provide more food without compromising environmental sustainability has been clearly articulated (Obersteiner et al. 2010; Foley et al. 2011), with research suggesting that human activities linked to agriculture have strongly contributed to surpassing safe global thresholds related to biodiversity, carbon, nitrogen and phosphorus (Rockström et al. 2009; Bennett and Carpenter 2011). Still, policies that encourage the production and use of biofuels remain in place, providing a mandate and strong incentives for biofuel production to continue to grow in coming years (UNEP 2009; Taheripour et al. 2010). These developments suggest that biofuels are likely to remain at the forefront of strategic debates over how to meet human needs for food, energy and materials without compromising ecosystem functions and services. Further research is needed to understand the complexity of ecological, political, economic and social interactions in this system. There is a particular need for work that links macro-level analysis of international political economy with the kind of place-specific investigation of specific biofuel projects presented here.

Large-scale land deals are increasingly recognized as an accelerating phenomenon linked to intensified competition for arable land for the purpose of growing biofuels as well as food crops. The rapidly developing literature on this topic points out current and likely future consequences for food security (Robertson and PinstrupAndersen 2010; HLPE 2011), social relations (Borras and Franco 2010; Vermeulen and Cotula 2010; Zoomers 2010), and ecological goods and services that underpin livelihoods 
(de Schutter 2011). How biofuel policies as a driver translate into specific pressures and outcomes in the coming years will be mediated by these processes as well as a changing global economic context in which BRICS (Brazil, Russia, India, China, South Africa) and middle-income countries are taking on new and more influential roles (Kahn 2011; Schoeman 2011). Future - and ideally, collaborative - research could investigate spatial patterns in these political and economic shifts, and overlay them with an analysis of financial flows, land use changes, social impacts, and the transfer of resources associated with international trade in biofuels. This interdisciplinary agenda would extend the themes of this thesis - power, development and scale with respect to biofuels - into a project with much larger scope, reach and impact.

\section{FINAL THOUGHTS}

The Jatropha project in Mpeketoni provides reasons for optimism that growing Jatropha might one day benefit small-scale farmers in Kenya. The project's collaborative approach, sharing of information and experiences, and evidence of mutual learning between donors, project coordinators and farmers suggest that, if Jatropha grows well and the project continues to be carefully managed, it may indeed be possible for these different groups of actors to leverage the same resources to achieve multiple goals.

A broader view of Jatropha activities in Kenya suggests that not all coalitions of interests hold as much promise as that found in Mpeketoni. Efforts to coordinate research activities and to bring together multiple 'stakeholders' through the policy development process were clearly in place. At the same time, this thesis has documented numerous examples of competition and jostling between key actors, including allegations that some 
of the crop's promoters engaged in shady business and were unwilling to acknowledge dissent. Despite actors' stated goals of producing clean energy, reducing poverty, improving food security and promoting rural development, at the time of research most Jatropha activities remained focused on propagating the crop rather than deriving useful products from it. Crucially, neither a market-based nor a community-based approach to Jatropha-led development had been implemented to the point where it was producing any significant quantities of fuel from Jatropha.

The contradictions between the stated motivations of influential actors and the observed outcomes to date highlight the politics of Kenya's Jatropha industry. Highly relevant is Ferguson's (1994) observation that knowing the interests of development actors is not sufficient to explain development outcomes. Actors who compete for limited resources or try to secure their own position are likely interfering with, rather than helping to create, the conditions that would be necessary to actually reach their stated goals. Mosse's (2005) proposition rings true in this case: that several actors appear to have put as much energy into maintaining coherent representations and legitimizing their positions as they have into engaging with farmers on their own terms.

The future of Jatropha in Kenya remains an open question. Whether influential actors will choose to use mechanisms such as the National Biofuels Committee, the Kenya Biodiesel Asociation and their own projects on the ground to pursue the degree of convergence observed in Mpeketoni will provide further material for debates over what kinds of development can be achieved using biodiesel.

This research has helped to problematize discourses about small-scale biofuel production as well as to explore the interactions between discourses of small- and large- 
scale undertakings. While some aspects of Kenya's convoluted political economy of biodiesel may be a function of the individuals involved, the competitive and creative struggle between actors described here is very likely sustained and escalated by some unique features of Jatropha as a 'new' energy crop. For many biofuels, contrasting pressures support very different interpretations of development at multiple scales: internationally, climate change and energy security discourses push a large scale, commercial agenda, while locally, the prospect of improved access to energy for remote communities promotes a rural development agenda. Additional discourses related to food security, land rights and land use change open further sites for competition and maneuvering among actors with different primary agendas. As in Kenya, weak or absent biofuel regulations add to a "free-for-all" atmosphere where seemingly contradictory activities can continue to operate side by side.

The newness and discursive versatility that have shaped the trajectory of Jatropha in Kenya equally apply to other biofuels, particularly those that are perceived to have characteristics associated with sustainability (e.g. those that are not food crops, and could be produced by smallholders). Compared to other agricultural development schemes, biofuels have additional layers of contested meaning because of the politics of energy and the environment that are involved. The multiple discourses that this research shows have been activated to encourage the spread of Jatropha among small farmers in Kenya are equally relevant in other contexts where biofuels are concerned. 


\section{REFERENCES}

Abdallah, H. 2009. Uganda to extract biodiesel from 'wonder plant' jatropha. The East African, December 7.

Achten, W.M.J., W.H. Maes, R. Aerts, L. Verchot, A. Trabucco, E. Mathijs, V.P. Singh, and B. Muys. 2010. Jatropha: From global hype to local opportunity. Journal of Arid Environments 74 (1):164-165.

Achten, W.M.J., E. Mathijs, L. Verchot, V.P. Singh, R. Aerts, and B. Muys. 2007. Jatropha biodiesel fueling sustainability? Biofuels Bioproducts \& BiorefiningBiofpr 1:283-91.

Achten, W.M.J., L. Verchot, Y.J. Franken, E. Mathijs, V.P. Singh, R. Aerts, and B. Muys. 2008. Jatropha bio-diesel production and use. Biomass \& Bioenergy 32 (12):1063-1084.

Aerospace Center (U.S.). 1969 (rev. 1994). "M-5" [cartographic material]. Edition 7. 1:1,000,000. Operational navigation chart, ONC, Sheet M-5. St. Louis, Mo.: Defense Mapping Agency Aerospace Center.

AFP. 2011. Brazil ready to invest in energy sector of Pakistan. Business Recorder, March 9.

Anderson, D. 2005. Histories of the hanged: the dirty war in Kenya and the end of empire. London: Weidenfeld and Nicolson.

APEC. 2010. Summary of APEC biofuels activities 2008 [cited August 11 2010]. Available from http://www.biofuels.apec.org/activities summary.html.

Ariza-Montobbio, P., S. Lele, G. Kallis, and J. Martinez-Alier. 2010. The political ecology of Jatropha plantations for biodiesel in Tamil Nadu, India. Journal of Peasant Studies 37 (4):875 - 897

Aron, M. 2010. Endless musing costs Kenya big bucks. The Standard, June 15.

Bacovsky, D., M. Dallos, and M. Worgetter. 2010. Status of 2nd generation biofuels demonstration facilities. In Commercialising 1st-and 2nd-generation liquid biofuels from biomass, edited by I. B. T. 39: IEA.

Bailis, R.E., and J. Baka. 2010. Greenhouse gas emissions and land use change from Jatropha curcas-based jet fuel in Brazil. Environmental science and Technology 44 (2):8684-8691.

Baka, J. 2011. Biofuels and wasteland grabbing: how India's biofuel policy is facilitating land grabs in Tamil Nadu, India. In International Conference on Global Land Grabbing. Sussex.

Baxter, J. 2010. Case studies in qualitative research. In Qualitative research methods in human geography, edited by I. Hay. Oxford: Oxford University Press, 81-98.

Bebbington, A.J., S. Hickey, and D.C. Mitlin. 2008. Introduction. In Can NGOs make a difference? The challenge of development alternatives, edited by A. J.

Bebbington, S. Hickey and D. C. Mitlin. London and New York: Zed Books, 337.

Bekunda, M., C.A. Palm, C.d. Fraiture, P. Leadley, L. Maene, L.A. Martinelli, J. McNeely, M. Otto, N.H. Ravindranath, R.L. Victoria, H. Watson, and J. Woods. 2009. Biofuels in developing countries. In Biofuels: Environmental Consequences and Interactions with Changing Land Use. Proceedings of the Scientific Committee on Problems of the Environment (SCOPE) International Biofuels 
Project Rapid Assessment, 22-25 September 2008, Gummersbach Germany, edited by S. B. R.W. Howarth. Ithaca NY: Cornell University, 243-263.

Bennett, E.M., and S.R. Carpenter. 2011. Reconsideration of the planetary boundary for phosphorus. Environmental Research Letters 6:014009 (12 pp).

Bernstein, H. 2010. Class dynamics of agrarian change. Halifax: Fernwood.

Bhattacharyya, P. 2010. Lack of science means jatropha 'could fail poor'. Science and Development Network, August 9.

Bii, B. 2009. Biofuel project set for Coast. Daily Nation, February 16.

Bird Life International. 2011. Kenya's environment authority advises jatropha is 'not viable' in coastal Kenya. Bird Life International.

Blacker, J. 2007. The demography of Mau Mau: fertility and mortality in Kenya in the 1950s: a demographer's viewpoint. African Affairs 106 (423):205-227.

Blaikie, P., and H. Brookfield. 1987. Defining and debating the problem. In Land degradation and society, edited by P. Blaikie and H. Brookfield. London and New York: Methuen, 1-26.

Boerstler, F. 2010. The potential for the production of biodiesel for lighting and cooking using Jatropha (Jatropha curcas L. Euphorbiaceae) by small scale farmers on the Kenyan coast: Doctoral thesis / dissertation. Munich: GRIN Verlag.

Borras, S.M., and J. Franco. 2010. From threat to opportunity? Problems with the idea of a "code of conduct" for land-grabbing. Yale Human Rights and Development Law Journal 13:507-523.

Borras, S.M., P. McMichael, and I. Scoones. 2010. The politics of biofuels, land and agrarian change: editors' introduction. Journal of Peasant Studies 37 (4):575 - 592

Brittaine, R., and N. Lutaladio. 2010. Jatropha: a smallholder energy crop: the potential for pro-poor development. In Integrated Crop Management. Rome: Food and Agriculture Organization of the United Nations.

Brown, L. 2007. Massive diversion of US grain to fuel cars is raising world food prices. In Plan B Updates. Washington DC: Earth Policy Institute.

Browne. 2009. African jatropha boom raises concerns. New York Times, October 9.

Bryant, R.L. 1998. Power, knowledge and political ecology in the third world: a review. Progress in Physical Geography 22 (1):79-94.

Caniëls, M.C.J., and H.A. Romjin. 2010. The Jatropha biofuels sector in Tanzania 20059: Evolution towards sustainability? Eindhoven, The Netherlands: Eindhoven Centre for Innovation Studies, Eindhoven University of Technology.

Carroll, W. 2005. Introduction: social democracy in neoliberal times. In Challenges and perils: social democracy in neoliberal times, edited by W. Carroll and R. S. Ratner. Halifax: Fernwood, 7-16.

Chakrabortty, A. 2008. Secret report: biofuel caused food crisis: Internal World Bank study delivers blow to plant energy drive. Review of 4 July 2008. Guardian Online, 3 July.

Cheboi, S. 2008. 'Evil tree' turns out a saviour as fuel prices bite. Daily Nation, October 6.

CIA. 1988. Kenya: Map \#801061 [cartographic material]: Central Intelligence Agency (U.S.).

Clayton, J. 2010. Africa seeks clean, profitable biofuel. Times Online, May 31.

Cleantech. 2009. Could biodiesel solve rural India's job woes? Cleantech Group, May 6. 
Clement, W., and L. Vosko. 2003. Introduction. In Changing Canada: political economy as transformation, edited by W. Clement and L. Vosko. Montreal: McGillQueen's University Press, xi-xxxii.

Comim, F. 2005. Capabilities and happiness: potential synergies. Review of Social Economy 63 (2):161-176.

Cooper, F. 2002. Africa since 1940: The past of the present. Edited by M. Klein, New approaches to African history. Cambridge, UK: Cambridge University Press.

Cope, M. 2010. Coding qualitative data. In Qualitative research methods in human geography, edited by I. Hay. Oxford: Oxford University Press, 281-94.

Cotula, L., N. Dyer, and S. Vermeulen. 2008. Fuelling exclusion? The biofuels boom and poor people's access to land. London: IIED.

Cotula, L., S. Vermeulen, R. Leonard, and J. Keeley. 2009. Land grab or development opportunity? Agricultural investment and international land deals in Africa. London / Rome: FAO, IIED and IFAD.

Coussou, E. 2009. Tanzania puts faith in jatropha plant. BBC, December 11.

Creutzig, F., and D. Kammen. 2010. Getting the carbon out of transportation fuels. In Global sustainability: a Nobel cause, edited by H. J. Schellnhuber, M. Molina, N. Stern, V. Huber, et al. Cambridge: Cambridge University Press, 307-18.

Currie, K., and L. Ray. 1987. The Kenya state, agribusiness and the peasantry. Review of African Political Economy (38):89-96.

Daily Nation. 2010. Jatropha: let us hear views from all sides. Daily Nation, May 30. de Schutter, O. 2011. How not to think of land-grabbing: three critiques of large-scale investments in farmland. Journal of Peasant Studies 38 (2):249-279.

DeFries, R., and C. Rosenzweig. 2010. Toward a whole-landscape approach for sustainable land use in the tropics. Proceedings of the National Academy of Sciences 107 (46): 19627-19632.

Diener, E., and M.E.P. Seligman. 2004. Beyond money: toward an economy of wellbeing. Psychological science in the public interest 51 (1):1-31.

Dowling, R. 2010. Power, subjectivity, and ethics in qualitative research. In Qualitative research methods in human geography, edited by I. Hay. Oxford: Oxford University Press, 26-39.

Edwards, M., and D. Hulme. 1992. Scaling-up the developmental impact of NGOs: concepts and experiences. In Making a difference: NGOs and development in a changing world, edited by M. Edwards and D. Hulme. London: Earthscan, 13-27.

Eisentraut, A. 2010. Sustainable production of second-generation biofuels: potential and perspectives in major economies and developing countries. International Energy Agency.

Elkins, C. 2005. Imperial reckoning: the untold story of Britain's gulag in Kenya. USA: Henry Holt and Co.

Escobar, A. 1995. Encountering development: the making and unmaking of the Third World. Princeton: Princeton University Press.

European Union. 2010. Commission sets up system for certifying sustainable biofuels. Brussels.

Fairhead, J., and M. Leach. 1997. Webs of power and the construction of environmental policy problems: forest loss in Guinea. In Discourses of development: 
anthropological perspectives, edited by R. D. Grillo and R. L. Stirrat. Oxford: Berg, 35-57.

Fairless, D. 2007. The little shrub that could - maybe. Nature 449:652-5.

FAO. 2008. An introduction to the basic concepts of food security. In Food security information for action practical guides. Rome: EC-FAO Food Security Programme.

- 2008. Soaring food prices: the need for international action. In High-level conference on world food security: the challenges of climate change and bioenergy. Rome.

2008. The state of food and agriculture: biofuels: prospects, risks, and opportunities. Rome: FAO.

FAO, and PISCES. 2009. Small-scale bioenergy initiatives: brief description and preliminary lessons on livelihood impacts from case studies in Asia, Latin America and Africa.

FAOSTAT. 2011. Food and Agriculture Organization of the United Nations. 2011 [cited June 27 2011]. Available from http://faostat.fao.org.

Fast, S. 2009. The biofuels debate: searching for the role of environmental justice in environmental discourse. Environments Journal 37 (1):83-100.

Feldman, S., and P. Gellert. 2006. The seductive quality of central human capabilities: sociological insights into Nussbaum and Sen's disagreement. Economy and Society 35 (3):423-452.

Ferguson, J. 1994. The anti-politics machine: "development," depoliticization, and bureaucratic power in Lesotho. Minneapolis: University of Minnesota Press.

- 2006. Global shadows: Africa in the neoliberal world order. Durham: Duke University Press.

Ferrett, G. 2007. Biofuels 'crime against humanity'. BBC News, October 27.

Foley, J.A., N. Ramankutty, K.A. Brauman, E.S. Cassidy, J.S. Gerber, M. Johnston, N.D. Mueller, C. O'Connell, D.K. Ray, P.C. West, C. Balzer, E.M. Bennett, S.R. Carpenter, J. Hill, C. Monfreda, S. Polasky, J. Rockström, J. Sheehan, S. Siebert, D. Tilman, and D.P.M. Zaks. 2011. Solutions for a cultivated planet. Nature 478:337-342.

Forsyth, T. 1996. Science, myth and knowledge. Geoforum 27 (3):375-92.

Foucault, M. 1977. Nietzsche, genealogy, history. In Language, counter-memory, practice: selected essays and interviews by M. Foucault, edited by D. Bouchard. Ithaca: Cornell University Press.

- 1980. Power / knowledge: selected interviews and other writings, 1972-1977. Edited by C. Gordon. New York: Pantheon Books.

Francis, G., R. Edinger, and K. Becker. 2005. A concept for simultaneous wasteland reclamation, fuel production, and socio-economic development in degraded areas in India: need, potential and perspectives of Jatropha plantations. Natural Resources Forum 29:12-24.

Friends of the Earth. 2010. Africa: up for grabs. Benin City, Nigeria: Friends of the Earth Europe and Friends of the Earth Africa.

Fuess, S.M., and H. Van den Berg. 1998. Does GDP distort Mexico's economic performance? Southern Economic Journal 64 (4):973-986. 
Fukuda-Parr, S. 2003. The Human Development paradigm: Operationalizing Sen's ideas on capabilities. Feminist Economics 9 (2-3):301-317.

Gakii, M. 2010. Green power lights up rural Kenyans lives. Daily Nation, December 27.

Gathura, G. 2007. Kenya ready to start producing biodiesel. Daily Nation, November 19.

- 2010. Miracle tree may lack the magic touch it's fabled to have after all. Daily Nation, May 27.

Gaventa, J. 2006. Finding the spaces for change: a power analysis. IDS Bulletin 37 (6):23-33.

Gaventa, J., and A. Cornwall. 2006. Challenging the boundaries of the possible: participation, knowledge and power. IDS Bulletin 37 (6):122-128.

GEXSI. 2008. Global market study on Jatropha: Final Report. London / Berlin: Prepared for WWF.

Ghosh, S. 2007. Will the world embrace jatropha revolution? Commodity Online, April 23.

Gibbs, H.K., M. Johnston, J. Foley, T. Holloway, C. Monfreda, N. Ramankutty, and D. Zaks. 2008. Carbon payback times for crop-based biofuel expansion in the tropics: the effects of changing yield and technology. Environmental Research Letters 3 (034001): 10pp.

Gibson-Graham, J.K. 2002. Beyond global vs. local: economic politics outside the binary frame. In Geographies of power: placing scale, edited by A. Herod and M. W. Wright. Malden: Blackwell, 25-60.

Gibson, R.B. 2000. Specification of sustainability-based environmental assessment decision criteria and implications for determining "significance" in environmental assessment. In Research and development monograph series: Canadian Environmental Assessment Agency

Gillon, S. 2010. Fields of dreams: negotiating an ethanol agenda in the Midwest United States. Journal of Peasant Studies 37 (4): 723 - 748.

Government of Kenya. 2008. Strategy for the development of the bio-diesel industry in Kenya 2008-2012. edited by Ministry of Energy Renewable Energy Department. Nairobi.

- 2009. Proceedings of the Kenya Biodiesel Workshop, June 9th, 2009. edited by Ministry of Energy Renewable Energy Department. Nairobi.

Government of Kenya, and GTZ. 2008. A roadmap for biofuels in Kenya: opportunities and obstacles. Nairobi: Report prepared by Endelevu Energy and Energy for Sustainable Development Africa.

Grass, M. 2009. Jatropha curcas L.: Visions and Realities. Journal of Agriculture and Rural Development in the Tropics and Subtropics 110 (1):29-38.

Green Africa Foundation. 2008. Jatropha curcas farmers' guide. Nairobi: Green Africa Foundation.

Grillo, R.D. 1997. Discourses of development: the view from anthropology. In Discourses of development: anthropological perspectives, edited by R. D. Grillo and R. L. Stirrat. Oxford and New York: Berg, 1-33.

GTZ. 2009. Jatropha reality check: a field assessment of the agronomic and economic viability of Jatropha and other oilseed crops in Kenya. Nairobi: GTZ.

Hall, J., S. Matos, and C.H. Langford. 2008. Social exclusion and transgenic technology: the case of Brazilian agriculture. Journal of Business Ethics 77:45-63. 
Hall, J., S. Matos, L. Severino, and N. Beltrao. 2009. Brazilian biofuels and social exclusion: established and concentrated ethanol versus emerging and dispersed biodiesel. Journal of Cleaner Production 17:S77-S85.

Harsh, M., P. Mbatia, and W. Shrum. 2010. Accountability and inaction: NGOs and resource lodging in development. Development and Change 41 (2):253-278.

Harvey, D. 2006. Spaces of global capitalism: towards a theory of uneven geographical development. London, New York: Verso.

Hecht, S.B. 1985. Environment, development and politics: capital accumulation and the livestock sector in Eastern Amazonia. World Development 13 (6):663-684.

Heller, J. 1996. Physic nut. Jatropha curcas L. Promoting the conservation and use of underutilized and neglected crops. Gatersleben / Rome: Institute of Plant Genetics and Crop Plant Research / International Plant Genetic Resources Institute.

Henning, R. 2004. "The jatropha system" - economy and dissemination strategy. In Renewables 2004. Bonn.

Hilhorst, D. 2001. Village experts and development discourse: "Progress" in a Philippine Igorot village. Human Organization 60 (4):401-11.

HLPE. 2011. Land tenure and international investments in agriculture. Rome: A report by the High Level Panel of Experts on Food Security and Nutrition of the Committee on World Food Security.

Hood, J. 2009. School club's bio diesel project goes global. Chicago Tribune, December 1 .

Hopwood, B., M. Mellor, and G. O'Brien. 2005. Sustainable development: Mapping different approaches. Sustainable Development 13 (1):38-52.

Houston Chronicle. 2009. Rocket science: jet test should spark quest for new biofuels. Houston Chronicle, January 1.

Houtart, F. 2010. Agrofuels: big profits, ruined lives and ecological destruction. London and New York: Pluto Press and the Transnational Institute.

Howarth, R.W., S. Bringezu, M. Bekunda, C. de Fraiture, L. Maene, L. Martinelli, and O. Sala. 2009. Rapid assessment on biofuels and environment: overview and key findings. In Biofuels: environmental consequences and interactions with changing land use. Proceedings of the Scientific Committee on Problems of the Environment (SCOPE) International Biofuels Project Rapid Assessment, 22-25 September 2008, Gummersbach Germany, edited by R. W. H. S. Bringezu. Ithaca, NY, USA: Cornell University, 1-13.

Hulme, D. 2008. Reflections on NGOs and development: the elephant, the dinosaur, several tigers but no owl. In Can NGOs make a difference? The challenge of development alternatives, edited by A. J. Bebbington, S. Hickey and D. C. Mitlin. London: Zed Books, 337-345.

Hunsberger, C. 2009. Growing fuel: Kenyans are experimenting with jatropha to determine the best scale of production. Alternatives Journal 35 (2):23-5.

ICRISAT. 2011. ICRISAT promotes pro-poor biofuels initiative. 2007 [cited June 29 2011]. Available from http://test1.icrisat.org/Media/2007/media5.htm.

IPCC. 2007. Climate change 2007: Synthesis report. Contribution of Working Groups I, II and III to the Fourth Assessment Report of the Intergovernmental Panel on Climate Change. edited by P. [Core Writing Team, R.K and Reisinger, A. (eds.)]. Geneva: IPCC. 
Jagannathan, P. 2010. Don't fall for jatropha plants, warns UN body. The Economic Times, July 26.

Jain, S., and M.P. Sharma. 2010. Prospects of biodiesel from Jatropha in India: A review. Renewable and Sustainable Energy Reviews 14 (2):763-771.

Jamah, A. 2010. Environmentalists label biofuel project ecological disaster. The Standard, June 7.

Jatrophabook. 2011. Jatropha statistics. 2011 [cited May 30 2011]. Available from http://www.jatrophabook.com/statistics jatropha curcas projects.asp.

Johnston, M., J.A. Foley, T. Holloway, C. Kucharik, and C. Monfreda. 2009. Resetting global expectations from agricultural biofuels. Environmental Research Letters 4 (1).

Johnston, R.J. 2000. Power. In The dictionary of human geography, edited by R. J. Johnston, D. Gregory, G. Pratt and M. Watts. Malden, USA: Blackwell.

Jongschaap, R.E.E., W.J. Corré, P.S. Bindraban, and W.A. Brandenburg. 2007. Claims and facts on Jatropha curcas L.: Global Jatropha curcas evaluation, breeding and propagation programme. Wageningen: Plant Research International.

Kagwe, W. 2010. Group says no to biofuel project. Daily Nation, June 21.

Kahn, M. 2011. The fall of the Wall, the rise of the BRICs and the new Scramble for Africa. Foresight 13 (3):38-49.

Katerere, F. 2009. Brazil to invest $\$ 6$ billion in Mozambique biofuels, O Pais says. Bloomberg News, November 20.

Kaufmann, G. 1997. Watching the developers: a partial ethnography. In Discourses of development: anthropological perspectives, edited by R. D. Grillo and R. L. Stirrat. Oxford: Berg, 107-31.

Kenya Land Alliance. 2004. The national land policy in Kenya: addressing historical injustices. Nakuru: Kenya Land Alliance.

Kenya National Bureau of Statistics. 2010. Kenya 2009 population and housing census highlights. Nairobi.

Kenya National Dialogue and Reconciliation. 2008. Agenda 4 implementation framework. 2008. Report of the Commission of Inquiry into Post-Election Violence.

Kirubi, C., Jacobson, A., Kammen, D., Mills, A. 2009. Community-based electric microgrids can contribute to rural development: evidence from Kenya. World Development:1-14.

Klopp, J.M. 2000. Pilfering the public: The problem of land grabbing in contemporary Kenya. Africa Today 47 (1):7-26.

Knaup, H. 2008. Green gold rush: Africa becoming a biofuel battleground. Spiegel International Online, September 5.

Koplow, D. 2006. Biofuels: at what cost? Government support for ethanol and biodiesel in the United States. Geneva: The Global Subsidies Initiative of the International Institute for Sustainable Development.

La Via Campesina. 2009. Industrial agrofuels fuel hunger and poverty. In The Via Campesina Notebooks. Jakarta.

Lambin, E., and P. Meyfroidt. 2011. Global land use change, economic globalization, and the looming land scarcity. Proceedings of the National Academy of Sciences 108 (9):3465-3472. 
Lane, J. 2009. The blunder crop. Biofuels Digest, March 24.

- 2009. Personal communication by E-mail correspondence, March 26., March 26.

Lele, S. 1991. Sustainable development: a critical review. World Development 19

(6):607-621.

Lewis, D. 2003. NGOs, organizational culture, and institutional sustainability. Annals of the American Academy of Political and Social Sciences 590:212-226.

Li, G., and M. Chang. 2010. Taiwan to help Pacific states plant biofuel trees. Focus Taiwan, May 13.

Lin, J. 2010. The sustainability of biofuels: limitations of the meta-standard approach. Governance of Clean Development Working Paper 11. Norwich: University of East Anglia.

Long, N. 1992. An actor-oriented paradigm. In Battlefields of knowledge: the interlocking of theory and practice in social research and development, edited by N. Long and A. Long. London and New York: Routledge, 3-43.

Loos, T.K. 2009. Socio-economic impact of a Jatropha-project on smallholder farmers in Mpanda, Tanzania: case study of a public-private-partnership project in Tanzania. M.Sc., Institute for Agricultural Economics and Social Sciences in the Tropics and Subtropics, University of Hohenheim, Hohenheim, The Netherlands.

Lucheli, I. 2010. Award for making diesel from trees. The Standard, August 7.

Luoma, J.R. 2009. Hailed as a miracle biofuel, jatropha falls short of hype. Guardian Environment Network, May 5.

Mackenzie, F. 1998. Land, ecology and resistance in Kenya, 1880-1952. Edinburgh: Edinburgh University Press Ltd.

Maes, W.H., W.M.J. Achten, B. Reubens, D. Raes, R. Samson, and B. Muys. 2009. Plant-water relationships and growth strategies of Jatropha curcas L. seedlings under different levels of drought stress. Journal of Arid Environments 73:877884.

Maliti, T. 2010. Brazil to help Kenya produce biodiesel. Business Day, July 7.

Mbogo, S. 2007. Kenyan farmers to cash in on biodiesel demand. Business Daily, March 21.

-2009. Jatropha offers 'green hope' for arid areas. Business Daily Africa, April 17, 2009.

-2010. Study says biofuel crop can improve earnings of farmers in marginal lands. Business Daily, August 5.

Melillo, J.M., J.M. Reilly, D.W. Kicklighter, A.C. Gurgel, T.W. Cronin, S. Paltsev, B.S. Felzer, X. Wang, A.P. Sokolov, and C.A. Schlosser. 2009. Indirect emissions from biofuels: how important? Science 326:1397-99.

Messemaker, L. 2008. The green myth? Assessment of the Jatropha value chain and its potential for pro-poor biofuel development in Northern Tanzania, International Development Studies, Faculty of Geosciences, Utrecht University, Utrecht.

Milder, J.C., J.A. McNeely, S.A. Shames, and S.J. Scherr. 2008. Biofuels and ecoagriculture: can bioenergy production enhance landscape-scale ecosystem conservation and rural livelihoods? International Journal of Agricultural Sustainability $6(2): 105-121$.

Miriri, D. 2008. Kenya sees $\$ 500$ million biofuels investment in 2 years. Reuters Africa, October 30. 
Mohiuddin, Y. 2010. Doubts over India's 'miracle' biodiesel crop. Agence France-Presse, January 26.

Moreno, C., and A. Mittal. 2008. Food and energy sovereignty now: Brazilian grassroots position on agroenergy. The Oakland Institute and Terra de Direitos.

Mosse, D. 2005. Cultivating development: an ethnography of aid policy and practice. London: Pluto Press.

Moyo, D. 2009. Dead aid. Vancouver: Douglas \& McIntyre.

Muller, A., J. Schmidhuber, J. Hoogeveen, and P. Steduto. 2008. Some insights in the effect of growing bio-energy demand on global food security and natural resources. Water Policy 10:83-94.

Munshi, D., and P. Kurian. 2005. Imperializing spin cycles: a postcolonial look at public relationsh, greenwashing, and the separation of publics. Public Relations Review 31:513-520.

Muok, B., and L. Källbäck. 2008. Feasibility study of Jatropha curcas as a biofuel feedstock in Kenya. Nairobi: Policy Innovation Systems for Clean Energy Security; African Centre for Technology Studies; Swedish Trade Council.

Mutch, T. 2010. Jatropha biofuels: the true cost to Tanzania. The Ecologist, February 15. Mutua, K. 2007. The wonder shrub. The East African, January 22.

Myers, G.A. 1999. Political ecology and urbanisation: Zanzibar's construction materials industry. Journal of Modern African Studies 37 (1):83-108. 2005. Disposable cities: garbage, governance and sustainable development in urban Africa. Edited by Anonymous. Burlington, VT: Ashgate.

Nation Correspondent. 2010. Kenya set to use fuel from plants. Daily Nation, June 15.

Ndong, R., M. Montrejaud-Vignoles, O. Saint Girons, B. Gabrielle, R. Pirot, M. Domergue, and C. Sablayrolles. 2009. Life cycle assessment of biofuels from Jatropha curcas in West Africa: a field study. GCB Bioenergy 1:197-210.

Ndurya, M., and G. Kihara. 2009. Canadian company eyes Tana Delta for biofuel projects. Business Daily Africa, April 17, 2009.

Neumann, R.P. 2009. Political ecology: theorizing scale. Progress in Human Geography 33 (3):398-406.

Ng'ethe, R. 2007. The viability of Jatropha curcas $L$. as a biofuel feedstock and its potential contribution to the development of Kenya's biofuel strategy. Nairobi: For the Kenya Forest Service and Ministry of Energy (supported by the World Bank).

Njungiri, J. 2008. Tree that holds solution to fuel crisis and environmental conservation. Daily Nation, July 20.

Obala, R. 2010. Trophy tree to unlock Kenya's full potential. The Standard, June 24.

Obersteiner, M., M. Stafford Smith, C. Heipe, M. Brklacich, and W. Rudder. 2010. Green food systems for 9 billion. In Food security and global environmental change, edited by J. Ingram, P. Ericksen and D. Liverman. London: Earthscan, 301-317.

Ogg, C.W. 2009. Avoiding more biofuel surprises: the fuel, food and forest trade-offs. Journal of Development and Agricultural Economics 1 (1):12-17.

Omondi, G., and J. Ng'etich. 2010. Jatropha farmers walk on slippery ground. Business Daily, February 3.

Openshaw, K. 2000. A review of Jatropha curcas: an oil plant of unfulfilled promise. Biomass \& Bioenergy 19 (1):1-15. 
Orange, R. 2009. Jatropha seeds yield little hope for India's oil dream. The National, May 11.

Orwa, C., A. Mutua, R. Kindt, R. Jamnadass, and A. Simons. 2009. Agroforestree Database: a tree reference and selection guide, Version 4.0 Nairobi: ICRAF.

Otieno, J. 2007. Biofuels likely to boost energy but increase hunger, now critics warn. Daily Nation, August 27.

Oxfam International. 2008. Another inconvenient truth: how biofuel policies are deepening poverty and accelerating climate change. Oxfam Briefing Paper.

Parliamentary Commissioner for the Environment. 2008. Briefing on the Biofuel Bill 2008.

. 2009. Submission on the Sustainable Biofuels Bill.

Paton, D. 2009. Jatropha viability as biofuel crop falls into doubt. Business Daily, June 17.

Paulson, S., L.L. Gezon, and M. Watts. 2003. Locating the political in political ecology: an introduction. Human Organization 62 (3):205-217.

Peck, J. 2001. Neoliberalizing states: thin policies/hard outcomes. Progress in Human Geography 25 (3):445-455.

Peet, R., and M. Watts. 2003. Liberating political ecology. In Liberation ecologies: environment, development, social movements, edited by R. Peet and M. Watts. London and New York: Routledge, 1-47.

Petras, J., and H. Veltmeyer. 2001. Globalization unmasked: imperialism in the 21st century. Halifax; London: Fernwood; Zed.

Pimentel, D., A. Marklein, M.A. Toth, M.N. Karpoff, G.S. Paul, R. McCormack, J. Kyriazis, and T. Krueger. 2009. Food versus biofuels: environmental and economic costs. Human Ecology 37 (1):1-12.

Polack, A. 2009. Biofuels: how green is the gold rush in Senegal? Cafe Babel, January $25,2011$.

Pollan, M. 2006. The omnivore's dilemma: a natural history of four meals. New York: Penguin.

Pomerantz, P.R. 2004. Aid effectiveness in Africa: developing trust between donors and governments. Lanham: Lexington Books.

Prueksakorn, K., and S.H. Gheewala. 2008. Full chain energy analysis of biodiesel from Jatropha curcas $L$. in Thailand. Environmental Science Technology 42:33883393.

Reinhardt, G., S. Gartner, N. Rettenmaier, J. Munch, and E. von Falkenstein. 2007. Screening life cycle assessment of jatropha biodiesel. edited by $\mathrm{S}$. Commissioned by Daimler AG. Heidelberg: Institute for Energy and Environmental Research Heidelberg GmbH.

Renewable Fuels Agency. 2010. About the RTFO, 30 July 2010 [cited August 10 2010]. Available from http://www.renewablefuelsagency.gov.uk/aboutthertfo.

- 2011. Benchmarks of sustainability standards and certification schemes. 2010 [cited June 28 2011]. Available from http://webarchive.nationalarchives.gov.uk/20110407094507/http://renewablefuels agency.gov.uk/.

Reuters. 2009. Jatropha for biodiesel not a miracle crop: D1 Oils. Reuters, April 1. Robbins, P. 2004. Political ecology: a critical introduction. Malden: Blackwell. 
Roberts, M.J., and W. Schlenker. 2009. The U.S. biofuel mandate and world food prices: an econometric analysis of the demand and supply of calories. Seminar paper presented at University of California Energy Institute, Berkeley.

Robertson, B., and P. Pinstrup-Andersen. 2010. Global land acquisition: neo-colonialism or development opportunity? Food security 2:271-283.

Rockström, J., W. Steffen, K. Noone, A. Persson, I. F. S. Chapin, E. Lambin, T.M. Lenton, M. Scheffer, C. Folke, H. Schellnhuber, B. Nykvist, C.A.D. Wit, T. Hughes, S.v.d. Leeuw, H. Rodhe, S. Sörlin, P.K. Snyder, R. Costanza, U. Svedin, M. Falkenmark, L. Karlberg, R.W. Corell, V.J. Fabry, J. Hansen, B. Walker, D. Liverman, K. Richardson, P. Crutzen, and J. Foley. 2009. Planetary boundaries: exploring the safe operating space for humanity. Ecology and Society 14 (2):Art. 32.

Rosegrant, M. 2008. Biofuels and grain prices: Impacts and policy responses. In Testimony for the U.S. Senate Committee on Homeland Security and Governmental Affairs

Washington DC: International Food Policy Research Institute.

Ross, W. 2011. Kenyans fear Dakatcha Woodlands biofuel expansion. BBC, March 22.

Rossi, A., and Y. Lambrou. 2008. Gender and equity issues in liquid biofuel production: Minimizing the risks to maximize the opportunities. Rome: FAO.

Roundtable on Sustainable Biofuels. 2009. Annual Report 2009.

Sagar, A.D., and A. Najam. 1998. The human development index: a critical review. Ecological Economics 25 (3):249-264.

Sanderson, K. 2009. Green gold losing its glitter to be? The East African, November 2.

2009. Wonder weed plans fail to flourish. Nature 461:328-9.

Satterthwaite, D. 2003. The links between poverty and the environment in urban areas of Africa, Asia, and Latin America. Annals of the American Academy of Political and Social Sciences 590:73-92.

Schoeman, M. 2011. Of BRICs and mortar: the growing relations between Africa and the Global South. The International Spectator 46 (1):33-51.

Scott, J. 1990. Domination and the arts of resistance. New Haven: Yale University Press. Searchinger, T., R. Heimlich, R.A. Houghton, F. Dong, A. Elobeid, J. Fabiosa, S. Tokgoz, D. Hayes, and T.-H. Yu. 2008. Use of U.S. croplands for biofuels increases greenhouse gases through emissions from land-use change. Science 319:1238-40.

Sen, A. 1999. Development as freedom. Edited by Anonymous. New York: Knopf.

Senelwa, K. 2009. An eco-friendly way of growing cash and energy. Daily Nation, July 30.

Sharpe, M. 2006. Local shrub carries potential for clean fuel. Daily Nation.

Smith, N. 1992. Geography, difference and the politics of scale. In Postmodernism and the social sciences, edited by J. Doherty, E. Graham and M. Malek. New York: St. Martin's Press, 57-79.

- 2000. Scale. In The dictionary of human geography, edited by R. J. Johnston, D. Gregory, G. Pratt and M. Watts. Malden, USA: Blackwell Publishing, 724-7.

Soja, E. 1989. Postmodern geographies; the reassertion of space in critical social theory. London: Verso. 
Strickland, E. 2009. Can botanical tweaking turn jatropha into a biofuel wonder plant? Discover, July 21.

. 2009. Jatropha: not a miracle crop after all? . Discover, June 9.

Sulle, E., and F. Nelson. 2009. Biofuels, land access and rural livelihoods in Tanzania. London: IIED.

Tagnin, R., and D. Mattes. 2008. Conversion of the remaining biomes into agrofuels and food: burn them or eat them? Interfacehs: Journal on Integrated Management of Occupational Health and the Environment 3 (2):Article 6.

Taheripour, F., T.W. Hertel, W.E. Tyner, J.F. Beckman, and D.K. Birur. 2010. Biofuels and their by-products: global economic and environmental implications. Biomass and Bioenergy 34:278-289.

Thomas, T. 2009. The resource of dreams. Sun and wind energy (5):226-231.

Time. 2009. Biofuel gone bad: Burma's atrophying jatropha. Time, March 13.

Timilsina, G.R., and A. Shrestha. 2010. How much hope should we have for biofuels? Environment and Energy Article in press:1-15.

TNI. 2007. Agrofuels: towards a reality check in nine key areas. Amsterdam: Transnational Institute.

Tomomatsu, Y., and B. Swallow. 2007. Jatropha curcas biodiesel production in Kenya: economics and potential value chain development for smallholder farmers. Working Paper \#54. Nairobi: World Agroforestry Centre.

Trondsen, E.J. 2009. Though a wonder crop, Jatropha won't wean the world of fossil fuel soon. The East African, 10 April, 2009.

Tsing, A. 2000. Inside the economy of appearances. Review of July 5, 2010. Public Culture $12(1): 115-144$. 2005. Friction: an ethnography of global connection. Princeton: Princeton University Press.

TVNZ. 2008. Biofuel company jettisons plans. ONE News / Newstalk ZB, December 13.

U.S. Department of Energy. 2011. Obama announces steps to boost biofuels, clean coal., February 3, 20102010 [cited June 25 2011]. Available from http://www.energy.gov/news/8596.htm.

U.S. Government. 2007. Energy security and independence act. United States of America.

Ulmanen, J.H., G.P.J. Verbong, and R. Raven. 2009. Biofuel developments in Sweden and the Netherlands: Protection and socio-technical change in a long-term perspective. Renewable \& Sustainable Energy Reviews 13 (6-7):1406-1417.

UNEP. 2007. Global Environment Outlook 4. Nairobi: United Nations Environment Programme.

2009. Toward sustainable production and use of resources: assessing biofuels. Nairobi and Paris: UNEP.

USDA Foreign Agricultural Service. 2010. India biofuels annual 2010. New Delhi: Global Agricultural Information Network.

- 2011. Kenya's draft national biofuel policy. Nairobi: Global Agricultural Information Network.

van Eijck, E., and H. Romjin. 2008. Prospects for Jatropha biofuels in Tanzania: An analysis with Strategic Niche Management. Energy Policy 36:311-325. 
Vermeulen, S., and L. Cotula. 2010. Over the heads of local people: consultation, consent, and recompense in large-scale land deals for biofuels projects in Africa. Journal of Peasant Studies 37 (4):899 - 916.

Vivian, J. 1994. NGOs and sustainable development in Zimbabwe: no magic bullets. Review of July 1, 2010. Development and Change 25:167-193.

Von Blottnitz, H., and M.A. Curran. 2007. A review of assessments conducted on bioethanol as a transportation fuel from a net energy, greenhouse gas, and environmental life cycle perspective. Journal of Cleaner Production 15:607-619.

Wackernagel, M., and W. Rees. 1996. Our ecological footprint: reducing human impact on the Earth. Gabriola Island: New Society Publishers.

Wadhams, N. 2009. How a biofuel 'miracle' ruined Kenyan farmers. Time, October 4.

Wahl, N., R. Jamnadass, H. Baur, C. Munster, and M. Iiyama. 2009. Economic viability of Jatropha curcas L. plantations in Northern Tanzania - Assessing farmers' prospects via cost-benefit analysis. Nairobi: World Agroforestry Centre.

Waitt, G. 2005. Doing discourse analysis. In Qualitative research methods in human geography, edited by I. Hay. Oxford: Oxford University Press, 163-91. 2010. Doing Foucauldian discourse analysis - revealing social identities. In Qualitative research methods in human geography, edited by I. Hay. Oxford: Oxford University Press, 217-40.

Walker, P.A. 2005. Political ecology: where is the ecology? Progress in Human Geography 29 (1):73-82.

Wallace, T. 2004. NGO dilemmas: Trojan horses for global neoliberalism? In The new imperial challenge: Socialist Register 2004, edited by L. Panitch and C. Leys. Halifax: Fernwood, 202-219.

Waring, M. 1999. Counting for nothing: what men value and what women are worth. Toronto: University of Toronto Press.

Waters, A.R. 1972. Change and evolution in the structure of the Kenya coffee industry. African Affairs 71 (283):163-175.

WCED. 1987. Our common future. Oxford, New York: Oxford University Press.

Weis, T. 2008. The (not-so) sudden crisis of the global food economy. Canadian Dimension 42 (4).

2010. The accelerating biophysical contradictions of industrial capitalist agriculture. Journal of Agrarian Change 10 (3):315-341.

Weller, S. 2007. Power and scale: the shifting geography of industrial relations law in Australia. Antipode 39 (5):896-919.

Weyerhaeuser, H., T. Tennigkeit, S. Yufang, and F. Kahrl. 2007. Biofuels in China: An analysis of the opportunities and challenges of Jatropha curcas in Southwest China. Beijing: ICRAF China.

Whitaker, M., and G. Heath. 2010. Life cycle assessment comparing the use of Jatropha biodiesel in the Indian road and rail sectors. Golden, Colorado: National Renewable Energy Laboratory.

Wolinsky, H. 2009. The economics of biofuels: President Obama's emphasis on energy policy gives a boost to the alternative fuel business in the USA. European Molecular Biology Organization Reports 10 (6):551-553.

Worldwatch Institute. 2007. Biofuels for transport: global potential and implications for sustainable energy and agriculture. London: Earthscan. 
WWF. 2009. Biofuel industry study, Tanzania: an assessment of the current situation. Dar es Salaam, Tanzania: World Wide Fund for Nature Tanzania Programme Office.

Xinhua. 2011. Firm plans to generate electricity from ethanol. Business Daily, January 6, 2011.

Yin, R.K. 1996. Case study research. Second ed. Thousand Oaks: Sage.

Zoomers, A. 2010. Globalisation and the foreignisation of space: seven processes driving the current global land grab. Journal of Peasant Studies 37 (2):429-447. 


\section{APPENDICES}

\section{Appendix 1: Sample research questions for semi-structured interviews}

\section{Sample questions for farmers growing Jatropha:}

1. What factors have affected your farming decisions over the past 10 years?

2. How did you first learn about Jatropha? (Who introduced you to it? When?)

3. What did you hear about it in the beginning?

4. Why did you decide to plant it?

5. How would you say your Jatropha is doing? Has this matched what you were told?

6. Why do you think it has done well / not done well?

7. Do you think it will improve in the future?

8. Have you gained any benefits from growing Jatropha? (first general, then prompt) e.g. income, intercropping, animal control, time savings, water use, other?

9. Has growing Jatropha caused any problems for you? (first general, then prompt) e.g. financial costs, impacts on other crops, interferes with other activities, other?

10. Has growing Jatropha caused any environmental changes on your farm? (e.g. soil, water)

11. What has your experience been with trying to grow Jatropha to use locally?

12. What successes have you achieved with this project?

13. What problems have you encountered?

14. Who do you think could benefit from using Jatropha oil locally? In what ways? (e.g. income, economic opportunities, environmental benefits, time savings, health)

15. Who would not benefit? Why not?

16. What do you think will happen to the project over the next 5 years or so? In the long term?

17. What do you think the best outcome could be? What would it take to get there?

18. What would cause you to switch from growing Jatropha to something else?

\section{If not growing Jatropha:}

1. Do you know about Jatropha?

2. If so, what have you heard about it?

3. Why have you decided not to plant it? 
Sample questions for groups spearheading local energy projects (or group leaders)

1. What is the structure of the project - how does it work? (Farmers to sell seeds? Bring own seeds and pay to use press? Commercial / semi-commercial / non-commercial?)

2. For what purposes will the energy be used? (Is there a plan for this?)

3. What does it take for someone to become a member?

4. How are decisions made within the group?

5. Why did you decide to get involved with this project?

6. What do you think the benefits will be? Who will benefit most? Least? (kinds of benefits: financial, social, environmental, livelihood / economic activities)

7. What problems have you experienced? What future problems do you expect?

8. What is your best-case scenario for the project over the next year? 5 years? Beyond?

9. What would it take to achieve this outcome? (What things will affect the success or lack of success of the project?)

10. What would you like to tell other people in Kenya who are interested in starting a project like this one?

\section{Sample questions for semi-structured interviews with NGO, government and} private sector representatives

1. How did you first encounter Jatropha? / Who introduced you to it? When?

2. What did you hear about it in the beginning?

3. What types of its use are you involved with?

4. What other types of use are you aware of in Kenya? Outside Kenya?

5. Why did you decide to promote Jatropha (if applicable)? (motivations - what did you see as the benefits?)

- What is your priority or emphasis?

6. Who do you see as the major players surrounding its use?

7. What has gone well with Jatropha in Kenya / your Jatropha projects?

8. What has not gone well / what challenges have you encountered?

9. Who benefits most from Jatropha production as it is currently happening in Kenya? (if necessary, prompt for kinds of benefits: income, environmental, social, livelihood)

10. Who benefits least? Why?

11. What do you think is the best approach to growing Jatropha in Kenya? (large plantations, small farms, other strategy)

12. How does it compare to other biodiesel crops like castor, croton or sunflower?

13. What (if any) doubts do you have about its ability to play a positive role in Kenya?

14. Do you see influences from outside Kenya affecting the Jatropha situation inside Kenya? (examples from other countries, foreign investment, existence of export market, changes in global oil prices...)

15. Where do you see the industry going in the next 5-10 years? In the long term?

16. What is your ideal scenario for Jatropha (or biodiesel in general) in Kenya? What do you think it would take to get there?

17. Who else do you think I should talk to?

18. Do you have any publications about Jatropha that I can access? 


\section{Appendix 2: Farmer survey}

REGION .............. HOUSEHOLD NUMBER......... CONSENT? Understand / Interview / Audio / Photos

Name of Interviewee..............................................Date 2009/.............. Time (am / pm) Interviewer.

Email. ; Phone.

; Address

\section{1: Location of Farm}

Division.

Longitude.

Latitude

Altitude

0.2: Agronomic Information (Rainfall \& Temperature from Database)

Soil type (circle)... Chalky, Clay, Loamy, Peaty, Sandy, Silty

Current land use (circle)... Agroforestry, Farming, Forest, Grazing, Scub / Wasteland

\section{1: Interviewee}

Age............., Gender............., household head? (yes / no)

Education level:(1.none, 2.primary, 3.secondary, 4.polytech, 5.college/univ) Years formal education..........

Occupation 1 Occupation 2

Main source of income 1 .

Main source of income 2.

\section{2: Physical Conditions of Farm/Farmer}

Nearest town

Distance to the major town. . $\mathrm{km}$

Water source used for domestic needs. For farming.....

How far from all weather road? $\mathrm{km}$, On foot? ..min 


\section{3: Social Conditions of Farm/Farmer}

Involved in farmers group? (yes / no), If yes, since when Years

Did you migrate from another place?(no/ yes), From[

] when

1.4: Household Profile: TOTAL.................those staying at homesteads, children $<15$

Adult male Adult female ..; Children male. Children female

Do you receive remittances from relatives who live in other places?

\section{5: Financial / Asset Profile}

LAND No. of Plots Total acres

Land ownership (freehold, communal, trust, government)

CROPS GROWN Crop 1 . No. acres. Crop 2 No. acres Crop 3 No. acres......

LIVESTOCK no. of cattle......, no. of sheep. no. of goats.

GOODS ... do you have the following items? A radio......., A mobile phone......., A bicycle........,

A car...........A tractor......., A plough......... A water tank or well...........

\subsection{Energy sources used}

Lighting.............. Cooking

Other.

\subsection{Perceptions of change}

What changes have you noticed in this area over the past 10 years?

\section{IF NOT GROWING JATROPHA}

Do you know about jatropha? (yes/no)

What have you heard about it?

Why have you decided not to plant it? 


\section{IF GROWING JATROPHA}

3.1: When did you learn about Jatropha (year)?

3.2: Who introduced it to you?

3.3: Do you receive technical support for planting Jatropha? ( yes / no). 3.4: If yes, from whom?.

3.5: If yes, what kids of technical support you get?.

3.6: Do you have access to buyers? ( yes / no) 3.7: Do you have access to a processing device? ( yes/ no)

\begin{tabular}{|c|c|c|c|c|c|c|}
\hline $\begin{array}{l}\text { Age } \\
\text { Classes }\end{array}$ & $\begin{array}{c}0-1 \text { Year } \\
\text { Old }\end{array}$ & $\begin{array}{c}\text { 1-2 Years } \\
\text { Old }\end{array}$ & $\begin{array}{c}2-3 \\
\text { Years } \\
\text { Old } \\
\end{array}$ & $\begin{array}{c}34 \text { Years } \\
\text { Old }\end{array}$ & $\begin{array}{c}4-5 \\
\text { Years } \\
\text { Old } \\
\end{array}$ & $\begin{array}{c}5+ \\
\text { Years }\end{array}$ \\
\hline \multicolumn{7}{|c|}{ 4.1: When/what month(s) and year(s) was this plantation planted? } \\
\hline \multicolumn{7}{|c|}{$\begin{array}{l}4.2 \text { How were you using this land before you planted } \\
\text { Jatropha? }\end{array}$} \\
\hline \multicolumn{7}{|c|}{ 4.3:How many acres do you have planted in each age class? ${ }^{*}(1$ acre $=0.404 \mathrm{ha})$} \\
\hline \multicolumn{7}{|c|}{ 4.4:How many trees do you have planted in each age class? ${ }^{\star \star \star \star}(1,000$ trees for 1 acre at $2 \mathrm{~m} \times 2 \mathrm{~m})$} \\
\hline \multicolumn{7}{|c|}{ 4.5: What type of plantation is it? (monoculture, intercropped, fence, other) } \\
\hline \multicolumn{7}{|c|}{ 4.6:If intercropped, what crop(s) are planted with Jatropha? (maize, beans cassava, peas, other) } \\
\hline \multicolumn{7}{|c|}{ 4.7:What propagation method did you use? (seeds, seedlings, cuttings, other) } \\
\hline & & & & & & \\
\hline
\end{tabular}




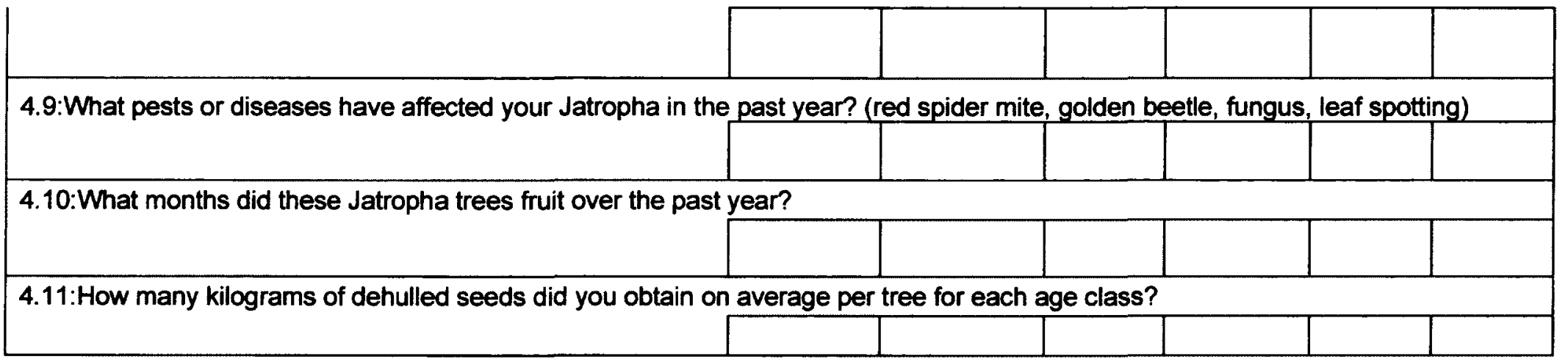

For each task, how many times have you completed it? How many days of work did it take? Who performed it?

During what month? What was the cost of the task in terms of inputs or hiring equipment?

\begin{tabular}{|c|c|c|c|c|c|}
\hline & No. times & $\begin{array}{l}\text { Person- } \\
\text { days }\end{array}$ & $\begin{array}{c}\text { Who did } \\
\text { task? }\end{array}$ & $\begin{array}{c}\text { Time of } \\
\text { year }\end{array}$ & $\begin{array}{c}\text { Cost of } \\
\text { task }\end{array}$ \\
\hline Land preparation (first year) & N/A & & & & \\
\hline \multicolumn{6}{|l|}{ Planting (first year) } \\
\hline \multicolumn{6}{|l|}{ Pest control (past year) } \\
\hline \multicolumn{6}{|l|}{ Irrigation (past year) } \\
\hline \multicolumn{6}{|l|}{ Fertilizer (past year) } \\
\hline \multicolumn{6}{|l|}{ Weeding (past year) } \\
\hline \multicolumn{6}{|l|}{ Pruning (past year) } \\
\hline Hanvest (past year) & & & & & \\
\hline
\end{tabular}

How many seeds did you harvest in the past year?

kg. How many sold?

$\mathrm{kg}$ To whom?

What price did you receive? $\mathrm{KSh} / \mathrm{kg}$ 